\title{
Dinuclear Ruthenium and Platinum Complexes: Design, Synthesis, Characterization and Potential Applications
}

by

Gaëtan LeClair, M.Sc.

\author{
A thesis submitted to the \\ Faculty of Graduate Studies and Research \\ in partial fulfillment of \\ the requirements for the degree of \\ Doctor of Philosophy
}

Department of Chemistry

Carleton University

Ottawa, Ontario

August 2008

(C) copyright

2008, Gaëtan LeClair 


$\begin{array}{ll}\begin{array}{l}\text { Library and } \\ \text { Archives Canada }\end{array} & \begin{array}{l}\text { Bibliothèque et } \\ \text { Archives Canada }\end{array} \\ \begin{array}{l}\text { Published Heritage } \\ \text { Branch }\end{array} & \begin{array}{l}\text { Direction du } \\ \text { Patrimoine de l'édition }\end{array} \\ \begin{array}{l}\text { 395 Wellington Street } \\ \text { Ottawa ON K1A 0N4 } \\ \text { Canada }\end{array} & \begin{array}{l}\text { 395, rue Wellington } \\ \text { Ottawa ON K1A 0N4 } \\ \text { Canada }\end{array}\end{array}$

Your file Votre référence ISBN: 978-0-494-43898-5

Our file Notre référence

ISBN: 978-0-494-43898-5

NOTICE:

The author has granted a nonexclusive license allowing Library and Archives Canada to reproduce, publish, archive, preserve, conserve, communicate to the public by telecommunication or on the Internet, loan, distribute and sell theses worldwide, for commercial or noncommercial purposes, in microform, paper, electronic and/or any other formats.

The author retains copyright ownership and moral rights in this thesis. Neither the thesis nor substantial extracts from it may be printed or otherwise reproduced without the author's permission.
AVIS:

L'auteur a accordé une licence non exclusive permettant à la Bibliothèque et Archives Canada de reproduire, publier, archiver, sauvegarder, conserver, transmettre au public par télécommunication ou par l'Internet, prêter, distribuer et vendre des thèses partout dans le monde, à des fins commerciales ou autres, sur support microforme, papier, électronique et/ou autres formats.

L'auteur conserve la propriété du droit d'auteur et des droits moraux qui protège cette thèse. $\mathrm{Ni}$ la thèse ni des extraits substantiels de celle-ci ne doivent être imprimés ou autrement reproduits sans son autorisation.
In compliance with the Canadian Privacy Act some supporting forms may have been removed from this thesis.

While these forms may be included in the document page count, their removal does not represent any loss of content from the thesis.
Conformément à la loi canadienne sur la protection de la vie privée, quelques formulaires secondaires ont été enlevés de cette thèse.

Bien que ces formulaires aient inclus dans la pagination, il n'y aura aucun contenu manquant.

\section{Canada}




\begin{abstract}
Near infra-red electrochromes find many applications, especially in the telecommunication industry as optical attenuators in fiber optic networks at the 1550 , 1310 and $980 \mathrm{~nm}$ bands. Dinuclear ruthenium complexes based on the diacylhydrazide (DCH) or oxamide bridging ligands are NIR electrochromic materials that are well known.
\end{abstract}

This research project involved the preparation macromolecular materials containing dinuclear ruthenium complex moieties by polymerization of functionalized complexes that could be processed into free standing, transparent thin films which were then evaluated in prototype devices for potential applications.

Firstly, second-generation dendrimers were investigated. Unfortunately, the devised synthetic routes proved unsuccessful and only first-generation dendrimers were obtained. Subsequently, linear and hyperbranched polyurethane polymers were prepared from diol ruthenium complexes and suitable isocyanates. Crosslinked DCH ruthenium complex films were insoluble in common organic solvents and demonstrated the promising NIR electrochromic properties. Moreover, when these films were probed at $1550 \mathrm{~nm}$ in a reflective configuration, an optical attenuation of $17.5 \mathrm{~dB} / \mu \mathrm{m}$ was recorded, which corresponds to a three fold increase when compared to similar devices operating in a transmissive configuration. Biurea complex analogues absorb near $1200 \mathrm{~nm}$, and films were prepared. However, due to lower electrochromic material loading and incomplete crosslinking, the optical attenuation at both the 980 and $1310 \mathrm{~nm}$ bands only reached 5 $\mathrm{dB} / \mu \mathrm{m}$. 
Another aspect of this project was to investigate the potential of a glucose biosensor application using glucose oxydase while monitoring the NIR absorption. The response time of an all-solution configuration was rather slow, relying only on slow diffusion dynamics. Response time was even slower with previously prepared thin films.

Finally, the same DCH ligand system was used to prepare a series of dinuclear platinum complexes to investigate their emissive properties. It was found that the bridging ligand had negligible effects on the photoluminescence of the complex. Increasing the electron donating potential of the peripheral ligand did promote a bathochromic shift, its magnitude dependant on the ligand. Contrary to the ruthenium complexes, the platinum complexes did not exhibit a mixed valence state. While emission at $600 \mathrm{~nm}$ was achieved, NIR phosphorescence could be attained by using other peripheral ligands. 


\section{Acknowledgments}

Although the path to a $\mathrm{PhD}$ degree is filled with obstacles and trials, it provides an unequivocal learning opportunity and in all my years as a university student, never did I learn so much. Research does not follow a straight path and things may go awry, and it will, possibly for long periods of time, but learning from these mistakes and mishaps provides the occasion to develop extremely valuable troubleshooting skills. In the grand scheme of things, everything eventually falls in place.

I would like to express my gratitude towards my supervisor Dr Zhi Yuan (Wayne) Wang for giving me the opportunity to pursue my graduate studies in the field of material science. I had the freedom to pursue ideas and when I lost focus from the possibilities, he pointed me in the right direction with constructive advice.

Next in line is my partner, Annick, whom has been a solid foundation in my life for almost nine years. She has helped me grow and mature into the person I am today. I thank you dear, for believing in me and supporting me in my times of need.

My thanks go to my lab mates and friends who made the last 5 years of my life in Steacie Building 'interesting' to say the least. It was a first for me to be part of a large group, made up of people from various parts of the world, permitting me to experience and learn about other cultures without travelling half way across the world.

I wish to thank my family for their guidance and moral support throughout the years. The world is increasingly more complicated and their wisdom has proven invaluable towards my life experiences.

I would like to express my gratitude to Carleton University and the Ontario government for financial support throughout this endeavour. 
Lastly, I am gratefull to the technicians and support staff of the Ottawa-Carleton Chemistry Institute for spectral acquisition, 'MacGyvering' gadgets and making sure that essential forms were properly and timely filled so that I could eventually graduate. 


\section{Table of Contents}

Abstract $\quad$ i

Acknowledgments $\quad$ iii

List of Figures vii

List of Tables $\quad$ ix

List of abbreviations $\quad \mathrm{X}$

Chapter 1 - Introduction 1

1.1 - Electrochromic materials $\quad 1$

1.2 - Electrochemical characterization of electrochromic materials 2

$\begin{array}{ll}1.3 \text { - Other characterization parameters } & 7\end{array}$

1.4 - NIR-active electrochromic materials 9

1.4.1 - Metal oxides 9

1.4.2 - Hexacyanometallates: Prussian blue 11

1.4.3 - Radical anions of conjugated diimides and diquinones 13

$\begin{array}{ll}1.4 .4-\text { Porphyrins and phthalocyanines } & 14\end{array}$

$\begin{array}{ll}1.4 .5 \text { - Conjugated polymers } & 16\end{array}$

1.4.6 - Transition metal complexes $\quad 19$

1.5 - Applications 25

1.6 - Rationale and objectives $\quad 29$

Chapter 2-Bridging and peripheral ligands 30

2.1 - Introduction $\quad 30$

2.1.1 - Synthetic methods for bridging ligands 31

2.1.2 - Synthetic methods for non-bipyridine peripheral ligands 34

$2.2-$ Results and discussion $\quad 35$

2.2.1 - Bridging ligands $\quad 35$

2.2.2 - Peripheral ligands 41

2.3 - Conclusion $\quad 42$

2.4 - Experimental $\quad 42$

Chapter 3 - Dinuclear ruthenium and platinum complexes 53

3.1 - Introduction $\quad 53$ 
3.2 - Results and discussion $\quad 55$

3.2.1 - Ruthenium complexes $\quad 55$

3.2.2 - Platinum complexes $\quad 69$

3.3 - Conclusion $\quad 83$

3.4 - Experimental $\quad 84$

Chapter 4 - Macromolecular materials of ruthenium complexes 95

4.1 - Introduction $\quad 95$

4.2 - Results and discussion $\quad 98$

4.2.1 - Dendrimers 98

$\begin{array}{ll}4.2 .2 \text { - Linear polymers } & 103\end{array}$

4.2.3 - Hydrogels and sol-gels 108

4.2.4 - Hyperbranched polymers 110

4.3 - Conclusion 111

4.4 - Experimental 113

Chapter 5 - Device applications based on dinuclear ruthenium complexes 122

5.1 - Introduction 122

5.2 - Results and discussion $\quad 126$

5.2.1 - Glucose biosensor 126

$\begin{array}{ll}5.2 .2 \text { - Reflective NIR variable optical attenuator } & 129\end{array}$

$5.3-$ Conclusion $\quad 135$

5.4 - Experimental 136

Claim to original research 139

$\begin{array}{ll}\text { References } & 141\end{array}$

Appendices $\quad 153$

Appendix $1-{ }^{1} \mathrm{H}$ and ${ }^{13} \mathrm{C}$ NMR spectra of ligands 153

Appendix 2 - NMR of green impurity from biurea complex 184

Appendix 3 - NMR of piperidine biurea complex soluble in DCM 186

Appendix 4 - Quantum yield determination of $44 \quad 188$

Appendix 5 - Crystallography data of $46 \quad 190$

Appendix 6 - Reflective VOA attenuation measurement apparatus 199 


\section{List of Figures}

Figure 1.1 - Simulated CV of a reversible one-electron redox couple ${ }^{3} \quad 3$

Figure 1.2 - Solvent optimal voltametric operating range ${ }^{4} \quad 5$

Figure 1.3 - OTTLE cell assembly: a) innards, b) side view, and c) assembled cell 7

Figure 1.4-Schematic representations of a) response time and b) contrast ratio and

electrochemical stability $\quad 8$

Figure 1.5 - 3-D model of PB and corresponding redox reactions 12

Figure 1.6 - General structure of a) diimides and b) diquinones $\quad 13$

Figure 1.7 - Structure of quinone-imine EC $\quad 14$

Figure 1.8 - Structures of a) porphyrin, b) phthalocyanine and c) metallized porphyrin ( $\beta$

$\begin{array}{ll}\text { and meso positions are defined) } & 14\end{array}$

Figure 1.9-Selected conductive polymers $\quad 17$

Figure 1.10 - Polyaniline redox states 18

Figure 1.11 - Partial MO diagram for an octahedral complex: a) LMCT and b) MLCT 20

Figure 1.12 - Bis-dithiolene square planar complexes. 21

Figure 1.13 - Various dinuclear metal complexes (counter ions omitted for clarity) 22

Figure 1.14 - Example of a dinuclear molybdenum complex 24

Figure 1.15 - The a) trinuclear and b) hexanuclear ruthenium complexes 25

Figure 1.16 - NIR window in a) OFF mode and b) ON mode $\quad 26$

$\begin{array}{ll}\text { Figure 1.17 - Night vision system } & 28\end{array}$

Figure 2.1 - General synthetic routes to symmetric and unsymmetric DCH ligands 31

$\begin{array}{ll}\text { Figure 2.2 - Alternative biurea ligand synthesis } & 32\end{array}$

Figure 2.3 - Oxamide ligand synthesis $\quad 33$

Figure 2.4 - Synthesis of 2-phenylpyridine and quinoxaline peripheral ligands 35

Figure 2.5 - Diol-DCH synthesis via ethyl acetoacetate coupling 37

Figure 2.7 - Variable temperature effect on amide ${ }^{1} \mathrm{H}$ region of $17 \quad 40$

Figure 2.8 - Peripheral ligands considered $\quad 41$

Figure 3.1 - Model of a) DCH and b) OXA dinuclear ruthenium complexes $\quad 54$

Figure $3.1-C V$ of 30,31 and $36 \quad 56$

Figure 3.2 - Potential energy curves of a weakly coupled (a) and a strongly coupled (b)

mixed valence state 59

Figure 3.3 - Spectroelectrochemistry of 36 and $\mathrm{Ru} / \mathrm{RI} / \mathrm{Ru}{ }^{\mathrm{III}}$ states of 33 and 38

Figure 3.4 - Spectroelectrochemistry of 36G and CV (inset) 63

$\begin{array}{ll}\text { Figure } 3.5-\text { ESI-MS of 36G } & 64\end{array}$

Figure 3.6 - CV of 39S and 39I $\quad 66$

Figure 3.7 - Spectroelectrochemistry of 39, 39S and 39I 67

Figure 3.8-ESI-MS of $35 \quad 69$

Figure 3.9 - Structures of platinum complexes 44-46 70

Figure 3.10 - ESI-MS of $46 \quad 71$

Figure 3.11 - Photoluminescence spectra of 44-45 and absorption spectra (inset) of 44-46 $\begin{array}{ll}\left(1 \times 10^{-6} \mathrm{M} \text { solutions in DCM, not degassed) }\right. & 72\end{array}$

Figure 3.12 - ORTEP drawing of 46

Figure $3.13-\mathrm{CV}$ of 44 in DCM (0.1M TBAH, $200 \mathrm{mV}$ scan rate) 76

$\begin{array}{ll}\text { Figure 3.14 - TGA of 44-46 } & 77\end{array}$

$\begin{array}{ll}\text { Figure 3.15 - Structure of 47-49 and stereoisomers } & 78\end{array}$

Figure 3.16-ESI-MS of isolated fractions of 47 
Figure 3.17 - Absorption spectra of 47-49 in DCM (inset: spectra expansion) $\quad 81$

Figure 3.18 - Visible PL of 47-49 (excited at $365 \mathrm{~nm}$ ) 82

Figure 3.19 - PL spectra of 47-48 in DCM (excited at $360 \mathrm{~nm}$ ) 82

Figure 3.20 - Visible PL of 49 and ligand mpbq ( $350 \mathrm{~nm}$ excitation) 83

Figure 4.1 - Dendrimer depiction showing generation levels $(\mathrm{C}=$ core $) \quad 97$

Figure 4.2-G2 dendron 51 reaction scheme $\quad 99$

Figure 4.3 - G2 dendrimer 57 pathway via Suzuki coupling 100

Figure 4.4 - Stick (top) and 3-D model (bottom) of ruthenium complex of 53 (hydrogens

$\begin{array}{ll}\text { omitted for clarity) } & 101\end{array}$

Figure 4.5 - Tetra DCH G1 dendrimer synthesis 102

Figure 4.6 - Spectroelectrochemical properties of 59 (CV in inset) 103

Figure 4.7 - Polyester and polyurethane synthesis (bpy omitted for clarity) 104

Figure 4.8 - Hydroxyacid complex synthesis 105

Figure 4.9 - Ligand 61 and triazole 'click' chemistry (showing possible isomers) 106

Figure 4.10 - ESI-MS of the attempted complexation of 61

Figure 4.11 - Absorption spectra of solgel films containing 35 (inset: picture of ' $\mathrm{A}$ '

films) $\quad 110$

Figure 4.12 - Sample spin-coated crosslinked films containing 41

Figure 5.1 - Glucose oxidase sensoring scheme considered $\quad 122$

Figure 5.2 - GOX active site mechanism $\quad 123$

Figure $5.3-$ a) transmisive and b) reflective VOA constructs $\quad 124$

Figure 5.4 - ITO NIR reflectance (100 nm thick coating) 125

Figure 5.5 - Oxidation of $\mathbf{3 4}$ with hydrogen peroxide 126

Figure 5.6 - Enzymatic oxidation of 34 by GOX at various glucose concentrations 127

Figure 5.7 - CV of crosslinked polyurethane film of $\mathbf{4 1} \quad 130$

Figure 5.8 - Chronoamperometry of a crosslinked polyurethane film of 41 using a 5

second stepping time 132

Figure 5.9 - Chronoamperometry of a crosslinked polyurethane film of 41 using a 2.5

second stepping time

Figure 5.10 - Chronoamperometry at $1310 \mathrm{~nm}$ of a crosslinked polyurethane film of $\mathbf{3 9}$

using a 5 second stepping time

Figure 5.11 - Chronoamperometry at $980 \mathrm{~nm}$ of a crosslinked polyurethane film of 39 using a 5 second stepping time 


\section{List of Tables}

Table 1.1 - Coloration efficiency dependence of $\mathrm{WO}_{3}$ electrochromes $\quad 11$

Table 1.2 - Optical properties of some polythiophenes 19

Table 2.1 - Identification, melting points and yields of hydroxyl ligands prepared 36

Table 2.2 - Identification, melting points and yields of other ligands 38

Table 3.1 - Electrochemical properties of the ruthenium complexes $\quad 57$

Table 3.2 - Spectroelectrochemical properties of ruthenium complexes 61 


\section{List of abbreviations}

$\begin{array}{ll}\text { AIBN } & \text { Azobisisobutyronitrile } \\ \text { Alq }_{3} & \text { tris(8-hydroxyquinolinato)aluminium } \\ \text { AM } & \text { acrylamide } \\ \text { APS } & \text { ammonium persulfate } \\ \text { ATR } & \text { attenuated total reflectance } \\ \text { bpy } & 2,2 \text {-bipyridine } \\ \text { CDI } & 1,1 \text { '-carbonyldiimidazole } \\ \text { CE } & \text { counter electrode } \\ \text { COSY } & \text { correlation spectroscopy } \\ \text { CTAB } & \text { cetyl trimethylammonium bromide } \\ \text { CV } & \text { cyclic voltammetry } \\ \text { DABCO } & \text { 1,2-diazabicyclo[2,2,2]octane } \\ \text { dB } & \text { decibel } \\ \text { DCC } & \text { dicyclohexylcarbodiimide } \\ \text { DCH } & \text { diacyl hydrazyde } \\ \text { DCM } & \text { dichloromethane } \\ \text { DEAD } & \text { diethylazodicarboxylate } \\ \text { DIAD } & \text { diisopropylazodicarboxylate } \\ \text { DMAP } & \text { dimethylamino pyridine } \\ \text { DME } & \text { 1,2-dimethoxyethane } \\ \text { DMF } & \text { N,N-dimethylformamide } \\ \text { DMSO } & \text { dimethylsulfoxide } \\ \text { DW } & \text { distilled water } \\ \text { EC } & \text { electrochromic } \\ \text { ECD } & \text { electrochromic display } \\ \text { EDOT } & \text { 3,4-ethylenedioxythiophene } \\ \text { EI } & \text { electron ionisation } \\ \text { EPA } & \text { anodic potential } \\ \text { EPC } & \text { cathodic potential } \\ \text { ESI } & \text { elestrospray ionisation } \\ \text { ESR } & \text { electron spin resonance } \\ \text { FAD } & \text { flavin-adenine dinucleotide } \\ \text { FT-IR } & \text { Fourrier transform infrared } \\ \text { GOX } & \text { glucose oxidase } \\ \text { GPC } & \text { gel permeation chromatrography } \\ \text { ID } & \text { refractive index } \\ \text { HMBC } & \text { heteronuclear multiple bond correlation } \\ \text { HMDI } & \text { hexamethylene diisocyanate } \\ \text { HOMO } & \text { highest occupied molecular orbital } \\ \text { HSQC } & \text { heteronuclear single quantum correlation } \\ \text { ICP-MS } & \text { inductively coupled plasma mass spectrometry } \\ \text { iR } & \text { infrared } \\ & \text { indium-doped tin oxide } \\ \text { ITO } & \end{array}$




$\begin{array}{ll}\text { LUMO } & \text { lowest unoccupied molecular orbital } \\ \text { MBA } & \text { methylene bisacrylamide } \\ \text { MeCN } & \text { acetonitrile } \\ \text { MLCT } & \text { metal-to-ligand charge transfer } \\ \text { MMLCT } & \text { metal-metal-to-ligand charge transfer } \\ \text { Mp } & \text { melting point } \\ \text { mpbq } & \text { 2-Methyl-3-phenyl-benzo[g]quinoxaline } \\ \text { mpq } & \text { 2-Methyl-3-phenylquinoxaline } \\ \text { MS } & \text { mass spectrometry } \\ \text { NHE } & \text { normal hydrogen electrode } \\ \text { NIR } & \text { near infrared } \\ \text { NMR } & \text { nuclear magnetic resonnance } \\ \text { NOESY } & \text { nuclear overhauser effect spectroscopy } \\ \text { ORTEP } & \text { Oak Ridge thermal ellipsoid program } \\ \text { OTTLE } & \text { optically transparent thin layer electrode } \\ \text { OXA } & \text { oxamide } \\ \text { PB } & \text { prussian blue } \\ \text { PC } & \text { polycarbonate } \\ \text { PG } & \text { prussian green } \\ \text { PL } & \text { photoluminescence } \\ \text { ppy } & \text { 2-phenylpyridine } \\ \text { pq } & \text { 2-phenylquinoline } \\ \text { PW } & \text { prussian white } \\ \text { PX } & \text { prussian brown } \\ \text { RBF } & \text { round bottomed flask } \\ \text { RE } & \text { refererence electrode } \\ \text { R } & \text { retention factor } \\ \text { SCE } & \text { standard calomel electrode } \\ \text { TBAH } & \text { tetrabutylammoniym hexafluorophosphate } \\ \text { TEA } & \text { riethylamine } \\ \text { terp } & \text { terpyridine } \\ \text { TGA } & \text { thermogravimetric analysis } \\ \text { THF } & \text { tetrahydrofuran } \\ \text { TLC } & \text { thin layer chromatography } \\ \text { TMED } & \text { tetramethylene ethylene diamine } \\ \text { TMP } & \text { trimethylolpropane } \\ \text { TMP-NCO } & \text { tromethylolpropane, carbamate with xylene diisocyanate } \\ \text { Tris } & \text { 2-Amino-2-(hydroxymethyl)-1,3-propanediol } \\ \text { UV } & \text { ultraviolet } \\ \text { Vis } & \text { visible } \\ \text { VOA } & \text { variable optical attenuator } \\ \text { WE } & \text { working electrode } \\ & \end{array}$




\section{Chapter 1 - Introduction}

\section{1 - Electrochromic materials}

Electrochromism, a term first used by Platt ${ }^{1}$, is defined as a reversible change in absorbance produced by electroactive materials when switching between oxidation states. One example is aqueous ferrous cyanide which is pale yellow but, upon oxidation, becomes bright yellow due to the ferric cyanide formed ${ }^{2}$. This change in absorbance can be at any wavelength in the electromagnetic spectrum although most electrochromes (EC) absorb in the visible portion of the spectrum. Since two differently-colored states are always considered, these are often referred to the bleached and colored states where the former represents the lesser colored or colorless form of an EC. This coloration can develop through anodic (oxidative) or cathodic (reductive) processes. For example, tungsten, titanium, molybdenum and cobalt oxides change color cathodically while iron, iridium and niobium oxides change color anodically ${ }^{3}$. The coloration mechanism of these oxides and other electrochromes will be discussed in more detail in section 1.4.1.

Electrochromes are typically divided in three categories. Electrochromes that remain in solution following a redox reaction are of type I, those soluble in bleached form but become colored solid electrodeposits are of type II, and lastly, type III electrochromes are defined as being solid in both redox states ${ }^{3}$. 


\section{Chapter 1 - Introduction}

\section{2 - Electrochemical characterization of electrochromic materials}

Electrochromes can be studied either by chemical or electrochemical means. However, the latter is more practical since foreign species are not introduced into the equation (assuming high chemical purity). Electrochemical cells can be made up of two (static) or three (dynamic) electrodes. In a two electrode system, the potential at both electrodes is altered by current flowing through the cell which must be controlled with a high degree of precision. This is however not possible when using a two electrode system due to a potential drop across the cell arising from the solution resistance and polarization of the counter electrode (CE) completing the circuit. Control can be ensured by using a third electrode. The potential of the cell where the electrochemical reaction of interest occurs, is measured not by the potential difference between the working electrode (WE) and the $\mathrm{CE}$, but rather between the WE and the third electrode, the reference electrode (RE), which no net current passes through, effectively keeping the potential constant. The shape of the current-voltage curve (i.e. voltammogram) obtained is dictated by the flux of materials at the electrode which can be described by Fick's law. Fick's first law relates the flux of materials, $\mathrm{j}_{\mathrm{i}}$, to its concentration gradient, $\left(\partial \mathrm{c}_{\mathrm{i}} / \partial x\right)$, by

$$
j_{i}=-D_{i}\left(\frac{\partial c_{i}}{\partial x}\right)
$$

Equation 1.1

where $\mathrm{D}$ is the diffusion coefficient of the species. It should be stated that the concentration gradient arises from consumption of species near the electrode ${ }^{2}$.

In cyclic voltammetry, the current is monitored against an applied potential. When scanning towards more positive potentials, oxidation occurs and the current 


\section{Chapter 1 - Introduction}

generated peaks near the redox potential of the material analyzed. Once the end of the potential range is reached, it is reversed and the reduction peak is observed. Figure 1.1 depicts a typical cyclic voltammogram (CV). Usually, the current is cycled from negative to positive and back, but the initial scanning direction is subject to the material analyzed and user preferences. The anodic potential, $\mathrm{E}_{\mathrm{pa}}$, is the potential at which the anodic current, $I_{p a}$, reaches its apex. In the same way, the cathodic potential, $\mathrm{E}_{\mathrm{pc}}$, is the potential at which the anodic current, $I_{p c}$, reaches its minimum value. Comparing the shape and amplitude of both redox waves yields additional information about the system stability. Potential discrepancies between both waves denote some irreversibility and can be caused by product degradation, and more commonly, by adsorption or deposition of the electroactive species on the electrode. To obtain the redox potential, $\mathrm{E}$, the average of $\mathrm{E}_{p c}$ and $\mathrm{E}_{p c}$ is taken.

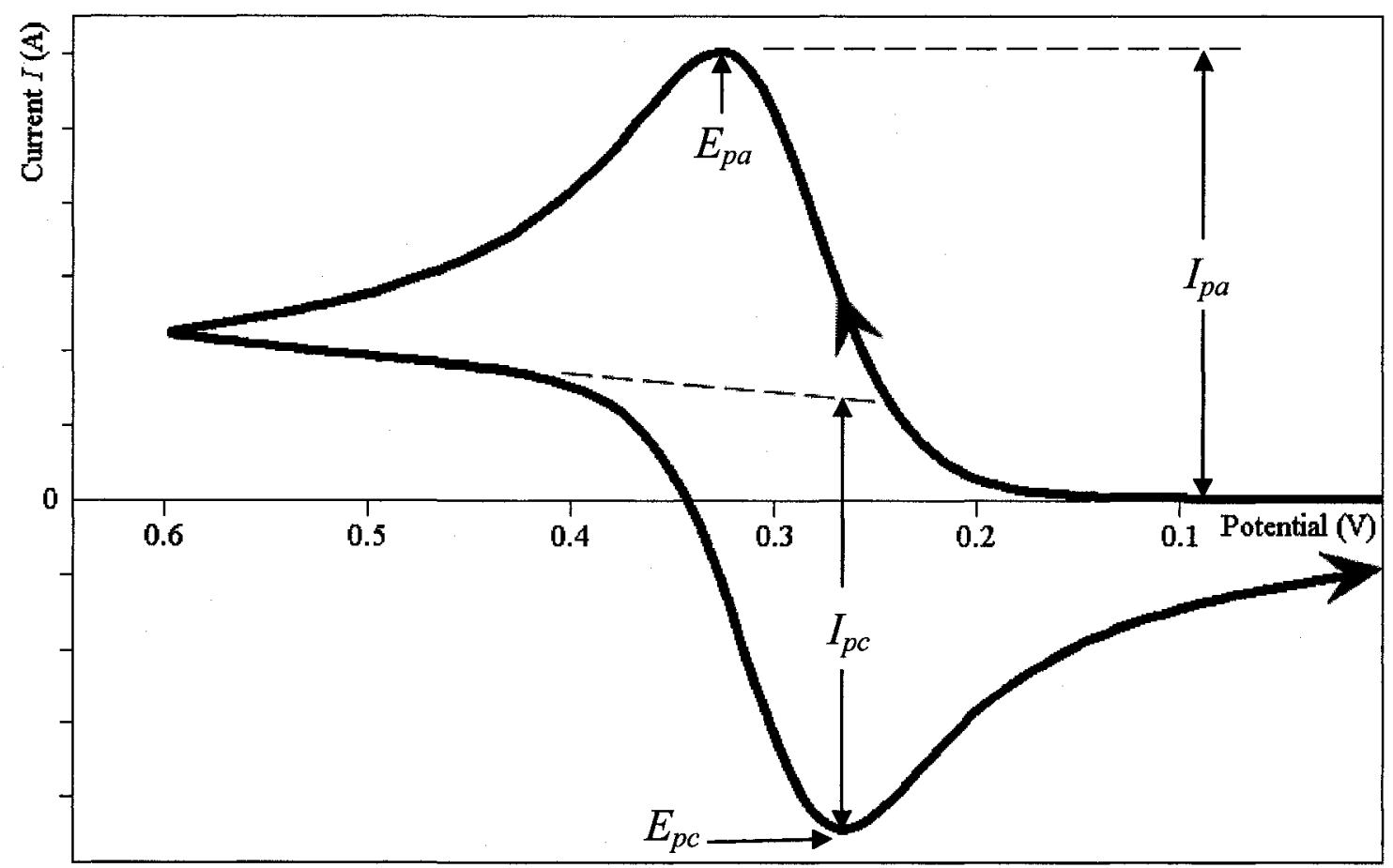

Figure 1.1 - Simulated CV of a reversible one-electron redox couple ${ }^{3}$ 
Redox potentials are normally referenced against aqueous-based electrodes such as the normal hydrogen (NHE) or the saturated calomel (SCE) electrodes. Since organic compounds are mostly insoluble in water, $\mathrm{CV}$ is generally done in compatible organic solvents, which renders aqueous based reference electrodes unusable and, unfortunately there are no reliable reference electrodes for use in organic solvents. To overcome this, a silver (or platinum) wire can be used as a pseudo reference electrode. The IUPACrecommended reference materials of choice are the ferrocene/ferrocenium $\left(\mathrm{Fc}^{+} / \mathrm{Fc}\right)$ or bis(biphenyl)chromium(0)/ bis(biphenyl)chromium(I) couples ${ }^{4,5}$. The reference value of the $\mathrm{Fc}^{+} / \mathrm{Fc}$ system depends on the solvent and supporting electrolyte employed. Tetraalkyl ammonium hexafluorophosphate or perchorate salts are commonly used as electrolytes and, fortunately, formal potentials of $\mathrm{Fc}^{+} / \mathrm{Fc}$ in selected solvents have been conveniently tabulated by Connely ${ }^{6}$. While the choice of solvent and electrolyte depends on the analyte, both must be of high purity. Even in trace amounts, impurities can drastically affect electrochemical measurements either by interacting with the analyte in question or by diminishing the usable potential range of the solvent (see Figure 1.2). For instance, anhydrous propylene carbonate which generally has a potential range of -3.6 to $3.2 \mathrm{~V}$, which is reduced to -2.5 to $2.5 \mathrm{~V}$ when contaminated with $0.1 \mathrm{M}$ water. Granted, in this scenario, the usable range is adequate for most analytes but the effects are still significant. Another example, acetonitrile, a versatile solvent for electrochemical measurements, is often contaminated by water, ammonia, acetic acid, propionitrile, acrylonitrile, allyl alcohol, acetone and benzene ${ }^{4}$. Dissolved oxygen can also be problematic; being redox active itself, it can form reactive species which can interfere 
with the analyte of interest. Purging the solvent with inert gas such as nitrogen or argon tackles this issue.

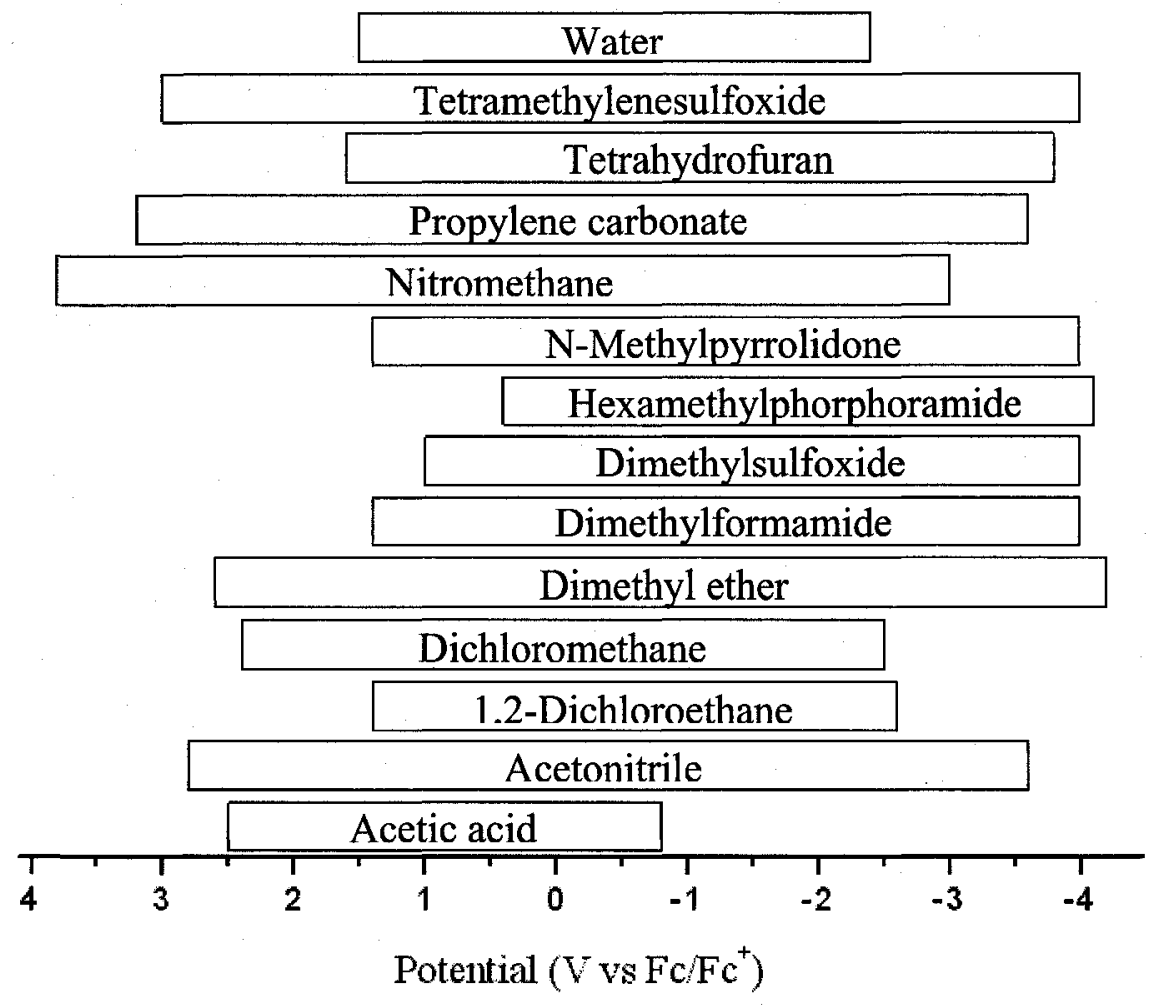

Figure 1.2 - Solvent optimal voltametric operating range ${ }^{4}$

Spectroelectrochemistry, the spectral analysis of the different EC material oxidation states, is done by hyphenating a potentiostat to a spectrophotometer. An optically transparent thin layer electrode (OTTLE) cell (Figure 1.3) is used to house the three electrodes and the solution or the solid film to be analyzed (both situation still require a supporting electrolyte to ensure conductivity between electrodes). Thin platinum wire manually braided and arranged to form a crude mesh, act as the WE while another piece of platinum wire makes up the CE. The RE is composed of a silver wire and serves as a pseudo-reference. These electrodes are kept in place via a two layer 


\section{Chapter 1 - Introduction}

laminate low-density polyethylene spacer (light gray area of Figure 1.3a). This laminate is produced by arranging all the pieces between microscope slides, clamping the unit and heating at $120^{\circ} \mathrm{C}$ in an oven for a few minutes, until both plastic layers melt into one another. The resulting thickness is normally less than a millimeter and the path length can be measured accurately using a digital caliper. Heating for too long results in distorting the spacer's shape causing irreversible damage since the thickness of the plastic will equal that of the electrodes and prevents adequate sealing. Two quartz windows, one with drilled filling holes, form a sandwich (Figure 1.3b) with the spacer. Appropriate rubber spacers at the metal-glass interface are placed to prevent damage to the windows from over tightening. The assembled cell (Figure 1.3c) fits into standard cell holders and in situ optical measurements can then be made at different potentials to observe the optical properties of the different oxidation states of the EC. Even with such a small volume, the diffusion rate of the electroactive species is quite limited and the electrolysis of the entire sample is very slow. The area of interest is encompassed by the mesh of the WE where the oxidation process is rapid and the electrochromic specie within this area is uniformly of the same state. Opaque tape can used to mask the area around the WE so that the incident beam of the spectrometer passes through this area only. 


\section{Chapter 1 - Introduction}

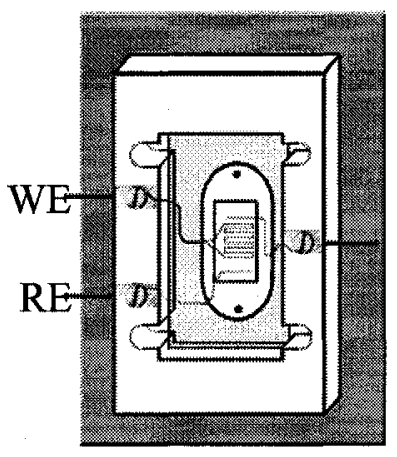

a)

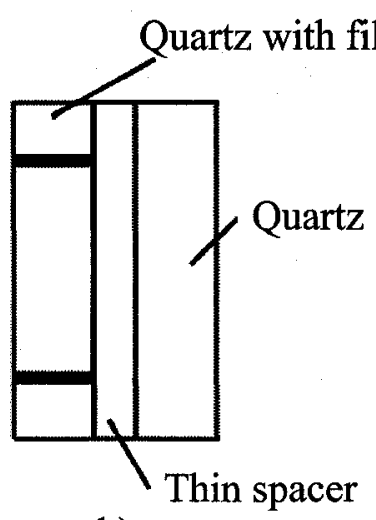

b)

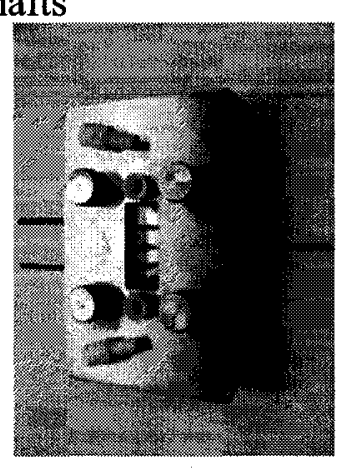

c)

Figure 1.3 - OTTLE cell assembly: a) innards, b) side view, and c) assembled cell

\section{3 - Other characterization parameters}

Unfortunately, the chromism of a material does not guarantee direct applications. It must also be stable and provide efficient switching between the targeted redox states. The optical performance of an electrochrome is evaluated by applying square wave potential steps that switch the material's redox states. Integrating the current-time trace generated by the potential pulse and measuring the film area yields the injected charge

density, $\mathrm{Q}\left(\mathrm{C} \cdot \mathrm{cm}^{-2}\right)$. The color efficiency, $\eta$, is described as the amount of color formed (change in absorbance) between redox states for a given $Q$ (equation 2) and should be as high as possible.

$$
\text { Absorbance }=\eta \times Q
$$

Equation 1.2

The response time is defined as the time required to attain the colored state from its bleached state (or vice versa) and the order of magnitude of this parameter may dictate the applications of the electrochrome in question particularly when fast switching times are required (Figure $1.4 \mathrm{a}$ ). The intensity of the colored state will gradually diminish with 
each ON/OFF cycle due to material degradation (electrochrome and/or electrode). It is also possible that the coulombic efficiency of the redox process is less than $100 \%$ and thus a small portion of one state will not switch to the other. After a certain number of cycles (figure 1.4b), the device is deemed inoperable and it is this number of cycles that defines the cycle life. The contrast ratio, which is another mean to evaluate the color intensity, can also be determined using Figure $1.4 \mathrm{~b}$ and is defined as the transmission ratio between bleached and colored states. For example, in Figure 1.4b, the bleached state has $100 \%$ transmittance while the colored state has $20 \%$ transmittance, giving a contrast ratio of 5. Finally, when power requirement is an important parameter, such as in display or memory applications, the memory effect may be considered and electrochromes that do not require a continuous potential to maintain their colored state, are used.
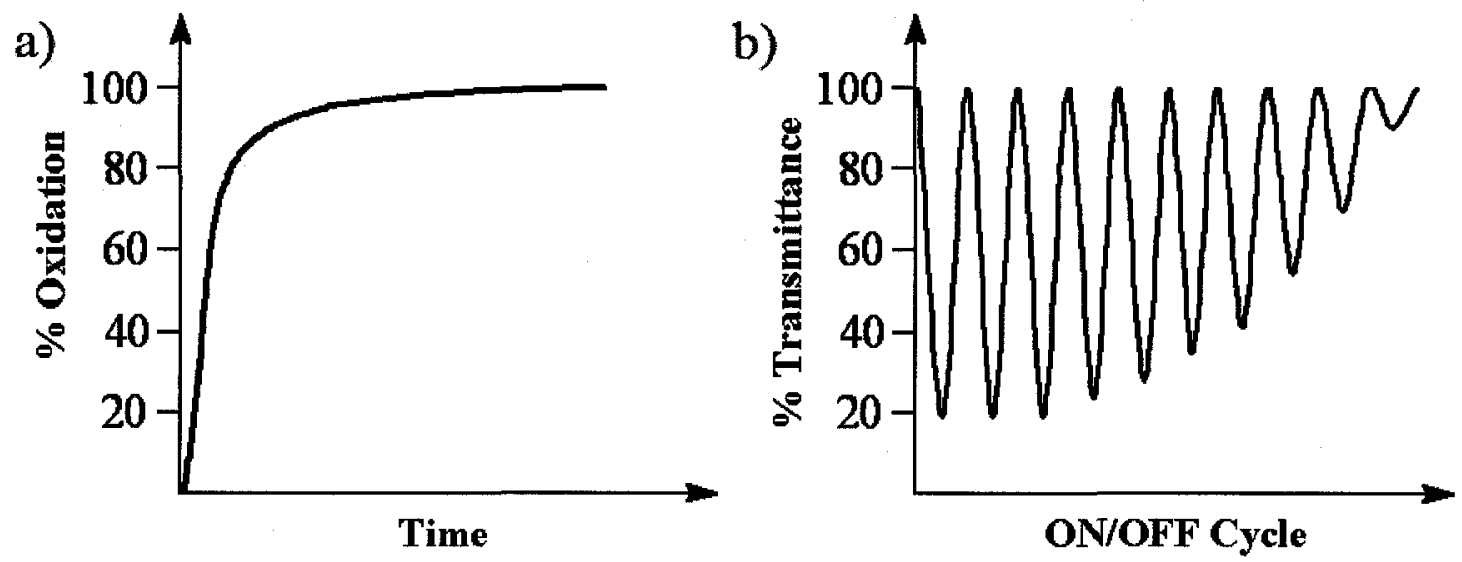

Figure 1.4 - Schematic representations of a) response time and b) contrast ratio and electrochemical stability 
1.4 - NIR-active electrochromic materials

\subsection{1 - Metal oxides}

Many metal oxides express electrochromism ${ }^{7,8}$ but only oxides of tungsten ${ }^{2,3,9}$,

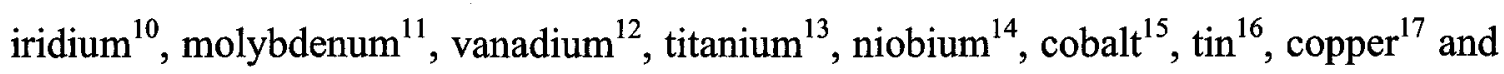
iron $^{18}$ have significant activity beyond the visible region of the electromagnetic spectrum ( $>700 \mathrm{~nm}$ ). Tungsten oxide is by far the most widely employed electrochrome in visible applications. It is colorless or light blue in the bleached state, but intense blue in the reduced form. To maintain charge neutrality, this reduction also involves ion insertion; the redox reaction taking place is

$$
W O_{3}+x\left(M^{+}+e^{-}\right) \rightarrow M_{x} W_{(1-x)}^{V I} W_{x}^{V} O_{3}
$$

Equation 1.3

where $\mathrm{M}$ is the inserted cation which can be an alkaline metal or $\mathrm{H}^{+}$and where $x$ is the degree of insertion. This system is fully reversible when $\mathrm{x}<0.2$. Higher degree of insertion irreversibly leads to 'bronze' formation, i.e. a golden-brown reflective metallic surface $^{3}$. It is widely accepted that the color formation mechanism stems from an intervalence transition by the $\mathrm{W}^{\mathrm{V}}$ electrons hopping to neighbouring $\mathrm{W}^{\mathrm{VI}}$ sites. However, electron spin resonance (ESR) spectroscopy, recorded at $4.2 \mathrm{~K}$, of a $\mathrm{H}_{x} \mathrm{WO}_{3}$ film with a low degree of insertion, did not detect unpaired electrons on the $\mathrm{W}^{\mathrm{V}}$ sites. Therefore it has been proposed that ground state electrons are paired or that electrons are localized over larger regions of $\mathrm{W}^{\mathrm{V}}$ sites $^{19}$.

The visible blue color of reduced $\mathrm{WO}_{3}$ implies absorbance of the longer wavelengths and thus, not surprisingly, its $\lambda_{\max }$ appears at $980 \mathrm{~nm}$. The morphology of 


\section{Chapter 1 - Introduction}

$\mathrm{WO}_{3}$ and the introduction of impurities can impact the position of $\lambda_{\max }$ which can range from $900 \mathrm{~nm}$ to $1300 \mathrm{~nm}^{20,21}$. While a fast reduction of this oxide is achieved, its reoxidation to the bleached state is dependent on the morphology of the material and can require a longer time period to reach an acceptable level. This slower response time can limit its potential applications, particularly when speed is not an important issue such as it would be the case with smart glass ${ }^{3}$. While a variety of preparation methods could improve the switching speed of derived films, it was the development of faster liquid crystal displays that shattered any hopes of using $\mathrm{WO}_{3}$ in display technologies ${ }^{22}$.

Nevertheless, metal oxides do present some advantages. Their main advantage is their high photostability in comparison to most organic-based electrochromes, giving metal oxides the upper hand on cycle life. However, metal oxides are not without issues as they do demonstrate some photodegradation, are chemically unstable, especially towards water, form brittle films regardless of the preparation method, and have low color efficiencies ${ }^{3}$.

Preparation of metal oxide films is achieved via numerous methods such as thermal evaporation, chemical vapour deposition, sputtering, electrodeposition, and solgels $^{3}$. Each method has its advantages and will influence the resulting film morphology from amorphous to crystalline. Once again, using tungsten oxide as the exemplar material, Table 1.1 shows the colour efficiencies $(\eta)$ obtained via various preparation techniques. The insertion coefficient $(x)$ also governs $\eta$, but since this value is restricted to $x<0.2$, to maintain reversibility, increasing $\eta$ relies on improving preparative methods. 
Table 1.1 - Coloration efficiency dependence of $\mathrm{WO}_{3}$ electrochromes

\begin{tabular}{lllll}
\hline Preparative route & Morphology & $\eta\left(\mathrm{cm}^{2} \mathrm{C}^{-1}\right)$ & $\lambda_{\text {obs }}(\mathrm{nm})$ & Reference \\
\hline Electrodeposition & Amorphous & 118 & 633 & 23 \\
Thermal evaporation & Amorphous & 115 & 633 & 24 \\
Sputtering & Polycrystalline & 42 & 650 & 24 \\
Sol-gel & Crystalline & 70 & 685 & 25 \\
Sol-gel & Crystalline & 167 & 800 & 26 \\
Spin-coated gel & Crystalline & 64 & 650 & 27 \\
\hline
\end{tabular}

It is interesting to note that high $\eta$ values can be achieved for both amorphous and crystalline films. Amorphous films have some degree of porosity and facilitate cationic diffusion, explaining the high $\eta$ values. The surface area may also be playing a role. It is unclear why the crystalline film, obtained by the sol-gel methodology, has a $\eta$ value of $167 \mathrm{~cm}^{2} \mathrm{C}^{-1}$, but since it was evaluated at a longer wavelength, the direct comparison to the other preparative routes is unreliable.

\subsection{2 - Hexacyanometallates: Prussian blue}

Pussian blue, PB, ferrocyanide or iron(III) hexacyanoferrate(II) is the main metallate of this family of electrochromes. PB was discovered by Diesbach in 1704 and has been used in paints as a blue pigment and was the main component of 'blueprints' for several decades ${ }^{3}$. It is simply prepared by mixing solutions of hexacyanoferrate(III) salt with iron(II) chloride followed by the collection of the insoluble blue precipitate. However, in this state, PB can only be used as a pigment. PB is characterized by a mixedvalence system where iron(III) is chelated by cyanide ligands, while the iron(II) is chelated to the nitrogen of the cyanides. The resulting conjugation between the iron atoms (Figure 1.5) makes it ideal for intervalence charge-transfer (IVCT) and it is this 


\section{Chapter 1 - Introduction}

electron hopping that generates the coloring transition. The absorbance resulting from the IVCT is centered near $700 \mathrm{~nm}$ and its onset extends to $1200 \mathrm{~nm}^{3}$. Thin films of PB can be prepared using various techniques, but electrodeposition is preferred ${ }^{28-33}$.
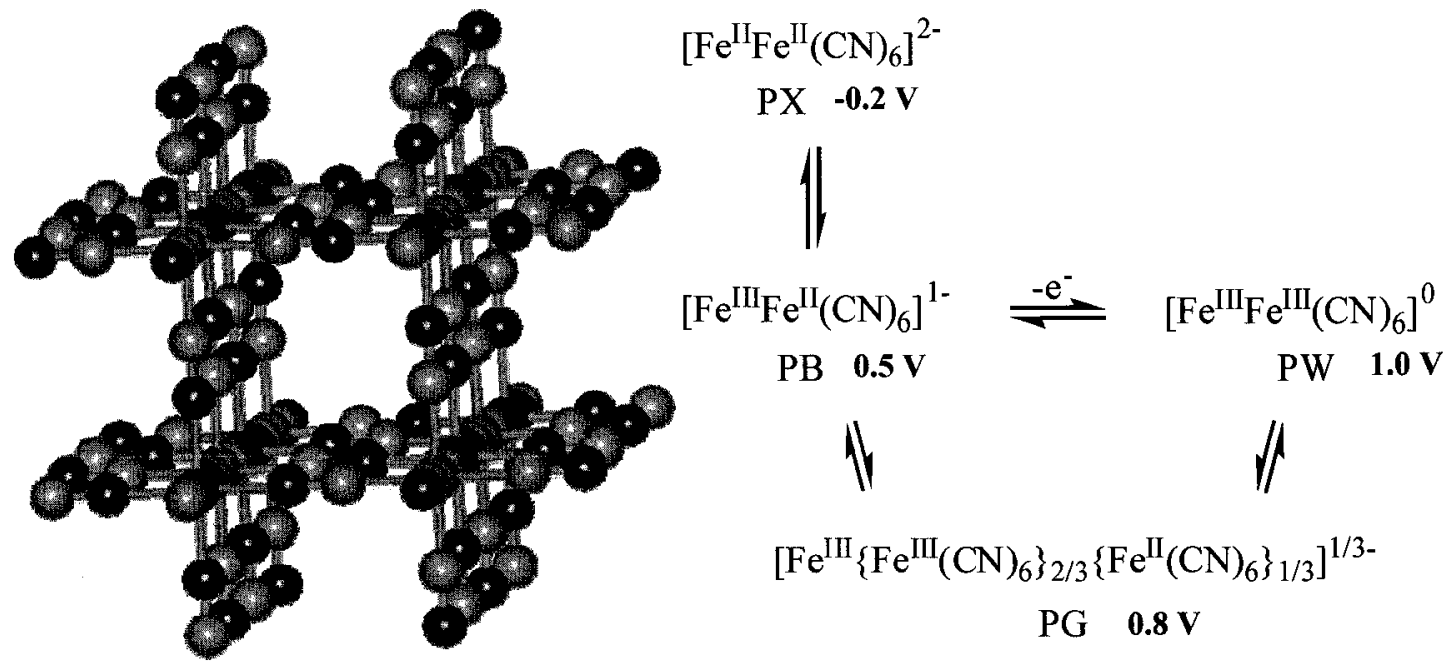

Figure 1.5 - 3-D model of $\mathrm{PB}$ and corresponding redox reactions

When fully oxidized to $\mathrm{Fe}(\mathrm{III})-\mathrm{Fe}(\mathrm{III}), \mathrm{PB}$ presents a white/transparent color and is named Prussian white (PW). The chromism of this cyanometallate does not stop here: the fully reduced PB turns brown and is similarly called Prussian brown (PX). Moreover, there is also an intermediate form between $\mathrm{PB}$ and $\mathrm{PW}$ where partial oxidation is achieved and a green color develops - this one is cleverly called Prussian green (PG). Polychromism, the ability of an electrochrome to display multiple colours, is somewhat of a rare property. Since the discovery of electrochromic properties of $\mathrm{PB}$, many mixed metal analogues of PB have been prepared, either by mixing the usual iron(II) salt to $\mathrm{M}(\mathrm{III}) \mathrm{CN}_{6}$ or by electrochemical means. The resulting materials were not as impressive as PB: some of which demonstrate electrochromism only in the UV spectrum, some are 
only capable of two- or three-colors (no PG analogue) and others, such as the palladiumiron cyanometallate analogue, only show redox activity from the iron atoms ${ }^{3}$.

\subsection{3 - Radical anions of conjugated diimides and diquinones}

Both diimides and diquinones (Figure 1.6) can be reduced to radical anions and their extended conjugation promotes a low bandgap transition that appears in the NIR region. The diimide radical anions absorb broadly at $1250 \mathrm{~nm}$; additionally when its concentration within the polymer matrix is increased, this absorbance is extended well past $2.5 \mu \mathrm{m}^{34}$. Conversely, the absorbance of diquinone radials is a function of substituents and can range from 900 to $1700 \mathrm{~nm}^{35}$. Both have been incorporated into polymers and used to make films.

a)

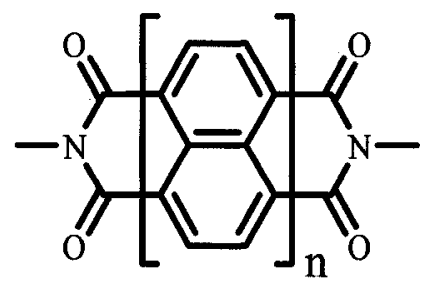

$$
\mathrm{n}=1,2,3,4
$$

b)

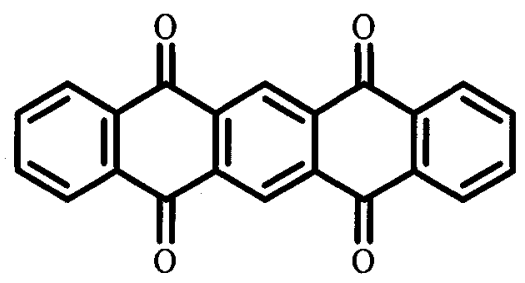

Figure 1.6 - General structure of a) diimides and b) diquinones

These compounds make great electrochromes, but as is the case with most organic-based ECs, they are susceptible to photodegradation ${ }^{3}$. Moreover, their radical anions can also undergo oxidative degradation, increasing their manufacturing costs ${ }^{36}$. Electrochromes containing both quinones and imides have also been prepared, combining their properties into one single molecule (Figure 1.7) ${ }^{37}$. The 6-nitro anthraquinone imide radical anion absorbs from $500 \mathrm{~nm}$ and has an onset of $1700 \mathrm{~nm}$ while its neutral form 
has no optical absorbance past $400 \mathrm{~nm}$. Substituting the nitro group for a bromide causes a hypsochromic shift, effectively tuning the absorbance.<smiles></smiles>

Figure 1.7 - Structure of quinone-imine EC

\subsection{4 - Porphyrins and phthalocyanines}

Porphyrins are a naturally occurring ring systems built from four pyrroles which are conjugated through methynes (Figure 1.8). These can be prepared with various functional groups at the eight $\beta$ positions and four meso positions. Their phthalocyanine (PC) cousins have an extra phenyl moiety fused to the two $\beta$ positions of each pyrrole ring. Given their highly delocalized $\pi$ system, these are highly coloured molecules and are often found bound to metals such as magnesium in chlorophyll and iron in haemoglobin.

a)

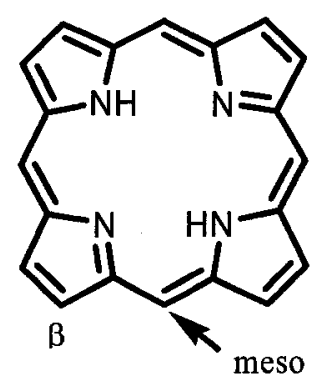

b)

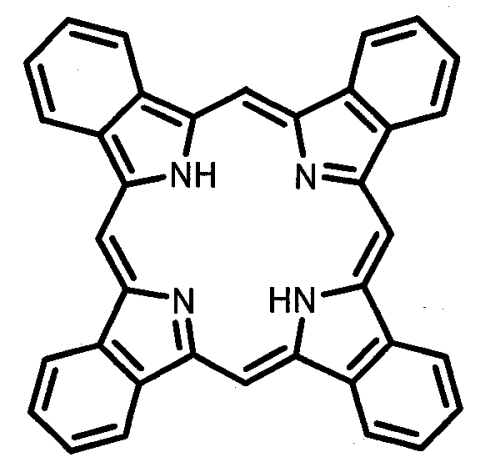

c)

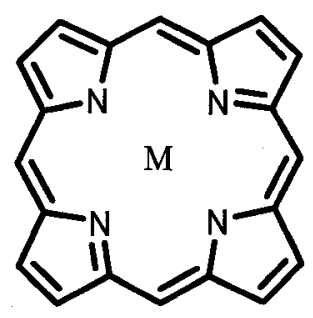

Figure 1.8 - Structures of a) porphyrin, b) phthalocyanine and c) metallized porphyrin ( $\beta$ and meso positions are defined) 


\section{Chapter 1 - Introduction}

These complexes are usually blue or green and consequently the absorbance maximum is found in the far red region. If the metal center is small, it can lie within the ring cavity; however larger metals such as lanthanides, form sandwich-type molecules akin to ferrocene. The most studied complex of this type is bis(phthalocyaninato)lutetium(III) which was discovered in $1970^{38}$. Not only does this complex exhibit a visible elecrochromism process ranging from green in its reduced form to yellow-tan in oxidized form, it also shows broad NIR absorbance most intense between 1200 and $1400 \mathrm{~nm}^{39}$. Metalloporphyrins constituted of the smaller metals barely break the NIR barrier, absorbing between 600 and $700 \mathrm{~nm}$.

It is also possible to prepare meso-meso fused arrays to redshift the absorbance maximum but, due to an almost $90^{\circ}$ dihedral angle between porphyrin units, the conjugation effect does not extend from one ring to another ${ }^{40}$. To permit the overlap of the $\pi$ orbitals, the dihedral angle must be eliminated; this can be achieved through oxidative double ring closure of the meso-meso linked porphyrins ${ }^{41-43}$. These triply fused dimers and oligomers (porphyrin tape) do exhibit NIR absorbance due to an extended conjugation and are also redox active $e^{44}$. However, literature on their electrochromic or spectroelectrochemical properties is not yet available. Other than fusion through the meso positions, rigidification has also been achieved through the $\beta$ positions by tetraamino benzene condensation with a diketone porphyrin ${ }^{45}$, through a phenyl fused to two pyrroles $^{46}$, and finally through a pyrrolo[3,4-c]pyrrole ${ }^{47}$ (fused pyrrole dimer). Yet, even though these systems are rigid, their absorbance past $800 \mathrm{~nm}$ was not recorded. Without this information, comparison with the triple-fused system is not possible though it is 


\section{Chapter 1 - Introduction}

expected that a three point fusion would enhance orbital overlap more efficiently than a two point fusion.

\subsection{5 - Conjugated polymers}

Extended conjugation is key in red-shifting the absorbance of organic molecules. In fact, each double bond added to an existing $\pi$ system induces a bathochromic shift of approximately $30 \mathrm{~nm}^{48}$. In theory, a molecule's absorption could be tailored quite precisely. Unfortunately, conjugation requires $\pi$ orbital overlap for electron delocalisation and the $\sigma$ bonds that separate the $\pi$ bonds can rotate, weakening or even nullifying the electron mobility based on the dihedral angle. This also holds true in conjugated polymers where many unsaturated monomers are bound together in linear fashion although with so many long chains interacting and potentially becoming entangled, twisting due to steric repulsion is inevitable. Nevertheless, with hundreds, even thousands of repeat units in each chain, the probability of sections of polymer that remain planar is quite high and every variant length of planar section is possible. As the absorption is dictated by the extent of conjugation, the resulting absorbance completely encompasses the visible and NIR regions and polymers are often black in appearance.

The first prepared conductive polymer was polyacetylene which is actually an insulator but when exposed to iodine a $10^{8}$-fold increase in conductivity is observed ${ }^{49}$. Following this discovery, it was thus understood that conjugated polymers required doping, in order to create formal charges on the polymer backbone and to truly render them conductive. Polyacetylene, like any other alkene, is unfortunately susceptible to oxidation and thus has seen few applications. In contrast, aromatic structures are very 
stable and so conjugated polymers derived from aniline, thiophene, 3,4ethylenedioxythiophene (EDOT), pyrrole, furan and fluorene were of interest (Figure 1.9). Of these, thiophene and aniline polymers are the most frequently encountered electrochromes in the literature ${ }^{3}$.

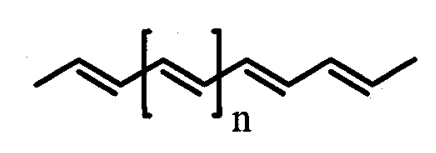

Polyacetylene

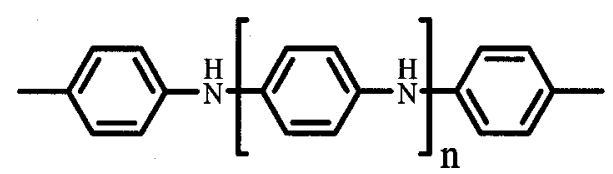

Polyaniline

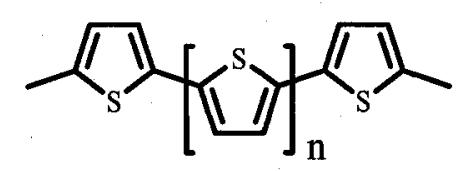

Polythiophene

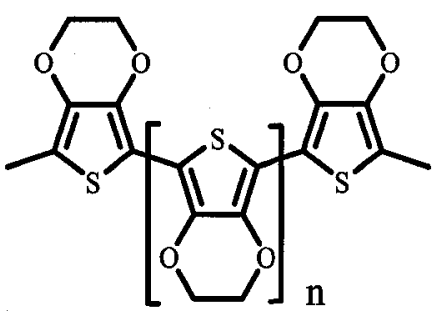

PEDOT

Polypyrrole

Figure 1.9 - Selected conductive polymers

At first glance, all the structures presented in Figure 1.9 are conjugated except for polyaniline which requires oxidative doping (through chemical or electrochemical processes) to become conductive and conjugated. Interestingly, by controlling the level of doping in polyaniline, it is possible to observe four redox states (Figure 1.10): the initial form (leucoemeraldine), is yellow in color and absorbs mainly in the UV region; the first oxidation specie (emeraldine salt) is green and is conductive; the second oxidation form named emeraldine base, is blue and partially conjugated, with some absorption in the NIR region; the fully oxidized and conjugated form of polyaniline (pernigraniline), is black and exhibits increased absorbance in the NIR region. 


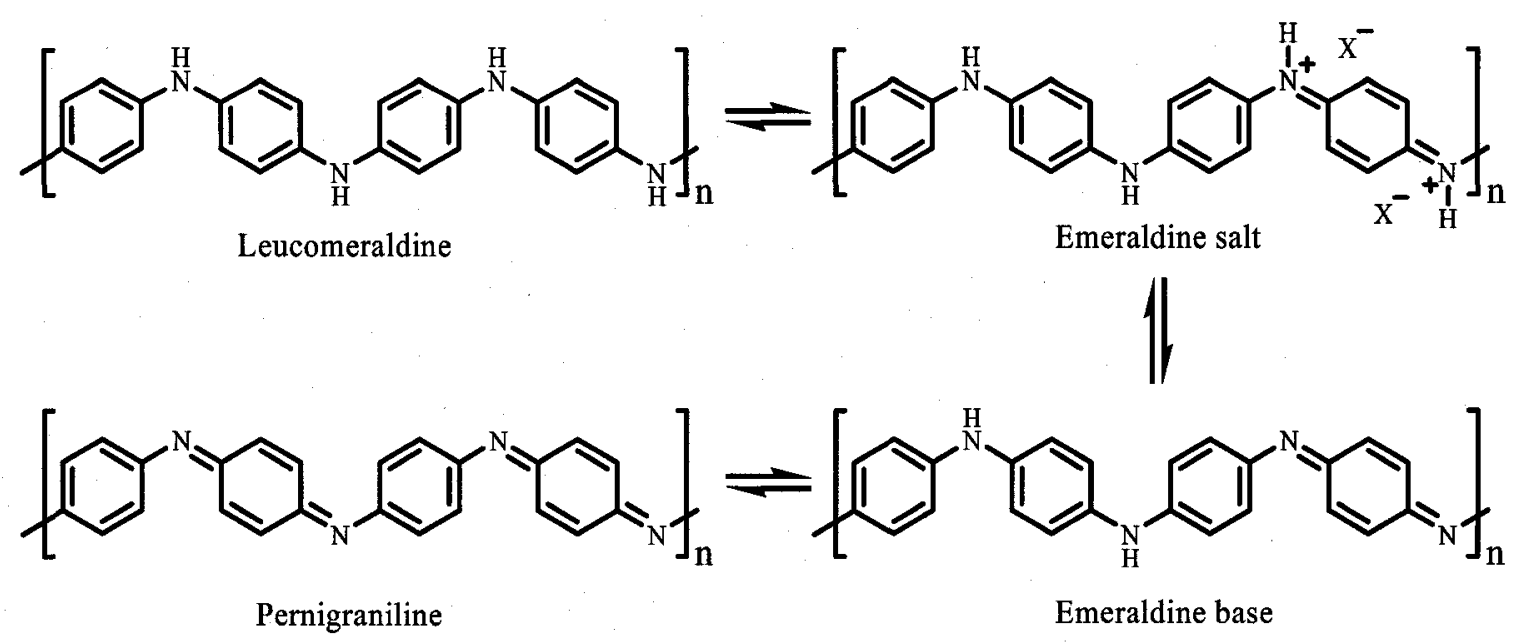

Figure 1.10 - Polyaniline redox states

Because of their rigid structure, the solubility of conjugated polymers is often poor and is an issue when material processing is considered. However, this can be overcome by the addition of aliphatic pendant chains on the monomers ${ }^{50}$. This solution is not without disadvantage as the symmetry of the monomer is usually lost and the polymerization can proceed via head-to-head, head-to-tail or tail-to-tail.

Finally, conductivity is closely related to response time which depends on the regular stacking of the chains in solid state. A regio-regular polymer is able to crystallize properly, or at least has a better chance of forming crystallite regions. The thiophene class of polymers can illustrate the optical effects of stereo-control over the polymer properties and a few examples are provided in table $1.2^{51}$. The effects of head-to-head and tail-totail assembly are purely steric and induce a dihedral angle at the common $\sigma$ bond of the polymer. This obviously reduces the electron delocalisation potential and a hypsochromic shift is observed for highly hindered oligomers ${ }^{3}$. As expected, regio-regular polythiophenes are more redshifted due to minimized steric hindrance and smaller 
dihedral angle. Other configurations result in hypsochromic shifts, some of which are less pronounced than others.

Table 1.2 - Optical properties of some polythiophenes

\begin{tabular}{llll}
\hline Monomer used & $\begin{array}{l}\lambda_{\max }(\mathrm{nm}) \text { of } \\
\text { undoped polymer }\end{array}$ & $\begin{array}{l}\text { Polymer color } \\
\text { (reduced) }\end{array}$ & $\begin{array}{l}\text { Polymer color } \\
\text { (oxidized) }\end{array}$ \\
\hline & 530 & Purple & Pale blue \\
\hline & 415 & Yellow & Violet \\
\hline
\end{tabular}

\subsection{6 - Transition metal complexes}

If metal oxides are the most studied electrochromes, transition metal complexes would stand in second place. Coordination complexes are typically easier to purify as their color makes it possible to visually track their evolution through a chromatography column - no fraction collection is required (unless overlap with another coloured compound occurs). The optical transitions that are responsible for the color involve the metal center and the coordinating ligands. The electronic transitions caused by light 
absorption can either be $d-d$ transitions or charge transfer bands. In a $d-d$ transition, a d orbital electron from the metal is excited and promoted to a more energetic $d$ orbital. The charge transfer bands require the participation of both the ligand and metal - when an electron from the ligand is excited to an empty orbital of the metal, ligand to metal charge transfer, or LMCT occurs ${ }^{52}$. There are normally four types of possible LMCTs (A, B, C and D) and they depend on electron and empty orbital availability (Figure 1.11a). The opposite, a metal to ligand charge transfer, or MLCT, where an electron from the metal ion is promoted to an empty ligand orbital is also possible but, as the name implies, it requires that the empty ligand orbital is of higher energy than the occupied metal orbital involved (Figure 1.11b). $\mathrm{MX}_{6}$ complexes, where $\mathrm{X}$ is a halogen, exhibit LMCT due to the halide low-energy occupied orbitals. MLCTs are observed when the coordinating ligands contain $\mathrm{CO}, \mathrm{CN}$ or aromatic amines such as bipyridines, which all have high energy empty orbitals ${ }^{52}$.

a)

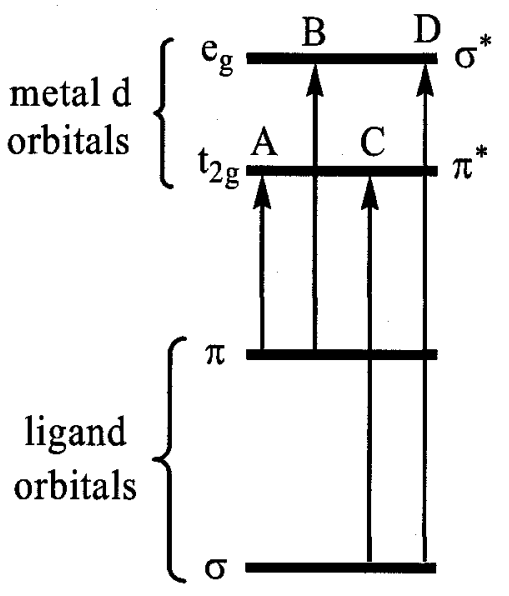

b)

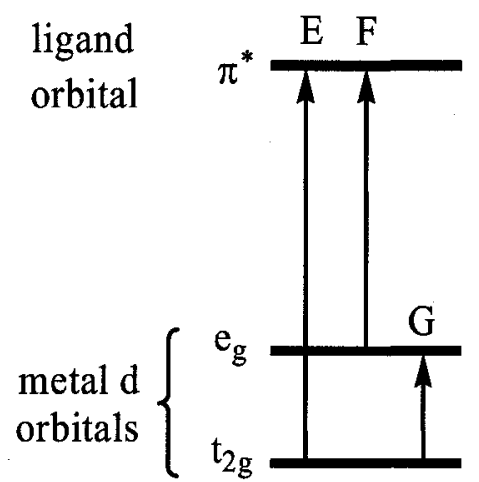

Figure 1.11 - Partial MO diagram for an octahedral complex: a) LMCT and b) MLCT

All the transitions shown in Figure 1.11 are allowed transitions even though $\mathrm{G}$ is not a charge transfer transition, but a $d-d$ transition. The Laporte ${ }^{53}$ rule states that when a 


\section{Chapter 1 - Introduction}

molecule has a center of symmetry, transitions within a given set of $p$ or $d$ orbitals are forbidden. However, a complex is almost never symmetric, in part due to the Jahn-Teller effect and asymmetric vibrations, and thus the normally forbidden $G$ transition is allowed. Even so, these transitions have the same optical characteristics as any other $d$-d transitions ${ }^{52}$. Charge transfer transitions are normally of high energy and fall in the UVVis spectrum.

The first reported series of NIR absorbing metal complexes are the square planar Ni, Pd and Pt dithiolenes (Figure 1.12) which, once oxidized to the radical anion, show an intense, broad, low energy transition that can range from 700 to $1400 \mathrm{~nm}$ depending on the nature of the dithiolate ligand ${ }^{3}$.
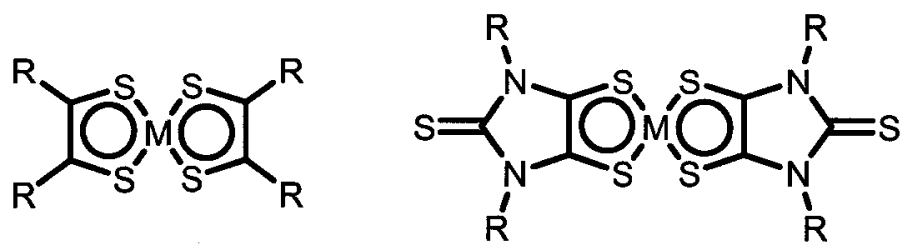

Figure 1.12 - Bis-dithiolene square planar complexes.

Because MLCTs and LMCTs are usually high energy transitions and thus only dd transitions have the required energy to be observed in the NIR region. However, $d-d$ transitions are much weaker than charge transfer transitions and experimentally, high molar extinction coefficients with the NIR active redox state of the dithiolene complexes are observed ${ }^{54}$. The weak d-d transitions are present and can be observed when the metal dithiolate is in a redox state that is not NIR active. Otherwise, the strong NIR transitions of the radical anion overlap and mask them completely. Schrauzer and Mayweg ${ }^{55}$ assigned the strong NIR transitions of the anion to $\pi \rightarrow \pi$ transitions while Gray ${ }^{56-58}$ and 
coworkers assigns them to $\mathrm{L}(\pi) \rightarrow \pi^{*}$ demonstrating that the transition assignment matter is subject to controversy and no definite answer is available although low bandgap charge transfers should be involved ${ }^{52}$. One thing is certain: electron delocalisation plays an important role in these NIR transitions and it has been shown through various complexes that the inductive effect of the $R$ functional groups (Figure 1.11) on the $\lambda_{\max }$ is significant $^{54}$.

Also of interest are the dinuclear ruthenium complexes. These complexes are coordinated through a bridging ligand and show strong electronic coupling of the two metal centers. Since the discovery of the Creutz-Taube ${ }^{59}$ complex, also known as 22-FVII, which shows some degree of electron transfer between the two metals, many analogues using various bridging ligands have appeared in the literature (Figure 1.13), 32 , $60-65$

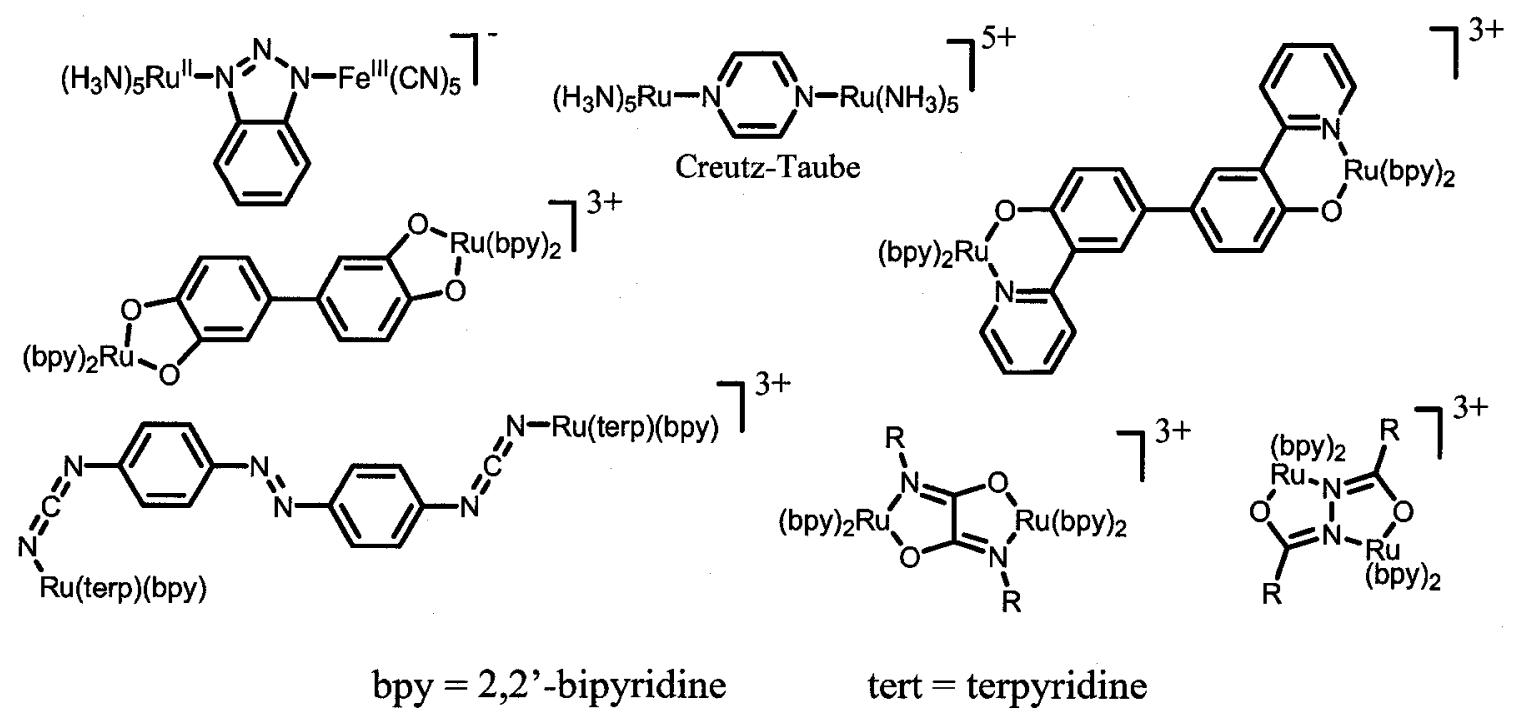

Figure 1.13 - Various dinuclear metal complexes (counter ions omitted for clarity)

What makes these dinuclear complexes NIR active? To answer this question, redox properties must be considered. Since most of the above examples are symmetrical, 
a single redox couple might be expected, but in fact, two couples are observed in these systems. All of the dinuclear ruthenium complexes shown above are usually isolated in the $\mathrm{Ru}^{\mathrm{II}} / \mathrm{Ru}^{\mathrm{II}}$ state and can be oxidised to a $\mathrm{Ru}^{\mathrm{II}} / \mathrm{Ru}^{\mathrm{III}}$ mixed-valence state with further oxidation to the $\mathrm{Ru} / \mathrm{III} / \mathrm{Ru}$ III state. As well as being electropolychromic in the visible region, monitoring of the mixed-valence oxidation state in the NIR region shows a broad intense NIR absorbance that ranges from 1100 to $2000 \mathrm{~nm}$. This transition is attributed to an inter-valence charge transfer, IVCT, between the two metal atoms, due to the electron on the $\mathrm{Ru}^{\text {II }}$ that can transfer to the $\mathrm{Ru}^{\text {III }}{ }^{52,59}$. Even though NIR research has focused primarily on ruthenium complexes because of their relatively simple synthesis and ideal electrochemical properties ${ }^{3}$, in theory any other metal that can undergo a one-electron oxidation is a potential candidate for NIR activity.

So far, the only other metal explored for such application is molybdenum ${ }^{66-71}$. Ward, McCleverty and coworkers have prepared a series of tris(pyrazolyl)borato-oxo molybdenum(V) complexes bridged by various conjugated diphenolates (Figure 1.14) ${ }^{66-}$ ${ }^{71}$. These also show two one-electron redox couples and, not only is the mixed valence $\mathrm{Mo}^{\mathrm{V}}-\mathrm{Mo}^{\mathrm{VI}} \mathrm{NIR}$ active (from 900 to $1554 \mathrm{~nm}$ ), the fully oxidized $\mathrm{Mo}^{\mathrm{VI}}-\mathrm{Mo}^{\mathrm{VI}}$ state is NIR active as well (832 to $1033 \mathrm{~nm}$ ) via a low energy $\mathrm{LMCT}^{3,67,68}$. Interestingly, two Mo-Mo complexes, in their fully oxidized state, based on the 2,5-(4-hydroxyphenyl)thiophene and 4,4'-dihydroxy azobenzene bridging ligands, absorb in the red and blue respectively. The azo group seems to be increasing the bandap to the point that the LMCT appears near the UV region ${ }^{68}$. 


\section{Chapter 1 - Introduction}
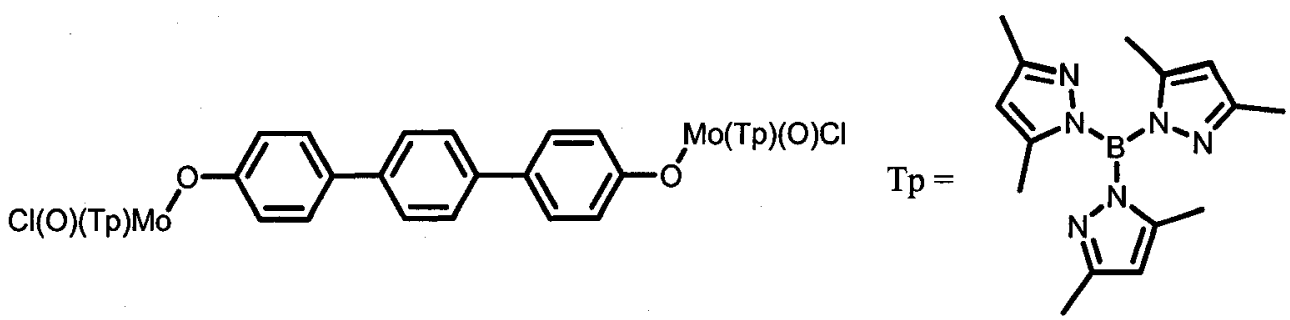

Figure 1.14 - Example of a dinuclear molybdenum complex

The various dinuclear complexes described above are proving to be good electrochromes, but is there room for improvement? If two metal centers are good, wouldn't three be better? Ward and coworkers have made a hexaphenolic conjugated bridging ligand, chelated with three ruthenium cations (Figure 1.15a) and instead of

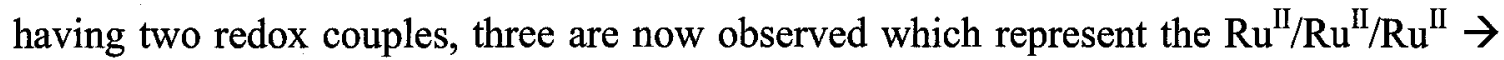
$\mathrm{Ru}^{\mathrm{II}} / \mathrm{Ru}^{\mathrm{II}} / \mathrm{Ru}^{\mathrm{III}} \rightarrow \mathrm{Ru}^{\mathrm{II}} / \mathrm{Ru}^{\mathrm{III}} / \mathrm{Ru}^{\mathrm{III}} \rightarrow \mathrm{Ru}^{\mathrm{III}} / \mathrm{Ru}^{\mathrm{III}} / \mathrm{Ru}^{\mathrm{III}}$ states which are all accessible at fairely low potentials, e.g. $1.03 \mathrm{~V}$ for the fully oxidized state. What is really interesting with this complex is that all four states are NIR active and that their molar extinction coefficients in the NIR are significantly higher than any previously reported dinuclear complex $^{72}$. Wang ${ }^{73}$ and coworkers have prepared a hexanuclear dendrimer-like ruthenium complex (Figure 1.15b), where the three inner ruthenium atoms are conjugated with the phenyl core, which only displays two redox couples. The close proximity of the six ruthenium atoms and the sheer steric bulk of the bipyridines force a dihedral angle that is large enough to interrupt any possible electron delocalisation through the phenyl core ${ }^{73}$. 
a)

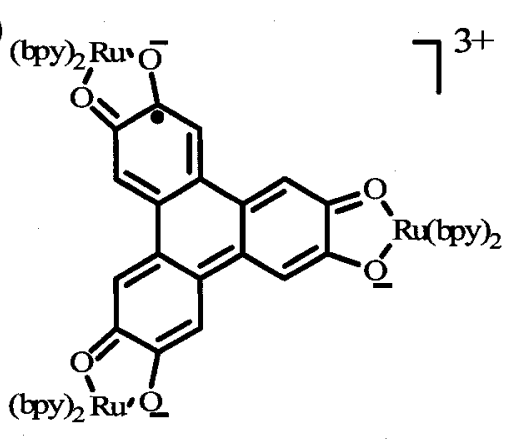

b)

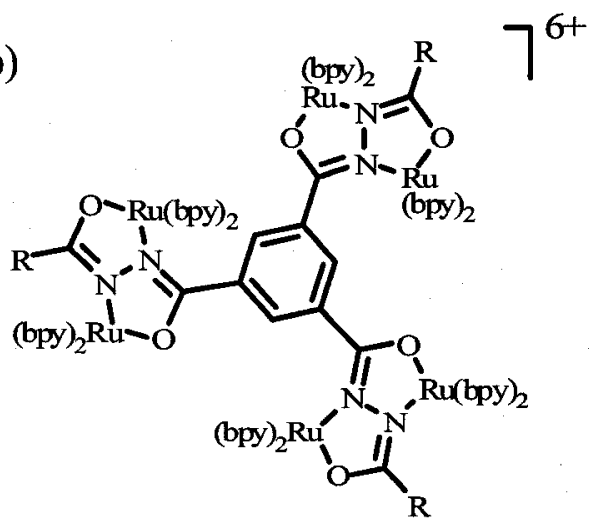

Figure 1.15 - The a) trinuclear and b) hexanuclear ruthenium complexes

1.5 - Applications

Visible electrochromes find uses in smart glass (chemical curtains) ${ }^{74-76}$, electrochromic displays $(\mathrm{ECD})^{77-79}$, light modulation $^{80-82}$, and sensors ${ }^{83-86}$. These applications are based on modifying light transmission, optical contrast or the redox color changes. The only commercialized visible electrochromic devices are rear-view mirrors, developed by the Gentex Corporation, which attenuate glare from vehicle head lights via a sensor or manual switch ${ }^{24}$. This principle is being implemented to sunglasses, ski goggles, and motorcycle helmets ${ }^{75,87,88}$. NIR electrochromes find similar applications, but in a different region of the electromagnetic spectrum. A classic example is that of NIR active smart windows that can keep buildings cool in the summer by dissipating the thermal energy either by absorption or reflection, and warm in the winter by allowing the heat radiation to pass through (figure 1.16$)^{75,89,90}$. 

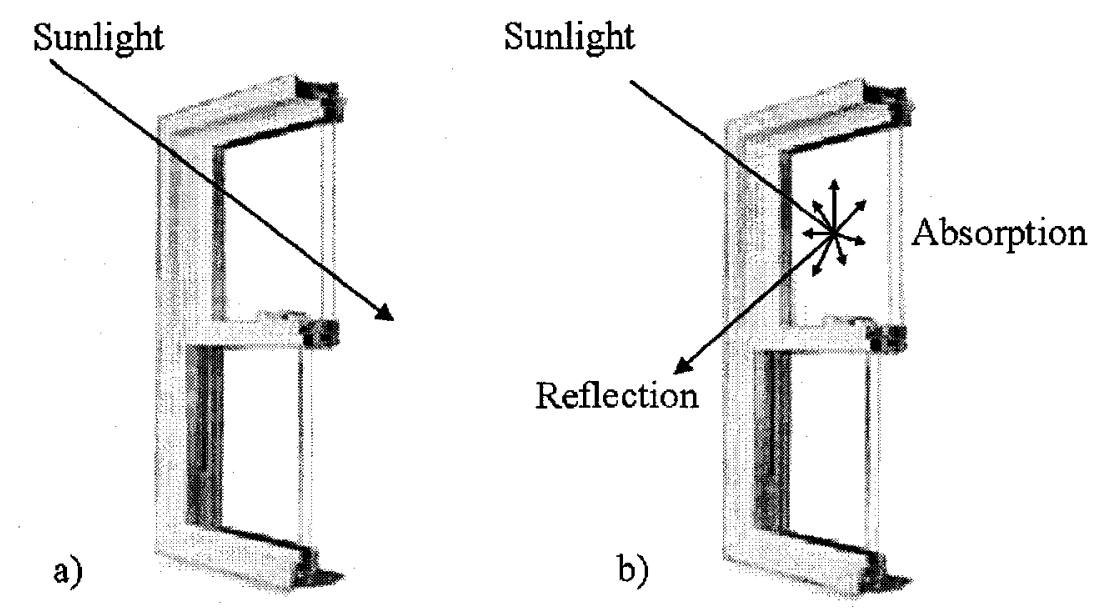

Figure 1.16 - NIR window in a) OFF mode and b) ON mode

NIR active materials show promising results in the energy generation domain. With a significant portion of the solar irradiance spectrum being in the NIR region, any compound that absorbs in this region, coupled to current photovoltaic (PV) systems, would increase the efficiency of solar panels by expanding the energy range of photons harvested $^{91}$. Granted, these materials do not need to be electrochromic, but only NIR absorbent ${ }^{92}$. A recent paper by Yan and coworkers discusses a PV cell containing NIR active phthalocyanines that has a $1.95 \%$ energy conversion efficiency ${ }^{92}$. While this is a relatively small percentage, particularly when compared to current silicon-based commercial solar panels which achieve about $10 \%$ efficiency, the phthalocyanine-based device absorbs from 400 to $1000 \mathrm{~nm}$ and could still be improved by the introduction of materials that can absorb lower wavelength to cover a broader range of the solar irradiation spectrum.

NIR wavelengths also show great potential in medical applications as a diagnostic tool since they can penetrate biological tissue up to a few centimeters ${ }^{93,94}$. Biomolecules, tagged with a NIR marker can be tracked and monitored via absorbance; however, since 
photoluminescence is significantly more sensitive than absorption monitoring, research into NIR emitting molecules is on the rise. As such, NIR tags are normally used in biosensors. For example, NIR biosensor schemes, coupled to oxidase enzymes, can be used to monitor blood sugar levels ${ }^{95}$. Further details on biosensors will be presented in chapter 5 .

Another application of NIR active compounds is through night vision gear which can unveil the night's darkest secrets. This technology is based on collecting the IR light that is invisible to the human eye and rendering it visible. The process starts by collecting the invisible photons onto a photocathode that is capable of ejecting multiple electrons for each photon absorbed (signal amplification). Those electrons are then accelerated by a strong electric field and impact on a phosphor screen which recreates the invisible image into visible green light (Figure 1.17). The third generation technology utilize a gallium arsenide photocathode that is sensitive for both NIR and IR photons ( $800 \mathrm{~nm}$ and up), resulting in a 30000-50000x increase in amplification ${ }^{96-98}$. Although these devices are generally used in the military by troops to 'see' in the dark, they can also be used in aircrafts' targeting systems to 'lock-on' air and ground targets because of the heat radiating from the vehicle engines ${ }^{99,100}$.

Since the NIR region is the most sensitive to night vision equipment, the ability to mask these wavelengths would result in effective camouflage ${ }^{99}$. A patterned NIR electrochromic insignia could be used to send messages to friendly troops via switching to simulate Morse code or simply as identification. A NIR ECD would permit troops to receive and send text messages without the risk of unveiling their position due to visible light from a display or sounds from audio transmitters. On the other hand, the matter of 


\section{Chapter 1 - Introduction}

masking heat signature is more complex since there is much more energy to 'mask' in a vehicle, not to mention that targeting systems can detect a broader range of heat wavelengths ${ }^{99,100}$. Such a countermeasure system would require an electrochromic material that would span the entire NIR-IR region to ensure 'invisible' status".

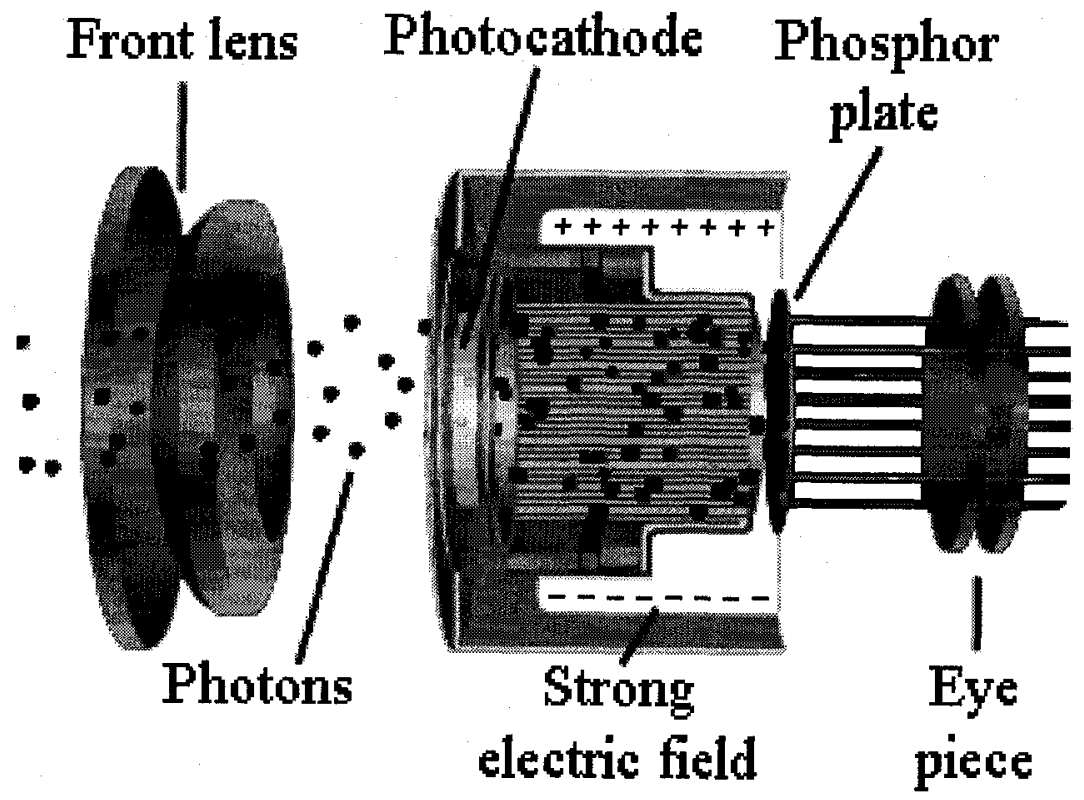

Figure 1.17 - Night vision system

Lastly, a very popular application of NIR electrochromes is in light modulation or variable optical attenuators (VOA) used by the telecommunication industry to convert electrical signals into optical signals and vice-versa. Silica fibre optics has its highest transparency in the NIR region and so redox materials have become important in achieving faster information encoding as bandwidth demands increase ${ }^{101}$. This application will also be discussed in further detail in chapter 5 . 


\section{6 - Rationale and objectives}

Dinuclear ruthenium complexes, based on $\mathrm{DCH}$, oxamides and other analogues have been previously extensively studied. This research project involved the preparation of macromolecular materials containing the dinuclear complexes in order to evaluate their solid state optical properties and performance. The potential of using other metals with these bridging ligands was also investigated by studying the properties of $\mathrm{DCH}$ complexes of platinum.

The results reported in this dissertation pertain to the optical properties of polymerized dinuclear ruthenium complexes as well as those of small molecules of novel dinuclear platinum complexes. Performance of the ruthenium complexes was evaluated by NIR attenuation and optical sensor configurations. The objectives of this project are:

1. to prepare film-forming macromolecular materials, containing the dinuclear ruthenium moiety, using newly synthesized hydroxyl-functionalized complex monomers and maximize their ruthenium content;

2. to evaluate the NIR optical properties of solid films in a reflective VOA design and to compare its performance to that of analogue transmissive VOAs;

3. to develop a redox biosensoring scheme using an oxidase enzyme and dinuclear ruthenium complex to evaluate the advantage of a NIR optical sensor compared to traditional amperometric sensors; and

4. to develop a viable synthetic route to analogous dinuclear platinum complexes to assess their physicochemical, electrochemical, and emissive properties. 


\section{Chapter 2 - Bridging and peripheral ligands}

\section{1 - Introduction}

Polymers containing the DCH-Ru moiety can be prepared via two pathways. The simplest approach is to first synthesize the polymer then perform a complexation step. Even small molecular weight polymers have long chains which can get tangled and knotted preventing the bulky $\mathrm{Ru}(\mathrm{bpy})_{2}$ of approaching each and every ligand site, limiting the uptake of metal ${ }^{102}$. There are also solubility issues due to hydrogen bonding of the amide function that can interfere. Although the percentage of metal within the final product can be measured via various methods, such as acid digestion followed by inductively coupled plasma mass spectrometry (ICP-MS) analysis ${ }^{103}$, the fact remains that the polymer ligand sites may not be fully complexed and will introduce batch to batch variability. Cheng ${ }^{104}$ and coworkers prepared a ligand polymer and obtained a very high degree of metal uptake with only a small percentage of vacant ligand sites, showing that the complexation of a polymer ligand is viable. The second method, still simple in concept, is to prepare the polymer using polymerizable complexes. This approach ensures that every ligand site is complexed, yielding materials having a high metal content.

The main inconvenience of the first method is that the low molecular weight of the polyhydrazide as it precipitates as oligomers, even in high boiling, high polarity solvents ${ }^{105}$. Thus the second method's potential will be assessed in this study by preparing a series of difunctionalized ligands that will be polymerisable, even after the complexation. The first method has already been explored by our group with limited success. 


\section{Chapter 2-Bridging and peripheral ligands}

\subsection{1 - Synthetic methods for bridging ligands}

The bridging ligands considered for this project are diacyl hydrazides, also known as dicarbonyl hydrazines (DCH), biureas (an extension of the $\mathrm{DCH}$ group), and oxamides (OXA). Many viable routes to DCH ligands exist and the most common method is to combine a monoacyl hydrazide, which is prepared by hydrazinolysis of methyl or ethyl esters, with an acid chloride to yield the desired ligand ${ }^{106}$. Symmetrical ligands are obtained by using reagents that have identical $\mathrm{R}$ groups. The reaction of the same acid chloride to hydrazine monohydrate also yields a symmetrical ligand, however the 'wet' condition can induce by-products that may be difficult to remove (Figure 2.1). Another straightforward method to obtain simple symmetrical ligands is through hydrazinolysis of anhydrides ${ }^{107}$. Ligands having aromatic $\mathrm{R}$ groups are normally hydrophobic and have limited solubility in organic solvents due to extensive hydrogen bonding while aliphatic ligands can be water soluble. Also, hydrazide ligands can be dehydrated to cyclic oxadiazoles, which are themselves useful as luminescent materials ${ }^{108-110}$ and enzyme inhibitors ${ }^{111-114}$, although they no longer function as ligands.

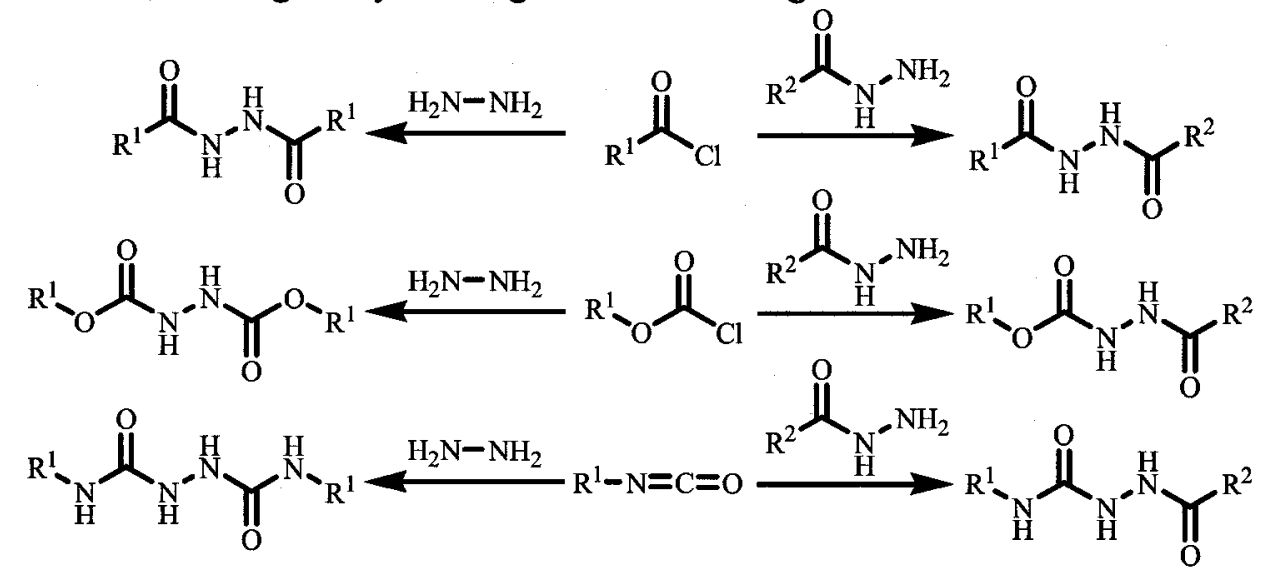

Figure 2.1 - General synthetic routes to symmetric and unsymmetric DCH ligands 


\section{Chapter 2 - Bridging and peripheral ligands}

Chloroformates can be used with hydrazine hydrate or hydrazides to produce a urethane type ligand which is essentially the same as the DCH system. Similarly, if an isocyanate is utilized, semi-biureas and biureas are obtained ${ }^{115}$ (Figure 2.1). Isocyanates react very rapidly with nucleophiles and so the preparation of functionalized biureas through this route is very limited. One method capable of overcoming this obstacle is aminolysis of dialkylazodicarboxylates, such as diethylazodicarboxylate (DEAD) or diisopropylazodicarboxylate (DIAD), by primary or secondary aliphatic amines ${ }^{116}$. The resulting azobiurea is converted to the biurea by reducing the azo bond with a hydrazine hydrate at room temperature ${ }^{117}$ (Figure 2.2). The reduction of the azo bond can also be achieved through the oxidation of iodides ${ }^{116}$ by the azo group although an extra purification step is necessary compared to the reduction using hydrazine which produces nitrogen gas. While this method only forms symmetrical ligands, it permits the introduction of isocyanate-unfriendly functional groups such as carboxylic acids, alcohols and other amines.

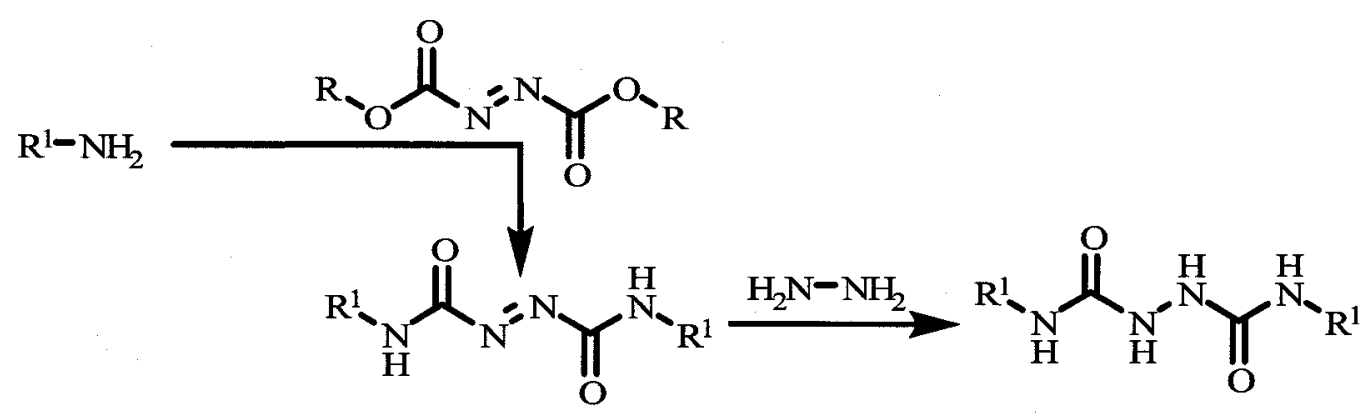

Figure 2.2 - Alternative biurea ligand synthesis

Less common methods to prepare DCH ligands include oxidative coupling of aromatic hydrazides using oxone ${ }^{118-120}$, sodium perborate ${ }^{121}$ or arylsulphonyl peroxides ${ }^{122}$ and enzymatic coupling of hydrazides to carboxylic acids ${ }^{123}$. 


\section{Chapter 2 - Bridging and peripheral ligands}

Lastly, OXA based ligands, which are structural analogues of the DCH series of ligands, also form dinuclear metal complexes and can be prepared by aminolysis of diethyl oxalate or by the simple action of oxalyl chloride with amines. The use of diethyl oxalate is more versatile as it allows the introduction of many functional groups and does not produce inorganic by-products. Unsymmetrical oxamides are obtained using ethyl chlorooxoacetate and its reaction with one equivalent of an amine. Once this intermediate is isolated, aminolysis of the ethyl group is achieved using a second amine (figure 2.3). Oxamides are formed readily at room temperature with aliphatic amines but aminolysis using aromatic amines necessitates heat due to their lower nucleophilicity from conjugation with the aromatic ring. Another route to oxamides is through the reductive coupling of isocyanates using samarium diiodide ${ }^{124}$. However, as with any isocyanate, functionalisation is limited. Lastly, a method using diisopropenyl oxalate ${ }^{125}$ also yields oxamides via aminolysis though it is rendered obsolete by the inexpensive diethyl oxalate which performs just as well if not better.

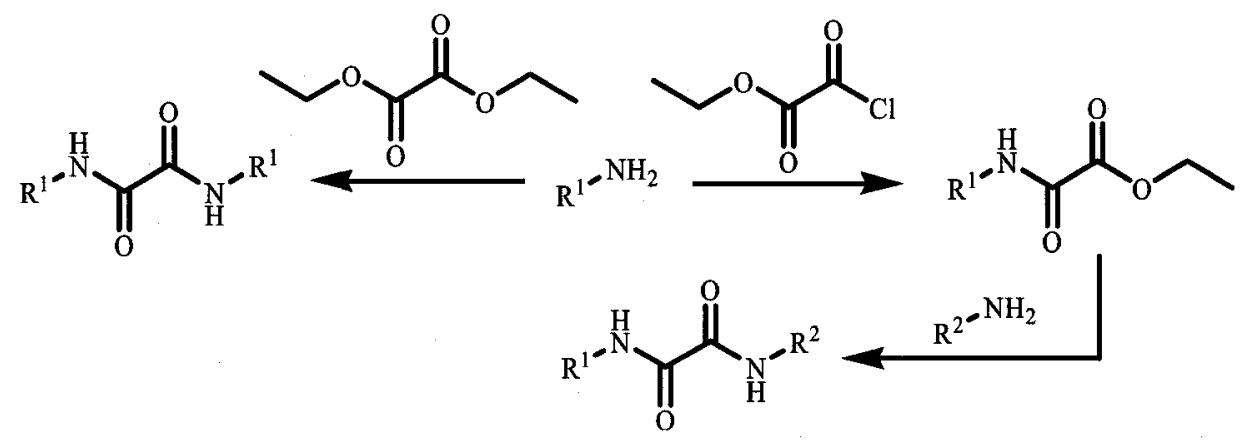

Figure 2.3 - Oxamide ligand synthesis

All these systems act as bridging ligands, between oxygen and nitrogen to form the desired dinuclear complexes (to be discussed in chapter 3). 


\section{Chapter 2 - Bridging and peripheral ligands}

2.1.2 - Synthetic methods for non-bipyridine peripheral ligands

2,2'-Bypiridine (bpy) is a very popular ligand, often used as the starting point of many octahedral complexes. As discussed in chapter 1, bipyridines have high energy, empty orbitals and when complexed to a metal, the resulting optical transitions are MLCTs. Functionalization of bipyridine modifies the energy levels of these empty orbitals such that the transition energies also change. For instance, (bpy) ${ }_{3} \mathrm{Ru}^{\mathrm{II}}$, has a MLCT band at $452 \mathrm{~nm}$ in acetonitrile, while the 4,4'-dicarboxylic acid derivative is red-shifted to $483 \mathrm{~nm}^{126,127}$. The absorption can also be red-shifted by extending the conjugation of the bpy ligand ${ }^{128}$. Adding electron donating groups to bpy, such as amines, has an opposite effect, blue-shifting the absorbance. These modifications require much effort with little effect and it is for this reason that all ruthenium complexes studied in the scope of this project are of the $\mathrm{Ru}(\mathrm{bpy})_{2} \mathrm{~L}_{2}$ nature and electronic tuning of the bandgap will be studied through the bridging ligand.

Moreover, probing the electronic effects of both bridging and peripheral ligands is also applicable for the novel dinuclear platinum complexes. Platinum cyclometallation using 2-phenyl pyridine is often encountered in the literature and is a reference point to study the electronic effects of the peripheral ligand. Commercially available 2-phenyl pyridine can be synthesized by Suzuki coupling of 2-chloro-pyridine to phenylboronic acid $^{129}$. Since extending the conjugation seems to induce the largest bathochromic shifts, commercially available 2-phenylquinoline, also readily available via Suzuki coupling methodology, was chosen to evaluate the red-shifting potential. The hypsochromic shift (blue-shift) was evaluated using quinoxaline derivatives, having an extra heteroatomic 
nitrogen. This diaza ligand is simply synthesized by iodine-catalyzed, condensation of the adequate 1,2 -diamine to 1,2 -dione (Figure 2.4$)^{130}$.

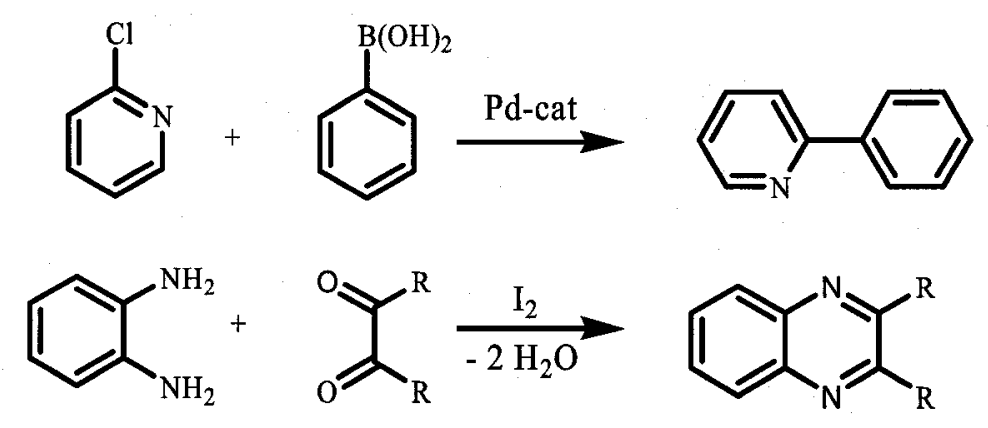

Figure 2.4 - Synthesis of 2-phenylpyridine and quinoxaline peripheral ligands

$2.2-$ Results and discussion

\subsection{1 - Bridging ligands}

When choosing a functional group to act as the polymerizable moiety, several criteria such as commercial availability, price and foreseeable reactivity of the final product should be considered. As such, hydroxyl-containing hydrazides and amines were chosen to prepare the target hydroxyl ligands (Table 2.1). Aliphatic hydroxyl amines having various main chain lengths are commercially available to prepare diol biurea and diol oxamide ligands. In preparing diol DCH ligands, the usual acid chloride method is obviously not available unless a monohydroxyl ligand is the target. Additionally, all of the oxidative hydrazide coupling methods previously mentioned failed to produce the desired aliphatic diol ligand. In fact, these methods are reported to be efficient when using an aromatic hydrazide; however, they were not evaluated for aliphatic hydrazides $^{118,121,122}$. 
Table 2.1 - Identification, melting points and yields of hydroxyl ligands prepared

\begin{tabular}{|c|c|c|c|c|c|}
\hline $\mathrm{R}^{2}$ & & $\operatorname{Mp}\left({ }^{\circ} \mathrm{C}\right)^{\mathrm{a}}$ & Yield $(\%)^{\mathrm{b}}$ & Remarks & Ref. \\
\hline $\mathrm{R}^{1}=\left(\mathrm{CH}_{2}\right)_{3} \mathrm{OH} ; \mathrm{R}^{2}=\mathrm{CH}_{2} \mathrm{CH}_{3}$ & $\mathbf{1}$ & $102-103$ & 58 & e & - \\
\hline $\mathrm{R}^{1}=\left(\mathrm{CH}_{2}\right)_{5} \mathrm{OH} ; \mathrm{R}^{2}=\mathrm{CH}_{2} \mathrm{CH}_{3}$ & 2 & $98-99$ & 36 & $\mathrm{e}$ & - \\
\hline $\mathrm{R}^{1}=\left(\mathrm{CH}_{2}\right)_{3} \mathrm{OH} ; \mathrm{R}^{2}=\mathrm{NH}\left(\mathrm{CH}_{2}\right)_{2} \mathrm{CH}_{3}$ & 3 & $122-123$ & 90 & $\mathrm{e}$ & - \\
\hline $\mathrm{R}^{1}=\left(\mathrm{CH}_{2}\right)_{5} \mathrm{OH} ; \mathrm{R}^{2}=\mathrm{NH}\left(\mathrm{CH}_{2}\right)_{2} \mathrm{CH}_{3}$ & 4 & $125-126$ & 93 & e & - \\
\hline $\mathrm{R}^{1}=\mathrm{R}^{2}=\left(\mathrm{CH}_{2}\right)_{5} \mathrm{OH}$ & 5 & $147-148$ & 21 & $\mathrm{f}$ & - \\
\hline $\mathrm{R}^{1}=\mathrm{R}^{2}=\mathrm{NH}\left(\mathrm{CH}_{2}\right)_{3} \mathrm{OH}$ & 6 & $252-253$ & $78^{\mathrm{d}}$ & $\mathrm{f}$ & - \\
\hline $\mathrm{R}^{1}=\mathrm{R}^{2}=\mathrm{NH}\left(\mathrm{CH}_{2}\right)_{5} \mathrm{OH}$ & 7 & $258-259$ & $82^{d}$ & $\mathrm{f}$ & - \\
\hline $\mathrm{R}^{1}=\mathrm{R}^{2}=\mathrm{NHC}\left(\mathrm{CH}_{3}\right)\left(\mathrm{CH}_{2} \mathrm{OH}\right)_{2}$ & 8 & $141-142$ & $56^{d}$ & $\mathrm{~g}$ & - \\
\hline $\mathrm{R}^{1}=\mathrm{R}^{2}=\mathrm{O}\left(\mathrm{CH}_{2}\right)_{2} \mathrm{OH}$ & 9 & $165-166$ & 51 & $\mathrm{f}$ & 131 \\
\hline $\mathrm{R}^{1}=\mathrm{R}^{2}=\mathrm{N}$ & 10 & $212-213$ & 27 & $\mathrm{~h}$ & - \\
\hline $\mathrm{R}^{1}=\mathrm{R}^{2}=\mathrm{N}$ & 11 & $186-187$ & $55^{\mathrm{d}}$ & $\mathrm{h}$ & - \\
\hline & & $\operatorname{Mp}\left({ }^{\circ} \mathrm{C}\right)^{a}$ & Yield (\%) & Remarks & Ref. \\
\hline $\mathrm{R}^{1}=\left(\mathrm{CH}_{2}\right)_{5} \mathrm{OH} ; \mathrm{R}^{2}=\mathrm{CH}_{2} \mathrm{CH}_{2} \mathrm{CH}_{3}$ & 12 & $133-134$ & 60 & $\mathrm{e}$ & - \\
\hline $\mathrm{R}^{1}=\mathrm{R}^{2}=\left(\mathrm{CH}_{2}\right)_{3} \mathrm{OH}$ & 13 & $162-163$ & 73 & $\mathrm{f}$ & 132 \\
\hline $\mathrm{R}^{1}=\mathrm{R}^{2}=\left(\mathrm{CH}_{2}\right)_{5} \mathrm{OH}$ & 14 & $157-158$ & 47 & $\mathrm{f}$ & 132 \\
\hline $\mathrm{R}^{1}=\mathrm{R}^{2}=\square \mathrm{OH}$ & 15 & $350^{\mathrm{c}}$ & 44 & $\mathrm{f}$ & 133 \\
\hline $\begin{array}{l}\text { a uncorrected melting points from th } \\
\text { b isolated yields from this project; } \\
\text { c decomposed } \\
\text { d } \\
\text { d based on starting azodicarboxylate } \\
\text { e monohydroxyl ligand - useful as a } \\
{ }^{f} \text { useful as monomers for linear poly } \\
g^{g} \text { tetrahydroxyl ligand - useful for hy } \\
\text { h secondary amide biurea to solve a }\end{array}$ & or & $\begin{array}{l}\text { ligand; } \\
\text { side grou } \\
\text { ed polym } \\
\text { cussed ir }\end{array}$ & $\begin{array}{l}\text { in polymer; } \\
\text {; } \\
\text { hapter } 3\end{array}$ & & \\
\hline
\end{tabular}

These ligands were considered and prepared for use in various types (pendant groups, linear polymers, hyperbranched, crosslinked and dendrimers) of polymerization by their respective ruthenium complex. Their syntheses vary little within a category and yields are modest to excellent. The modest yields can be explained to loss due to high water solubility during the workup, especially for short aliphatic chain ligands. All of the 
hydroxyl ligands were white powders or microcrystals that precipitated from the reaction medium and thus only required filtering and washing with solvent to obtain them in pure form. Uncorrected melting points are high for most ligands, reflecting their high tendency to hydrogen bonding, and are lower for ligands having longer alkyl chains.

Hydrazinolysis of $\gamma$-caprolactone yields 6-hydroxyhexanoic hydrazide ${ }^{134}$, which is useful in preparing mono-hydroxyl ligands as well as synthetic intermediates for other types of ligands. A method to dimerize this hydroxyl hydrazide was available. Patents from Broussard and coworkers cite a method to prepare symmetrical aliphatic hydrazides using a $\beta$-ketoester ${ }^{135,136}$. The reaction proceeds by hydrazone formation between the ketoester and hydrazide which increases the electrophilic nature of the hydrazide carbonyl and becomes prone to attack by the free hydrazide. The equilibrium is driven to the formation of the symmetrical hydrazide by the stabilisation by-product, 3-methyl-4pyrazolone, that is formed (Figure 2.5). Diol 5 was only obtained in $21 \%$ compared to the $90+\%$ reported in Broussard's patent. However the yields in the patent were for mono phenolic and unfunctionalized aliphatic hydrazides, not aliphatic diols.
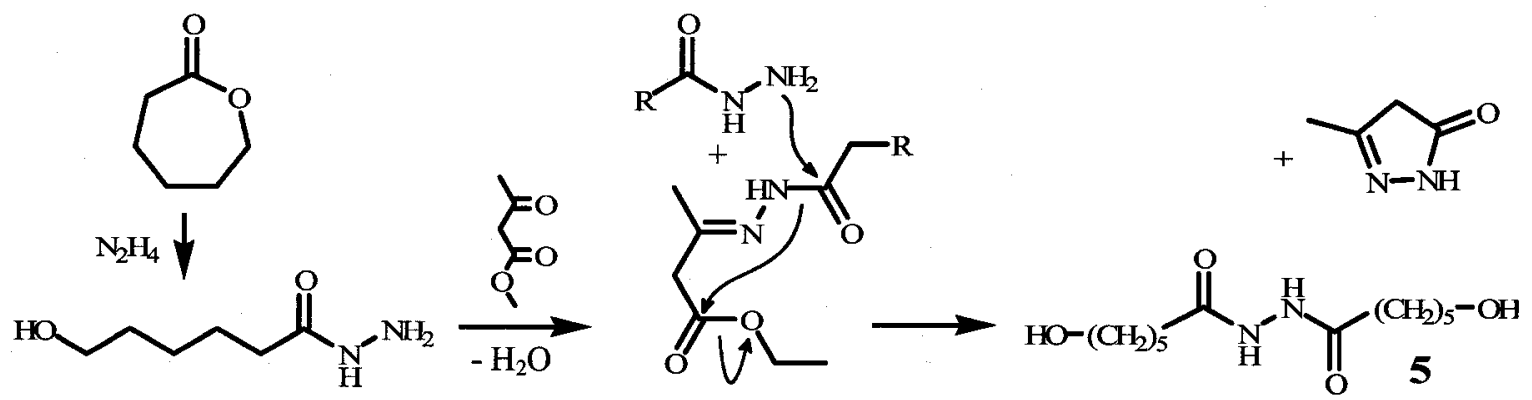

Figure 2.5 - Diol-DCH synthesis via ethyl acetoacetate coupling 


\section{Chapter 2 - Bridging and peripheral ligands}

Other ligands (Table 2.2) were synthesized to prepare model dinuclear complexes in order to assess their usefulness prior to preparing the functionalized analogues. 16-19 were selected to prepare dinuclear platinum complexes, discussed in chapter 3.

Table 2.2 - Identification, melting points and yields of other ligands

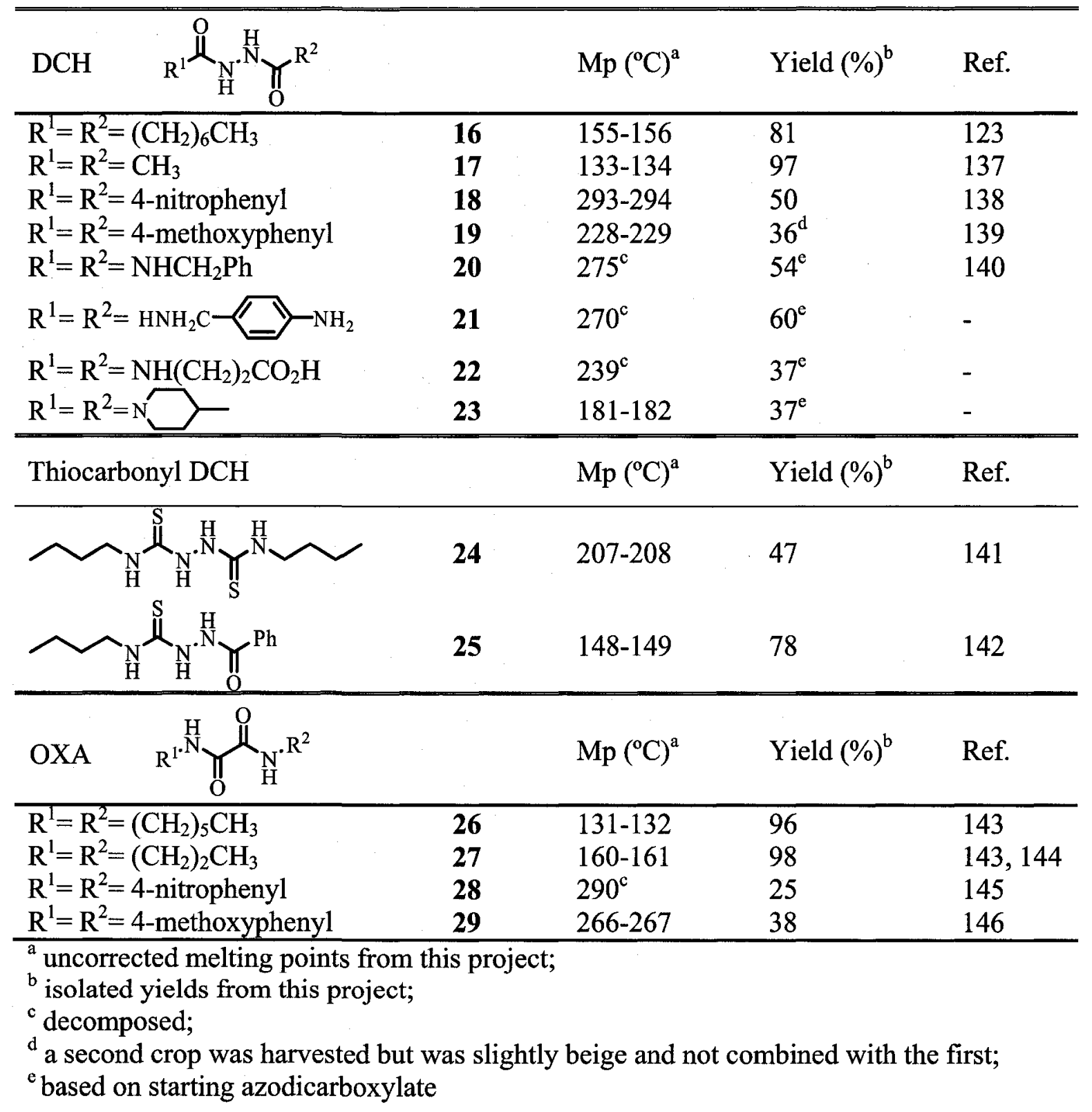




\section{Chapter 2 - Bridging and peripheral ligands}

The thiocarbonyl ligands $\mathbf{2 4}$ and $\mathbf{2 5}$ were prepared in order to assess the influence of sulfur on the electrochemical and optical properties of dinuclear ruthenium complexes. The presence of the nitrogen(s) should place the NIR absorption of the resulting complexes at $1100-1200 \mathrm{~nm}$. The sulfur atoms having a lower electronegativity and higher energy orbitals, could increase the highest occupied molecular orbital (HOMO) of the complex to a greater extent than its oxygen counterpart and an enhanced bathochromic shift should be observed from these complexes, potentially shifting the NIR absorption at lower wavelengths. The antagonist effects from the nitrogen and sulfur could nullify themselves.

Characterization of the ligands is straightforward: they have high melting point temperatures because of hydrogen bonding, infrared spectroscopy (IR) confirms the presence of the amide moiety $\left(\mathrm{C}=\mathrm{O} @ 1630-1690 \mathrm{~cm}^{-1}\right.$ and $\left.\mathrm{NH} @ 3100-3300 \mathrm{~cm}^{-1}\right)$ and the $\mathrm{NH}$ protons are highly deshielded $(7.5-10 \mathrm{ppm})$ in ${ }^{1} \mathrm{H}$ NMR due in part to intramolecular hydrogen bonding but also to the positive character of the nitrogen through resonance. Mass spectrometry of these ligands is somewhat problematic at times, especially when the volatility is low. Another characteristic of the amide protons is the possibility of tautomers (Figure 2.6). This resonance process is normally faster than the NMR time scale and thus not observed. However, for the DCH ligands such as 17, two smaller resonances at 8.9 and $9.9 \mathrm{ppm}$, in addition to the $\mathrm{NH}$ resonance at $9.7 \mathrm{ppm}$ are observable at room temperature. Increasing the temperature of the sample to $340 \mathrm{~K}$ eliminates both resonances forcing them to coalesce, proving that they do not belong to an impurity (Figure 2.7). 


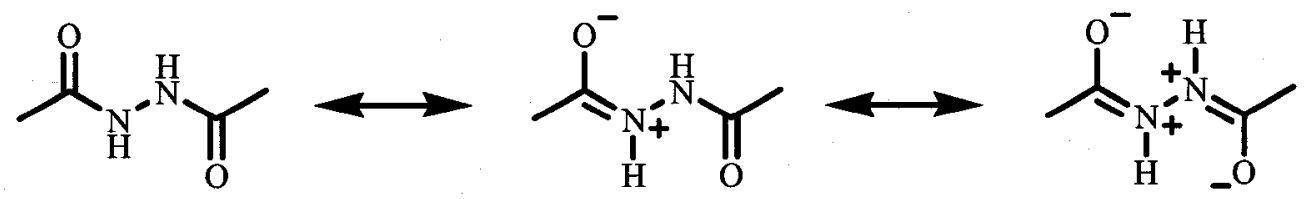

Figure 2.6 - Tautomerization of $\mathbf{1 7}$

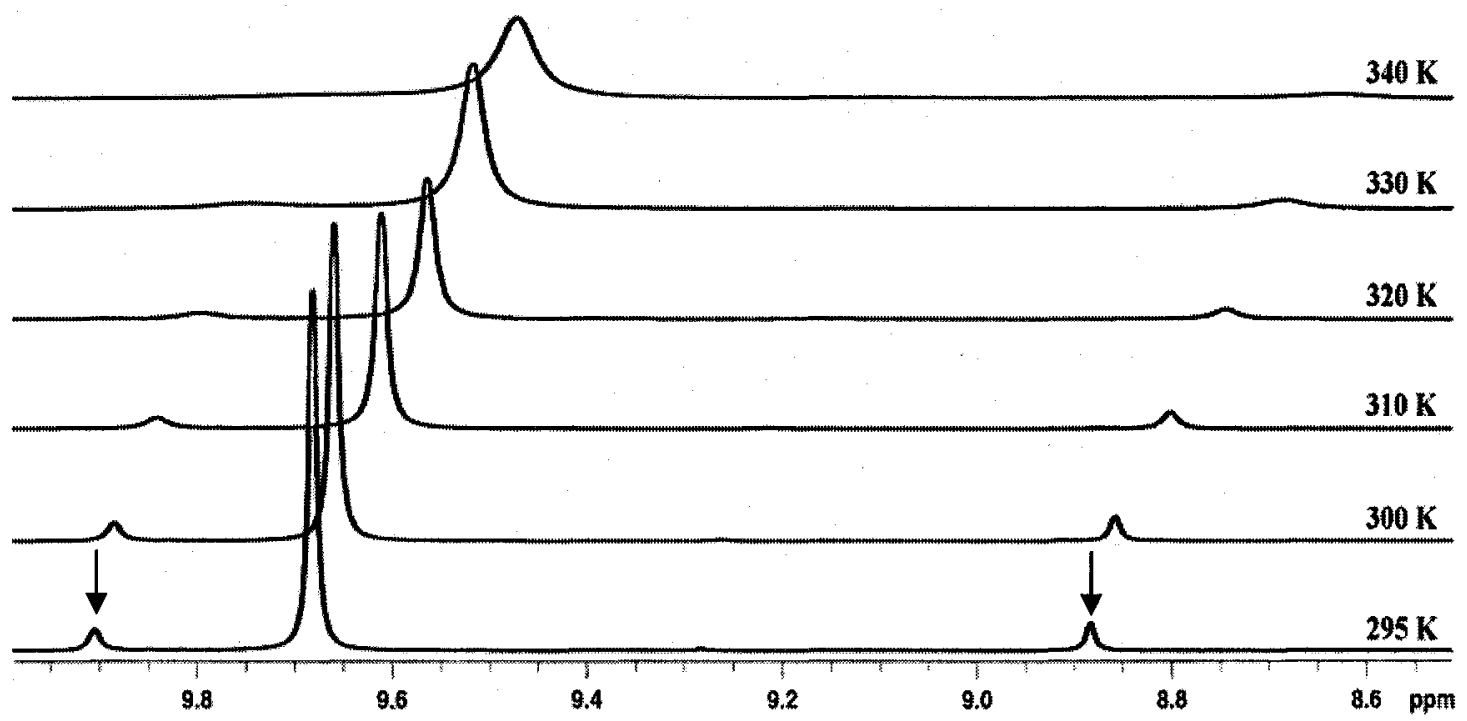

Figure 2.7 - Variable temperature effect on amide ${ }^{1} \mathrm{H}$ region of 17

The piperidine-based biureas $(\mathbf{1 0}, \mathbf{1 1}$ and $\mathbf{2 3})$ show a high degree of complexity in the ${ }^{1} \mathrm{H}$ NMR splitting of the methylene protons of the ring (see appendix 1). The ring, at room temperature, is comformationally locked and the methylenic protons are no longer equivalent as observed by large ${ }^{2} \mathrm{~J}$ coupling constants. This is also confirmed by HSQC 2D NMR where each methylenic carbon of the ring correlates to two proton signals. Furthermore, the splitting patterns of each proton of a given methylene are not identical, showing the angular dependence on the magnitude of the coupling constants. The assignment of resonances to proton groups is a routine exercise with the help of a COSY spectrum. However, a $300 \mathrm{MHz}$ field does not provide sufficient resolution to be able to 


\section{Chapter 2 - Bridging and peripheral ligands}

observe all coupling details and so the smaller constants, are assumed to be of the same magnitude.

\subsection{2 - Peripheral ligands}

When platinum is involved, cyclometallating ligands are often encountered and many derivatives of 2-phenyl pyridine are synthetically or commercially available ${ }^{147}$. Extending the conjugation usually induces a bathochromic shift of the metal complex, while increasing the nitrogen content has the opposite effect. Equipped with this knowledge, ligands 30-32 were chosen to probe the optical properties of dinuclear platinum complexes. Ligand $\mathbf{3 0}$ was obtained commercially while the two others, 2methyl-3-phenyl-quinoxaline (31) and 2-methyl-3-phenyl-benzo[g]quinoxaline (32), were synthesized (Figure 2.8) using a published procedure based on the iodine catalyzed condensation reaction ${ }^{130}$.
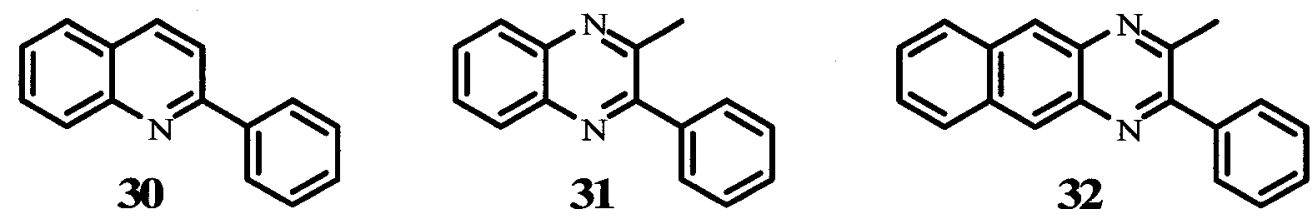

Figure 2.8 - Peripheral ligands considered

The condensation reaction was performed as described and the workup was simple. The pure ligands $\mathbf{3 1}$ and $\mathbf{3 2}$ were obtained and their spectral characterization agreed well with literature values ${ }^{130}$. The difference between 30 and 31 is obvious enough. Ligand $\mathbf{3 2}$ is an interesting case where the conjugation is extended even more than 31. The antagonist effects could nullify themselves and the resulting optical properties may be quite similar to the complex based on ligand $\mathbf{3 0 .}$ 


\section{Chapter 2 - Bridging and peripheral ligands}

\section{3 - Conclusion}

A series of hydroxyl-containing bridging ligands were prepared to encompass most types required for various polymerizations as well as electronic properties of the dinuclear metal complexes. Two thiocarbonyl derivatives were also prepared to establish the effect of sulfur on the optical properties of dinuclear ruthenium complexes.

Synthetic modifications of the bipyridine peripheral ligands were not explored in matters regarding ruthenium complexes since their effects are known. However, a few cyclometallating peripheral ligands were considered to generate a short series of novel dinuclear platinum complexes.

\section{4 - Experimental}

NMR experiments were performed on a Bruker AMX $400 \mathrm{MHz}$ or Advance 300 $\mathrm{MHz}$ spectrometer in either DMSO- $d_{6}, \mathrm{CDCl}_{3}, \mathrm{D}_{2} \mathrm{O}$ or a $\mathrm{D}_{2} \mathrm{O} / \mathrm{D}_{2} \mathrm{SO}_{4}$ mixture when solubility was too low to record ${ }^{13} \mathrm{C}$ spectra and are reported in ppm (multiplicity, integration, assignment, coupling constants). Coupling constants are given in Hertz and multiplicity terms used are: $\mathrm{s}$ (singlet), $\mathrm{d}$ (doublet), $\mathrm{t}$ (triplet), $\mathrm{q}$ (quadruplet), $\mathrm{m}$ (multiplet), and combinations such as dd (doublet of doublet). 2D NMR (COSY, HSQC, HMBC and NOESY) experiments were recorded when required. Infrared (IR) spectra were recorded on a Varian Scimitar 1000 series FT-IR spectrometer using an attenuated total reflectance (ATR) accessory. Mass spectra were acquired at the University of Ottawa Regional Mass Spectrometry Center on a Kratos Concept IIH mass spectrometer in electron ionization $(\mathrm{EI})$ mode $(70 \mathrm{eV})$ and peaks are reported as $\mathrm{m} / \mathrm{z}(\%$ intensity 


\section{Chapter 2 - Bridging and peripheral ligands}

relative to the base peak). Melting points were obtained on a Fisher-Johns apparatus equipped with a thermocouple (upper limit of $350^{\circ} \mathrm{C}$ ) and are uncorrected.

All the chemicals for preparing the ligands were used as received. Solvents were ACS grade or better and used as received except for THF, which was distilled over sodium benzophenone ketyl. Triethylamine (TEA) was only distilled once a yellow coloration developed. 6-Hydroxyhexanoic hydrazide ${ }^{134}$, 4-hydroxybutanoic hydrazide ${ }^{148}$ and ligands 9, 13-20, 24-29 and 31-32 were synthesized by known methods (see Tables 2.1 and 2.2 for references). The other new ligands (1-8, 10-12 and 20-22) were prepared by modifications of current methods.

NMR spectra can be found in Appendix 1. The spectra also include a structure of each compound with the numbering scheme used for chemical shift assignments.

General procedure for the synthesis of mono hydroxyl DCH ligands

4-Hydroxybutanoic hydrazide $(1.02 \mathrm{~g}, 8.51 \mathrm{mmol})$ was dissolved in a $100 \mathrm{~mL}$ round-bottomed flask (RBF) with $40 \mathrm{~mL}$ of THF and 2 of $\mathrm{mL} \mathrm{H}_{2} \mathrm{O}$ (to ensure complete dissolution of the hydrazide) containing an equimolar amount of TEA. Propionyl chloride ( 0.95 molar equivalent), diluted in $10 \mathrm{~mL}$ THF was added dropwise to the hydrazideTEA mixture as such to maintain ambient temperature under an inert atmosphere. Once the addition complete, the temperature was increased to maintain a gentle reflux for a period of two hours. The reaction solvent was evaporated using a roto-evaporator. It was found that the ligand was water soluble and so an aqueous workup was not to be considered. Instead, the solid was triturated using hot chloroform to extract the ligand. NMR of the white solid obtained after removing the chloroform showed that some TEA- 


\section{Chapter 2 -Bridging and peripheral ligands}

$\mathrm{HCl}$ still remained ( $8 \%$ in the case of 1$)$. However, this salt will have no consequence during the complexation step and no further attempts were made to purify the ligand. Yields are corrected for TEA salt present.

4-hydroxy-N'-propionylbutanehydrazide (1). Yield: $58 \%$. FT-IR: $3207 \mathrm{~cm}^{-1}(\mathrm{NH})$ and $1591 \mathrm{~cm}^{-1}(\mathrm{C}=\mathrm{O}) .{ }^{1} \mathrm{H}$ NMR $\left(300 \mathrm{MHz}, \mathrm{DMSO}-d_{6}\right): 9.62(\mathrm{~s}, 2 \mathrm{H}, \mathrm{H} 5) ; 4.47\left(\mathrm{t}, 1 \mathrm{H}, \mathrm{OH},{ }^{3} \mathrm{~J}\right.$ $=5 \mathrm{~Hz}) ; 3.38\left(\mathrm{~m}, 2 \mathrm{H}, \mathrm{H} 4,{ }^{3} \mathrm{~J}=5 \mathrm{~Hz},{ }^{3} \mathrm{~J}=6 \mathrm{~Hz}\right) ; 2.13\left(\mathrm{t}, 2 \mathrm{H}, \mathrm{H} 2,{ }^{3} \mathrm{~J}=7 \mathrm{~Hz}\right) ; 2.10(\mathrm{q}, 2 \mathrm{H}$, $\left.\mathrm{H} 7,{ }^{3} \mathrm{~J}=8 \mathrm{~Hz}\right) ; 1.64\left(\mathrm{~m}, 2 \mathrm{H}, \mathrm{H} 3,{ }^{3} \mathrm{~J}=8 \mathrm{~Hz},{ }^{3} \mathrm{~J}=6 \mathrm{~Hz}\right)$ and $1.00\left(\mathrm{t}, 3 \mathrm{H}, \mathrm{H} 8,{ }^{3} \mathrm{~J}=8 \mathrm{~Hz}\right) .{ }^{13} \mathrm{C}$ NMR (75 MHz, DMSO-d $)$ ): 172.3 (C1); 171.6 (C6); 60.6 (C4); 30.4 (C2); 28.9 (C3); $26.8(\mathrm{C} 7)$ and 10.1 (C8). MP: $102-103^{\circ} \mathrm{C}$. EI-MS: $174\left(\mathrm{M}^{+}, 1.4 \%\right), 156(3.8), 125$ (4.7), $100(18), 88(87), 69(32)$ and $57(100)$.

6-hydroxy-N'-propionyhexanehydrazide (2). Yield: $36 \%$. FT-IR: $3217 \mathrm{~cm}^{-1}(\mathrm{NH})$ and $1593 \mathrm{~cm}^{-1}(\mathrm{C}=\mathrm{O}) .{ }^{1} \mathrm{H}$ NMR (300 MHz, DMSO-d $\left.)_{6}\right): 9.65(\mathrm{~s}, 2 \mathrm{H}, \mathrm{H} 7) ; 4.38\left(\mathrm{t}, 1 \mathrm{H}, \mathrm{OH},{ }^{3} \mathrm{~J}\right.$ $=6 \mathrm{~Hz}) ; 3.37\left(\mathrm{~m}, 2 \mathrm{H}, \mathrm{H} 6,{ }^{3} \mathrm{~J}=6 \mathrm{~Hz}\right) ; 2.11\left(\mathrm{q}, 2 \mathrm{H}, \mathrm{H} 9,{ }^{3} \mathrm{~J}=8 \mathrm{~Hz}\right) ; 2.10\left(\mathrm{t}, 2 \mathrm{H}, \mathrm{H} 2,{ }^{3} \mathrm{~J}=\right.$ $8 \mathrm{~Hz}) ; 1.50\left(\mathrm{~m}, 2 \mathrm{H}, \mathrm{H} 3,{ }^{3} \mathrm{~J}=8 \mathrm{~Hz}\right) ; 1.40\left(\mathrm{~m}, 2 \mathrm{H}, \mathrm{H} 5,{ }^{3} \mathrm{~J}=8 \mathrm{~Hz}\right) ; 1.30\left(\mathrm{~m}, 2 \mathrm{H}, \mathrm{H} 4,{ }^{3} \mathrm{~J}=\right.$ $8 \mathrm{~Hz}$ ) and $1.00\left(\mathrm{t}, 3 \mathrm{H}, \mathrm{H} 10,{ }^{3} \mathrm{~J}=8 \mathrm{~Hz}\right) .{ }^{13} \mathrm{C}$ NMR $\left(75 \mathrm{MHz}, \mathrm{DMSO}-d_{6}\right): 172.3$ (C1); 171.5 (C8); 61.0 (C6); 33.7 (C2); 32.7 (C5); 26.8 (C9); 25.6 (C4); 25.5 (C3) and 10.1 (C10). MP: $98-99{ }^{\circ} \mathrm{C} . \mathrm{EI}-\mathrm{MS}: 184(2.9 \%), 167$ (6.2), 125 (96), 101 (15), $86(100), 69(33)$ and $57(53)$. 


\section{Chapter 2 - Bridging and peripheral ligands}

General procedure for the synthesis of semi biurea DCH ligands

4-Hydroxybutanoic hydrazide $(1.0 \mathrm{~g}, 8.5 \mathrm{mmol})$ was dissolved in a $100 \mathrm{~mL} \mathrm{RBF}$ with $40 \mathrm{~mL}$ THF and $2 \mathrm{~mL} \mathrm{H}_{2} \mathrm{O}$ (to ensure dissolution of the hydrazide). 0.95 molar equivalent of propionyl isocyanate, diluted in $20 \mathrm{~mL}$ THF was added dropwise to the hydrazide solution as such to maintain ambient temperature while maintaining an inert atmosphere. Stirring at room temperature was maintained for a period of two hours. The reaction solvent was evaporated using a roto-evaporator as the product was soluble in THF. It was also found that this ligand was water soluble. The solid was triturated using ethyl ether to extract any propylamine by-product that could have formed by water hydrolysis of the isocyanate. The solid was filtered and washed with $2 \times 10 \mathrm{~mL}$ portions of acetone to remove any starting hydrazide and finally washed with ethyl ether and dried under vacuum for one hour. The solid was NMR pure.

2-(4-hydroxybutanoyl)-N-propylhydrazinecarboxamide (3). Yield: $90 \%$. FT-IR: 3312 $\mathrm{cm}^{-1}, 3210 \mathrm{~cm}^{-1}, 3105 \mathrm{~cm}^{-1}(3 \mathrm{x} \mathrm{NH})$ and $1668 \mathrm{~cm}^{-1}(\mathrm{C}=\mathrm{O}) .{ }^{1} \mathrm{H}$ NMR (300 MHz, DMSO$\left.d_{6}\right): 9.38(\mathrm{~s}, 1 \mathrm{H}, \mathrm{H} 5) ; 7.58(\mathrm{~s}, 1 \mathrm{H}, \mathrm{H} 6) ; 6.29\left(\mathrm{t}, 1 \mathrm{H}, \mathrm{H} 8,{ }^{3} \mathrm{~J}=6 \mathrm{~Hz}\right) ; 4.49(\mathrm{~s}, 1 \mathrm{H}, \mathrm{OH}) ; 3.39$ $\left(\mathrm{m}, 2 \mathrm{H}, \mathrm{H} 4,{ }^{3} \mathrm{~J}=5 \mathrm{~Hz},{ }^{3} \mathrm{~J}=6 \mathrm{~Hz}\right) ; 2.93\left(\mathrm{dt}, 2 \mathrm{H}, \mathrm{H} 9,{ }^{3} \mathrm{~J}=7 \mathrm{~Hz},{ }^{3} \mathrm{~J}=6 \mathrm{~Hz}\right) ; 2.11(\mathrm{t}, 2 \mathrm{H}, \mathrm{H} 2$, $\left.{ }^{3} \mathrm{~J}=7 \mathrm{~Hz}\right) ; 1.64\left(\mathrm{~m}, 2 \mathrm{H}, \mathrm{H} 3,{ }^{3} \mathrm{~J}=7 \mathrm{~Hz}\right) ; 1.37$ (tq, 2H, H10, $\left.{ }^{3} \mathrm{~J}=7 \mathrm{~Hz}\right)$ and $0.81(\mathrm{t}, 3 \mathrm{H}, \mathrm{H} 11$, ${ }^{3} \mathrm{~J}=7 \mathrm{~Hz}$ ). ${ }^{13} \mathrm{C}$ NMR (75 MHz, DMSO-d 6 ): 172.6 (C1); 158.7 (C7); 60.8 (C4); 41.4 (C9); 30.6 (C2); 28.7 (C3); 23.5 (C10) and 11.7 (C11). MP: 122-123 ${ }^{\circ} \mathrm{C}$. EI-MS: $203\left(\mathrm{M}^{+}, 0.6\right.$ \%), 185 (7.0), $126(18), 118(48), 100$ (74), 87 (61), 69 (48), 58 (43) and 43 (100). 


\section{Chapter 2 - Bridging and peripheral ligands}

2-(6-hydroxyhexanoyl)-N-propylhydrazinecarboxamide (4). Yield: 93 \%. FT-IR: 3312 $\mathrm{cm}^{-1}, 3210 \mathrm{~cm}^{-1}, 3105 \mathrm{~cm}^{-1}(3 \mathrm{x} \mathrm{NH})$ and $1670 \mathrm{~cm}^{-1}(\mathrm{C}=0)$. ${ }^{1} \mathrm{H}$ NMR $(300 \mathrm{MHz}$, DMSO$\left.d_{6}\right): 9.36(\mathrm{~s}, 1 \mathrm{H}, \mathrm{H} 7) ; 7.58(\mathrm{~s}, 1 \mathrm{H}, \mathrm{H} 8) ; 6.23\left(\mathrm{t}, 1 \mathrm{H}, \mathrm{H} 10,{ }^{3} \mathrm{~J}=6 \mathrm{~Hz}\right) ; 4.33\left(\mathrm{t}, 1 \mathrm{H}, \mathrm{OH},{ }^{3} \mathrm{~J}=\right.$ $6 \mathrm{~Hz}) ; 3.37\left(\mathrm{dt}, 2 \mathrm{H}, \mathrm{H} 6,{ }^{3} \mathrm{~J}=6 \mathrm{~Hz},{ }^{3} \mathrm{~J}=5 \mathrm{~Hz}\right) ; 2.95\left(\mathrm{dt}, 2 \mathrm{H}, \mathrm{H} 11,{ }^{3} \mathrm{~J}=7 \mathrm{~Hz}\right) ; 2.07$ (t, $2 \mathrm{H}$, $\left.\mathrm{H} 2,{ }^{3} \mathrm{~J}=7 \mathrm{~Hz}\right) ; 1.50\left(\mathrm{~m}, 2 \mathrm{H}, \mathrm{H} 3,{ }^{3} \mathrm{~J}=7 \mathrm{~Hz}\right) ; 1.40$ (m, 2H, H5); 1.37 (m, 2H, H12); 1.28 (m, $2 \mathrm{H}, \mathrm{H} 4,{ }^{3} \mathrm{~J}=7 \mathrm{~Hz}$ ) and $0.82\left(\mathrm{t}, 3 \mathrm{H}, \mathrm{H} 13,{ }^{3} \mathrm{~J}=7 \mathrm{~Hz}\right) .{ }^{13} \mathrm{C}$ NMR $\left(75 \mathrm{MHz}\right.$, DMSO- $\left.d_{6}\right)$ : 172.5 (C1); 158.6 (C9); 61.1 (C6); 41.4 (C11); 33.7 (C2); 32.7 (C5); 25.6 (C4); 25.3 (C3); 23.5 (C12) and 11.7 (C13). MP: 125-126 ${ }^{\circ} \mathrm{C}$. EI-MS: $231\left(\mathrm{M}^{+}, 0.7 \%\right), 146$ (20), $112(64), 97(44), 69(100)$ and $55(62)$.

6-hydroxy-N'-(6-hydroxyhexanoyl)hexanehydrazide (5). 6-Hydroxyhexanoic hydrazide $(1.46 \mathrm{~g}, 1 \mathrm{mmol})$ and methyl acetoacetate $(0.58 \mathrm{~g}, 0.5 \mathrm{mmol})$ are refluxed in $10 \mathrm{~mL}$ toluene for three hours. The mixture is cooled to $80^{\circ} \mathrm{C}$ and the organic phase is extracted with $2 \mathrm{~mL}$ of a $9 \% \mathrm{HCl}$ solution to eliminate the pyrazolone impurity. According to the source patent ${ }^{136}$, the product remains in the organic phase but due to the increased polarity of the diol, it emerged as a white precipitate as both phases cooled. It was recovered, washed with a little cold water and $5 \mathrm{~mL}$ cold acetone. $0.55 \mathrm{~g}$ of the diol was obtained, $21 \%$ yield. FT-IR: $3215 \mathrm{~cm}^{-1}$ and $1593 \mathrm{~cm}^{-1}(\mathrm{C}=0) .{ }^{1} \mathrm{H}$ NMR $(300 \mathrm{MHz}$, DMSO- $\left.d_{6}\right): 9.64$ (s, 1H, H7); $4.36(\mathrm{~s}, 1 \mathrm{H}, \mathrm{OH}) ; 3.37$ (t, 2H, H6, $\left.{ }^{3} \mathrm{~J}=6 \mathrm{~Hz}\right) ; 2.09$ (t, $2 \mathrm{H}$, $\left.\mathrm{H} 2,{ }^{3} \mathrm{~J}=7 \mathrm{~Hz}\right) ; 1.50\left(\mathrm{tt}, 2 \mathrm{H}, \mathrm{H} 3,{ }^{3} \mathrm{~J}=7 \mathrm{~Hz}\right) ; 1.41\left(\mathrm{tt}, 2 \mathrm{H}, \mathrm{H} 5,{ }^{3} \mathrm{~J}=7 \mathrm{~Hz}\right)$ and $1.21(\mathrm{tt}, 2 \mathrm{H}$, $\mathrm{H} 4,{ }^{3} \mathrm{~J}=7 \mathrm{~Hz}$ ). ${ }^{13} \mathrm{C}$ NMR (75 MHz, DMSO-d $)$ : $171.5(\mathrm{C} 1) ; 61.1$ (C6); 33.7 (C2); 32.7 (C5); 25.6 (C4) and 25.5 (C3). MP: 147-148 ${ }^{\circ} \mathrm{C}$. EI-MS: $242\left(\mathrm{M}^{+}-\mathrm{H}_{2} \mathrm{O}, 0.2 \%\right), 225(0.4)$, 183 (5.9), 170 (4.2), $146(23), 115$ (71), 97 (48), 69 (100), 55 (36) and 41 (49). 


\section{Chapter 2 - Bridging and peripheral ligands}

General procedure for the synthesis of diol biureas

DIAD (3 $\mathrm{g}, 14.8 \mathrm{mmol})$ diluted in $10 \mathrm{~mL}$ ethyl ether is added dropwise to a 100 $\mathrm{mL}$ RBF containing 3-hydroxypropylamine (3 $\mathrm{g}, 40 \mathrm{mmol}$ ) diluted in $40 \mathrm{~mL}$ ethyl ether at room temperature with stirring. Orange solids quickly appeared. The stirring was maintained for two hours. The solids were filtered, washed with ethyl ether and air dried. The reaction solvent system varied with the solubility of the amine used, such as a 5:6 mixture of ethyl ether and methanol when preparing ligand (10). When methanol was involved, ethyl ether was added to the reaction, after the two hour period, to completely precipitate the azo product. Also, when secondary amines were employed (piperidines), the use of DEAD instead of DIAD was necessary for the aminolysis to proceed due to the lower nucleophilicity of the amine. Warning: DEAD decomposes violently when exposed to heat and reactions should always be performed at room temperature or lower.

The azo derivative was suspended (or dissolved) in $20 \mathrm{~mL}$ ethanol and hydrazine monohydrate was added dropwize, no more than 5 drops every 15 minutes, until the orange coloration completely disappears or in the case of the piperidine-based systems, a pale yellow fine powder was obtained. The biurea tends to degrade when too much hydrazine is added. The biurea suspension was diluted with ethyl ether and the solid was filtered, washed with ethyl ether and air dried.

$N^{l}, N^{2}$-Bis(3-hydroxypropyl)hydrazine-1,2-dicarboxamide (6). Yield: $78 \%$ (based on azodicarboxylate). FT-IR: $3389 \mathrm{~cm}^{-1}(\mathrm{NH}), 3207 \mathrm{~cm}^{-1}(\mathrm{OH})$ and $1659 \mathrm{~cm}^{-1}(\mathrm{C}=\mathrm{O}) .{ }^{1} \mathrm{H}$ NMR (300 MHz, DMSO-d $): 7.59(\mathrm{~s}, 1 \mathrm{H}, \mathrm{H} 6) ; 6.36\left(\mathrm{t}, 1 \mathrm{H}, \mathrm{H} 2,{ }^{3} \mathrm{~J}=6 \mathrm{~Hz}\right) ; 4.45(\mathrm{t}, 1 \mathrm{H}$, $\left.\mathrm{OH},{ }^{3} \mathrm{~J}=5 \mathrm{~Hz}\right) ; 3.42\left(\mathrm{dt}, 2 \mathrm{H}, \mathrm{H} 5,{ }^{3} \mathrm{~J}=5 \mathrm{~Hz},{ }^{3} \mathrm{~J}=6 \mathrm{~Hz}\right) ; 3.09\left(\mathrm{dt}, 2 \mathrm{H}, \mathrm{H} 3,{ }^{3} \mathrm{~J}=5 \mathrm{~Hz},{ }^{3} \mathrm{~J}=\right.$ 


\section{Chapter 2 - Bridging and peripheral ligands}

$6 \mathrm{~Hz}$ ) and $1.54\left(\mathrm{tt}, 2 \mathrm{H}, \mathrm{H} 4,{ }^{3} \mathrm{~J}=6 \mathrm{~Hz}\right) .{ }^{13} \mathrm{C}$ NMR (75 MHz, DMSO-d 6 ): $159.3(\mathrm{Cl}) ; 58.9$ (C5); 36.8 (C3) and 33.3 (C4). MP: $252-253{ }^{\circ} \mathrm{C}$. EI-MS: $234\left(\mathrm{M}^{+}, 0.4 \%\right), 159(6.6), 133$ (50), $115(12), 102(36)$ and $56(100)$.

$N^{I}, N^{2}$-Bis(3-hydroxypentyl)hydrazine-1,2-dicarboxamide (7). Yield: $82 \%$ (based on azodicarboxylate). FT-IR: $3285 \mathrm{~cm}^{-1}(\mathrm{NH}), 3221 \mathrm{~cm}^{-1}(\mathrm{OH})$ and $1657 \mathrm{~cm}^{-1}(\mathrm{C}=\mathrm{O}) .{ }^{1} \mathrm{H}$ NMR (400 MHz, DMSO-d $\left.d_{6}\right): 7.33(\mathrm{~s}, 1 \mathrm{H}, \mathrm{H} 8) ; 6.08\left(\mathrm{t}, 1 \mathrm{H}, \mathrm{H} 2,{ }^{3} \mathrm{~J}=6 \mathrm{~Hz}\right) ; 4.14(\mathrm{t}, 1 \mathrm{H}$, $\left.\mathrm{OH},{ }^{3} \mathrm{~J}=5 \mathrm{~Hz}\right) ; 3.38\left(\mathrm{dt}, 2 \mathrm{H}, \mathrm{H} 7,{ }^{3} \mathrm{~J}=6 \mathrm{~Hz},{ }^{3} \mathrm{~J}=5 \mathrm{~Hz}\right) ; 3.0\left(\mathrm{dt}, 2 \mathrm{H}, \mathrm{H} 3,{ }^{3} \mathrm{~J}=6 \mathrm{~Hz},{ }^{3} \mathrm{~J}=\right.$ $5 \mathrm{~Hz}) ; 1.4(\mathrm{~m}, 4 \mathrm{H}, \mathrm{H} 4$ and $\mathrm{H} 6)$ and $1.27(\mathrm{~m}, 2 \mathrm{H}, \mathrm{H} 5) .{ }^{13} \mathrm{C}$ NMR (100 MHz, DMSO-d 6 ): 158.6 (C1); 60.7 (C7); 39.2 (C3); 32.2 (C6); 29.6 (C4) and 22.8 (C5). MP: $258-259{ }^{\circ} \mathrm{C}$. EI-MS: $290\left(\mathrm{M}^{+}, 1.8 \%\right), 260(0.3), 187$ (4.2), 161 (52), 130 (6.3), 112 (14), 102 (33), 85 $(12), 69(64), 55(58)$ and $41(100)$.

4-Hydroxy-N'-(4-hydroxypiperidine-1-carbonyl)piperidine-1-carbohydrazide (10). Yield: $27 \%$ (based on azodicarboxylate). FT-IR: $3280 \mathrm{~cm}^{-1}(\mathrm{NH}$ and $\mathrm{OH})$ and $1626 \mathrm{~cm}^{-1}(\mathrm{C}=\mathrm{O})$. ${ }^{1} \mathrm{H}$ NMR (300 MHz, DMSO-d $): 8.09$ (s, $\left.1 \mathrm{H}, \mathrm{H} 5\right) ; 4.69$ (d, $\left.1 \mathrm{H}, \mathrm{OH},{ }^{3} \mathrm{~J}=4 \mathrm{~Hz}\right) ; 3.71$ (ddd, $\left.2 \mathrm{H}, \mathrm{H} 2,{ }^{2} \mathrm{~J}=11 \mathrm{~Hz},{ }^{3} \mathrm{~J}=3 \mathrm{~Hz}\right) ; 3.61\left(\mathrm{ddd}, 1 \mathrm{H}, \mathrm{H} 4,{ }^{3} \mathrm{~J}=3 \mathrm{~Hz},{ }^{3} \mathrm{~J}=4 \mathrm{~Hz}\right) ; 2.86(\mathrm{ddd}, 2 \mathrm{H}$, $\left.\mathrm{H} 2{ }^{\prime},{ }^{2} \mathrm{~J}=11 \mathrm{~Hz},{ }^{3} \mathrm{~J}=3 \mathrm{~Hz}\right) ; 1.67\left(\mathrm{ddd}, 2 \mathrm{H}, \mathrm{H} 3,{ }^{2} \mathrm{~J}=10 \mathrm{~Hz},{ }^{3} \mathrm{~J}=3 \mathrm{~Hz}\right.$ ) and $1.24(\mathrm{ddd}, 2 \mathrm{H}$, $\left.\mathrm{H} 3{ }^{\prime},{ }^{2} \mathrm{~J}=10 \mathrm{~Hz},{ }^{3} \mathrm{~J}=3 \mathrm{~Hz}\right) .{ }^{13} \mathrm{C}$ NMR $\left(75 \mathrm{MHz}, \mathrm{DMSO}-d_{6}\right): 157.9$ (C1); 66.0 (C4); 41.4 (C2) and 34.2 (C3). MP: 212-213 ${ }^{\circ} \mathrm{C}$. EI-MS: $286\left(\mathrm{M}^{+}, 5.0 \%\right), 185$ (99), 167 (5.9), 140 (7.9), $128(50), 113(22), 102(68), 84(49), 68(15), 56(100)$ and $42(76)$. 


\section{Chapter 2 - Bridging and peripheral ligands}

4-(Hydroxymethyl)-N'-(4-(hydroxymethyl)piperidine-1-carbonyl)piperidine-1-

carbohydrazide (11). Yield: $55 \%$ (based on azodicarboxylate). FT-IR: $3287 \mathrm{~cm}^{-1}(\mathrm{NH}$ and $\mathrm{OH}$ ) and $1612 \mathrm{~cm}^{-1}(\mathrm{C}=\mathrm{O}) .{ }^{1} \mathrm{H}$ NMR (300 MHz, DMSO- $\left.d_{6}\right): 8.04(\mathrm{~s}, 1 \mathrm{H}, \mathrm{H} 6) ; 4.46$ (s, 1H, OH); 3.98 (ddd, 2H, H2, $\left.{ }^{2} \mathrm{~J}=13 \mathrm{~Hz}\right) ; 3.23$ (d, 2H, H5, $\left.{ }^{3} \mathrm{~J}=6 \mathrm{~Hz}\right) ; 2.64$ (ddd, 2H, $\mathrm{H} 2$ ', $\left.{ }^{2} \mathrm{~J}=13\right) ; 1.59$ (ddd, $\left.2 \mathrm{H}, \mathrm{H} 3,{ }^{2} \mathrm{~J}=12 \mathrm{~Hz}\right) ; 1.52(\mathrm{~m}, 1 \mathrm{H}, \mathrm{H} 4)$ and 1.24 (ddd, 2H, H3', ${ }^{2} \mathrm{~J}=12 \mathrm{~Hz},{ }^{3} \mathrm{~J}=3 \mathrm{~Hz}$ ). ${ }^{13} \mathrm{C}$ NMR (75 MHz, DMSO- $\left.d_{6}\right): 158.3$ (C1); 66.2 (C5); 44.0 (C2); 39.0 (C4) and 29.0 (C3). MP: 186-187 ${ }^{\circ} \mathrm{C}$. EI-MS: $314\left(\mathrm{M}^{+}, 2.5 \%\right), 199$ (67), 184 (1.6), 158 (3.6), 142 (26), 128 (6.6), 114 (72), 96 (27), 84 (49), 69 (28), 55 (100) and 43 (76).

4-Methyl-N'-(4-methylpiperidine-1-carbonyl)piperidine-1-carbohydrazide (23). Yield: 37 \% (based on azodicarboxylate). FT-IR: $3238 \mathrm{~cm}^{-1}(\mathrm{NH})$ and $1634 \mathrm{~cm}^{-1}(\mathrm{C}=\mathrm{O}) .{ }^{1} \mathrm{H}$ NMR $\left(300 \mathrm{MHz}, \mathrm{DMSO}-d_{6}\right): 8.07$ (s, 1H, H6); 3.97 (ddd, 2H, H2, ${ }^{2} \mathrm{~J}=12 \mathrm{~Hz}$ ); 2.67 (ddd, 2H, $\mathrm{H} 2$, ${ }^{2} \mathrm{~J}=12 \mathrm{~Hz}$ ); 1.57 (ddd, 2H, H3, ${ }^{2} \mathrm{~J}=12$ ); 1.55 (ddq, 1H, H4); 1.02 (ddd, 2H, H3', ${ }^{2} \mathrm{~J}$ $\left.=12 \mathrm{~Hz},{ }^{3} \mathrm{~J}=10 \mathrm{~Hz}\right)$ and $1.24\left(\mathrm{~d}, 3 \mathrm{H}, \mathrm{H} 5,{ }^{3} \mathrm{~J}=6 \mathrm{~Hz}\right) .{ }^{13} \mathrm{C}$ NMR $\left(75 \mathrm{MHz}\right.$, DMSO- $\left.d_{6}\right)$ : $158.3(\mathrm{C} 1) ; 44.3(\mathrm{C} 2) ; 34.1(\mathrm{C} 3) ; 30.9(\mathrm{C} 4)$ and $22.4(\mathrm{C} 5)$. MP: 181-182 ${ }^{\circ} \mathrm{C}$. EI-MS: 282 (M+ $2.6 \%), 264$ (4.4), 183 (91), 168 (7.1), 142 (4.2), 126 (48), 98 (100), 84 (23), 69 (21), 55 (87) and 43 (40).

$N^{l}, N^{2}$-Bis(1,3-dihydroxy-2-methylpropan-2-yl)hydrazine-1,2-dicarboxamide (8). DEAD ( $2 \mathrm{~g}, 12 \mathrm{mmol}$ ) diluted in $15 \mathrm{~mL} \mathrm{1:1} \mathrm{ethyl} \mathrm{ether:methanol} \mathrm{is} \mathrm{added} \mathrm{dropwise} \mathrm{to} \mathrm{a} 100 \mathrm{~mL}$ RBF containing a 2-amino-2-methylpropane-1,3-diol (2.8 g, $26.6 \mathrm{mmol})$ solution in 50 $\mathrm{mL}$ ethyl ether:methanol 1:1, cooled using an ice bath (removed after the addition is complete). A pale orange precipitate forms quickly and the reaction is stirred for two 


\section{Chapter 2 - Bridging and peripheral ligands}

hours at room temperature. The mixture is poured in $100 \mathrm{~mL}$ ethyl ether. The solid is filtered off, washed with ethyl ether and air dried. The azo intermediate reduced as described above for diol biureas. The ethanol is evaporated on a roto-evaporator at low temperature $\left(30-35^{\circ} \mathrm{C}\right)$, yielding a sticky white residue. Triturate the solid using acetone, filter the powdery solid, wash with ethyl ether and air dry. Yield: $56 \%$ (based on azodicarboxylate). FT-IR: $3350 \mathrm{~cm}^{-1}(\mathrm{NH}), 3231 \mathrm{~cm}^{-1}(\mathrm{OH})$ and $1672 \mathrm{~cm}^{-1}(\mathrm{C}=\mathrm{O}) .{ }^{1} \mathrm{H}$ NMR (400 MHz, DMSO-d $): 7.71(\mathrm{~s}, 1 \mathrm{H}, \mathrm{H} 6) ; 5.87(\mathrm{~s}, 1 \mathrm{H}, \mathrm{H} 2) ; 4.87\left(\mathrm{t}, 2 \mathrm{H}, \mathrm{OH},{ }^{3} \mathrm{~J}=\right.$ $5 \mathrm{~Hz}) ; 3.45\left(\mathrm{dd}, 2 \mathrm{H}, \mathrm{H} 5,{ }^{2} \mathrm{~J}=11 \mathrm{~Hz},{ }^{3} \mathrm{~J}=5 \mathrm{~Hz}\right) ; 3.33\left(\mathrm{dd}, 2 \mathrm{H}, \mathrm{H} 5,{ }^{2} \mathrm{~J}=11 \mathrm{~Hz},{ }^{3} \mathrm{~J}=5 \mathrm{~Hz}\right)$; and $1.14(\mathrm{~s}, 3 \mathrm{H}, \mathrm{H} 4) .{ }^{13} \mathrm{C}$ NMR (100 MHz, DMSO- $\left.d_{6}\right): 158.4(\mathrm{C} 1) ; 64.4$ (C5); 56.8 (C3) and 18.8 (C4). MP: $141-142^{\circ} \mathrm{C}$. EI-MS: $271(0.6 \%), 246(0.7), 190(1.9), 164(6.5), 141$ (19), $132(42), 114(5.6), 100(93), 90(5.3), 74(90), 56(100)$ and $42(75)$.

$N^{I}$-(5-Hydroxypentyl)- $N^{2}$-propyloxalamide (12). Ethyl oxochloro acetate (4 g, 29.4 $\mathrm{mmol}$ ) diluted in $10 \mathrm{~mL}$ THF was added dropwize to a cooled (ice water), stirred solution of propylamine $(1.7 \mathrm{~g}, 28.8 \mathrm{mmol})$ and TEA $(2.97 \mathrm{~g}, 29.4 \mathrm{mmol})$ in $70 \mathrm{~mL}$ of THF. The solution is warmed to room temperature following the addition and stirring is maintained for 1 hour. The reaction mixture is then chilled in an ice bath, the TEA-HCl is filtered out and the solid is washed with $20 \mathrm{~mL}$ of cold THF. The filtrate is concentrated to a yellow oil. A portion of this oil ( $2 \mathrm{~g}, 12.6 \mathrm{mmol})$ was diluted in $10 \mathrm{~mL}$ ethyl ether and added dropwize to a solution of 5-hydroxypentamine $(1.45 \mathrm{~g}, 14 \mathrm{mmol})$ dissolved in $25 \mathrm{~mL}$ ethyl ether and enough methanol to ensure complete dissolution of the amine. Stirring is maintained for two hours. The mixture was then diluted with $50 \mathrm{~mL}$ ethyl ether, the white precipitate was filtered and washed with a 95:5 ethyl ether:methanol solution followed by 


\section{Chapter 2 - Bridging and peripheral ligands}

ethyl ether and air dried. Yield: $60 \%$. FT-IR: $3292 \mathrm{~cm}^{-1}(\mathrm{NH})$ and $1645 \mathrm{~cm}^{-1}(\mathrm{C}=\mathrm{O}) .{ }^{1} \mathrm{H}$ NMR (300 MHz, DMSO- $\left.d_{6}\right): 8.70$ (s, 2H, H2 and H9); $4.34(\mathrm{~s}, 1 \mathrm{H}, \mathrm{OH}) ; 3.37$ (t, 2H, H7, $\left.{ }^{3} \mathrm{~J}=6 \mathrm{~Hz}\right) ; 3.11(\mathrm{~m}, 2 \mathrm{H}, \mathrm{H} 3) ; 3.07(\mathrm{~m}, 2 \mathrm{H}, \mathrm{H} 10) ; 1.47(\mathrm{~m}, 2 \mathrm{H}, \mathrm{H} 5) ; 1.45(\mathrm{~m}, 2 \mathrm{H}, \mathrm{H} 11)$; $1.41(\mathrm{~m}, 2 \mathrm{H}, \mathrm{H} 6) ; 1.26\left(\mathrm{tt}, 2 \mathrm{H}, \mathrm{H} 4,{ }^{3} \mathrm{~J}=6 \mathrm{~Hz}\right)$ and $0.82\left(\mathrm{t}, 3 \mathrm{H}, \mathrm{H} 12,{ }^{3} \mathrm{~J}=7 \mathrm{~Hz}\right) .{ }^{13} \mathrm{C} \mathrm{NMR}$ (75 MHz, DMSO-d $)$ ): 160.1, 160.0 (C1, C8); 60.6 (C7); 40.6 (C10); 38.8 (C3); 32.2 (C6); 28.7 (C11); 22.9 (C4); 22.1 (C5) and 11.3 (C12). MP: 133-134 ${ }^{\circ} \mathrm{C}$. EI-MS: 216 $\left(\mathrm{M}^{+}, 4.2 \%\right), 188(2.4), 171(0.8), 159(8.3), 143(7.4), 130(43), 112(56), 103(20), 86$ (26), $69(97), 59(29)$ and $43(100)$.

$N^{l}, N^{2}$-Bis(4-aminobenzyl)hydrazine-1,2-dicarboxamide (21). DIAD (0.81 g, $\left.4 \mathrm{mmol}\right)$ diluted in $10 \mathrm{~mL}$ of ethyl ether is added dropwize to a 4-aminobenylamine $(1.0 \mathrm{~g}, 8.2$ mmol) solution in $25 \mathrm{~mL}$ of 9:1 ethyl ether:methanol. Stirring was maintained for 2 hours. The solvent was removed and the yellow azo solid was triturated with ethyl ether, filtered, washed with ethyl ether and air dried. Hydrazine hydrate was used as the reducing agent as described above for diol biureas. The white solid was isolated, washed with $10 \mathrm{~mL}$ cold methanol and $50 \mathrm{~mL}$ of ethyl ether. Yield: $60 \%$ (based on azodicarboxylate). FT-IR: $3294 \mathrm{~cm}^{-1}(\mathrm{NH}), 3219,3091 \mathrm{~cm}^{-1}\left(\mathrm{NH}_{2}\right)$ and $1657 \mathrm{~cm}^{-1}(\mathrm{C}=\mathrm{O})$. ${ }^{1} \mathrm{H}$ NMR (300 MHz, DMSO-d $\left.)_{6}\right): 7.58(\mathrm{~s}, 1 \mathrm{H}, \mathrm{H} 8) ; 6.91\left(\mathrm{~d}, 2 \mathrm{H}, \mathrm{H} 5,{ }^{3} \mathrm{~J}=8 \mathrm{~Hz}\right) ; 6.53(\mathrm{t}$, $\left.2 \mathrm{H}, \mathrm{H} 2,{ }^{3} \mathrm{~J}=6 \mathrm{~Hz}\right) ; 6.48\left(\mathrm{~d}, 2 \mathrm{H}, \mathrm{H} 6,{ }^{3} \mathrm{~J}=8 \mathrm{~Hz}\right) ; 4.91\left(\mathrm{~s}, 2 \mathrm{H}, \mathrm{NH}_{2}\right)$ and $4.03\left(\mathrm{~d}, 2 \mathrm{H}, \mathrm{H} 3,{ }^{3} \mathrm{~J}\right.$ $=6 \mathrm{~Hz}) .{ }^{13} \mathrm{C}$ NMR (75 MHz, DMSO- $\left.d_{6}\right): 158.6(\mathrm{C} 1) ; 147.3$ (C7); 128.1 (C5); 127.2 (C4); 113.6 (C6) and 42.5 (C3). MP: $270^{\circ} \mathrm{C}$ (dec.). EI-MS: 165 (0.7\%), 148 (21), 132 (1.2), $121(18), 106(100), 94(9.1), 78(20), 65(7.3), 52(7.1)$ and $43(8.4)$. 


\section{Chapter 2 - Bridging and peripheral ligands}

3,3'-(Hydrazine-1,2-diylbis(oxomethylene))bis(azanediyl)dipropanoic acid (22). DIAD

$(2.23 \mathrm{~g}, 11 \mathrm{mmol})$ diluted in $10 \mathrm{~mL}$ of ethanol is added dropwize to an aqueous solution (40 $\left.\mathrm{mL} \mathrm{H}_{2} \mathrm{O}\right)$ of $\beta$-alanine $(2.11 \mathrm{~g}, 23.7 \mathrm{mmol})$ and $\mathrm{NaOH}(0.96 \mathrm{~g}, \mathrm{mmol})$ in a $100 \mathrm{~mL}$ RBF. This was stirred at room temperature for 30 minutes and acidified with $2 \mathrm{M} \mathrm{HCl}$. The yellow precipitate was filtered and washed with ethyl ether and air dried. The azo intermediate was dispersed in ethanol and hydrazine hydrate was added one drop at a time every five minutes until the coloration completely disappeared. Precipitate the diacid in $100 \mathrm{~mL}$ ethyl ether, filter and air dry. Yield: $37 \%$ (based on azodicarboxylate). FT-IR: $3280 \mathrm{~cm}^{-1}(\mathrm{NH}), 3101 \mathrm{~cm}^{-1}(\mathrm{COOH})$ and $1666 \mathrm{~cm}^{-1}(\mathrm{C}=\mathrm{O}) .{ }^{1} \mathrm{H}$ NMR $\left(400 \mathrm{MHz}, \mathrm{D}_{2} \mathrm{O}\right)$ : $7.75(\mathrm{~s}, 1 \mathrm{H}, \mathrm{H} 6) ; 6.81(\mathrm{~s}, 1 \mathrm{H}, \mathrm{H} 2) ; 3.33\left(\mathrm{t}, 2 \mathrm{H}, \mathrm{H} 3,{ }^{3} \mathrm{~J}=7 \mathrm{~Hz}\right)$ and $2.35\left(\mathrm{t}, 2 \mathrm{H}, \mathrm{H} 4,{ }^{3} \mathrm{~J}=\right.$ 7Hz). ${ }^{13} \mathrm{C}$ NMR (100 MHz, $\mathrm{D}_{2} \mathrm{O}$ ): 183.1 (C5); $163.0(\mathrm{C} 1) ; 39.9$ (C3) and 39.3 (C4). MP: $239^{\circ} \mathrm{C}$ (dec.). EI-MS: 226 (4.6 \%), 168 (0.4), 155 (6.1), 140 (1.5), 129 (86), 114 (4.9), 98 (24), 87 (45), 70 (28), 60 (15), 55 (40) and 44 (100). 


\section{Chapter 3 - Dinuclear ruthenium and platinum complexes}

3.1 - Introduction

The electrochromic properties of dinuclear ruthenium complexes have been extensively studied ${ }^{3,52,60-65}$. The IVCT of the mixed valence oxidation state appears in the NIR region of the electromagnetic spectrum and can be tuned according to the donor strength of the ligands used. As previously mentioned, the substitution effect of the peripheral ligand is modest at best, producing small optical shifts of about $\pm 100 \mathrm{~nm}$, which represents small energy changes in the lowest unoccupied molecular orbitals (LUMO) of the complexes with little effect on the overall bandgap. Modifying the bridging ligand, on the other hand has a more pronounced effect, up to $400 \mathrm{~nm}$ hypsochromic shifts, which enabled the tuning of the NIR absorbance over a broader range of wavelengths ${ }^{149}$. Therefore, the impact of the bridging ligands on the HOMO energy levels of the complexes is as follows: the NIR absorbance is redshifted when the electron donating potential is enhanced (HOMO increase) and vice-versa. To further study this process, a series of dinuclear ruthenium complexes, based on the ligands of Chapter 2 were prepared and characterized. The structures of some reported DCH and OXA ruthenium complexes by previous group members, were resolved by $\mathrm{x}$-ray crystallography and as expected, show octahedral geometries. A simple stick structure of the DCH and OXA complexes is shown in Figure 3.1. 
a)

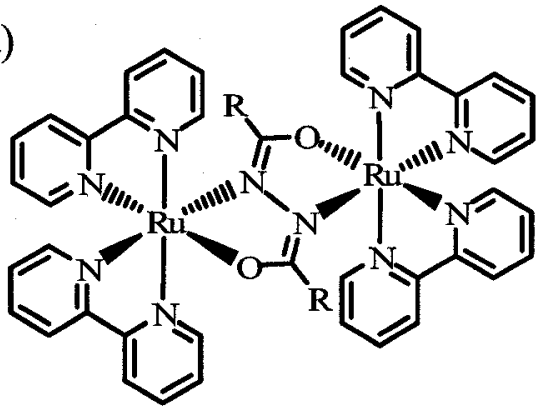

b)

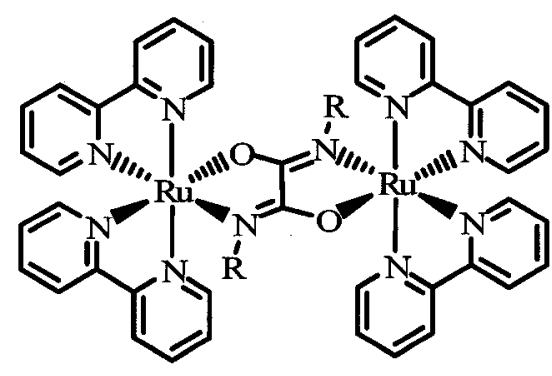

Figure 3.1 - Model of a) DCH and b) OXA dinuclear ruthenium complexes

Moreover, in order to study the effect of metal centers on optical properties, various dinuclear platinum complexes, with different electron donating potential, were prepared and their optical properties were evaluated. Since platinum complexes are known phosphorescent materials ${ }^{150-161}$, the possibility of NIR emission by a mixed valence oxidation state was intriguing.

Many dinuclear platinum complexes based on different ligand systems are known ${ }^{162-179}$. However, most bridging ligands employed do not permit electronic communication between the two platinum atoms and the so-called dinuclear complex behaves as two single platinum complexes. A few mixed valence $\mathrm{Pt}^{\mathrm{II}}-\mathrm{Pt}^{\mathrm{III}}$ state complexes have been reported through crystallography but no optical studies have been performed study their NIR potential ${ }^{158,}{ }^{180}$. Ma and coworkers prepared dinuclear platinum complexes based on pyrazolates that form angular complexes, bringing the two platinum atoms closer together. The close proximity favours some bonding character between the two metal centers through the $\sigma^{*}$ orbital and the resulting metal-metal-toligand charge transfer (MMLCT) is redshifted as the Pt-Pt distance is reduced ${ }^{181,182}$. In the cases of mononuclear platinum complexes, the usual $\pi \rightarrow \pi^{*}$ MLCT transition is 


\section{Chapter 3-Dinuclear ruthenium and platinum complexes}

observed; however, for dinuclear platinum complexes the more energetic $\sigma^{*}$ is filled and the transition is then $\sigma^{*} \rightarrow \pi^{*}$, which has a much smaller energy gap, causing the redshift of the transition ${ }^{182}$. As the platinum atoms are brought closer together, repulsive forces increase and may become dominant; it would appear that emission of red light, peaking at $690 \mathrm{~nm}$ for a Pt-Pt distance of $2.8 \AA$, is seriously approaching this $\operatorname{limit}^{182}$. At $690 \mathrm{~nm}$, just short of breaching the NIR barrier, emission at even longer wavelengths is likely impossible via MMLCT.

3.2 - Results and discussion

\subsection{1 - Ruthenium complexes}

Dinuclear ruthenium complexes of selected ligands discussed in Chapter 2, were prepared via a ligand exchange reaction and isolated as $\mathrm{PF}_{6}$ salts. The complexes were obtained, after purification using neutral alumina, as purple solids which were soluble in alcohol, acetone, acetonitrile, dimethylsulfoxide (DMSO) and N,N-dimethylformamide (DMF). It should be noted however that, the two latter solvents are generally avoided due to their problematic removal. The increased polarity of the complexes caused by the hydroxyl groups required water-deactivated alumina with water to allow the elution to proceed at a suitable rate. Yields of purified aliphatic DCH and OXA complexes, were generally good.

All the complexes prepared, regardless of functionalization, were redox active and their $\mathrm{CVs}$ showed two, reversible, one-electron redox waves representing the $\mathrm{Ru}^{\mathrm{II}} / \mathrm{Ru}^{\mathrm{II}}$ (ground state), $\mathrm{Ru}^{\mathrm{II}} / \mathrm{Ru}^{\mathrm{III}}$ (mixed valence state) and $\mathrm{Ru}^{\mathrm{III}} / \mathrm{Ru}^{\mathrm{III}}$ states (Figure 3.1). The 
redox potentials of the complexes were influenced by the substituents of the bridging ligand; adding electron-withdrawing groups increased the electron ionisation energy of the metal centers, effectively increasing the redox potential while electron-donating groups had the opposite effect. This effect can be further tuned by the number of groups added. Complex 36, having two extra nitrogens had a lower redox potential than complex 31 (Figure 3.1) which only has one extra nitrogen. This is all relative to complex $\mathbf{3 0}$ which does not contain any electron-donating groups and exhibited the highest redox potentials of the trio (see footnote ' $a$ ' of Table 3.1 for CV conditions).

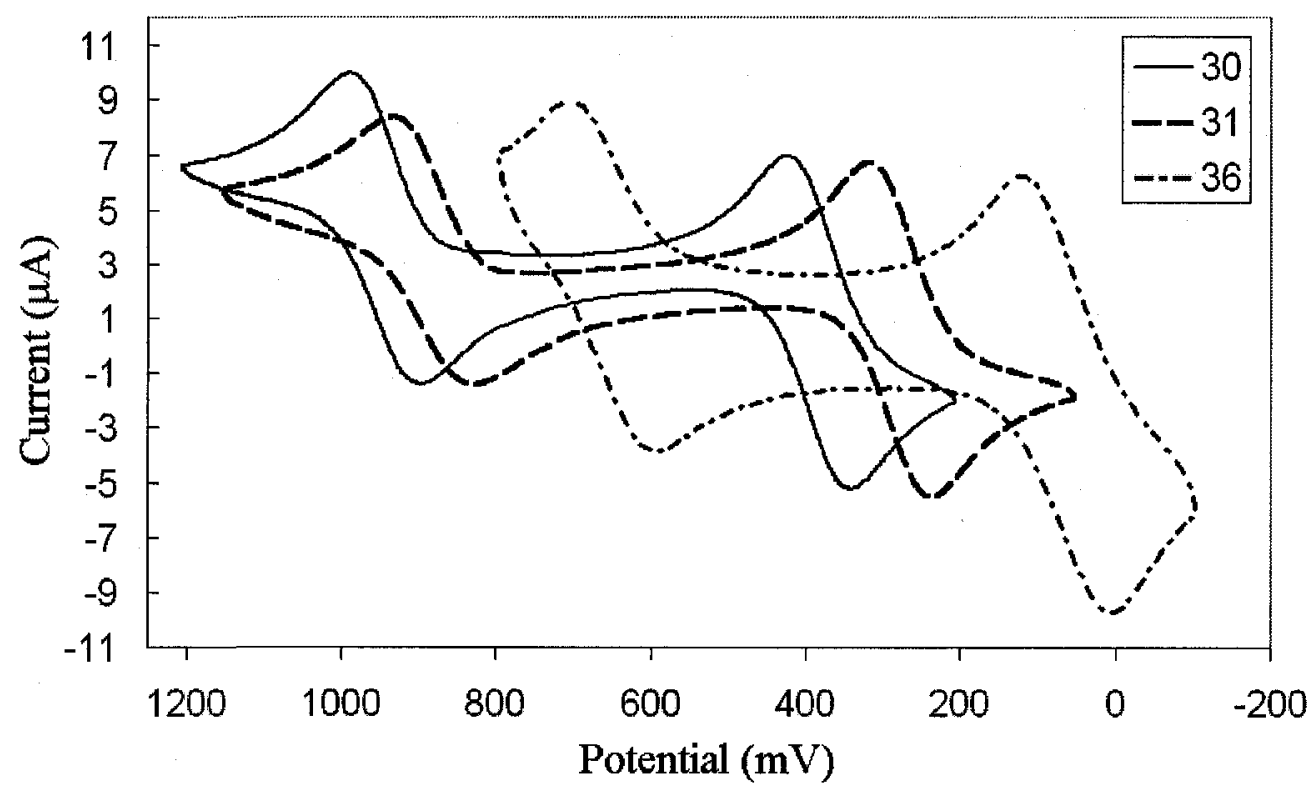

Figure $3.1-\mathrm{CV}$ of $\mathbf{3 0}, \mathbf{3 1}$ and $\mathbf{3 6}$

The redox potentials of the synthesized complexes are compiled in Table 3.1. When oxygen-based donating groups were involved, such as with $\mathbf{3 8}$, the redox potentials were lowered although the effect was less important than with nitrogen containing complexes. As an electron donor, oxygen is not as effective as nitrogen because of its 


\section{Chapter 3-Dinuclear ruthenium and platinum complexes}

higher electronegativity; it retains its valence electrons with a higher affinity translating to higher redox potentials.

Table 3.1 - Electrochemical properties of the ruthenium complexes

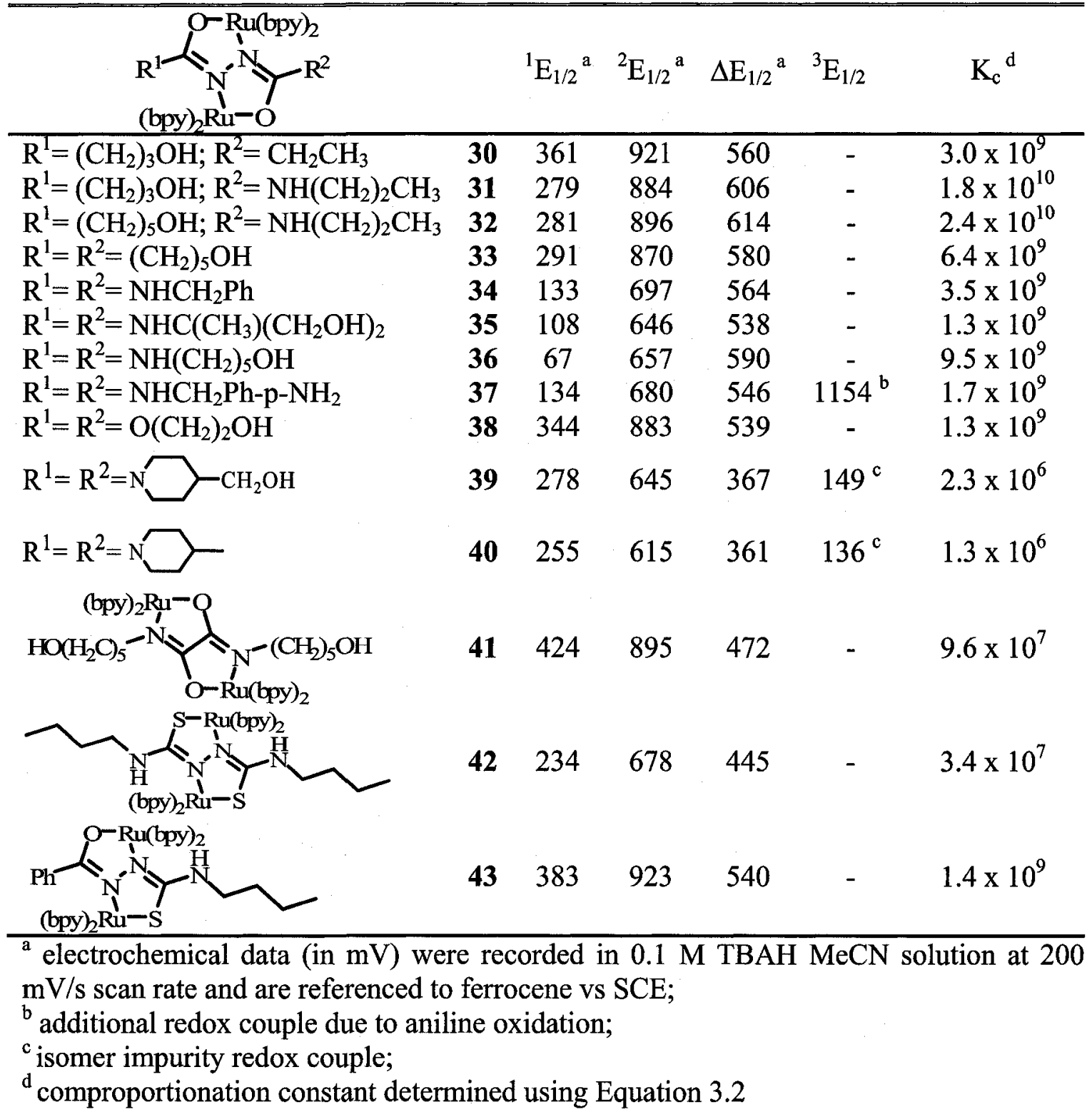

When the carbonyl oxygen was replaced by sulfur, in the cases of 42 and 43 , the redox potentials of the ruthenium complexes decreased. However, the observed effect may be due to the nitrogen donating potential rather than the presence of sulfur. 
Sulfurisation of diphenylhydrazide using $\mathrm{P}_{2} \mathrm{~S}_{5}$, as an attempt to prepare the dithio derivative, which would have provided a reference complex to better evaluate the effect of sulfur, only produced 2,5-diphenyl-1,3,4-thiadiazole by $\mathrm{H}_{2} \mathrm{~S}$ elimination.

The peak separation, $\Delta \mathrm{E}_{1 / 2}$, of complexes based on the $\mathrm{DCH}$ ligands were, on average, $570 \mathrm{mV}$ regardless of the electrodonating potential of the ligand used. A lower $\Delta \mathrm{E}_{1 / 2}$ was observed for the piperidine biureas (39 and 40), which did not appear to be significantly different from the other biurea complexes. Disubstituted biureas presented, on average, ${ }^{1} \mathrm{E}_{1 / 2}$ of $100 \mathrm{mV}$, while the piperidine biureas (tetrasubstituted biurea) had ${ }^{1} E_{1 / 2}$ of $260 \mathrm{mV}$. On the other hand, the ${ }^{2} \mathrm{E}_{1 / 2}$ of both groups was of the same order of magnitude, hence the smaller $\Delta \mathrm{E}_{1 / 2}$. To explain this difference, we turn to the mixed valence state which can transfer its electron to a neighbouring molecule, forming $\mathrm{Ru}^{\mathrm{II}} / \mathrm{Ru}^{\mathrm{II}}$ and $\mathrm{Ru} \mathrm{u}^{\mathrm{III}} / \mathrm{Ru}{ }^{\mathrm{III}}$ molecules (equation 3.1).

$$
R u^{I I} / R u^{I I}+R u^{I I I} / R u^{I I I} \stackrel{k_{c}}{\rightleftharpoons} R u^{I I} / R u^{I I I}
$$

This equilibrium is governed by the comproportionation constant $\left(\mathrm{k}_{\mathrm{c}}\right)$ and is calculated using $\Delta \mathrm{E}_{1 / 2}$ (equation 3.2$)^{183}$.

$$
k_{c}=10^{16.91 \Delta E_{1 / 2}}
$$

When the constant is large, the $\mathrm{Ru}^{\mathrm{II}} / \mathrm{Ru}^{\mathrm{III}}$ system coupling is strong, intermolecular electron transfer is no longer dominant, but rather, intramolecular electron transfer between both ruthenium atoms occurs and this charge 'sharing' imparts a 
stabilizing effect on the system. The comproportionation constant, $k_{\mathrm{c}}$, can be determined using the free energy of conproportionation, $\Delta \mathrm{G}_{\mathrm{c}}$ (equation 3.3) ${ }^{183}$.

$$
\Delta G_{c}=-R T\left(\ln k_{c}\right)
$$

$\Delta \mathrm{G}_{\mathrm{c}}$ is the sum of many free energy terms, including $\Delta \mathrm{G}_{\mathrm{r}}$, the free energy of resonance exchange ${ }^{183}$. Figure 3.2 depicts energy potential curves of a weakly coupling system (a) and a strongly coupling system (b). The free energy of resonance exchange is also shown.

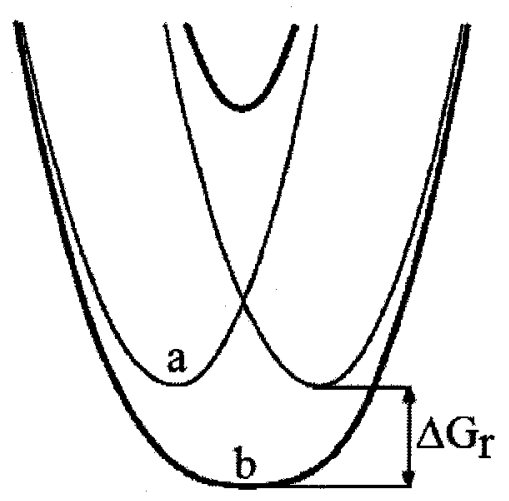

Figure 3.2 - Potential energy curves of a weakly coupled (a) and a strongly coupled (b) mixed valence state

Strong coupling systems, being more stable, will require extra energy to further oxidize the system, thus maintaining the ${ }^{2} \mathrm{E}_{1 / 2}$ at higher energies. It could be expected that a piperidine, with its nitrogen enriched by the two alkyl groups of the ring, would be a more efficient electron donor thus reducing the redox potentials to a greater degree than the biureas. This, however, does not appear to be the case since the opposite effect was 
observed; a lower $\Delta \mathrm{E}_{1 / 2}$ due to weaker coupling, possibly due to orbital misalignment with the carbonyl.

The $\Delta \mathrm{E}_{1 / 2}$, of the thio derivatives (42 and 43 ) behaved similarly to the $\mathrm{DCH}$ analogues, becoming lower as the number of sulfur increased. The smaller $\Delta \mathrm{E}_{1 / 2}$ compared to that of the DCH complexes, suggest that they too, have weaker coupling than the biureas.

Each redox state of the complexes was studied by spectroelectrochemistry and their optical properties are compiled in Table 3.2. The ground state $\left(\mathrm{Ru}^{\mathrm{II}} / \mathrm{Ru}^{\mathrm{II}}\right)$ is marked by two MLCTs in the UV-Vis region, resulting in an observed purple coloration, while the mixed valence state $\left(\mathrm{Ru}^{\mathrm{II}} / \mathrm{Ru}{ }^{\mathrm{III}}\right)$ only has one MLCT in the visible region, near 420 $\mathrm{nm}$, giving it a yellow color although a broad absorbance in the NIR is observed due to the IVCT transition. The third oxidation state $\left(\mathrm{Ru}^{\mathrm{III}} / \mathrm{Ru}^{\mathrm{III}}\right)$ has a light green tint, almost unperceivable and two MLCTs near $400 \mathrm{~nm}$ and 750-950 nm. The NIR transition of the third oxidation state is normally ignored due to complex degradation particularly when high potentials are required to attain this state. The three oxidation states of complex 36, as well as the NIR region of the mixed valence state of $\mathbf{3 3}$ and 38, are overlaid in Figure 3.3, showing the $\lambda_{\max }$ effect of donating group strength on the mixed valence state. 
Chapter 3 - Dinuclear ruthenium and platinum complexes

Table 3.2 - Spectroelectrochemical properties of ruthenium complexes

\begin{tabular}{|c|c|c|c|c|}
\hline$(\mathrm{bpy})_{2} \mathrm{Ru}=\mathrm{O}$ & & $\mathrm{Ru}^{\mathrm{II}} / \mathrm{Ru}{ }^{\mathrm{II}} \mathrm{a}$ & $\mathrm{Ru}^{\mathrm{II}} / \mathrm{Ru}{ }^{\mathrm{III}}$ a & $\mathrm{Ru}^{\mathrm{III}} / \mathrm{Ru}$ \\
\hline $\mathrm{R}^{1}=\left(\mathrm{CH}_{2}\right)_{3} \mathrm{OH} ; \mathrm{R}^{2}=\mathrm{CH}_{2} \mathrm{CH}_{3}$ & 30 & $\begin{array}{l}344(4.56) \\
516(3.91)\end{array}$ & $\begin{array}{c}426(4.38) \\
1483(4.25)\end{array}$ & $\begin{array}{l}347(4.31) \\
818(4.42)^{b}\end{array}$ \\
\hline $\mathrm{R}^{1}=\left(\mathrm{CH}_{2}\right)_{3} \mathrm{OH} ; \mathrm{R}^{2}=\mathrm{NH}\left(\mathrm{CH}_{2}\right)_{2} \mathrm{CH}_{3}$ & 31 & $\begin{array}{l}342(4.17) \\
509(4.09)\end{array}$ & $\begin{array}{c}438(4.12) \\
1188(3.66)\end{array}$ & $\begin{array}{l}417(4.19) \\
915(3.49)\end{array}$ \\
\hline$=\mathrm{NH}\left(\mathrm{CH}_{2}\right)_{2} \mathrm{CH}_{3}$ & 32 & $\begin{array}{l}344(4.23) \\
514(4.18)\end{array}$ & $\begin{array}{c}423(4.03) \\
1184(3.77)\end{array}$ & $\begin{array}{l}367(3.99) \\
910(4.11)\end{array}$ \\
\hline $\mathrm{R}^{1}=\mathrm{R}^{2}=(\mathrm{CH}$ & 33 & $\begin{array}{l}345(4.35) \\
520(4.31)\end{array}$ & $\begin{array}{c}429(4.13) \\
1492(4.12)\end{array}$ & $\begin{array}{l}342(4.07) \\
818(4.31)^{b}\end{array}$ \\
\hline $\mathrm{R}^{1}=\mathrm{R}^{2}=\mathrm{NHCH}_{2} \mathrm{Ph}$ & 34 & $\begin{array}{l}342(4.34) \\
502(4.26)\end{array}$ & $\begin{array}{c}440(4.19) \\
1162(3.94)\end{array}$ & $\begin{array}{l}392(4.14) \\
888(4.30)\end{array}$ \\
\hline $\mathrm{R}^{1}=\mathrm{R}^{2}=\mathrm{NHC}\left(\mathrm{CH}_{3}\right)\left(\mathrm{CH}_{2} \mathrm{OH}\right)_{2}$ & 35 & $\begin{array}{l}342(4.38) \\
506(4.32)\end{array}$ & $\begin{array}{c}448(4.26) \\
1075(4.01)\end{array}$ & $\begin{array}{l}418(4.31) \\
928(3.52)\end{array}$ \\
\hline $\mathrm{R}^{2}=\mathrm{NH}\left(\mathrm{CH}_{2}\right)_{5} \mathrm{OH}$ & 36 & $\begin{array}{l}342(4.40) \\
495(4.29)\end{array}$ & $\begin{array}{l}4.37(4.22) \\
1043(3.80)\end{array}$ & $\begin{array}{l}379(4.14) \\
908(4.27)\end{array}$ \\
\hline $\mathrm{R}^{2}=\mathrm{NHCH}$ & 37 & $\begin{array}{l}340(4.31) \\
502(4.18)\end{array}$ & $\begin{array}{c}450(4.12) \\
1115(3.67)\end{array}$ & $\begin{array}{l}385(4.19) \\
901(4.31)\end{array}$ \\
\hline $2^{2}=\mathrm{O}\left(\mathrm{CH}_{2}\right.$ & 38 & $\begin{array}{l}340(4.30) \\
506(4.25)\end{array}$ & $\begin{array}{c}444(4.18) \\
1403(3.94)\end{array}$ & $\begin{array}{l}415(4.06) \\
890(4.11)\end{array}$ \\
\hline & 39 & $\begin{array}{l}362(4.30) \\
502(4.16)\end{array}$ & $\begin{array}{c}453(4.20) \\
1244(3.85)\end{array}$ & $\begin{array}{l}385(4.13) \\
904(4.06)\end{array}$ \\
\hline & 40 & $\begin{array}{l}350(4.28) \\
506(4.21)\end{array}$ & $\begin{array}{c}454(4.19) \\
1192(3.73)\end{array}$ & $\begin{array}{l}386(4.13) \\
883(3.84)\end{array}$ \\
\hline & 41 & $\begin{array}{l}372(4.48) \\
530(4.38)\end{array}$ & $\begin{array}{c}463(4.23) \\
1650(4.17)\end{array}$ & $\begin{array}{l}336(4.18) \\
637(3.63)\end{array}$ \\
\hline$(\text { bpy })_{2}$ & 42 & $\begin{array}{l}335(4.30) \\
459(4.16)\end{array}$ & $\begin{array}{c}410(4.13) \\
1340(3.83) \\
2246(3.33)\end{array}$ & $\begin{array}{l}379(4.09) \\
861(4.01)\end{array}$ \\
\hline $\begin{array}{c}\mathrm{N} \\
(\mathrm{bpy})_{2} \mathrm{Ru}-\mathrm{S}\end{array}$ & 43 & $\begin{array}{l}342(4.30) \\
488(4.14)\end{array}$ & $\begin{array}{c}422(4.09) \\
1578(4.14) \\
2500(3.4)^{c}\end{array}$ & $\begin{array}{l}342(4.05) \\
662(3.78) \\
861(4.05) \\
\end{array}$ \\
\hline
\end{tabular}




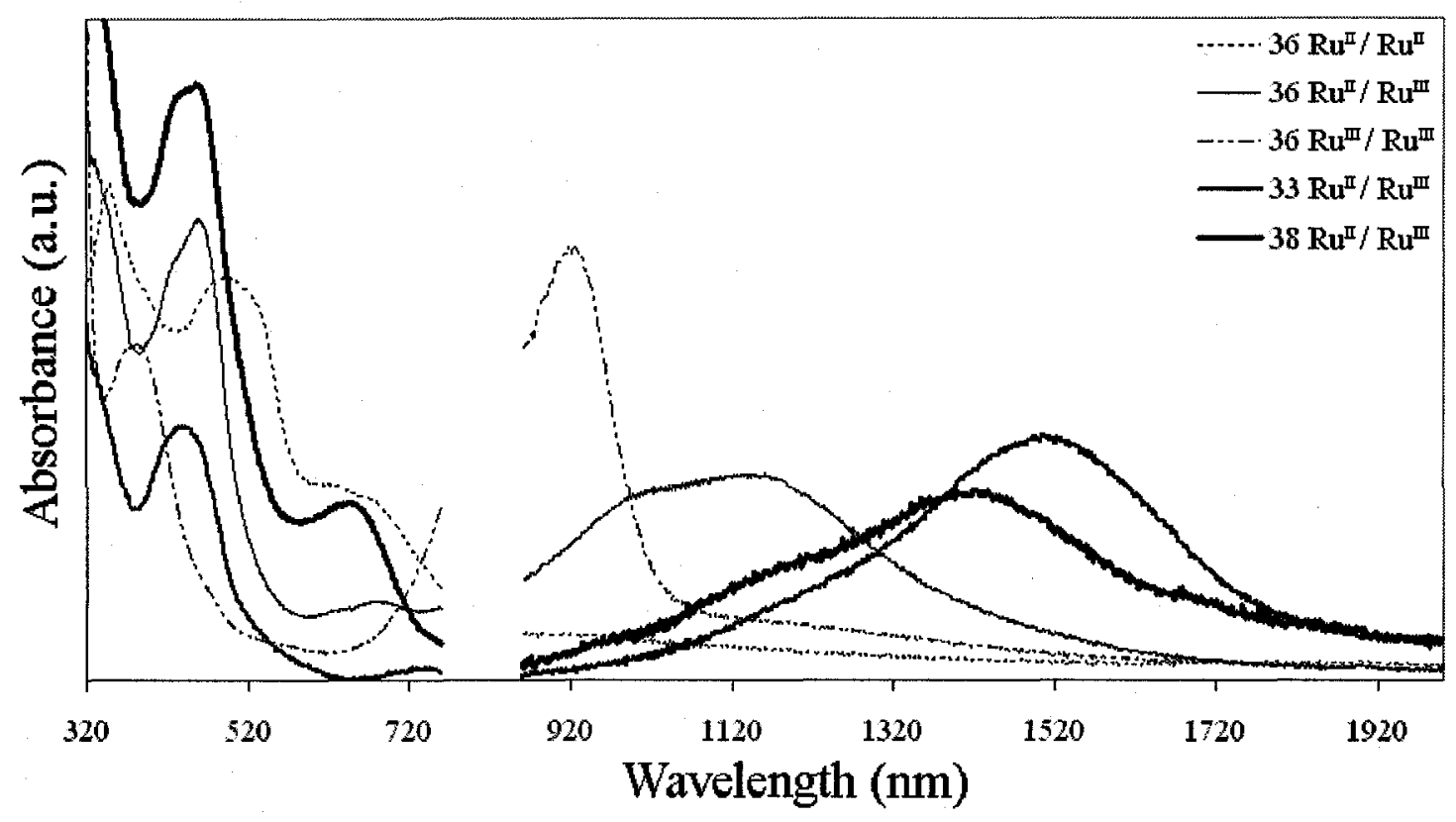

Figure 3.3 - Spectroelectrochemistry of 36 and $\mathrm{Ru}{ }^{\mathrm{II}} / \mathrm{Ru}{ }^{\mathrm{III}}$ states of 33 and 38

When semi-biurea and biurea complexes were prepared, excess base was added to compensate for the presence of the extra NH. The expected dinuclear product did form although the yield, after purification, was significantly lower than analogue complexes based on DCH ligands, due to an important formation of a green by-product, 36G. All attempts to crystallize this green product failed. A single redox wave was observed in its $\mathrm{CV}$, suggesting that it is mononuclear, or perhaps dinuclear with the metal centers far apart, preventing the formation of a mixed valence state. The UV-Vis-NIR of this green compound and corresponding CV (inset) are shown in (Figure 3.4). 
Chapter 3-Dinuclear ruthenium and platinum complexes

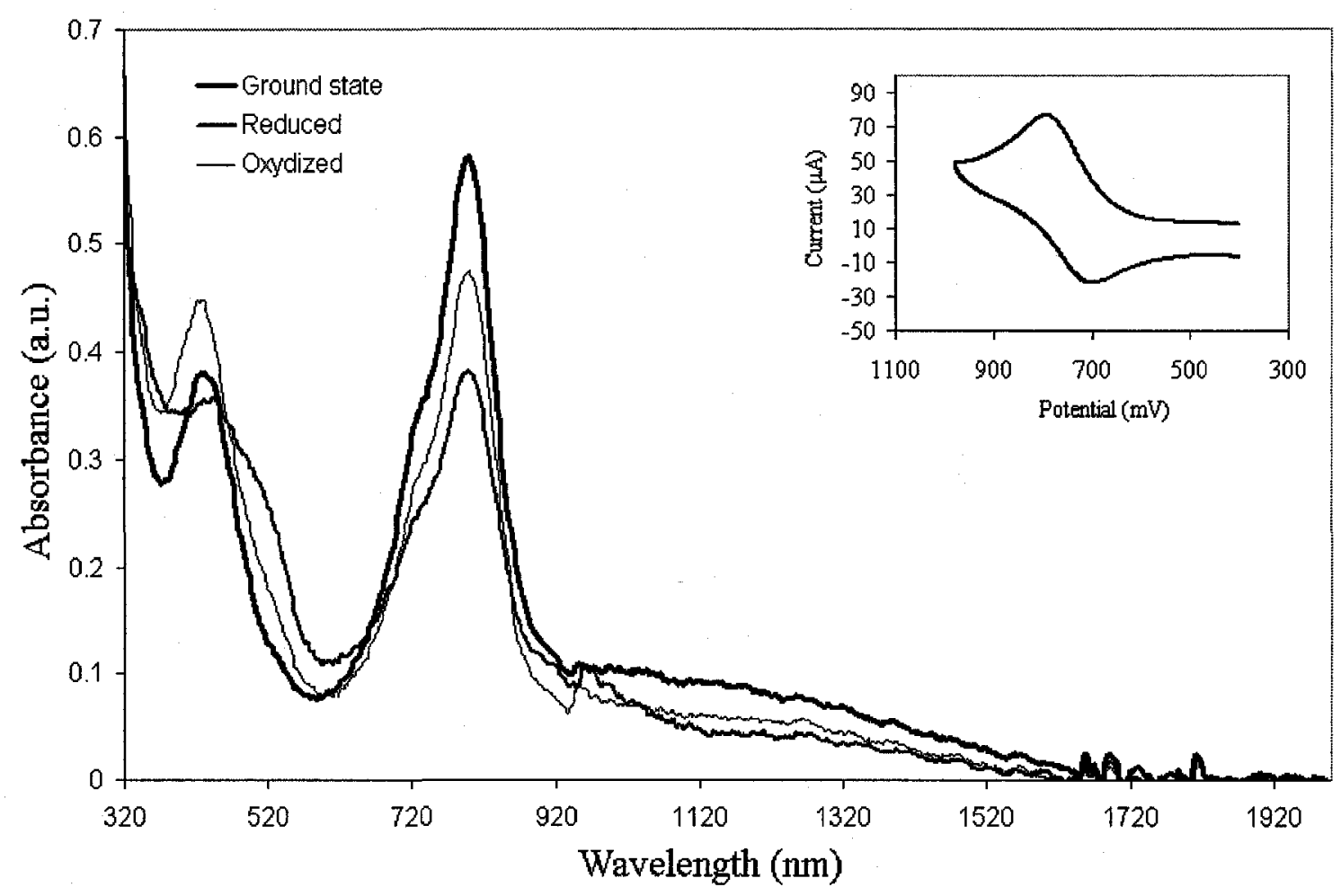

Figure 3.4 - Spectroelectrochemistry of 36G and CV (inset)

Unfortunately, spectroelectrochemistry did not provide additional information as the only change observed is the intensity of the 424 and $794 \mathrm{~nm}$ bands. NMR of this green species exhibited a great number of overlapping resonances in both the aromatic and aliphatic regions, suggesting an unsymmetrical dinuclear system, where the ruthenium atoms are not linked through the $\mathrm{DCH}$ moiety, or multiple mononuclear isomers (appendix 2). Electrospray ionisation mass spectrometry (ESI-MS) of this complex (Figure 3.5, possible, but unproven structure shown) demonstrated the usual ion patterns as seen in other complexes considered in this study, giving some credibility to the existence of an unsymmetrical dinuclear complex isomer. In addition, the elusive protonated molecular ion was observed $\left([\mathrm{M}+\mathrm{H}]^{+}, \mathrm{m} / \mathrm{z}=1405\right)$ as well as the acetonitrile monosolvated specie $\left([\mathrm{M}+\mathrm{MeCN}]^{+}, \mathrm{m} / \mathrm{z}=1446\right)$. The fact that there are many ionic 
species in the 700-1300 amu range, as opposed to almost none in 'normal' complexes (see Figure 3.7 for an example) is yet another puzzle piece pointing towards an unsymmetrical complex. As an effort to find some use for $\mathbf{3 6 G}$, its photoluminescence was probed. Excitation at $800 \mathrm{~nm}$ did not produce emission in the NIR region. If $\mathbf{3 6 G}$ is in fact dinuclear, where both ruthenium atoms are chelated differently and are no longer coupled thus behaving as two independent complexes, self-quenching could explain the lack of emission.

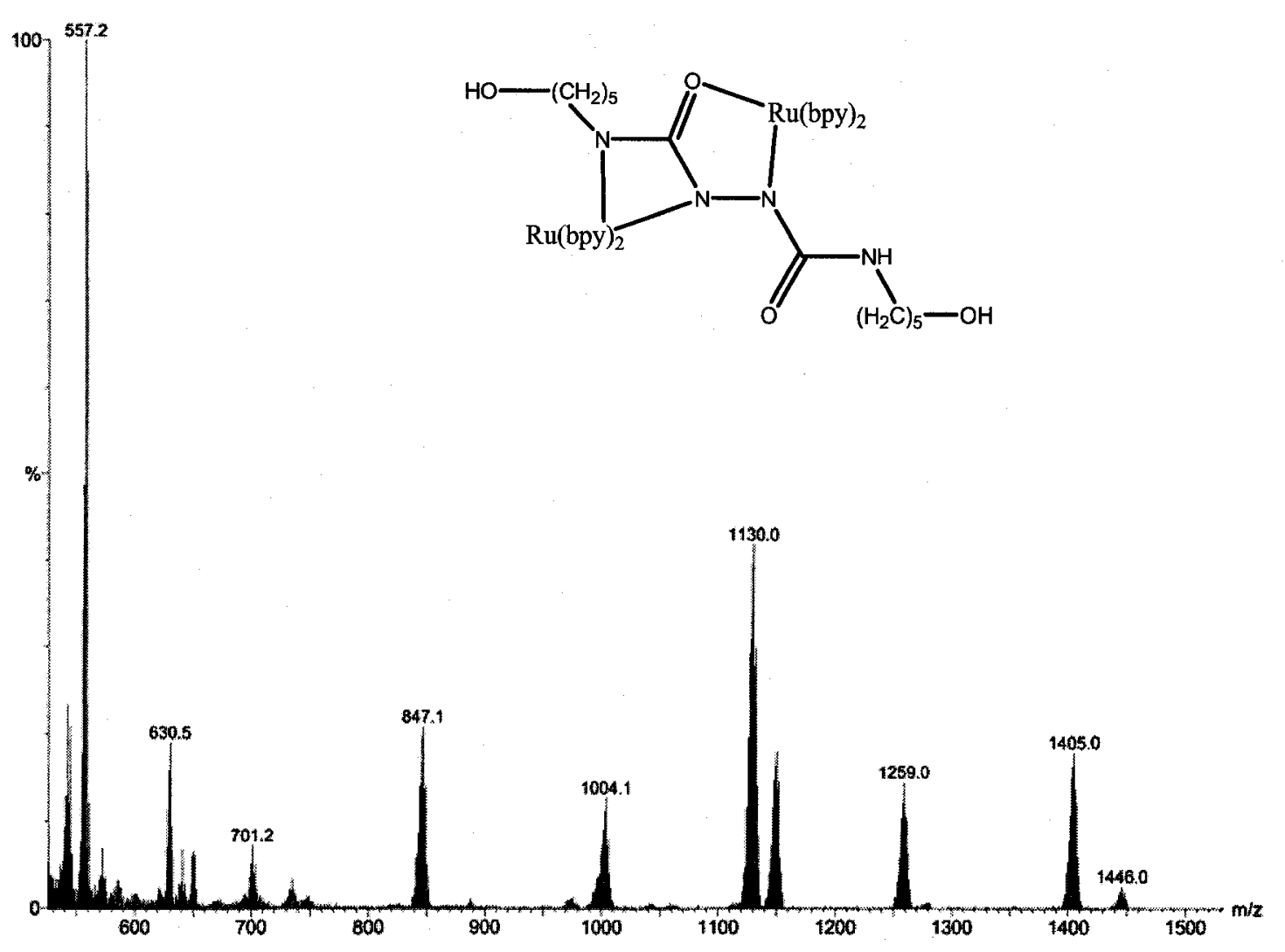

Figure 3.5 - ESI-MS of 36G

The biurea complexes are useful for optical attenuation at the other telecom wavelengths (980 and $1310 \mathrm{~nm}$ ) but applications may be limited by low yields and the 
increasing price of ruthenium(III) chloride. In order to be cost effective, higher yields are needed. Since the exchange reaction requires deprotonation of the hydrazide protons, it seemed likely that the primary amide protons, which can be deprotonated as well, would compete during the complexation reaction.

To validate this hypothesis, biurea analogues, based on piperidines, were prepared using the same azodicarboxylate chemistry used to create secondary amides that are devoid of acidic protons. Indeed, it was found that the amide protons were, at least partially, responsible for the formation of the green complex, since no green species was isolated during the purification of the piperidine complexes. These complexes had similar redox properties as the biureas and had an IVCT centered at $1200 \mathrm{~nm}$. The advantage of a broad absorption makes 39 suitable for the $1310 \mathrm{~nm}$ telecommunication band. The $\mathrm{Ru}^{\mathrm{II}} / \mathrm{Ru}$ III state absorption spans past $980 \mathrm{~nm}$, albeit at a lower molar extinction coefficient. Luckily, due to the reduced redox potentials, the $\mathrm{Ru}^{\mathrm{III}} / \mathrm{Ru}^{\mathrm{III}}$ state is stable enough to be considered for the $980 \mathrm{~nm}$ telecommunication band. The yield of $\mathbf{3 9}$ was 3 times higher than that of $\mathbf{3 6}$ but at $21 \%$, is still quite low. Unfortunately, solving the green complex problem generated another. A third redox wave can be seen, partially overlapping with ${ }^{1} \mathrm{E}_{1 / 2}$. The optical properties of the piperidine complex in this form were as expected and it was thought that the 'impurity' was a mono-ruthenium specie that did not absorb in the NIR. Mononuclear ruthenium complexes are usually soluble in halogenated solvents such as dichloromethane (DCM), but the diol dinuclear complexes are not. Washing 39 with DCM extracted a brown complex (39S, soluble) and left a purple solid behind (39I, insoluble). Both were analyzed and surprisingly, both 


\section{Chapter 3-Dinuclear ruthenium and platinum complexes}

complexes displayed two redox waves, with the ${ }^{2} \mathrm{E}_{1 / 2}$ overlapping with the other isolated specie (Figure 3.6).

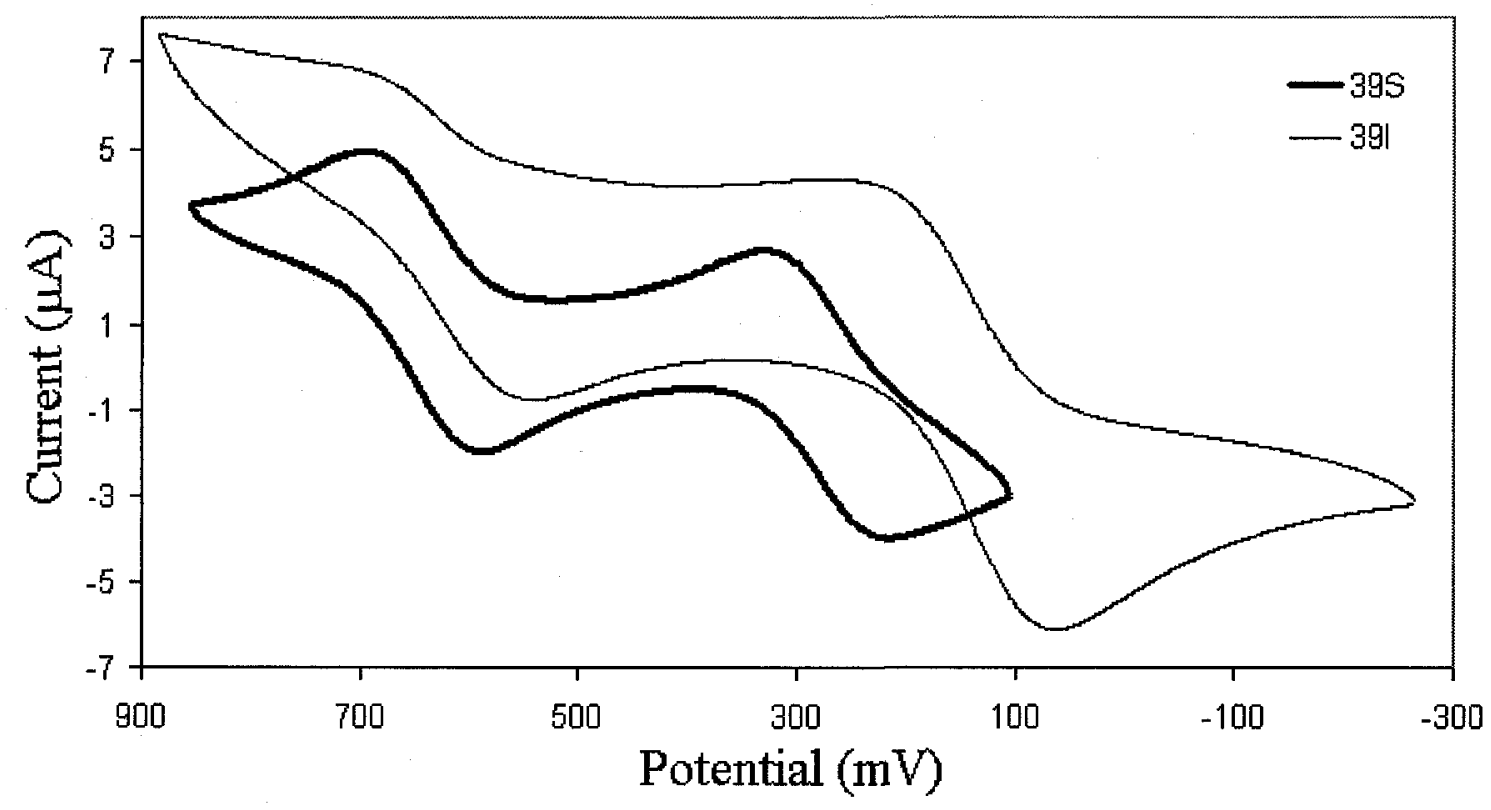

Figure $3.6-\mathrm{CV}$ of $39 \mathrm{~S}$ and $39 \mathrm{I}$

Spectroelectrochemistry also revealed that both complexes are NIR active; however, the NIR absorption of the $\mathrm{Ru}^{\mathrm{III}} / \mathrm{Ru}^{\mathrm{III}}$ state at $904 \mathrm{~nm}$ is not present for 39I, which is odd, given that the purple complex is usually the 'expected' product (Figure 3.7). 

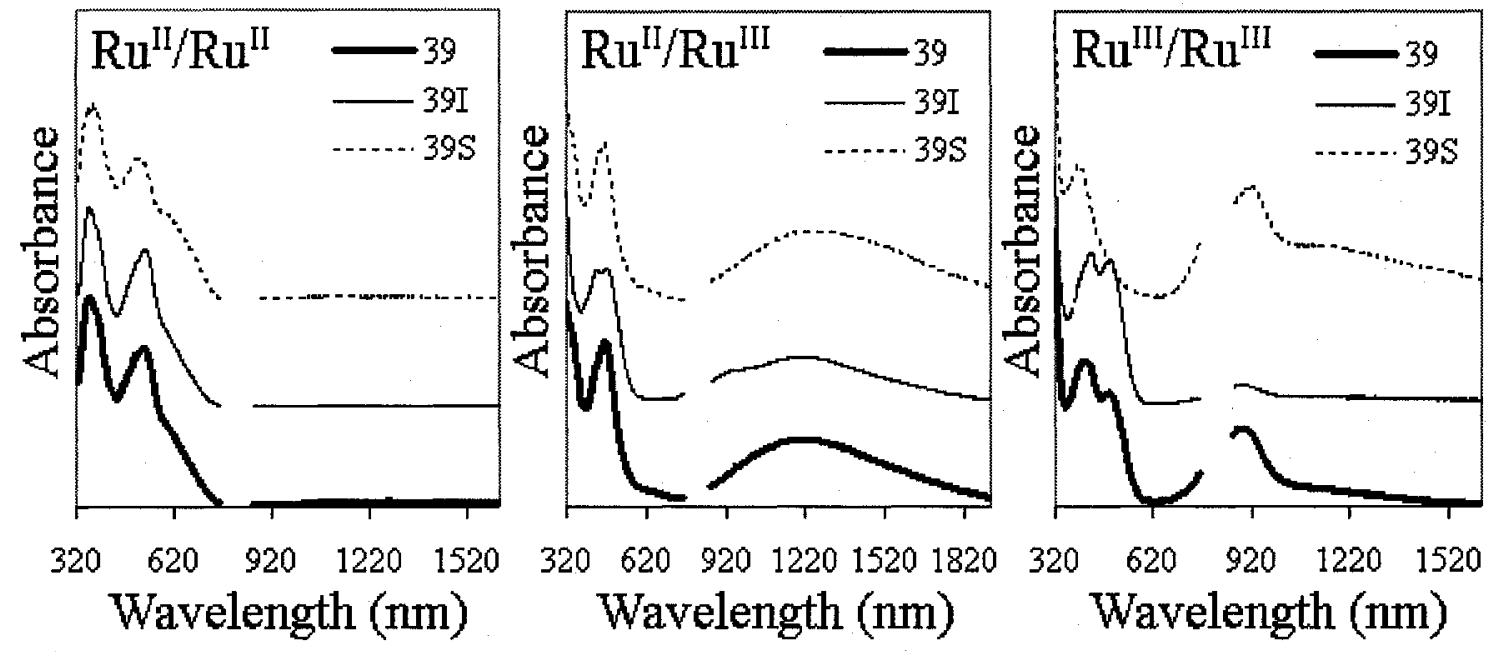

Figure 3.7 - Spectroelectrochemistry of 39, 39S and 39I

Crystallography would have unveiled the nature of the two compounds; however, suitable crystals were not obtained. ${ }^{1} \mathrm{H}$ NMR of 39I (appendix 1) was well resolved, the only low redox potential complex to be suitable for full resonance assignment, while 39S was not (appendix 3), proving that 39I is the expected dinuclear complex even without the usual purple color. The simplified ${ }^{1} \mathrm{H}$ spectrum of $39 \mathrm{I}$ indicates symmetry and adds additional support that this species is the expected product. Samples of the mixture and both isolated compounds were analyzed by ESI-MS and show the same fragment patterns, with different intensities, again suggesting isomers. Even with a primary amide, there is a competing chelation mode, creating the isomer. It is doubtful that these two complexes are stereoisomers as such compounds are not readily separated by simple chromatography. Since both are NIR active, each ruthenium must be chelated to one atom of the $\mathrm{DCH}$ moiety, either $\mathrm{O}$ or $\mathrm{N}$. It is feasible that two nitrogens, geminal to a carbonyl carbon could complex the ruthenium but with a four membered ring, the resulting strain would likely promote decomplexation or rearrangement. 


\section{Chapter 3-Dinuclear ruthenium and platinum complexes}

Other than CV and spectroelectrochemistry, characterization of the complexes was similar to that of the bridging ligands except for NMR as most complexes, especially the ones having low redox potentials, had an incredibly complex splitting pattern in the aromatic region of both ${ }^{1} \mathrm{H}$ and ${ }^{13} \mathrm{C}$ experiments which made it impossible to assign resonances. Firstly, unsymmetrical bridging ligands make all four bipyridines unequivalent - that's 32 aromatic protons, just from the bpy moieties. When the ligand is symmetrical, this is halved to 16 signals. Taking advantage of various 2D NMR experiments, the ${ }^{1} \mathrm{H}$ and ${ }^{13} \mathrm{C}$ resonances of complexes $39 \mathrm{I}$ and $\mathbf{4 1}$ have been completely assigned. The reason that the other complexes were not assigned by NMR is that the low redox potential complexes can be oxidized to the mixed valence state by molecular oxygen (especially in solution), albeit at a slow rate, and $\mathrm{Ru}^{\mathrm{III}}$ is paramagnetic, therefore trace amounts of it is detrimental to NMR data acquisition. Add the potential of stereoisomers, even in regular DCH complexes, and the situation worsens still ${ }^{64}$. The main characterization technique used to analyze the complexes was ESI-MS in positive mode. Since the complex is a salt and therefore positively charged, two main ions, [M$\left.\mathrm{PF}_{6}\right]^{+}$and $\left[\mathrm{M}-2 \mathrm{PF}_{6}\right]^{+2}$ are observed. Ruthenium has seven stable isotopes and the combined isotopic motif of two ruthenium atoms is readily recognizable. Occasionally, the protonated molecular ion is observed but this is rare since the complex is dissolved (Figure 3.8). 


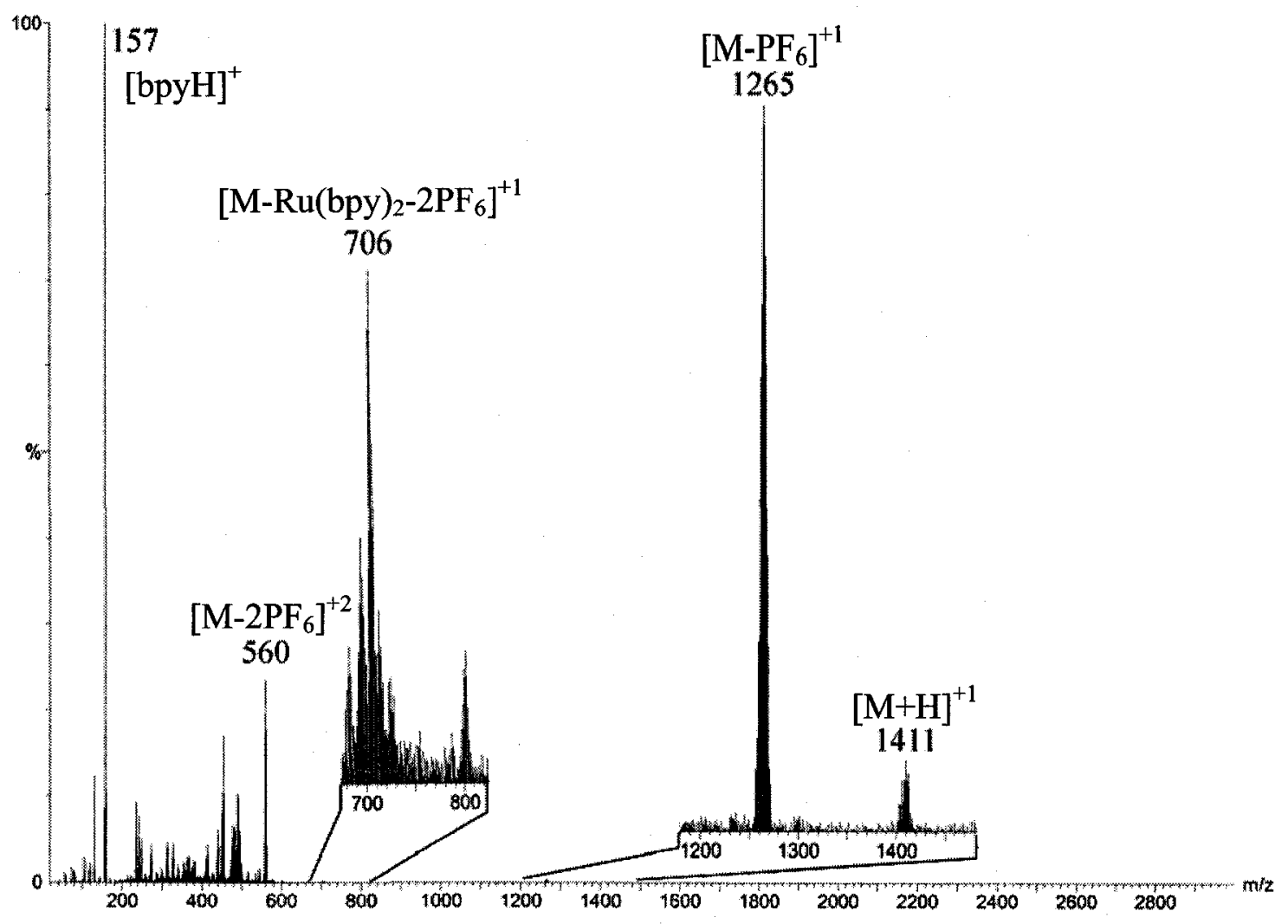

Figure 3.8 - ESI-MS of $\mathbf{3 5}$

When protonation does occur, it does so at the bridging ligand, destabilizes the complex, forcing the loss of $\mathrm{Ru}(\mathrm{bpy})_{2}$ and generates another characteristic peak, at $\mathrm{m} / \mathrm{z}=706$ in the case of $\mathbf{3 5}$.

The electrochemical and spectral characteristics of these complexes were considered as complementary techniques to ESI-MS in order to validate the structure of the new dinuclear complexes synthesized.

\subsection{2 - Platinum complexes}

Platinum complexes of 2-phenylpyridine (ppy) and analogous cyclometallating ligands are well known for their luminescent properties ${ }^{155,158,160,161,181,184-196}$. Three 
DCH dinuclear platinum complexes were successfully prepared (Figure 3.9) in high yield using an adapted method based on the ruthenium complex synthesis and the cyclometallated dichlorobridged ppy platinum complex ${ }^{147}$. The bridging ligands were chosen to represent electron poor (29) and rich (28) environments as well as a plain aliphatic ligand (16) to serve as a reference point. Unlike bpy, ppy is unsymmetrical and two stereoisomers can be envisaged (cis and trans). However, due to the carbanion generated on the ppy and the negative oxygen of the ligand, same-charge-repulsion should lead to a single isomer. There is also the trans effect that is observed with square planar complexes where certain ligands will tend to promote the formation of trans compounds. The sequence of ligands in increasing order of trans directing effect is: $\mathrm{F}^{-}$, $\mathrm{H} 2 \mathrm{O}, \mathrm{OH}^{-}<\mathrm{NH}_{3}<\mathrm{py}<\mathrm{Cl}^{-}<\mathrm{Br}^{-}<\mathrm{I}^{-}, \mathrm{SCN}^{-}, \mathrm{NO}_{2}^{-}, \mathrm{SC}\left(\mathrm{NH}_{2}\right)_{2}, \mathrm{Ph}^{-}<\mathrm{SO}_{3}^{2-}<\mathrm{PR}_{3}$, $\mathrm{AsR}_{3}, \mathrm{SR}_{2}, \mathrm{CH}_{3}{ }^{-}<\mathrm{H}^{-}, \mathrm{NO}, \mathrm{CO}, \mathrm{CN}^{-}$. While the $\mathrm{C}=\mathrm{O}$ is trans directing, the two nitrogen chelating sites are cis directing, resulting in both nitrogens being trans to each other. The ${ }^{1} \mathrm{H}$ NMR spectrum of $\mathbf{4 6}$ clearly shows the seven aromatic protons on ppy, an indication of symmetry, in addition of aromatics from the bridging ligand (see appendix 1).

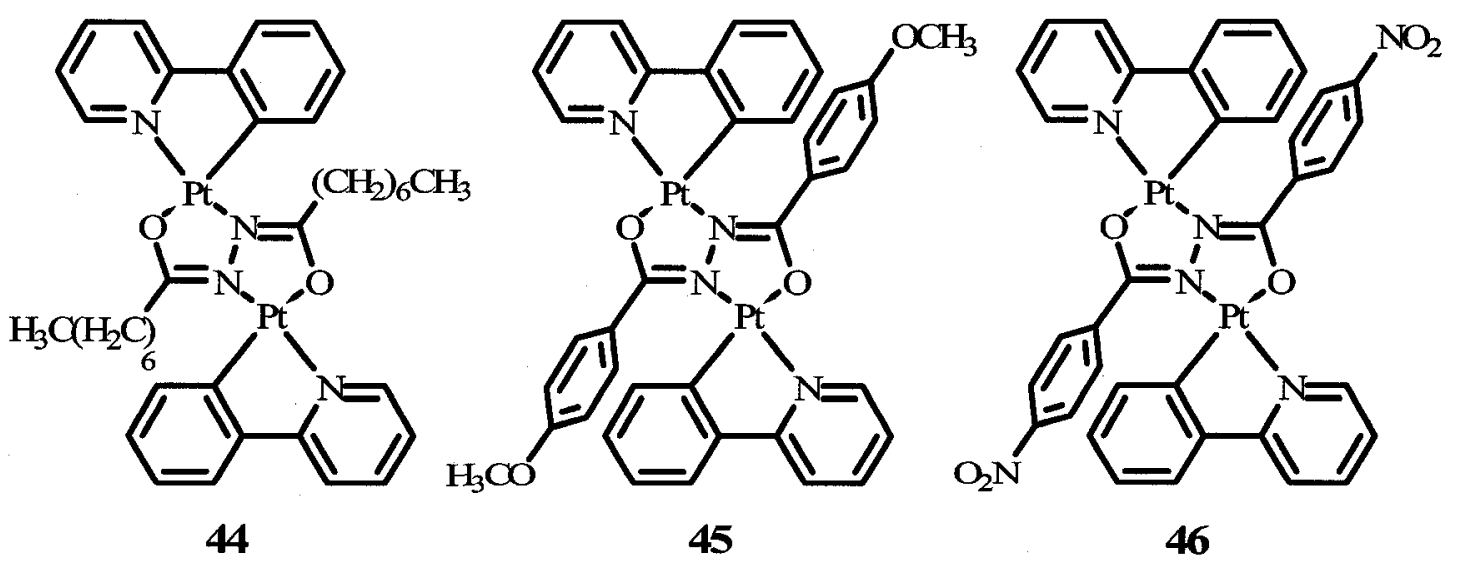

Figure 3.9 - Structures of platinum complexes 44-46 
ESI-MS of these complexes, being neutral, have different fragmentation patterns than their ionic ruthenium counterparts. The protonated molecular ion is observed as well as acetonitrile mono- and di-solvated species (Figure 3.10). Destabilisation of the complex from the protonation is also observed; however, protonation occurs at the ppy ligand. Proof of this lies in the observed ion corresponding to the $\left[\mathrm{Pt}(\mathrm{ppy})_{2} \mathrm{MeCN}\right]^{+}$ species. This ion's protonated ppy can be replaced by another acetonitrile molecule, giving the $\left[\mathrm{Pt}(\mathrm{ppy})(\mathrm{MeCN})_{2}\right]^{+}$species as seen in Figure 3.9.

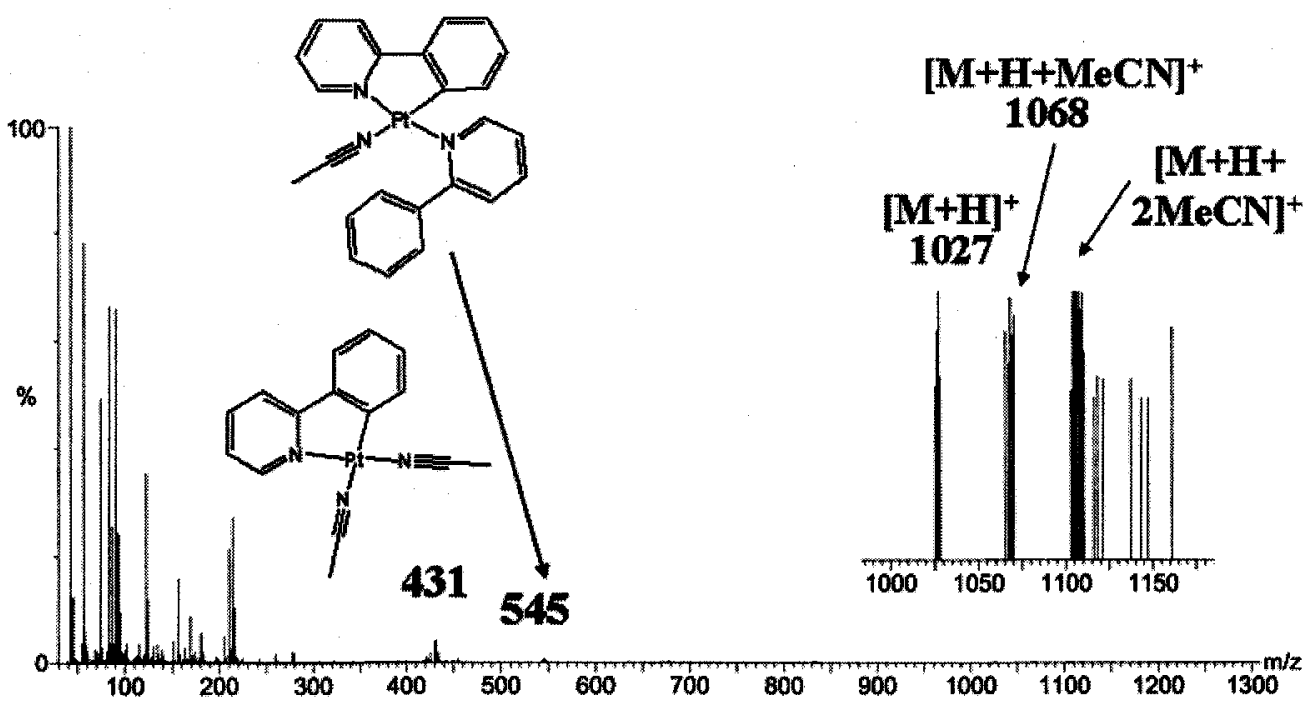

Figure 3.10 - ESI-MS of 46

The photoluminescence (PL) of DCM solutions of the ppy-based complexes, 44 and 45, when excited at $300 \mathrm{~nm}$, yielded green light (Figure 3.11). This emission results from excitation of the MLCT transition near $400 \mathrm{~nm}$ which gives the same PL spectrum when exciting from 250 to $400 \mathrm{~nm}$, except that the PL intensity increases with photon energy. One drawback is that prolong exposure to high energy photons diminishes the intensity of the PL over time, suggesting photodegradation or photobleaching of the complexes. As such, PL studies were performed at a $300 \mathrm{~nm}$ excitation wavelength for 


\section{Chapter 3-Dinuclear ruthenium and platinum complexes}

optimal signal strength. The complexes should therefore be kept in amber vials, in the dark or both.

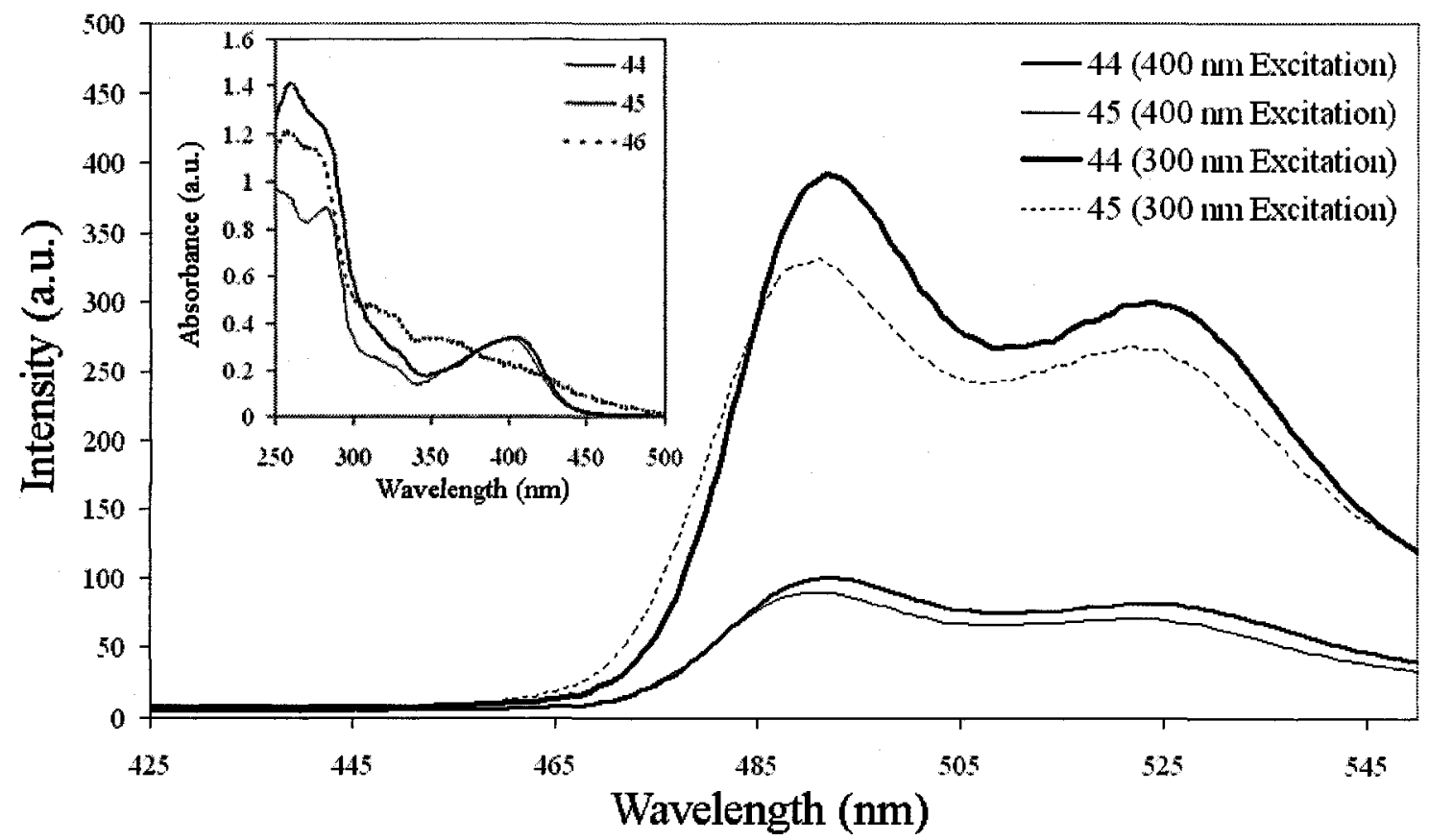

Figure 3.11 - Photoluminescence spectra of 44-45 and absorption spectra (inset) of 44-46 ( $1 \times 10^{-6} \mathrm{M}$ solutions in DCM, not degassed)

One interesting property of these complexes is their ability to produce light in the solid state. Normally, in solution, PL of compounds increases in intensity as the concentration increases; however, at a critical concentration, the intensity begins to fall due to aggregation and the ensuing self-quenching of the excited states ${ }^{196}$. This quenching should also be present in solids where energy dissipation through nonradiative pathways can readily occur. The mechanism of self-quenching is thought to proceed by excimer formation between an excited molecule and a ground state molecule and energy transfer to the ground state molecule ${ }^{195}$. This self-quenching does not seem to be present in the $\mathrm{DCH}$ dinuclear platinum complexes as the amorphous powder is 
phosphorescent at room temperature and the same PL features observed in solution are maintained. This could imply that these complexes have high quantum yields. This was investigated for 44 using a comparative method. The reference material should be chosen as such as the absorption and emission of both compounds to be compared have some overlap. Since 44 emits green light, centered at $550 \mathrm{~nm}$, fluorescein, which emits between 500-600 nm and has a quantum yield of 0.79, seemed like a good reference candidate. However, their absorption maxima differs greately due to the different optical transitions involved. Choosing an excitation wavelength to monitor the PL is problematic. Tris(8hydroxyquinolinato)aluminium $\left(\mathrm{Alq}_{3}\right)$, having MLCT optical transitions was deemed a more suitable reference material. Solutions of $\mathrm{Alq}_{3}$ were prepared in THF while solutions of 44 were in DCM. After searching the literature, the quantum yield of $\mathrm{Alq}_{3}$ in $\mathrm{THF}$ was not found and so only a direct comparison of $\Phi$ can be obtained. Linearity must also be maintained for the concentration range considered. The emission was plotted against the absorbance for each compound and the resulting slope or gradient was calculated for both compounds (see appendix 4 for plots). The quantum yield, $\Phi_{X}$, of the sample to be analyzed, was then calculated using equation 3.4 developed by Williams ${ }^{202}$

$$
\Phi_{X}=\Phi_{S T}\left(\frac{\text { Slope }_{X}}{\text { Slope }_{S T}}\right)\left(\frac{\eta_{D}{ }^{2} X}{\eta_{D}{ }^{2}}\right)
$$

Equation 3.4

where $\Phi_{\mathrm{ST}}$ is the quantum yield of the reference material, and $\eta_{\mathrm{D}}$ is the refractive index of each solvent used. The calculated quantum yield of 44 was $3 \%$ relative to $\mathrm{Alq}_{3}$. However, this is only a direct comparison to Alq3 and a more accurate value of $\Phi$ will require the actual quantum yield of $\mathrm{Alq}_{3}$ in THF. One thing is certain, by assuming that the $\Phi$ of $\mathrm{Alq}_{3}$ is $100 \%$, the true quantum yield of 44 will be much lower. 


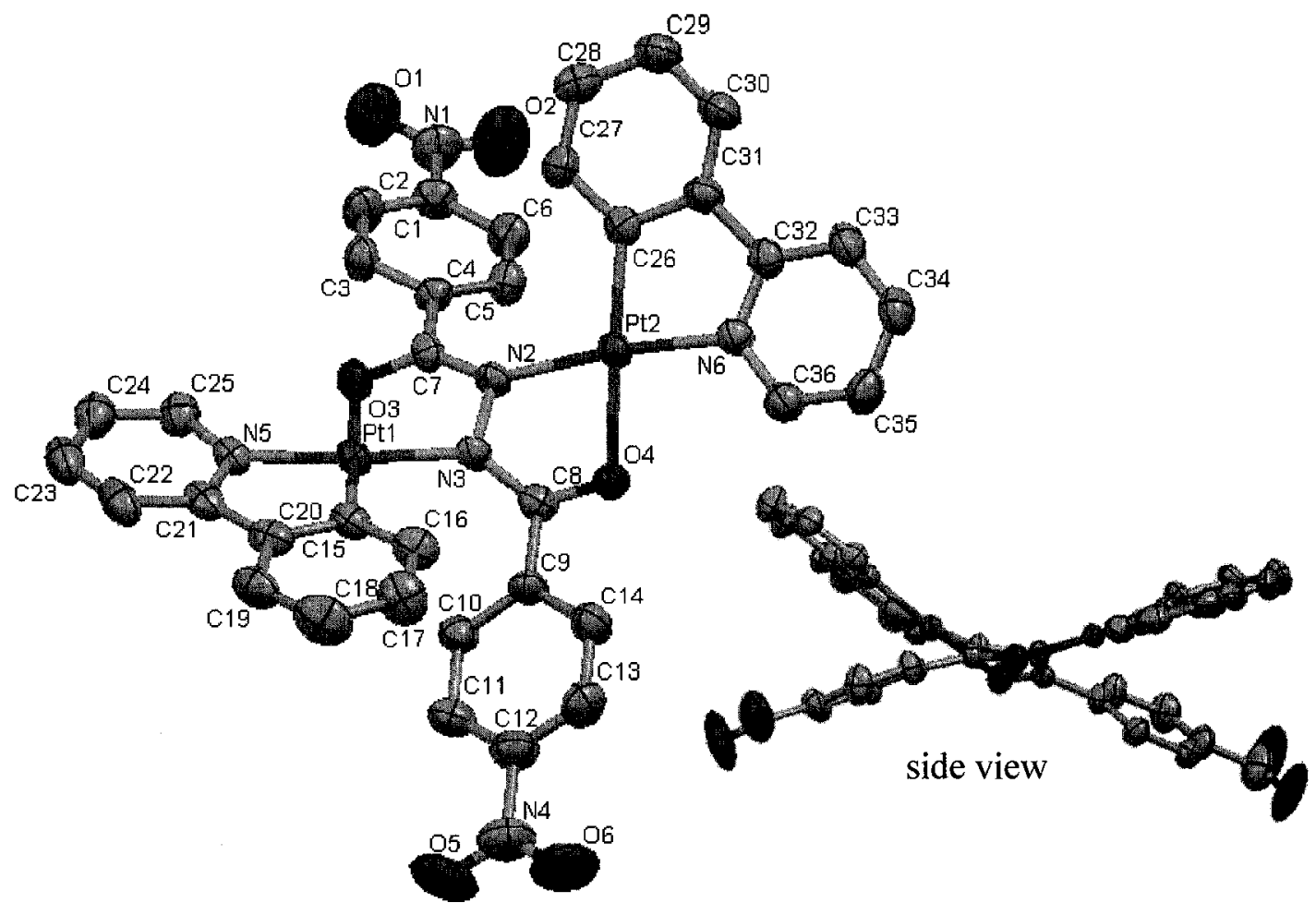

Figure 3.12 - ORTEP drawing of 46

Knowing that the dinuclear platinum complexes obtained were indeed chelated by the bridging ligand, their redox properties and ensuing spectral changes were studied. While there is some literature on $\mathrm{Pt}^{\mathrm{III}}$ complexes ${ }^{169,175,197-200}$, the oxidation state is mostly determined using crystallographic data). The normal oxidation states of platinum are +2 and +4 and oxidation can occur by removal of two valence electrons together or successively. Either way, high redox potentials should be expected due to the combined energy required to remove two valence electrons. Cyclic voltammetry (recorded using the same conditions as described in Table 3.1 except that DCM was used as the solvent) of each complex only displayed one oxidation half wave near $900 \mathrm{mV}$ and an almost unperceivable redox half wave. Both $\mathrm{E}_{\mathrm{PA}}$ and $\mathrm{E}_{\mathrm{PC}}$ lose intensity with each consecutive 
The effect of the bridging ligand on emission wavelength is quite small, indicating that the orbital energies are not greately affected. Complex 46 is not phosphorescent, even though the absorbance spectrum showed similar features, albeit redshifted by $70 \mathrm{~nm}$ due the nitro groups. The nitro groups quenched any luminescence via dissipation of excitation energies in a non-radiative mechanism, probably by vibrationnal modes. However, $\mathbf{4 6}$ did impart valuable structural information as suitable prismatic crystals were obtained by slow diffusion of ethyl ether in a dichloromethane solution of the complex. The ORTEP (Oak Ridge Thermal Ellipsoid Program) drawing of 46 in Figure 3.12 clearly shows the two platinum centers (purple) chelated in the expected dinuclear fashion compared to the ruthenium analogues. A square planar geometry was predicted, however, some deformation is observed due in part to $\pi$ stacking interactions between neighbouring molecules. The complex takes on a shape that ressembles a saddle point where the ppy-Pt-Pt-ppy forms a ' $U$ 'shape, while the bridging ligand does the opposite ' $\Omega$ '. The overall appearance is that of an ' $X$ '. The ellipsoids, representing the atoms and their relative positions, are larger for the nitro groups due to their vibrational movement. Bond lengths and angles, along with other pertinent crystallographic data can be found in appendix 5 . 
cycle (Figure 3.13), suggesting electrodeposition and/or decomposition of the platinum complexes. Unfortunately, it is not clear if this oxidation half wave is the first oneelectron oxidation to $\mathrm{Pt}^{\mathrm{III}}$ or the generation of $\mathrm{Pt}^{\mathrm{IV}}$. $\mathrm{Kvarm}^{201}$ suggests that electrochemical oxidation of the $\mathrm{Pt}^{\mathrm{II}}$ state is irreversible due to the rapid solvolysis of $\mathrm{Pt}^{\mathrm{III}}$ specie generated, effectively degrading the complex. Brooks ${ }^{147}$ reported on luminescent platinum complexes having an $\mathrm{E}_{\mathrm{PC}}$ in the order of $-2 \mathrm{~V}$. While we usually focus on the metal redox properties, the ligands can be redox active in the negative potential range and the $-2 V E_{\mathrm{PC}}$ wave would stem from the cyclometallating ligands employed ${ }^{195}$.

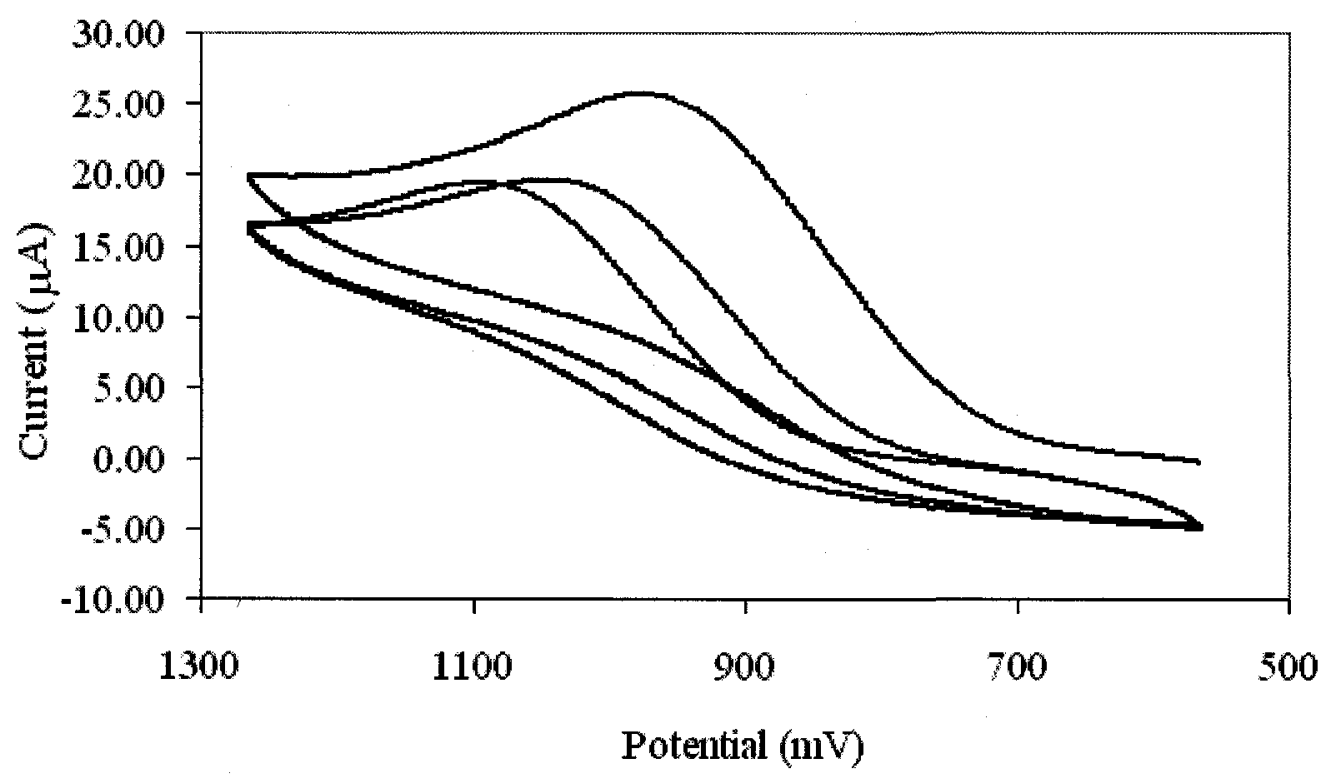

Figure 3.13 - CV of 44 in DCM (0.1M TBAH, $200 \mathrm{mV}$ scan rate)

Unfortunately, these dinuclear platinum complexes do not show reversibility in their redox properties; the spectroelectrochemistry was nonetheless verified and as expected, no significant spectral changes were observed. Thermogravimetric analysis (TGA) was performed on complexes 44-46 and it was found that they were quite 
thermally stable (Figure 3.14). A $5 \%$ weight loss temperature of 306,338 and $364^{\circ} \mathrm{C}$ was recorded for 44,45 and 46 respectively.

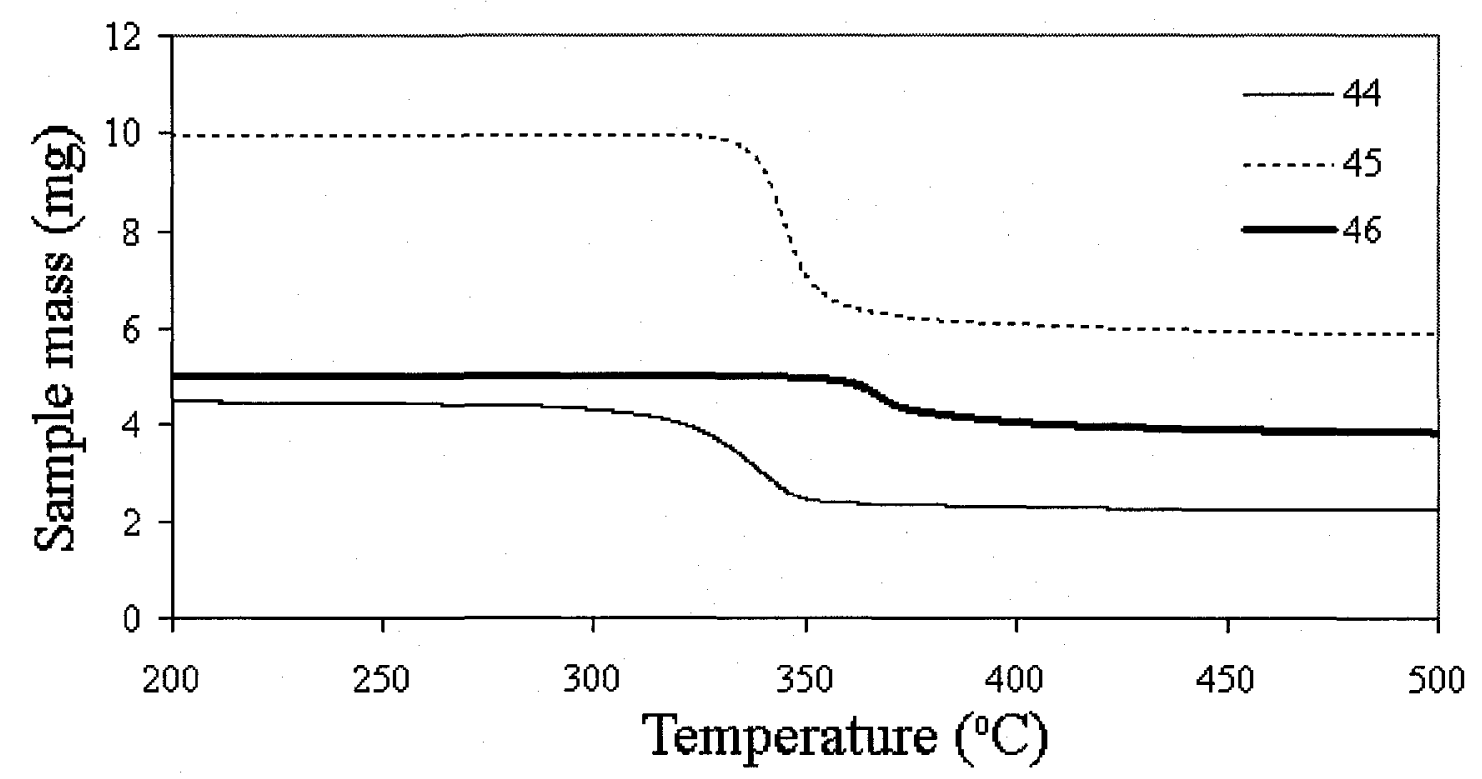

Figure 3.14 - TGA of 44-46

Undeterred by the lack of electrochromism of the ppy-based platinum complexes and wanting to achieve NIR phosphorescence, we proceeded to study the effect of the peripheral ligand and prepared three new complexes, 47, 48 and 49 (Figure 3.15). As with ppy, dichlorobridged platinum dimers of each peripheral ligand were prepared using a previously described procedure ${ }^{147}$. The DCH ligand, diacetyl hydrazine, was utilized in order to simplify the NMR of the resulting complexes and increase the chances of obtaining crystallographic-grade crystals. These complexes were also characterized by NMR and ESI-MS. 


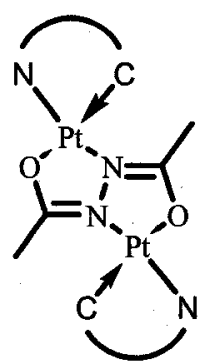

cis isomer

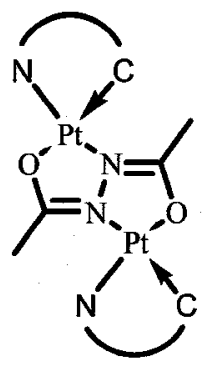

trans isomer

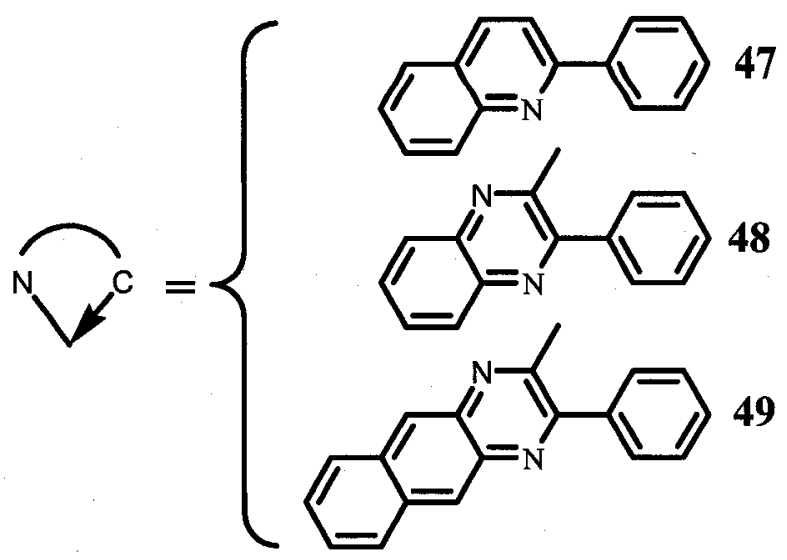

Figure 3.15 - Structure of 47-49 and stereoisomers

Following a simple purification through a silica gel plug, proton NMR of $\mathbf{4 7}$ showed multiple methyl groups as well as two doublets near $9.6 \mathrm{ppm}$. This suggested two isomers and from the peak integration, one isomer is present in $14 \%$ relative to the other. Since isomerization was not observed for ppy-based complexes, it was expected that a single isomer would also form for 47-49. The product was further purified on preparative chromatography $2 \mathrm{~mm}$ plates, using ethyl ether as the eluent. Two phosphorescent fractions were collected at $R_{f}=0.3-0.8$ and $R_{f}=0\left(R_{f}=\right.$ retention factor $)$. It was initially thought that the compound that did not elute was the starting dichlorobridged dimer as the ppy-based dimers hardly eluted on a TLC plate. NMR of the eluted fraction did show an enrichment of one isomer over the other but still, a significant intensity of the second methyl was observed. In fact, recording the ${ }^{1} \mathrm{H}$ NMR of the same solution of 47 four days later showed an enrichment of the minor isomer. This phenomenon is linked to fluxionality, that is, there is an equilibrium that exists between both isomers, preventing the isolation of one pure isomer. Full resonance assignment of 47 was not achievable. 
ESI-MS of both fractions of 47 (Figure 3.16) have the same spectrum, albeit with different intensities due to concentration variations, proving that they are in fact, isomers. It is very strange that one isomer hardly elutes while the other migrates at a higher rate. This dilemma can be explained using dipolar moments: the symmetric isomer of $\mathbf{4 7}$ (Figure 3.16) will have a nullified dipolar moment while the unsymmetrical isomer will have a net dipolar moment, increasing its overall polarity, hence the lower $R_{f}$. With the 2phenylquinoline peripheral ligand, being sufficiently bulky to allow isomers to form, it was expected that similar isomers would be observed for both 48 and 49 as well. Surprisingly, the fraction of $\mathbf{4 8}$ having an $\mathrm{R}_{\mathrm{f}}=0.3-0.8$, chromatographied using the same conditions as with 47, did not possess an NMR corresponding to the expected product. However, the fraction at $R_{f}=0$ proved to be pure 48 , devoid of a second isomer, which enforces the golden law - never throw out unanalyzed compounds! Using the dipolar moment analogy, the unsymmetrical isomer should have a lower $R_{f}$ than the symmetrical one. However, the proton NMR signals add up to a symmetrical environment. Perhaps this is due to the extra nitrogen, which increases the overall polarity of the molecule and limits elution. 


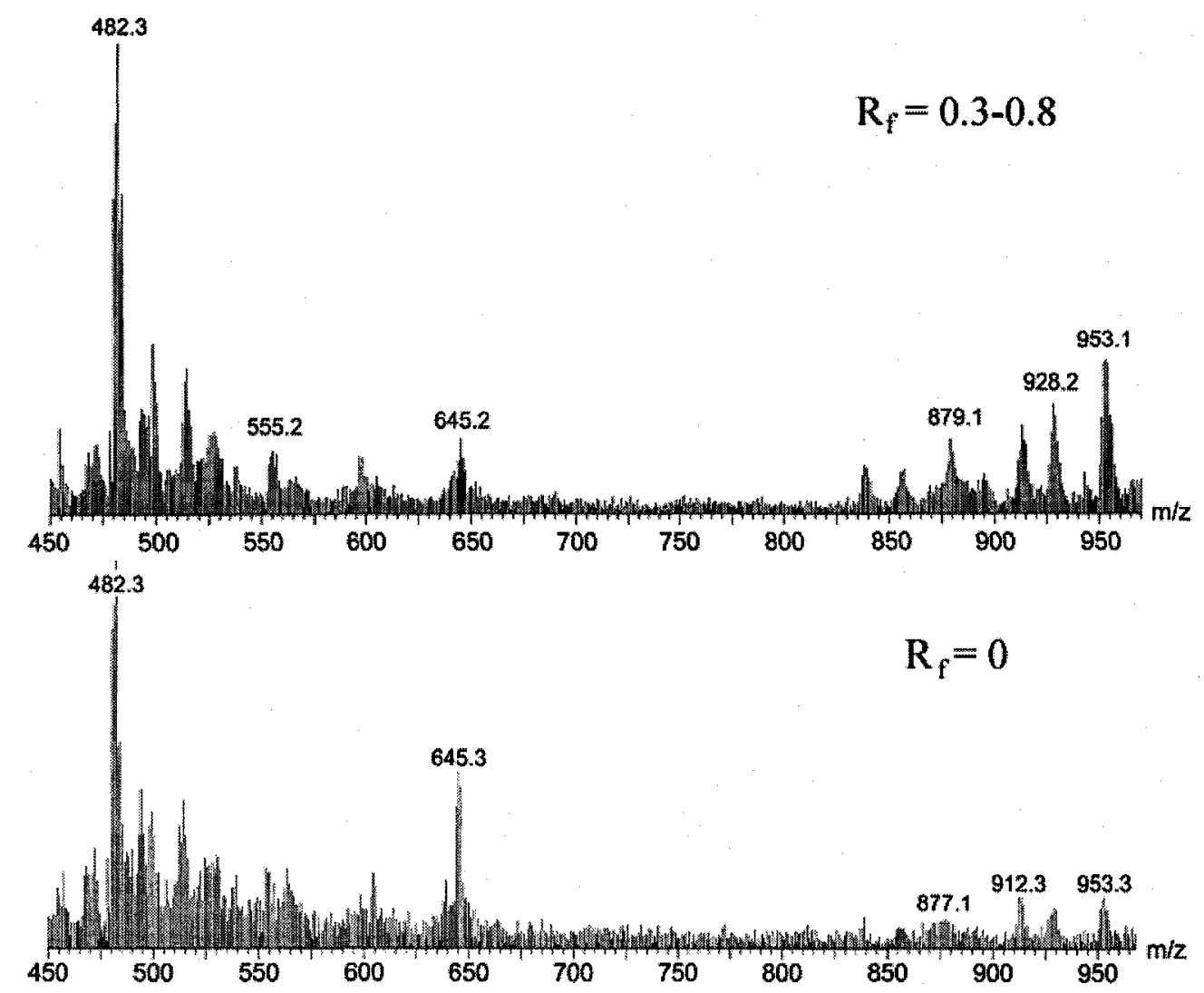

Figure 3.16 - ESI-MS of isolated fractions of 47

In the case of 49, none of the fractions collected showed a clean NMR spectra and it was not possible to determine if the dinuclear complex did in fact form. In addition, preparative chromatography of the crude compound yielded a yellow fraction having an $\mathrm{R}_{\mathrm{f}}=0.85-1.0$ which turned out to be the bare ligand, 2-Methyl-3-phenylbenzo[g]quinoxaline (mpbq), uncomplexed to platinum. Either the isolated dichlorobridged dimer still contained the excess ligand, which was carried over between reactions, or some decomposition occurred during the synthesis of the dinuclear complex. While NMR failed to elucidate the structure of 49, ESI-MS of both fractions $\left(R_{f}=0.4-0.8\right.$ and $R_{f}=0$ ) confirm the presence of the 49 , although probably two isomers as with 47 . 


\section{Chapter 3-Dinuclear ruthenium and platinum complexes}

The absorption spectrum of $\mathbf{4 7 - 4 9}$ (Figure 3.17) is quite similar to that of ppy series of dinuclear complexes although the MLCT band is highly affected: $430 \mathrm{~nm}$ for 47 , $490 \mathrm{~nm}$ for 48 , and $540 \mathrm{~nm}$ for 49.

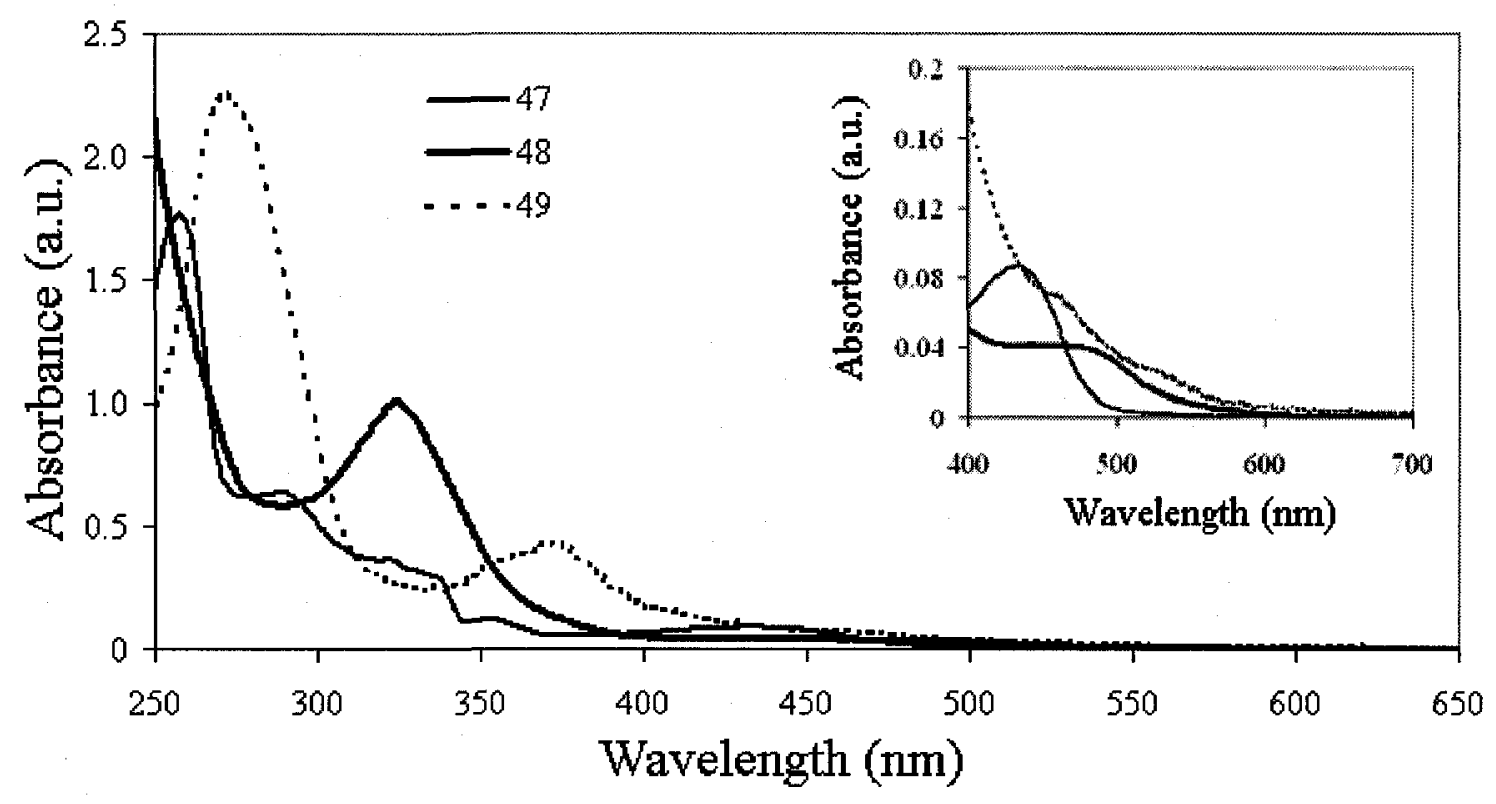

Figure 3.17 - Absorption spectra of 47-49 in DCM (inset: spectra expansion)

The bathochromic effect of the quinoline moiety on emissive properties in 47 was impressive, whereas yellow-orange light was observed (Figure 3.18), using a simple UV light $(365 \mathrm{~nm})$ compared to the green emission of 44 , a bathochromic shift of $65 \mathrm{~nm}$. However, in the case of 48, where the extra heteroatomic nitrogen's donating potential was expected to induce a hypsochromic shift, the opposite effect was observed and a bathochromic shift of $105 \mathrm{~nm}$ was induced compared to $44,40 \mathrm{~nm}$ more than in 47 , resulting in the emission of a deep red color. No visible emission was observed for 49 when exposed to the same UV light source which could implicate NIR emission. 


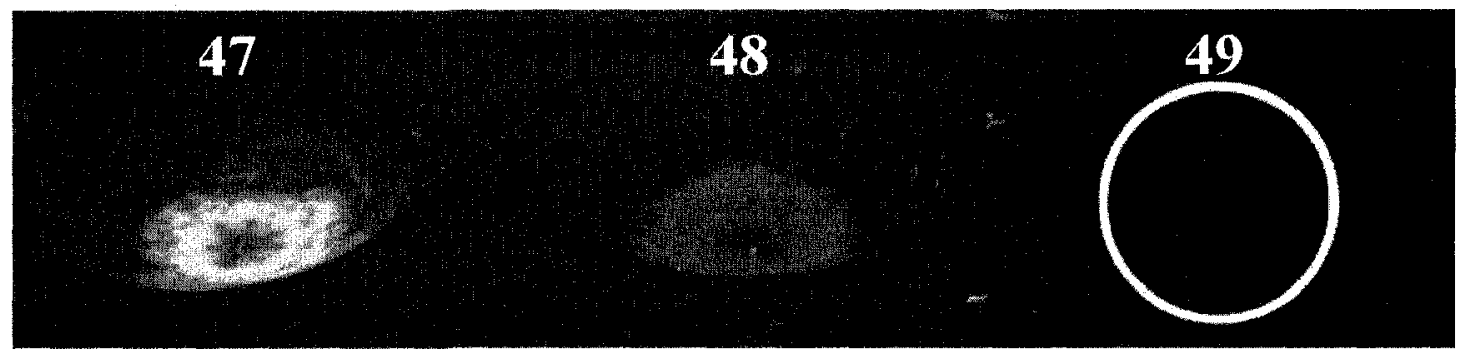

Figure 3.18 - Visible PL of 47-49 (excited at $365 \mathrm{~nm}$ )

Since excitation at $365 \mathrm{~nm}$ was sufficient to observe a strong emission of the solid state, the PL of 47-48 was also recorded, in DCM, at $360 \mathrm{~nm}$ excitation wavelength (Figure 3.19), even though each complex MLCT wavelength differed (Figure 3.17). Higher PL intensities can be achieved by using higher energy photons but the cost is high as the PL diminishes with time, suggesting degradation or photobleaching. The excitation wavelength was scanned from $250-500 \mathrm{~nm}$ for PL and as expected, only the intensity varied.

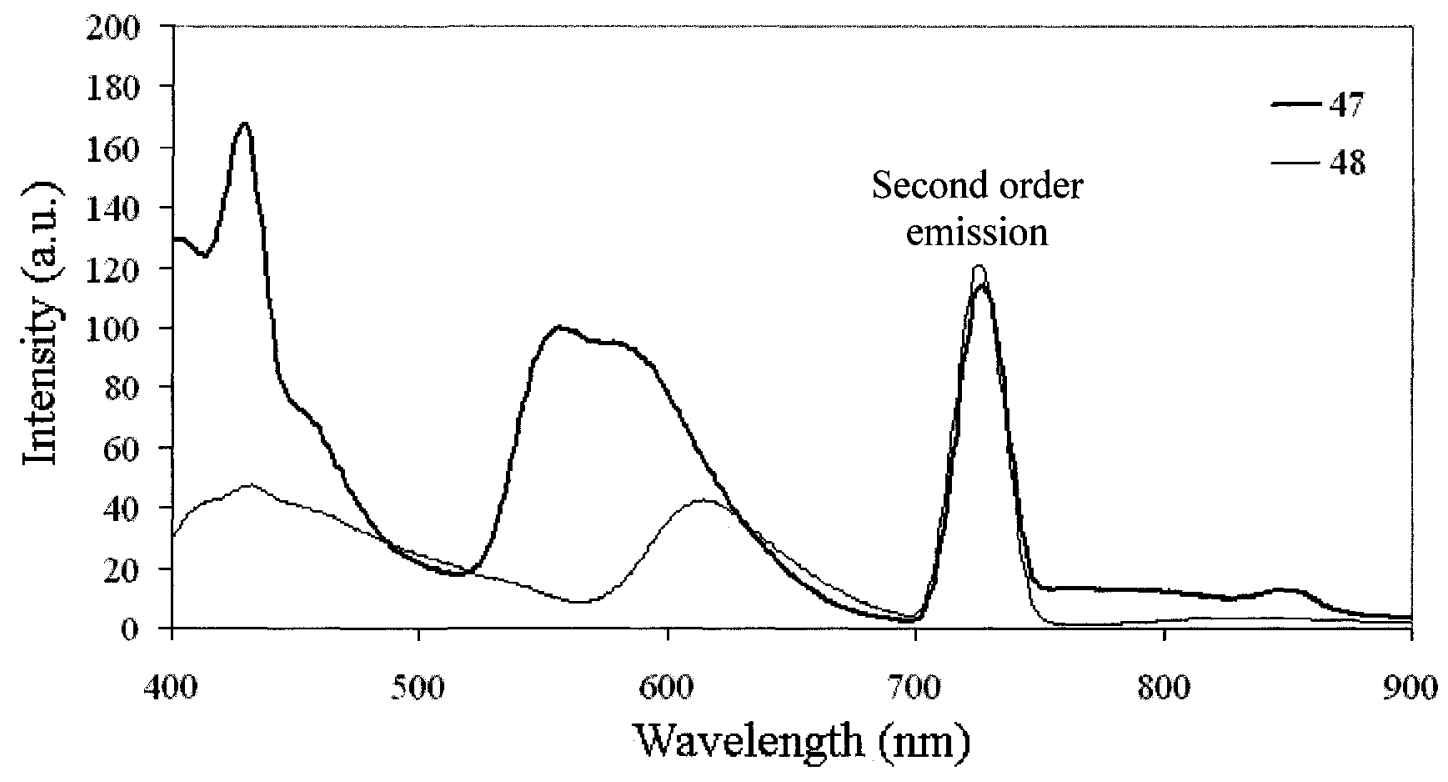

Figure 3.19 - PL spectra of 47-48 in DCM (excited at $360 \mathrm{~nm}$ ) 
Complex 49, which did not produce visible light in the solid state, emitted intense blue light in DCM. The blue emission at $478 \mathrm{~nm}$ is confirmed to belong to a $\pi \rightarrow \pi^{*}$ transition originating from the peripheral ligand, by comparing it to the PL of the free ligand (mpbq). Some NIR emission beginning at $840 \mathrm{~nm}$ can be observed (Figure 3.20) but it is an artefact from the double emission of the ligand emission.

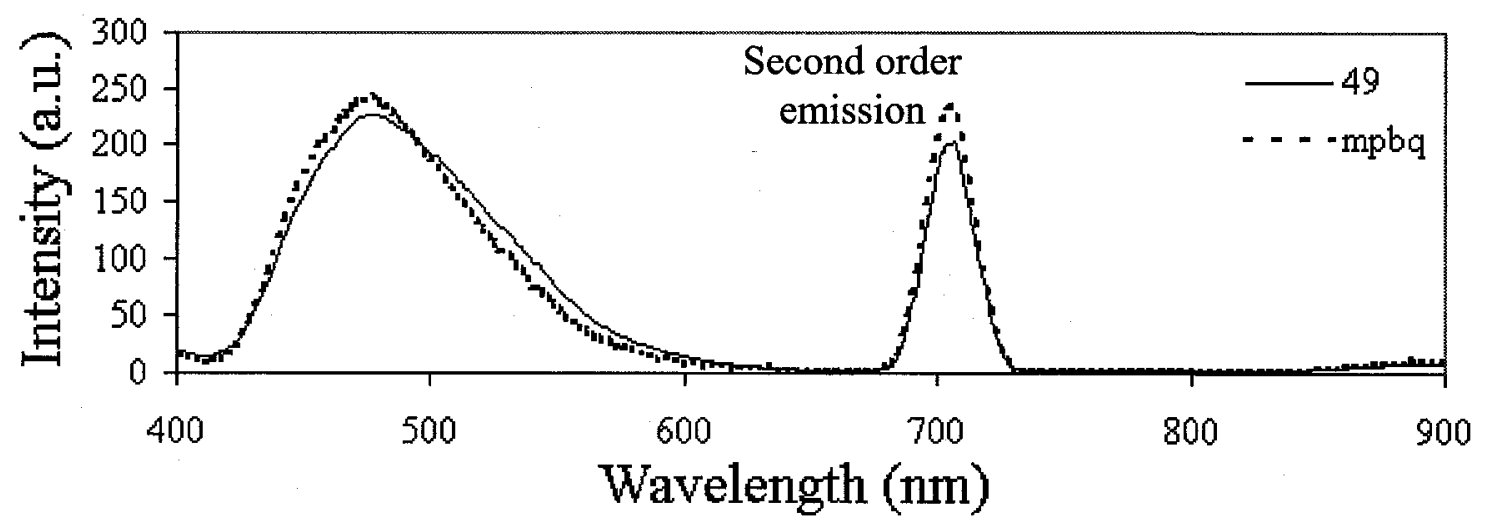

Figure 3.20 - Visible PL of 49 and ligand mpbq ( $350 \mathrm{~nm}$ excitation)

\section{$3.3-$ Conclusion}

A new series of hydroxyl-containing dinuclear ruthenium complexes were prepared and characterized. These will be used in various polymerization schemes, discussed in the next chapter. The redox and optical properties varied with the donor strength of the bridging ligand and this tuneability increases the versatility of the complexes and the possibility of studying their attenuation properties at all three telecommunication wavelengths. Some challenges still remain concerning the biureas such as elucidating the structure of the isomers observed. The thio derivatives could provide a solution to this problem, if hydroxyl groups can be introduced, by using 3,5- 
dihydroxybenzoic hydrazide for example or some other diol hydrazide. The thio derivatives were obtained in much higher yields and without impurities as encountered with the biureas. Thiocarbonyls appear to be stronger chelates and promote the formation of the desired dinuclear system.

Dinuclear platinum analogues were successfully prepared and fully characterized, with one structure resolved by x-ray crystallography. Even though they are not redox active and by definition, not electrochromic, they are phosphorescent, emitting visible light, regardless of the nature of the DCH bridging ligand. Varying the peripheral ligand showed potential in obtaining NIR phosphorescence by systematically increasing the conjugate $\pi$ system, which had a bathochromic effect on luminescence. Red emission was achieved with potential room for improvement since many peripheral ligand systems can be imagined. Broad NIR emission from 900 to $1700 \mathrm{~nm}$ was demonstrated for the mpbq peripheral ligand. However, it is not clear how this NIR PL is allowed, especially at a 400 $\mathrm{nm}$ excitation wavelength. Nevertheless, this ground work laid out the foundation to study dinuclear DCH platinum complexes as potential NIR light sources. With strong phosphorescence in the solid state, as well as good thermostability, these materials might even demonstrate potential as luminous sources.

\section{4 - Experimental}

NMR characterization was performed on a Bruker AMX $400 \mathrm{MHz}$ or Advance $300 \mathrm{MHz}$ spectrometer in $\mathrm{CDCl}_{3}, \mathrm{DMSO}-d_{6}$ or $\mathrm{CD}_{3} \mathrm{CN}$ and is reported in ppm (multiplicity, integration, assignment, coupling constants). Coupling constants are given 
in Hertz and multiplicity terms used are: $s$ (singlet), $d$ (doublet), $t$ (triplet), $q$ (quadruplet), m (multiplet), and combinations such as dd (doublet of doublet). 2D NMR (COSY, HSQC, HMBS and NOESY) experiments were recorded when required. Infrared (IR) spectra were recorded on a Varian Scimitar 1000 series FT-IR spectrometer using an attenuated total reflectance (ATR) accessory or by $\mathrm{NaCl}$ plate. Mass spectra of the ligands were acquired at the University of Ottawa Regional Mass Spectrometry Center on a Micromass Quattro LC Electrospray Mass Spectrometer (needle at 3.9-4.1 kV, methanol:MeCN 1:1 used as solvent) and peaks are reported as $\mathrm{m} / \mathrm{z}$ (ion fragment, $\%$ intensity relative to the base peak). Voltammetric-related experiments were conducted on a Bioanalytical Systems BAS-100 potentiostat. Visible absorption spectra were recorded on a Varian Cary 3 spectrometer while UV-Vis-NIR absorption spectra were recorded on a Perkin-Elmer Lambda 900 spectrometer. The OTTLE cell utilized was composed of quartz plates and the WE was a manually fashioned platinum wire linear mesh (see Figure 1.3a), with the RE and CE being silver and platinum wires respectively. Visible PL was obtained using a Shimadzu RF-1501 spectrofluorometer while NIR PL was obtained using a Photon Technology International QuantaMaster UV-Vis-NIR spectrofluorometer. Thermogravimetric analysis (TGA) was performed on a TA Instrument Hi-Res TGA2950 instrument using a $20^{\circ} \mathrm{C} /$ minute temperature ramp. Ruthenium(III) chloride trihydrate was purchased from Pressure Chemicals Co, potassium tetrachloroplatinate was purchased from TCI America, 2,2'-bipyridine, 2phenylpyridine, 2-phenylquinoline (pq) and 1-phenyl-1,2-propanedione were obtained from Aldrich Canada. All reagents and solvents were used as received. 
General procedure for the synthesis of the dinuclear ruthenium complexes ${ }^{203}$

cis- $\mathrm{Ru}(\mathrm{bpy}){ }_{2} \mathrm{Cl}_{2}(1.04 \mathrm{~g}, 2 \mathrm{mmol})$, prepared according to $\operatorname{Sullivan}^{204}$, bridging ligand $(1 \mathrm{mmol}), \mathrm{NaOH}(0.08 \mathrm{~g}, 2 \mathrm{mmol})$ and $50 \mathrm{~mL}$ of $5: 1 \mathrm{H}_{2} \mathrm{O}: \mathrm{EtOH}$ are placed in a 100 $\mathrm{mL}$ RBF and refluxed under argon for 16 hours. The purple solution was concentrated to half volume using a rotoevaporator and $\mathrm{NH}_{4} \mathrm{PF}_{6}(650 \mathrm{mg}, 4 \mathrm{mmol})$ in $15 \mathrm{~mL}$ of water was added to the solution. The resulting precipitate was filtered and air dried. The crude complex was purified by column chromatography on neutral alumina, conditioned with $3 \%$ water by weight. The eluent system varied from acetone, acetonitrile, wet acetonitrile or acetonitrile:Toluene, depending on the overall polarity of the complex. The purple fraction was collected, concentrated to dryness and redissolved in a minimum acetone or acetonitrile and precipitated in $500 \mathrm{~mL}$ ethyl ether. The fine purple powder was filtered and air dried under vacuum.

In the case where biurea bridging ligands were utilized, an extra equivalent of base was added to compensate for each additional NH present. Prior to the addition of $\mathrm{NH}_{4} \mathrm{PF}_{6}$, the excess base was neutralized using a $2 \mathrm{M} \mathrm{HPF}_{6}$ solution.

$\left[\left\{\mathrm{Ru}(\mathrm{bpy})_{2}\right\}_{2} \mu-\mathrm{CH}_{2} \mathrm{CH}_{3},\left(\mathrm{CH}_{2}\right)_{3} \mathrm{OH}\right.$-dicarbonyl hydrazine $]\left(\mathrm{PF}_{6}\right)_{2}(\mathbf{3 0})$. Yield: 74 \%. ESIMS: $1143\left(\left[\mathrm{M}-\mathrm{PF}_{6}\right]^{+}, 1.0 \%\right), 587\left(\left[\mathrm{M}-\mathrm{Ru}(\mathrm{bpy})_{2}-2 \mathrm{PF}_{6}\right]^{+}, 5.7\right)$ and $500\left(\left[\mathrm{M}-2 \mathrm{PF}_{6}\right]^{2+}, 100\right)$.

$\left[\left\{\mathrm{Ru}(\text { bpy })_{2}\right\}_{2} \mu-\mathrm{NH}\left(\mathrm{CH}_{2}\right)_{2} \mathrm{CH}_{3},\left(\mathrm{CH}_{2}\right)_{3} \mathrm{OH}\right.$-dicarbonyl hydrazine $]\left(\mathrm{PF}_{6}\right)_{2}$ (31). Yield: $58 \%$. ESI-MS: $1202\left(\left[\mathrm{M}-\mathrm{PF}_{6}\right]^{+}, 0.7 \%\right), 1055\left(\left[\mathrm{M}+\mathrm{H}-2 \mathrm{PF}_{6}\right]^{+}, 0.2\right), 643\left(\left[\mathrm{M}-\mathrm{Ru}(\mathrm{bpy})_{2}-2 \mathrm{PF}_{6}\right]^{+}\right.$, $0.1)$ and $528\left(\left[\mathrm{M}-2 \mathrm{PF}_{6}\right]^{2+}, 100\right)$. 
$\left[\left\{\mathrm{Ru}(\text { bpy })_{2}\right\}_{2} \mu-\mathrm{NH}\left(\mathrm{CH}_{2}\right)_{2} \mathrm{CH}_{3},\left(\mathrm{CH}_{2}\right)_{5} \mathrm{OH}\right.$-dicarbonyl hydrazine $]\left(\mathrm{PF}_{6}\right)_{2}$ (32). Yield: 62

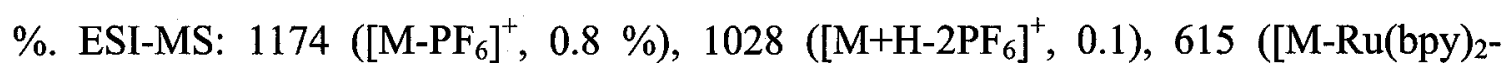
$\left.\left.2 \mathrm{PF}_{6}\right]^{+},<0.1\right)$ and $514\left(\left[\mathrm{M}-2 \mathrm{PF}_{6}\right]^{2+}, 100\right)$.

$\left[\left\{\mathrm{Ru}(\text { bpy })_{2}\right\}_{2} \mu-\left(\left(\mathrm{CH}_{2}\right)_{5} \mathrm{OH}\right)_{2}\right.$-dicarbonyl hydrazine $]\left(\mathrm{PF}_{6}\right)_{2}$ (33). Yield: $80 \%$. ESI-MS: $1231\left(\left[\mathrm{M}-\mathrm{PF}_{6}\right]^{+}, 2.3 \%\right), 673\left(\left[\mathrm{M}-\mathrm{Ru}(\mathrm{bpy})_{2}-2 \mathrm{PF}_{6}\right]^{+}, 1.5\right)$ and $544\left(\left[\mathrm{M}-2 \mathrm{PF}_{6}\right]^{2+}, 100\right)$.

$\left[\left\{\mathrm{Ru}(\text { bpy })_{2}\right\}_{2} \mu-\left(\mathrm{NHCH}_{2} \mathrm{Ph}\right)_{2}\right.$-dicarbonyl hydrazine $]\left(\mathrm{PF}_{6}\right)_{2}$ (34). Yield: $16 \%$. ESI-MS: $1414\left(\mathrm{M}^{+},<0.1 \%\right), 1269\left(\left[\mathrm{M}-\mathrm{PF}_{6}\right]^{+}, 0.9\right), 1123\left(\left[\mathrm{M}+\mathrm{H}-2 \mathrm{PF}_{6}\right]^{+}, 0.4\right), 710\left(\left[\mathrm{M}-\mathrm{Ru}(\mathrm{bpy})_{2^{-}}\right.\right.$ $\left.\left.2 \mathrm{PF}_{6}\right]^{+}, 0.2\right)$ and $562\left(\left[\mathrm{M}-2 \mathrm{PF}_{6}\right]^{2+}, 100\right)$.

[ $\left\{\mathrm{Ru}(\text { bpy })_{2}\right\}_{2} \mu-\left(\mathrm{NHC}\left(\mathrm{CH}_{3}\right)\left(\mathrm{CH}_{2} \mathrm{OH}\right)_{2}\right)_{2}$-dicarbonyl hydrazine $]\left(\mathrm{PF}_{6}\right)_{2}$ (35). Yield: $65 \%$. ESI-MS: $1411\left(\mathrm{M}^{+},<0.1 \%\right), 1265\left(\left[\mathrm{M}-\mathrm{PF}_{6}\right]^{+}, 0.9\right), 706\left(\left[\mathrm{M}-\mathrm{Ru}(\mathrm{bpy})_{2}-2 \mathrm{PF}_{6}\right]^{+}, 0.2\right)$ and $560\left(\left[\mathrm{M}-2 \mathrm{PF}_{6}\right]^{2+}, 24\right)$.

$\left[\left\{\mathrm{Ru}(\text { bpy })_{2}\right\}_{2} \mu\right.$ - $\left(\mathrm{NH}\left(\mathrm{CH}_{2}\right)_{5} \mathrm{OH}\right)_{2}$-dicarbonyl hydrazine $]\left(\mathrm{PF}_{6}\right)_{2}$ (36). Yield: $6 \%$. ESI-MS: $1406\left(\mathrm{M}^{+},<0.1 \%\right), 1261\left(\left[\mathrm{M}-\mathrm{PF}_{6}\right]^{+}, 1.1\right)$ and $558\left(\left[\mathrm{M}-2 \mathrm{PF}_{6}\right]^{2+}, 25\right)$.

$\left[\left\{\mathrm{Ru}(\text { bpy })_{2}\right\}_{2} \mu-\left(\mathrm{NHCH}_{2} \mathrm{Ph}-\mathrm{p}-\mathrm{NH}_{2}\right)_{2}\right.$-dicarbonyl hydrazine $]\left(\mathrm{PF}_{6}\right)_{2}$ (37). Yield: $7 \%$. ESIMS: $1299\left(\left[\mathrm{M}-\mathrm{PF}_{6}\right]^{+}, 1.0 \%\right), 1198\left(\left[\mathrm{M}+\mathrm{H}-2 \mathrm{PF}_{6}\right]^{+}, 0.4\right)$ and $577\left(\left[\mathrm{M}-2 \mathrm{PF}_{6}\right]^{2+}, 57\right)$. 
[\{Ru(bpy $\left.{ }_{2}\right\}_{2} \mu-\left(\mathrm{O}\left(\mathrm{CH}_{2}\right)_{2} \mathrm{OH}\right)_{2}$-dicarbonyl hydrazine $]\left(\mathrm{PF}_{6}\right)_{2}$ (38). Yield: 19 \%. ESI-MS: $1178\left(\left[\mathrm{M}-\mathrm{PF}_{6}\right]^{+}, 1.6 \%\right), 715\left(\left[\mathrm{M}+\mathrm{MeCN}+3 \mathrm{H}_{2} \mathrm{O}-\mathrm{Ru}(\mathrm{bpy})_{2}-2 \mathrm{PF}_{6}\right]^{+}, 0.4\right)$ and $517([\mathrm{M}-$ $\left.\left.2 \mathrm{PF}_{6}\right]^{2+}, 29\right)$.

$\left[\left\{R u(\text { bpy })_{2}\right\}_{2} \mu-(4-h y d r o x y m e t h y l \text { piperidine })_{2}\right.$-dicarbonyl hydrazine $]\left(P F_{6}\right)_{2}$ (39). Yield: $21 \%$. ${ }^{1} \mathrm{H}$ NMR (300MHz, $\left.\mathrm{CD}_{3} \mathrm{CN}\right): 9.07\left(\mathrm{~d}, 2 \mathrm{H}, \mathrm{H} 6,{ }^{3} \mathrm{~J}=5 \mathrm{~Hz}\right) ; 8.71\left(\mathrm{~d}, 2 \mathrm{H}, \mathrm{H} 15,{ }^{3} \mathrm{~J}=\right.$ $5 \mathrm{~Hz}) ; 8.50\left(\mathrm{~d}, 2 \mathrm{H}, \mathrm{H} 9,{ }^{3} \mathrm{~J}=8 \mathrm{~Hz}\right) ; 8.35\left(\mathrm{~d}, 2 \mathrm{H}, \mathrm{H} 12,{ }^{3} \mathrm{~J}=5 \mathrm{~Hz}\right) ; 8.32\left(\mathrm{~d}, 2 \mathrm{H}, \mathrm{H} 22,{ }^{3} \mathrm{~J}=\right.$ $5 \mathrm{~Hz}) ; 8.26\left(\mathrm{~d}, 2 \mathrm{H}, \mathrm{H} 19,{ }^{3} \mathrm{~J}=8 \mathrm{~Hz}\right) ; 8.16\left(\mathrm{dd}, 2 \mathrm{H}, \mathrm{H} 24,{ }^{3} \mathrm{~J}=8 \mathrm{~Hz}\right) ; 7.96\left(\mathrm{dd}, 2 \mathrm{H}, \mathrm{H} 13,{ }^{3} \mathrm{~J}=\right.$ $8 \mathrm{~Hz}) ; 7.91\left(\mathrm{dd}, 2 \mathrm{H}, \mathrm{H} 7,{ }^{3} \mathrm{~J}=8 \mathrm{~Hz}\right) ; 7.80\left(\mathrm{~d}, 2 \mathrm{H}, \mathrm{H} 25,{ }^{3} \mathrm{~J}=5 \mathrm{~Hz}\right) ; 7.76\left(\mathrm{dd}, 2 \mathrm{H}, \mathrm{H} 18,{ }^{3} \mathrm{~J}=\right.$ $8 \mathrm{~Hz}) ; 7.68\left(\mathrm{dd}, 2 \mathrm{H}, \mathrm{H} 23,{ }^{3} \mathrm{~J}=8 \mathrm{~Hz}\right) ; 7.45\left(\mathrm{dd}, 2 \mathrm{H}, \mathrm{H} 14,{ }^{3} \mathrm{~J}=5 \mathrm{~Hz}\right) ; 7.39\left(\mathrm{dd}, 2 \mathrm{H}, \mathrm{H} 16,{ }^{3} \mathrm{~J}\right.$ $=5 \mathrm{~Hz}) ; 7.10\left(\mathrm{dd}, 2 \mathrm{H}, \mathrm{H} 17,{ }^{3} \mathrm{~J}=8 \mathrm{~Hz}\right) ; 7.04\left(\mathrm{dd}, 2 \mathrm{H}, \mathrm{H} 24,{ }^{3} \mathrm{~J}=8 \mathrm{~Hz}\right.$ ); 2.91 (dd, 4H, H5, ${ }^{3} \mathrm{~J}$ $=6 \mathrm{~Hz}) ; 2.49\left(\mathrm{~d}, 2 \mathrm{H}, \mathrm{H} 2 \mathrm{a},{ }^{3} \mathrm{~J}=10 \mathrm{~Hz}\right) ; 2.32\left(\mathrm{t}, 2 \mathrm{H}, \mathrm{OH},{ }^{3} \mathrm{~J}=6 \mathrm{~Hz}\right) ; 2.03\left(\mathrm{dd}, 2 \mathrm{H}, \mathrm{H} 2 \mathrm{~b},{ }^{3} \mathrm{~J}\right.$ $=11 \mathrm{~Hz}) ; 1.60\left(\mathrm{dd}, 2 \mathrm{H}, \mathrm{H} 2 \mathrm{a},{ }^{3} \mathrm{~J}=11 \mathrm{~Hz}\right) ; 1.37\left(\mathrm{~d}, 2 \mathrm{H}, \mathrm{H} 2 \mathrm{~b},{ }^{3} \mathrm{~J}=10 \mathrm{~Hz}\right) ; 0.99(\mathrm{~d}, 2 \mathrm{H}, \mathrm{H} 3 \mathrm{~b}$, ${ }^{3} \mathrm{~J}=12 \mathrm{~Hz}$ ); 0.87 (s, 4H, H3b' and H4), -0.02 (ddd, 2H, H3a, ${ }^{3} \mathrm{~J}=10 \mathrm{~Hz}$ ) and -0.44 (ddd, 2H, H3a', $\left.{ }^{3} \mathrm{~J}=10 \mathrm{~Hz}\right) .{ }^{13} \mathrm{C}$ NMR $\left(75 \mathrm{MHz}, \mathrm{CD}_{3} \mathrm{CN}\right): 177.3(\mathrm{C} 1) ; 160.3$ (C21); 159.7 (C10); 159.5 (C20); 159.0 (C11); 153.9 (C25); 152.6 (C15); 152.3 (C16); 151.1 (C6); 136.8 (C13); 136.6 (C8); 136.3 (C18); 134.8 (C23); 127.1 (C7); 127.0 (C14); 126.7 (C17); 126.4 (C24); 124.4 (C22); 124.0 (C12); 123.9 (C9); 123.8 (C19); 67.4 (C5); 51.0 (C2'); 50.8 (C2); 38.3 (C4) and 27.8 (C3). ESI-MS: 1285 ([M-PF $]^{+}, 0.9 \%$ \%), 726 ([M$\left.\left.\mathrm{Ru}(\mathrm{bpy})_{2}-2 \mathrm{PF}_{6}\right]^{+}, 0.3\right)$ and $570\left(\left[\mathrm{M}-2 \mathrm{PF}_{6}\right]^{2+}, 100\right)$.

$\left[\left\{R u(b p y)_{2}\right\}_{2} \mu-(4-m e t h y l \text { piperidine })_{2}\right.$-dicarbonyl hydrazine $]\left(P F_{6}\right)_{2}$ (40). Yield: $56 \%$. ESI-MS: $1253\left(\left[\mathrm{M}-\mathrm{PF}_{6}\right]^{+}, 6.8 \%\right), 1107\left(\left[\mathrm{M}+\mathrm{H}-2 \mathrm{PF}_{6}\right]^{+}, 0.4\right), 694\left(\left[\mathrm{M}-\mathrm{Ru}(\mathrm{bpy})_{2}-2 \mathrm{PF}_{6}\right]^{+}\right.$, 4.4) and $554\left(\left[\mathrm{M}-2 \mathrm{PF}_{6}\right]^{2+}, 91\right)$. 
[\{Ru(bpy $\left.)_{2}\right\}_{2} \mu-\left(\left(\mathrm{CH}_{2}\right)_{5} \mathrm{OH}\right)_{2}$-oxamide $]\left(\mathrm{PF}_{6}\right)_{2}$ (41). Yield: $43 \%$. ${ }^{1} \mathrm{H}$ NMR $(300 \mathrm{MHz}$, $\left.\mathrm{CD}_{3} \mathrm{CN}\right): 8.98\left(\mathrm{~d}, 1 \mathrm{H}, \mathrm{H} 26,{ }^{3} \mathrm{~J}=5 \mathrm{~Hz}\right) ; 8.94\left(\mathrm{~d}, 1 \mathrm{H}, \mathrm{H} 7,{ }^{3} \mathrm{~J}=5 \mathrm{~Hz}\right) ; 8.47\left(\mathrm{~d}, 1 \mathrm{H}, \mathrm{H} 23,{ }^{3} \mathrm{~J}=\right.$ $8 \mathrm{~Hz}) ; 8.41\left(\mathrm{~d}, 1 \mathrm{H}, \mathrm{H} 10,{ }^{3} \mathrm{~J}=8 \mathrm{~Hz}\right) ; 8.32\left(\mathrm{~d}, 1 \mathrm{H}, \mathrm{H} 20,{ }^{3} \mathrm{~J}=6 \mathrm{~Hz}\right) ; 8.30\left(\mathrm{~d}, 1 \mathrm{H}, \mathrm{H} 13,{ }^{3} \mathrm{~J}=\right.$ $4 \mathrm{~Hz}) ; 8.10\left(\mathrm{ddd}, 1 \mathrm{H}, \mathrm{H} 24,{ }^{3} \mathrm{~J}=6 \mathrm{~Hz},{ }^{4} \mathrm{~J}=1 \mathrm{~Hz}\right) ; 8.06\left(\mathrm{ddd}, 1 \mathrm{H}, \mathrm{H} 9,{ }^{3} \mathrm{~J}=7 \mathrm{~Hz},{ }^{4} \mathrm{~J}=1 \mathrm{~Hz}\right.$ ); $7.89\left(\mathrm{~d}, 1 \mathrm{H}, \mathrm{H} 17,{ }^{3} \mathrm{~J}=6 \mathrm{~Hz}\right) ; 7.88,7.79(\mathrm{~m}, 2 \mathrm{H}, \mathrm{H} 8$ and $\mathrm{H} 25) ; 7.79\left(\mathrm{ddd}, 1 \mathrm{H}, \mathrm{H} 14,{ }^{3} \mathrm{~J}=\right.$ $\left.8 \mathrm{~Hz},{ }^{4} \mathrm{~J}=1 \mathrm{~Hz}\right) ; 7.73\left(\mathrm{ddd}, 1 \mathrm{H}, \mathrm{H} 19,{ }^{3} \mathrm{~J}=8 \mathrm{~Hz},{ }^{4} \mathrm{~J}=1 \mathrm{~Hz}\right) ; 7.43\left(\mathrm{~d}, 1 \mathrm{H}, \mathrm{H} 16,{ }^{3} \mathrm{~J}=5 \mathrm{~Hz}\right)$; $7.16\left(\mathrm{ddd}, 1 \mathrm{H}, \mathrm{H} 15,{ }^{3} \mathrm{~J}=7 \mathrm{~Hz},{ }^{3} \mathrm{~J}=6 \mathrm{~Hz},{ }^{4} \mathrm{~J}=1 \mathrm{~Hz}\right) ; 7.11\left(\mathrm{ddd}, 1 \mathrm{H}, \mathrm{H} 18,{ }^{3} \mathrm{~J}=7 \mathrm{~Hz},{ }^{3} \mathrm{~J}=\right.$ $\left.6 \mathrm{~Hz},{ }^{4} \mathrm{~J}=1 \mathrm{~Hz}\right) ; 3.49$ (m, 1H, H2); 2.88 (s, 2H, H6); 2.27 (m, 1H, H2); 0.65 (tt, 2H, H5, $\left.{ }^{3} \mathrm{~J}=7 \mathrm{~Hz}\right) ; 0.35(\mathrm{~m}, 1 \mathrm{H}, \mathrm{H} 3), 0.13(\mathrm{~m}, 1 \mathrm{H}, \mathrm{H} 4), 0.04\left(\mathrm{~m}, 1 \mathrm{H}, \mathrm{H} 3{ }^{\prime}\right)$ and $-0.01(\mathrm{~m}, 1 \mathrm{H}$, H4'). ${ }^{13} \mathrm{C}$ NMR (75MHz, $\left.\mathrm{CD}_{3} \mathrm{CN}\right): 172.7$ (C1); 160.4 (C21); 159.6 (C12); 159.2 (C11); 158.9 (C22); 154.2 (C17); 153.2 (C7); 152.4 (C16); 151.4 (C26); 136.8 (C9); 136.4 (C14); 136.1 (C24); 135.1 (C19); 127.7, 127.4 (C8 and C25); 127.0 (C15 and C18); 124.2 (C20); 124.0 (C10, C13 and C23); 62.0 (C6); 47.6 (C2); 33.0 (C5); 29.9 (C3) and

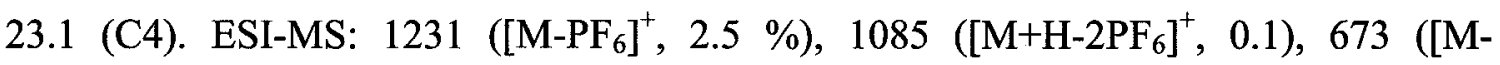
$\left.\left.\mathrm{Ru}(\mathrm{bpy})_{2}-2 \mathrm{PF}_{6}\right]^{+}, 3.1\right)$ and $543\left(\left[\mathrm{M}-2 \mathrm{PF}_{6}\right]^{2+}, 100\right)$.

[\{Ru(bpy $\left.)_{2}\right\}_{2} \mu-\left(\mathrm{NH}\left(\mathrm{CH}_{2}\right)_{3} \mathrm{CH}_{3}\right)_{2}$-dithiocarbonyl hydrazine $]\left(\mathrm{PF}_{6}\right)_{2}(42)$. Yield: $81 \%$. ESIMS: $1233\left(\left[\mathrm{M}^{-\mathrm{PF}_{6}}\right]^{+}, 1.7 \%\right), 1088\left(\left[\mathrm{M}+\mathrm{H}-2 \mathrm{PF}_{6}\right]^{+}, 0.4\right), 472(34), 414$ (17), 367 (53), 330 (75) and $290(36)$. 
[\{Ru(bpy) $\left.{ }_{2}\right\}_{2} \mu-\mathrm{NH}\left(\mathrm{CH}_{2}\right)_{3} \mathrm{CH}_{3}$, Ph-thiocarbonylcarbony-hydrazine] $\left(\mathrm{PF}_{6}\right)_{2}$ (43). Yield: 91 \%. ESI-MS: $1221\left(\left[\mathrm{M}-\mathrm{PF}_{6}\right]^{+}, 2.5 \%\right), 1076\left(\left[\mathrm{M}+\mathrm{H}-2 \mathrm{PF}_{6}\right]^{+}, 0.8\right), 664$ ([M-Ru(bpy) $)_{2}^{-}$ $\left.\left.2 \mathrm{PF}_{6}\right]^{+}, 0.5\right), 495(8.1), 454(5.4), 433(9.6), 413(10), 391(69), 373$ (39) and 359 (26).

General procedure for the synthesis of the peripheral ligands ${ }^{130}$

o-Phenylene diamine $(0.22 \mathrm{~g}, 2 \mathrm{mmol})$ and 1-phenyl-1,2-propanedione $(0.29 \mathrm{~g}, 2$ mmol) were dissolved in $1 \mathrm{~mL}$ of $\mathrm{MeCN} . \mathrm{I}_{2}(0.01 \mathrm{~g}, 10 \% \mathrm{~mol})$ was added to the stirring solution. An exotherm was observed and the mixture turns dark orange. The stirring was maintained for 15 minutes. The crude mixture was filtered through a small plug of silica gel and an orange fraction was eluted using $\mathrm{MeCN}$. The solvent was rotoevaporated and an orange solid was obtained. Yield: $95 \%$. NMR and ESI-MS agree with literature data $^{130}$.

General procedure for the synthesis of dichlorobridged platinum dimers ${ }^{147}$

Potassium tetrachloroplatinate $(0.4 \mathrm{~g}, \mathrm{mmol})$ and 2-phenylpyridine $(0.38 \mathrm{~g}, \mathrm{mmol})$ were heated to $80^{\circ} \mathrm{C}$ in $80 \mathrm{~mL}$ of 3:1 methoxyethanol:deionized water, under argon for 16 hours. The lime green mixture was cooled to room temperature, poured in $160 \mathrm{~mL}$ of deionized water and kept in a refrigerator for 3 hours. The solid was filtered, air dried, dissolved in DCM and filtered through a small plug of silica gel to remove metallic platinum that may have formed. When the dichlorobridged platinum dimer of mpbq was prepared, the aqueous filtrate was still orange and slightly opaque. Solids eventually began to form after three weeks, which were recovered and worked up as described above. The products were used, as-is, in the preparation of dinuclear platinum complexes. 
General procedure for the synthesis of dinuclear platinum complexes ${ }^{147}$

2-Phenylpyridine dichlorobridged platinum dimer $(0.1 \mathrm{~g}, 0.13 \mathrm{mmol})$ dissolved in $5 \mathrm{~mL} \mathrm{4:1} \mathrm{methoxyethanol:deionized} \mathrm{water} \mathrm{was} \mathrm{added} \mathrm{to} \mathrm{a} \mathrm{solution} \mathrm{of} 16(0.037 \mathrm{~g}, 0.13$ mmol) and $\mathrm{Na}_{2} \mathrm{CO}_{3}(0.35 \mathrm{~mL}$ of $1 \mathrm{M}$ solution $)$ in $5 \mathrm{~mL}$ of $4: 1$ methoxyethanol:deionized water contained in a modified $10 \mathrm{~cm}$ test tube (size 14 ground joint added). The mixture was heated to $80^{\circ} \mathrm{C}$ for 4 hours (or until no further precipitate forms; overnight for 45 and 46) under argon.

The workup from this point could be done in two ways: the ppy-based complex precipitates were simply filtered, washed with fresh solvent methoxyethanol:deionized water) followed by deionized water and air dried; or, in the case of the larger peripheral ligands, the solvent was completely removed under vacuum. Regardless of the method employed, the resulting solids were dissolved in DCM and filtered through a small silica gel column (DCM as eluent). This gave a satisfactory purity level for the ppy complexes; however, this was not the case with 47-49. These were purified by preparative chromatography on $20 \times 20 \times 0.02 \mathrm{~cm}$ silica gel plates using ethyl ether for 47-48 and 2:1 ethyl ether:DCM for 49. The phosphorescent fractions were isolated in each case (scraping the silica with a razor blade, grounding it into a powder, packing it in a small column and eluting the complex using ethyl ether, chloroform or a mixture of both). ${ }^{1} \mathrm{H}$ NMR and ESI-MS assisted in identifying the fraction containing the desired product. 
[\{Pt(ppy) $\left.{ }_{2}\right\}_{2} \mu$-(heptyl) ${ }_{2}$-dicarbonyl hydrazine] (44). Yield: $72 \% .{ }^{1} \mathrm{H}$ NMR $(300 \mathrm{MHz}$, $\mathrm{CDCl}_{3}$ ): 9.01 (d, 2H, H9, $\left.{ }^{3} \mathrm{~J}=5 \mathrm{~Hz}\right) ; 7.86$ (dd, 2H, H11, $\left.{ }^{3} \mathrm{~J}=7 \mathrm{~Hz}\right) ; 7.67$ (d, 2H, H12, ${ }^{3} \mathrm{~J}=$ $8 \mathrm{~Hz}) ; 7.48\left(\mathrm{dd}, 2 \mathrm{H}, \mathrm{H} 16,{ }^{3} \mathrm{~J}=5 \mathrm{~Hz}\right) ; 7.46\left(\mathrm{dd}, 2 \mathrm{H}, \mathrm{H} 17,{ }^{3} \mathrm{~J}=5 \mathrm{~Hz}\right) ; 7.14\left(\mathrm{dd}, 2 \mathrm{H}, \mathrm{H} 10,{ }^{3} \mathrm{~J}\right.$ $=6 \mathrm{~Hz}) ; 7.10\left(\mathrm{~d}, 2 \mathrm{H}, \mathrm{H} 15,{ }^{3} \mathrm{~J}=4 \mathrm{~Hz}\right) ; 7.08\left(\mathrm{~d}, 2 \mathrm{H}, \mathrm{H} 18,{ }^{3} \mathrm{~J}=4 \mathrm{~Hz}\right) ; 2.98\left(\mathrm{t}, 4 \mathrm{H}, \mathrm{H} 2,{ }^{3} \mathrm{~J}=\right.$ $8 \mathrm{~Hz}) ; 1.85(\mathrm{~s}, 4 \mathrm{H}, \mathrm{H} 3) ; 1.30(\mathrm{~s}, 8 \mathrm{H}, \mathrm{H} 5$ and $\mathrm{H} 6) ; 1.25(\mathrm{~s}, 8 \mathrm{H}, \mathrm{H} 4$ and $\mathrm{H} 7)$ and $0.84(\mathrm{t}, 6 \mathrm{H}$, $\left.\mathrm{H} 8,{ }^{3} \mathrm{~J}=6 \mathrm{~Hz}\right) .{ }^{13} \mathrm{C}$ NMR (75 MHz, $\mathrm{CDCl}_{3}$ ): $178.2(\mathrm{C} 1) ; 166.7$ (C13); 148.7 (C9); 145.0 (C14); 140.1 (C19); 138.1 (C11); 136.7 (C16); 129.9 (C15); 123.1 (C17); 122.9 (C18); 121.7 (C10); 118.3 (C12); 34.3 (C2); 31.8 (C3); 29.1 (C5 and C6); 27.4 (C3); 22.7 (C7) and 14.1 (C8). ESI-MS: $981\left([\mathrm{M}+\mathrm{H}]^{+}, 0.01 \%\right), 432$ ([Pt(ppy)(MeCN) $\left.]^{+}, 0.05\right), 214$ $\left(\left[\mathrm{Pt}(\mathrm{Hppy})(\mathrm{MeCN})_{2}\right]^{+2}, 1.4\right)$ and $156(\mathrm{Hppy}, 1.0)$.

[\{Pt(ppy) $\left.{ }_{2}\right\}_{2} \mu$-(4-methoxyphenyl $)_{2}$-dicarbonyl hydrazine $]$ (45). Yield: $70 \% .{ }^{1} \mathrm{H}$ NMR $\left(300 \mathrm{MHz}, \mathrm{CDCl}_{3}\right): 9.23$ (d, 2H, H7, $\left.{ }^{3} \mathrm{~J}=5 \mathrm{~Hz}\right) ; 8.52\left(\mathrm{~d}, 4 \mathrm{H}, \mathrm{H} 3,{ }^{3} \mathrm{~J}=9 \mathrm{~Hz}\right) ; 7.64$ (dd, 2H, $\left.\mathrm{H} 9,{ }^{3} \mathrm{~J}=8 \mathrm{~Hz}\right) ; 7.63\left(\mathrm{~d}, 2 \mathrm{H}, \mathrm{H} 10,{ }^{3} \mathrm{~J}=8 \mathrm{~Hz}\right) ; 7.29\left(\mathrm{~d}, 2 \mathrm{H}, \mathrm{H} 13,{ }^{3} \mathrm{~J}=8 \mathrm{~Hz}\right) ; 7.18(\mathrm{dd}, 2 \mathrm{H}$, $\left.\mathrm{H} 8,{ }^{3} \mathrm{~J}=5 \mathrm{~Hz}\right) ; 6.82\left(\mathrm{dd}, 2 \mathrm{H}, \mathrm{H} 14,{ }^{3} \mathrm{~J}=7 \mathrm{~Hz}\right) ; 6.72\left(\mathrm{~d}, 4 \mathrm{H}, \mathrm{H} 4,{ }^{3} \mathrm{~J}=9 \mathrm{~Hz}\right) ; 6.51(\mathrm{dd}, 2 \mathrm{H}$, $\left.\mathrm{H} 15,{ }^{3} \mathrm{~J}=7 \mathrm{~Hz}\right) ; 6.40\left(\mathrm{~d}, 2 \mathrm{H}, \mathrm{H} 16,{ }^{3} \mathrm{~J}=7 \mathrm{~Hz}\right)$ and $3.73(\mathrm{~s}, 6 \mathrm{H}, \mathrm{H6}) .{ }^{13} \mathrm{C}$ NMR $(75 \mathrm{MHz}$, $\left.\mathrm{CDCl}_{3}\right): 173.3$ (C1); 167.1 (C11); 162.0 (C5); 148.7 (C7); 143.7 (C12); 138.0 (C9); 136.0 (C16); 133.3 (C3); 132.3 (C17); 128.5 (C15); 125.7 (C2); 122.2 (C13); 121.9 (C14); $121.4 \quad(\mathrm{C} 8) ; \quad 118.3 \quad(\mathrm{C} 10) ; \quad 112.5 \quad$ (C4) $\quad$ and $55.4 \quad$ (C6). $\quad$ ESI-MS: 1089 $\left([\mathrm{M}+\mathrm{H}+\mathrm{MeCN}+\mathrm{MeOH}]^{+}, \quad 0.01 \%\right), \quad 648 \quad\left([\mathrm{M}+\mathrm{H}-\mathrm{Pt}(\text { ppy })]^{+}, \quad 0.03\right), \quad 432 \quad([\mathrm{Pt}($ ppy $)$ $\left.\left.(\mathrm{MeCN})_{2}\right]^{+}, 0.3\right), 214\left(\left[\mathrm{Pt}(\mathrm{Hppy})(\mathrm{MeCN})_{2}\right]^{+2}, 5.2\right)$ and $156(\mathrm{ppy}, 1.4)$. 
[\{Pt(ppy) $\left.{ }_{2}\right\}_{2} \mu$-(4-nitrophenyl) ${ }_{2}$-dicarbonyl hydrazine] (46). Yield: $67 \%$. ${ }^{1} \mathrm{H}$ NMR (300 $\left.\mathrm{MHz}, \mathrm{CDCl}_{3}\right): 9.13$ (d, 2H, H6, $\left.{ }^{3} \mathrm{~J}=5 \mathrm{~Hz}\right) ; 8.75\left(\mathrm{~d}, 4 \mathrm{H}, \mathrm{H} 3,{ }^{3} \mathrm{~J}=9 \mathrm{~Hz}\right) ; 8.05\left(\mathrm{~d}, 4 \mathrm{H}, \mathrm{H} 4,{ }^{3} \mathrm{~J}\right.$ $=9 \mathrm{~Hz}) ; 7.94\left(\mathrm{ddd}, 2 \mathrm{H}, \mathrm{H} 8,{ }^{3} \mathrm{~J}=8 \mathrm{~Hz},{ }^{4} \mathrm{~J}=1.2 \mathrm{~Hz}\right) ; 7.68\left(\mathrm{~d}, 2 \mathrm{H}, \mathrm{H} 9,{ }^{3} \mathrm{~J}=8 \mathrm{~Hz}\right) ; 7.31(\mathrm{~d}$, $\left.2 \mathrm{H}, \mathrm{H} 12,{ }^{3} \mathrm{~J}=8 \mathrm{~Hz}\right) ; 7.25\left(\mathrm{dd}, 2 \mathrm{H}, \mathrm{H} 7,{ }^{3} \mathrm{~J}=6 \mathrm{~Hz}\right) ; 6.81\left(\mathrm{dd}, 2 \mathrm{H}, \mathrm{H} 13,{ }^{3} \mathrm{~J}=7 \mathrm{~Hz}\right) ; 6.45$ (ddd, $\left.2 \mathrm{H}, \mathrm{H} 14,{ }^{3} \mathrm{~J}=7 \mathrm{~Hz},{ }^{4} \mathrm{~J}=1.2 \mathrm{~Hz}\right)$ and $6.28(\mathrm{~s}, 2 \mathrm{H}, \mathrm{H} 15) .{ }^{13} \mathrm{C} \mathrm{NMR}\left(75 \mathrm{MHz}, \mathrm{CDCl}_{3}\right)$ : 172.3 (C1); 166.9 (C10); 149.1 (C5); 148.7 (C6); 143.8 (C11); 139.2 (C2); 138.7 (C8); 137.5 (C16); 135.4 (C15); 132.6 (C3); 128.4 (C14); 122.8 (C12 and C13); 122.2 (C4); 121.8 (C7) and 118.6 (C9). ESI-MS: $1105\left([\mathrm{M}+\mathrm{H}+2 \mathrm{MeCN}]^{+}, 0.04 \%\right), 1068$ $\left([\mathrm{M}+\mathrm{H}+\mathrm{MeCN}]^{+}, 0.04\right), 1027\left([\mathrm{M}+\mathrm{H}]^{+}, 0.04\right), 545\left(\left[\mathrm{Pt}(\mathrm{ppy})_{2}+\mathrm{H}+\mathrm{MeCN}\right]^{+}, 0.4\right), 431$ ([Pt(ppy)(MeCN $\left.\left.)_{2}\right]^{+}, 3.2\right), 214\left(\left[\mathrm{Pt}(\mathrm{ppy})(\mathrm{MeCN})_{2}+\mathrm{H}\right]^{+2}, 14\right)$ and 156 (ppy, 7.8).

[\{Pt(2-Phenyl-quinoline $\left.)_{2}\right\}_{2} \mu-(\text { methyl })_{2}$-dicarbonyl hydrazine] (47). Crude yield: $58 \%$. ESI-MS: $996\left([\mathrm{M}+\mathrm{H}+\mathrm{DCM}]^{+}, 0.1 \%\right), 953\left([\mathrm{M}+\mathrm{H}+\mathrm{MeCN}]^{+}, 0.3\right), 928([\mathrm{M}+\mathrm{H}+\mathrm{MeCN}-$ $\left.\left.\mathrm{CH}_{3}\right]^{+}, 0.2\right), 913\left([\mathrm{M}+\mathrm{H}]^{+}, 0.2\right), 645\left(\left[\mathrm{Pt}(\mathrm{pq})_{2}+\mathrm{H}+\mathrm{MeCN}\right], 0.1\right), 482(0.9)$ and 214 (18). [\{Pt(2-Methyl-3-phenyl-quinoxaline $\left.)_{2}\right\}_{2} \mu$-(methyl $)_{2}$-dicarbonyl hydrazine] (48). Yield: $28 \% .{ }^{1} \mathrm{H}$ NMR (300 MHz, $\left.\mathrm{CDCl}_{3}\right): 9.56\left(\mathrm{~d}, 2 \mathrm{H}, \mathrm{H} 4,{ }^{3} \mathrm{~J}=9 \mathrm{~Hz}\right) ; 8.05\left(\mathrm{~d}, 2 \mathrm{H}, \mathrm{H} 7,{ }^{3} \mathrm{~J}=\right.$ $8 \mathrm{~Hz}) ; 8.00\left(\mathrm{dd}, 2 \mathrm{H}, \mathrm{H} 12,{ }^{3} \mathrm{~J}=7 \mathrm{~Hz},{ }^{4} \mathrm{~J}=2 \mathrm{~Hz}\right) ; 7.88\left(\mathrm{ddd}, 2 \mathrm{H}, \mathrm{H} 5,{ }^{3} \mathrm{~J}=9 \mathrm{~Hz},{ }^{3} \mathrm{~J}=7 \mathrm{~Hz},{ }^{4} \mathrm{~J}=\right.$ 2Hz); $7.79\left(\mathrm{~d}, 2 \mathrm{H}, \mathrm{H} 15,{ }^{3} \mathrm{~J}=7 \mathrm{~Hz}\right) ; 7.77\left(\mathrm{dd}, 2 \mathrm{H}, \mathrm{H} 6,{ }^{3} \mathrm{~J}=7 \mathrm{~Hz}\right) ; 7.20(\mathrm{~m}, 4 \mathrm{H}, \mathrm{H} 13$ and $\mathrm{H} 14) ; 3.14$ (s, 6H, H2) and 2.66 (s, 6H, H17. $\left.{ }^{13} \mathrm{C} \mathrm{NMR} \mathrm{(75} \mathrm{MHz,} \mathrm{CDCl}_{3}\right): 176.0$ (C1); 161.3 (C10); 151.6 (C9); 144.9 (C11); 142.4 (C16); 141.2 (C3 and C8); 136.6 (C15); 131.0 (C5); 130.0 (C6); 129.8 (C13); 128.2 (C7); 128.0 (C12); 126.4 (C4); 123.4 (C14); 
$27.1(\mathrm{C} 2)$ and $23.3(\mathrm{C} 17)$. ESI-MS: $1076\left([\mathrm{M}+\mathrm{H}+\mathrm{MeCN}]^{+},<0.1 \%\right), 994(<0.1), 943$ $\left([\mathrm{M}+\mathrm{H}]^{+}, 0.1\right), 675(0.1), 496(0.3) ; 265(1.2)$ and $214(97)$. $\left[\{\text { Pt(2-Methyl-3-phenyl-benzo[g]quinoxaline })_{2}\right\}_{2} \mu$-(methyl) $)_{2}$-dicarbonyl hydrazine] (49). Crude yield: $38 \%$. ESI-MS: $1082\left([\mathrm{M}+\mathrm{H}+\mathrm{MeCN}]^{+},<0.1 \%\right), 1044\left([\mathrm{M}+\mathrm{H}]^{+},<0.1\right), 775$ (0.4), $542(0.1), 454(1.7) ; 271(22)$ and $214(73)$.

\section{Quantum yield determination procedure}

Solutions of the reference material $\left(\mathrm{Alq}_{3}\right)$ and 44 were prepared at concentrations that gave a satisfactory linear absorbance (high correlation coefficients). The solution concentrations used were $0.004 \mathrm{mM}, 0.006 \mathrm{mM}, 0.008 \mathrm{mM}, 0.01 \mathrm{mM}$ and $0.015 \mathrm{mM}$. The excitation wavelength was set to $494 \mathrm{~nm}$. The phosphorescence was measured for each solution and it was plotted against the absorbance data. The slopes of the linear curves were obtained and used in equation 3.4 (see appendix 4 for plots). The quantum yield was $3 \%$ by comparison to $\mathrm{Alq}_{3}$. 


\title{
Chapter 4-Macromolecular materials of ruthenium complexes
}

\author{
4.1 - Introduction
}

Once a suitable electrochrome is designed and characterized, it is preferable to study its properties in solid form since devices based on solids tend to have a longer duty lifetime instead of encapsulated liquid-based design. While many techniques can be used to create homogeneous thin films on a substrate, casting, dip-coating and spin-coating are usually employed as they are readily accessible. Other techniques include screen printing and $R_{f}$ sputtering that require more elaborate instrumentation and stringent work conditions. Normally small molecules tend to create films of poor quality and usually require mixing into an inert polymeric matrix (doping). Since the dopant is not chemically bound to the matrix, aggregation can occur during and after solvent evaporation, where the dopant(s) still retains some mobility, creating heterogenous areas within the film. Another issue is the potential leaching of the dopant.

Incorporating the electrochromic moiety into a polymeric system through chemical bonding is a more reasonable choice since the gain in molecular weight and viscosity will result in better film forming ability. Also, leaching and aggregation will be avoided since the electrochrome can neither be moved nor removed. The easiest method to incorporate the ruthenium complex electrochrome into a polymer network is to prepare a polymer ligand followed by complexation. This method has been explored within our group previously. However, the monomeric diacyl hydrazides, oxamides and biureas all possess limited solubility, even in very polar solvents and the resulting polymers would 
also inherit this property and only oligomers would be obtained instead of high molecular weight polymers. Unfortunately, the complexation step of even oligomers can be problematic - will each and every ligand site host be fully complexed? This situation can be avoided altogether by polymerizing purified functionalized complexes thus ensuring that all ligand sites are complexed, and controlling the electrochrome content with a higher degree of certainty. Many polymeric systems were explored during this project and a very brief description of each is given below.

Linear polymers, the simplest polymers, are prepared by the reaction of difunctionalized monomers. This can be achieved by the reaction of an $\mathrm{AB}$ monomer containing both functional groups or by two monomers, AA and BB. Factors to consider are regioregularity and connectivity of the resulting polymer as unsymetrical monomers can undergo head-to-head, head-to-tail or tail-to-tail polymerization which affects the physical properties of the material ${ }^{205}$. The $\mathrm{AB}$ monomers, sometimes more difficult to prepare, are another route in obtaining regioregular polymers. Most $\mathrm{AA}+\mathrm{BB}$ polymerizations are of the condensation type, where the molecular weight obtained is highly dependant on the ratio of monomers utilized, which must be $1: 1$, otherwise, the excess of one monomer will cause chain termination, limiting the molecular weight ${ }^{205}$.

Another class of polymers is hyperbranched polymers which are formed when an $\mathrm{A}_{3}$ monomer reacts with a $\mathrm{BB}$ monomer, resulting in randomly branched macromolecules. Reaction time and temperature are key parameters to control in order to avoid insoluble matter which cannot be processed into films.

Other types of polymers include dendrimers, which are tree-like molecules, similar to hyperbranched polymers with the exception that they are grown in orderly 
fashion, created from dendrons (such as $\mathrm{AB}_{2}$ monomers), branching out symmetrically and forming globular networks (Figure 4.1). Two synthetic approaches are recognized: the divergent method, where the molecule is grown from the inside-out and conversely the convergent method $\mathrm{d}^{206}$. The divergent method can be more problematic when a multifunctionalized core reacts with a dendron, creating the first level of branching or first generation dendrimer (G1). If a trifunctionalized core is employed, the reaction must be performed at three sites and multiple products are often observed; this is even more troublesome as the generation increases since more reactive sites are added to the dendridic core. Fortunately, this can be simplified through the convergent method, where the terminal groups are formed first, leaving a single free group $\left(\mathrm{R}_{2} \mathrm{~B}\right)$ that can be attached to a compatible $A_{2} D$ dendron (where $D$ is a protected form of $B$ ) to increase the dendron generation, repeating at will to achieve the desired G-n dendrimer.

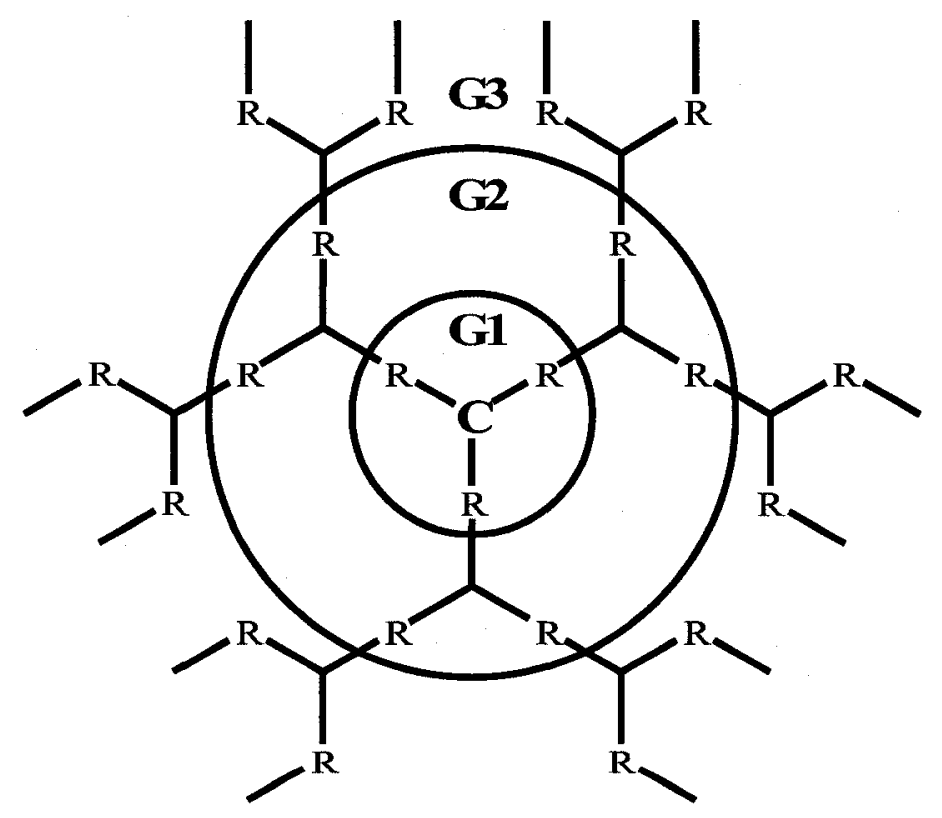

Figure 4.1 - Dendrimer depiction showing generation levels $(\mathrm{C}=$ core $)$ 


\section{Chapter 4-Macromolecular materials of ruthenium complexes}

Hydrogels, as the name implies, are water-soaked hyperbranched polymers which can be obtained by polymerization of acrylate and diacrylate (crosslinker) monomers in water. The resulting 'wet' solid acts as a water permeable membrane and is ubiquitously employed by biochemists for chromatography of proteins, DNA and other large molecular weight biomolecules.

Finally, sol-gels are high surface area, porous solids and tend to form good quality films. Silica sol-gels, for example, are produced by base hydrolysis of tetraalkoxysilanes, which condense into a polymeric network and dry into solid films. Surfactants are often added to the reaction mix to minimize shrinking and cracking.

4.2 - Results and discussion

\subsection{1 - Dendrimers}

$\mathrm{AB}_{2}$ monomers, also called dendrons, were devised to incorporate the $\mathrm{DCH}$ moiety. The first target dendron was a diester hydroxyl ligand (50) which was readily prepared by condensing dimethyl 5-(chlorocarbonyl)isophthalate to 6-hydroxyhexanoic hydrazide. The free $\mathrm{OH}$ group could then be coupled to an aromatic core, creating a simple G1 dendrimer. Previous members of our group had already achieved this generation level. Hydrazinolysis of $\mathbf{5 0}$ and subsequent condensation with an acid chloride should yield 51, a G2 dendron (Figure 4.2). However, the nucleophilicity of hydrazine was underestimated and while hydrazinolysis of both esters was achieved, hydrazinolysis of the DCH moiety also occurred, forming the tri-hydrazide $\mathbf{5 2}$ and the starting 6hydroxyhexanoic hydrazide. It was conceded that any other synthetic route requiring 
hydrazinolysis would not allow access to higher generation dendrimers than G1 and thus a different approach was required.

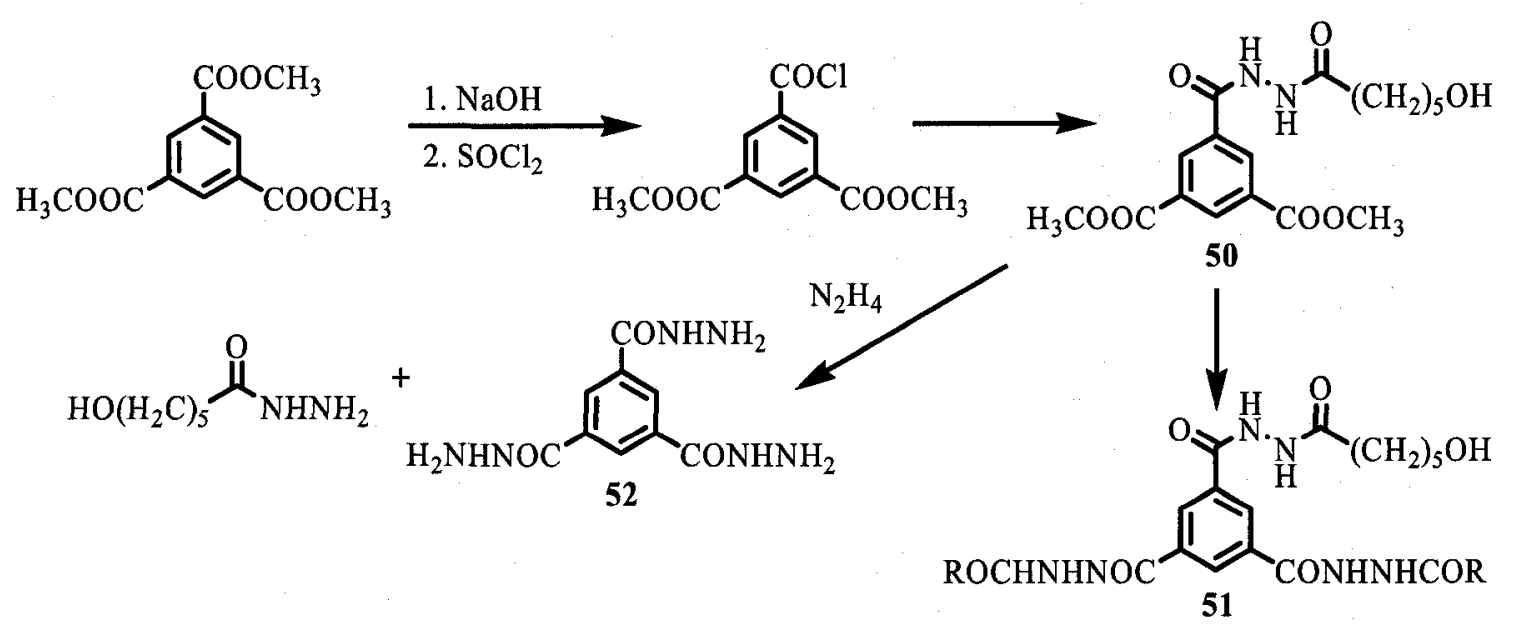

Figure $4.2-\mathrm{G} 2$ dendron 51 reaction scheme

Next, a synthetic route based on Suzuki coupling was explored. Isophthalic acid was selectively brominated at the 5 position using silver sulfate and bromine in concentrated sulfuric acid, as described by $\operatorname{Rau}^{207}$ (Figure 4.3). The acid chloride was then prepared and reacted with benzoic hydrazide, generating the G1 dendron 53. The boronic acid $\mathbf{5 5}$, prepared in 3 steps starting with 4-bromotoluene, was reacted with $\mathbf{5 2}$ to obtain a G1 dendrimer core 56. Suzuki coupling of $\mathbf{5 3}$ to $\mathbf{5 6}$ was attempted, but the G2 dendrimer 57 (Figure 4.3) was not obtained, as evidenced by ESI-MS analyis. It was thought that the free DCH ligand moieties were poisoning or inhibiting the catalyst and so the ruthenium complexes of both 53 and 56 were prepared to repeat the coupling (Figure 4.4). 

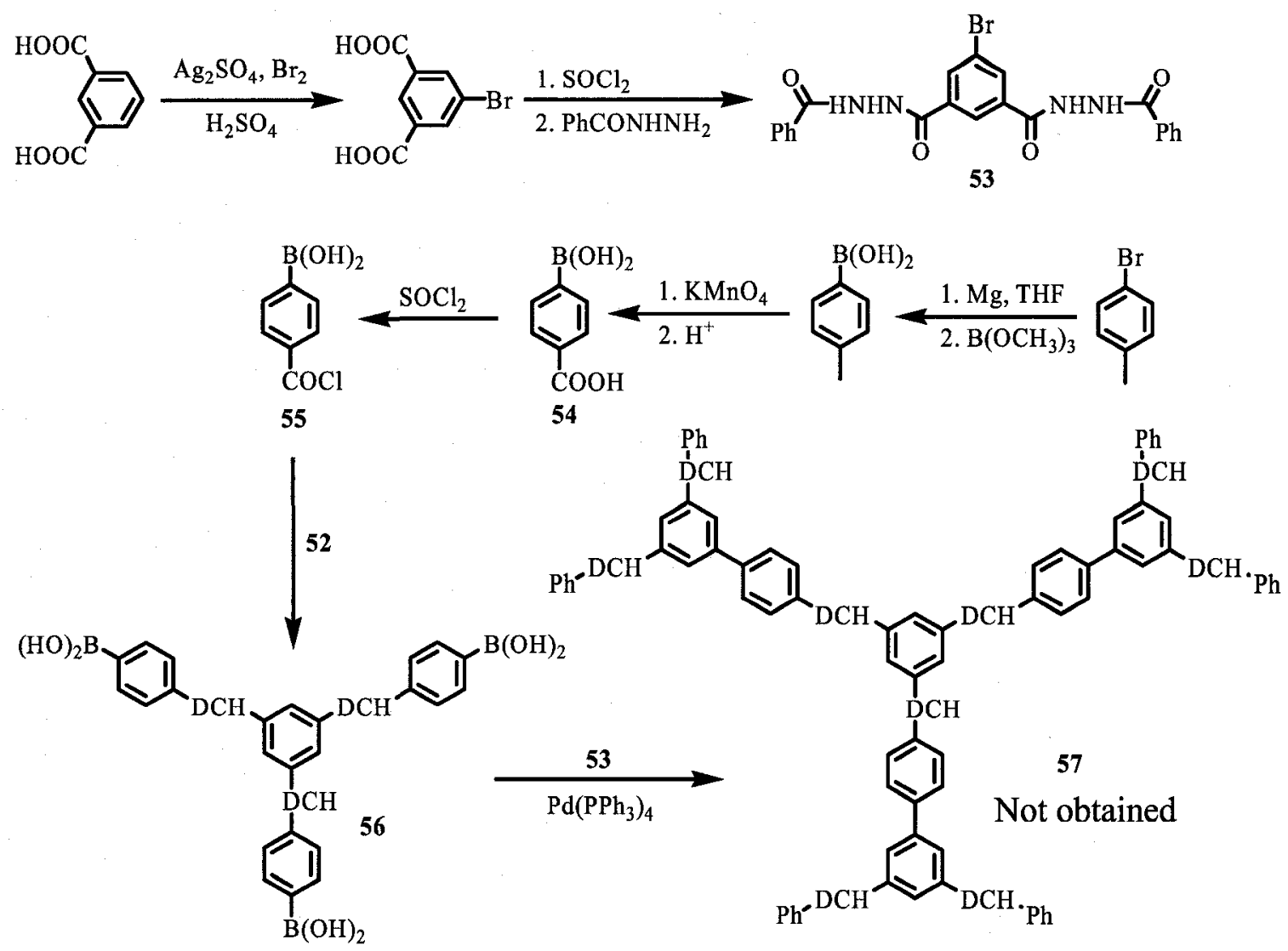

Figure 4.3 - G2 dendrimer 57 pathway via Suzuki coupling

It was thought unlikely that steric hindrance due to the $\mathrm{Ru}(\mathrm{bpy})_{2}$ moieties was responsible in preventing the coupling to occur; however, molecular modeling of the complex showed $\pi$ stacking from two nearby bpy with the bromophenyl moiety as well as two other bpy covering the two other sides, effectively guarding the $\mathrm{C}-\mathrm{Br}$ moiety against any approaching molecule (Figure 4.4), especially the bulky catalyst, $\mathrm{Pd}\left(\mathrm{PPh}_{3}\right)_{4}$. 


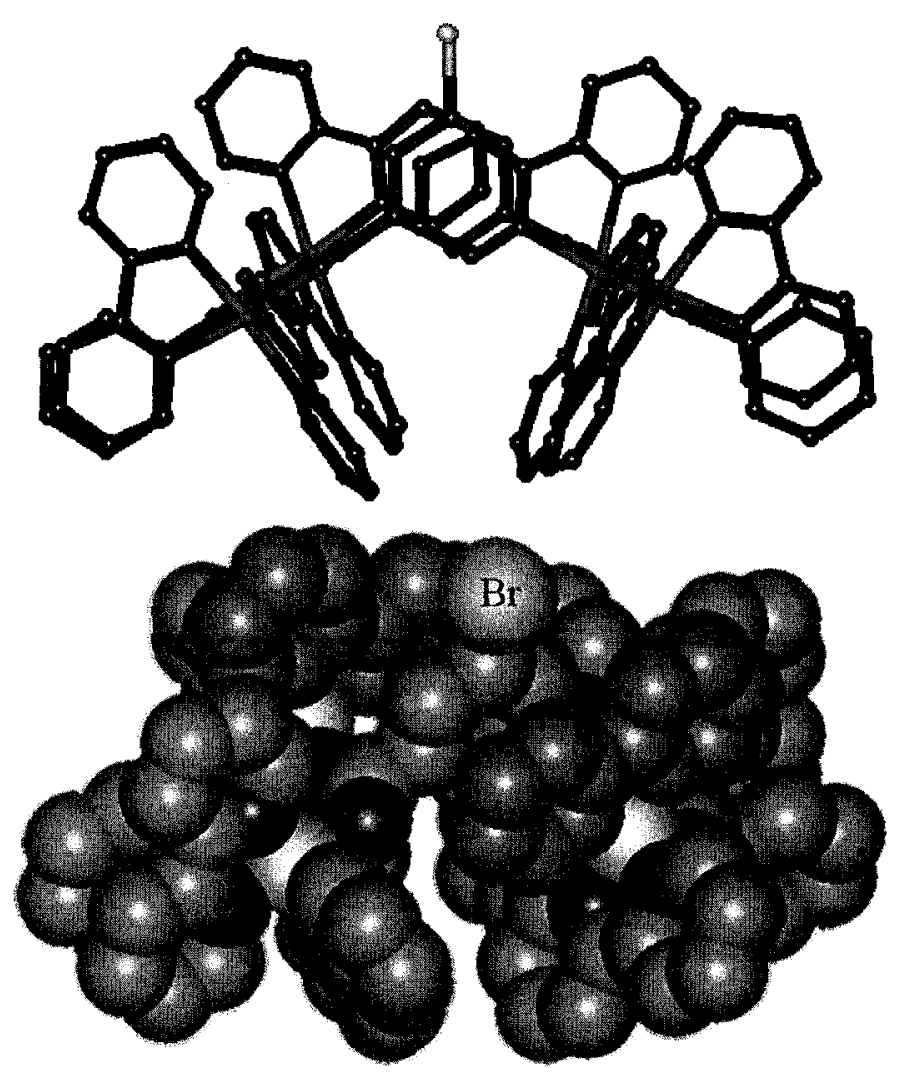

Figure 4.4 - Stick (top) and 3-D model (bottom) of ruthenium complex of $\mathbf{5 3}$ (hydrogens omitted for clarity)

Since G2 dendrimers seemed so elusive and G1 dendrimers containing six ruthenium atoms had already been synthesized, routes to make larger G1 dendrimers were explored. After consulting the literature, it was found that the double Micheal addition of acrylates to primary aliphatic amines was an elegant method for creating branched esters. 1,2-diaminobutane was added to excess methyl acrylate and the resulting tetra ester was subjected to hydrazinolysis to obtain a tetra hydrazide ${ }^{208}$ which could be capped with any acid chloride to give a tetra DCH dendridic ligand (Figure 4.5). Cinnamyl chloride was chosen for its ability to cyclize with other nearby cinnamyl 
groups when irradiated with $\mathrm{UV}^{209,210}$. Through this effort, the dendrimer ligand $\mathbf{5 8}$ was successfully prepared, as well as the octanuclear ruthenium complex $\mathbf{5 9}$, which was confirmed by ESI-MS $\left(\mathrm{m} / \mathrm{z}\right.$ peaks arising from the successive removal of $8 \mathrm{PF}_{6}$ counterions). $\mathrm{CV}$ and spectroelectrochemistry also confirm that $\mathbf{5 9}$ was obtained (Figure 4.6). Good quality films were obtained by spin coating and these were subjected to UV curing at $250 \mathrm{~nm}$, based on a method by Ito $^{209}$. IR of the film was taken after each irradiation period to monitor the intensity of the conjugated $\mathrm{C}=\mathrm{C}$ band and to determine the reaction endpoint. According to the procedure, cyclizing should be complete after a few minutes but even after 15 minutes of irradiation, no crosslinking was observed. It would appear that the bpy moieties, outnumbering the cynnamyl groups four to one, are absorbing the bulk of the energy and even at slow rates of cyclization, that no change was observed in the IR spectrum. Given the globular nature of the complex, the cinammyl groups are perhaps too far apart to react, or masked by the bpy. It is also likely that the bpy moieties, which outnumber the cinnamyl groups 4-to-1, would absorb the bulk of the available photons, preventing the curing to proceed. This could be overcome by using a photoinitiator or a thermal initiator such as AIBN or APS to initiate the crosslinking.

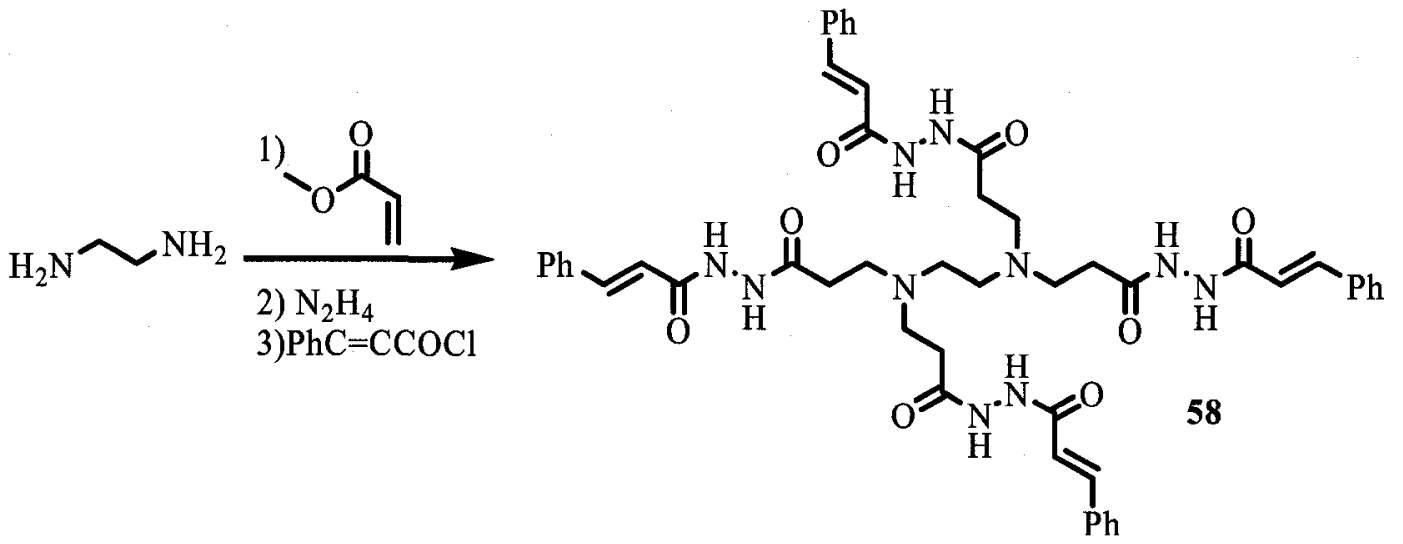

Figure 4.5 - Tetra DCH G1 dendrimer synthesis 


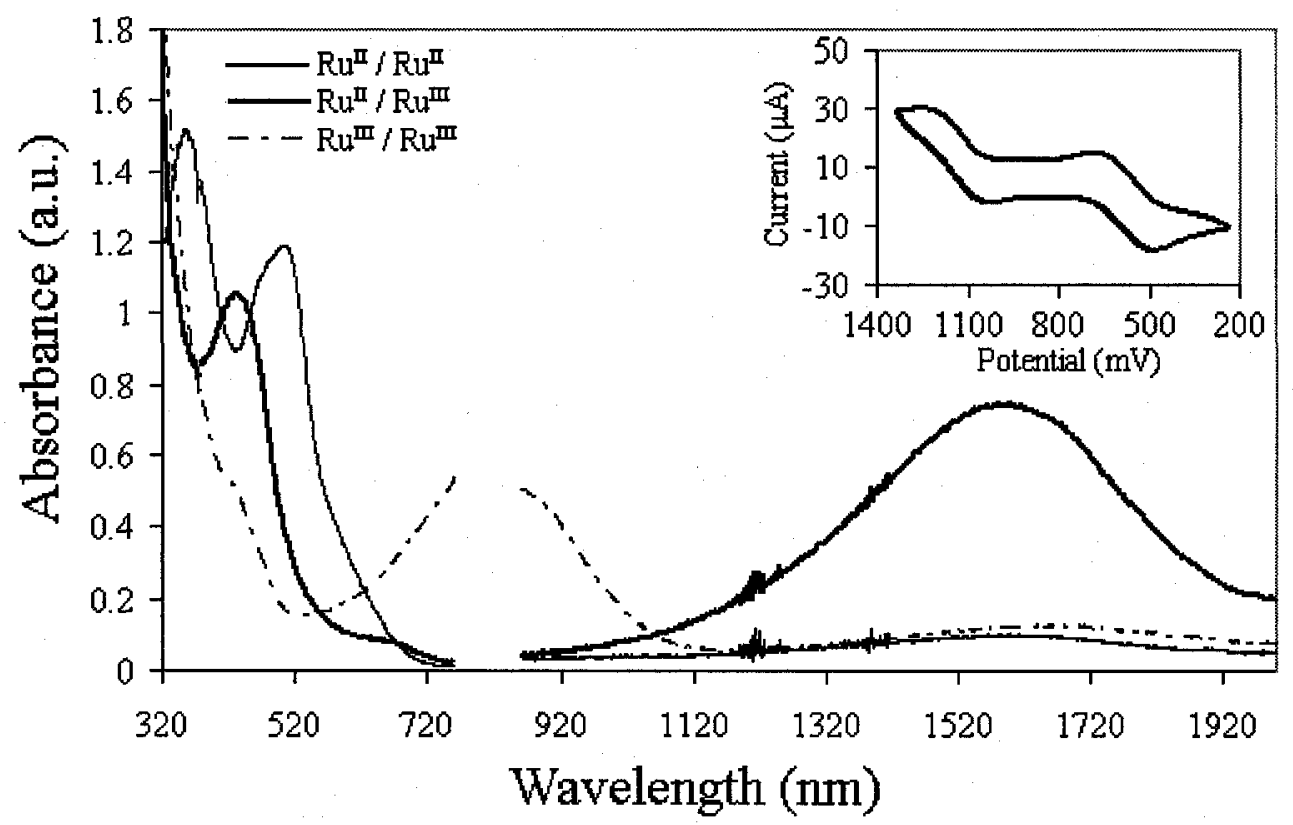

Figure 4.6 - Spectroelectrochemical properties of 59 (CV in inset)

\subsection{2 - Linear polymers}

Using the newly prepared hydroxyl-containing complexes, linear polymers were then considered. To avoid steric hindrance issues from the bpys as encountered in the previous section, the longest ligands ( $C_{5}$ chain) were chosen. Using a diacid chloride (AA), such as adipoyl chloride or terephthaloyl chloride, equimolar amounts of diol complex (BB) and triethylamine were reacted in a small testube using distilled $\mathrm{MeCN}$ under inert atmosphere to obtain polyesters (Figure 4.7). The reaction was quenched after 12 hours of stirring at room temperature, despite the low viscosity appearance (a sign of a low molecular weight polymer). The product was then precipitated in ethyl ether. IR of the resulting crude complex did show a new $\mathrm{C}=\mathrm{O}$ ester peak, but its intensity was only a fifth of the $\mathrm{O}-\mathrm{C}=\mathrm{N}$ band of the complex, confirming that either only a mixture of 
oligomers or a low molecular weigh polymer and monomer was obtained. Repeating the reaction at higher temperatures did not improve the quality of the product.

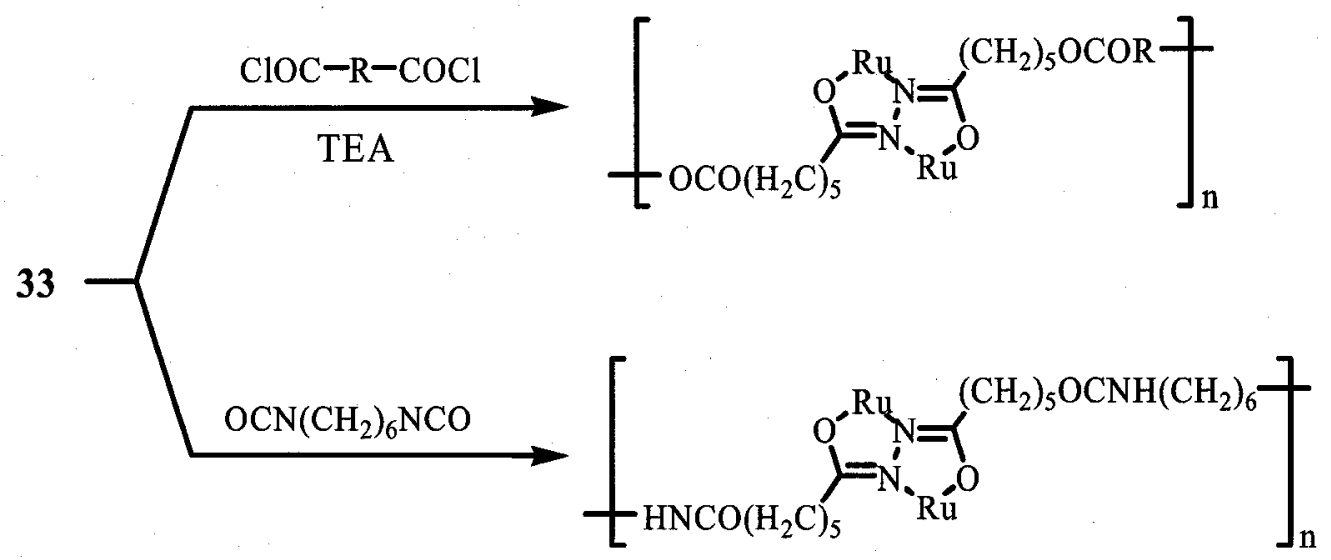

Figure 4.7 - Polyester and polyurethane synthesis (bpy omitted for clarity)

An investigation of polyurethanes (Figure 4.7) was also attempted using the same procedure without the use of a base and exchanging the diacid chloride for hexamethylenediisocyanate (HMDI). This time, an increase in viscosity was observed. Pouring the reaction mixture into $\mathrm{MeOH}$ did not produce a precipitate, suggesting that the molecular weight, while higher than that obtained via ester methodology, is still too low for practical use in devices.

Monomer ratio control is thought to be the main reason that high molecular weights were not achieved. Condensation polymerization requires a perfect $1: 1$ ratio in order to obtain high molecular weight. For example, if one monomer is only $95 \%$ pure, the theoretical repeat unit in the average polymer chain is 20 . The diol complex has a molecular weight in the $1200-1400 \mathrm{~g} / \mathrm{mol}$ range and are, as is the case with most research materials, precious. The reaction was thus performed on a $100 \mathrm{mg}$ scale of the complex, which translates to less than $0.1 \mathrm{mmol}$. The other monomers (acid chloride or isocynate) 
have a much lower molecular weight and accurately adding both reagents in equimolar amounts is challenging on its own. This issue is further compounded by trace humidity that consumes some of the monomer. This is more problematic with polyesters since formation of carboxylic acid, through reaction with water, will terminate the chain, preventing further growth on one end. With isocyanates, the hydrolysis product is an amine, which can still react with another isocynate, ensuring the chain growth. The only problem is that irregularities are introduced which create areas of lower electrochromic ruthenium density.

One possible solution to the molecular weight difference is to create an $A B$ monomer. Following the synthetic approach depicted in Figure 4.2, hydroxyacid complex 60 was prepared (Figure 4.8). In-situ polymerization via acid chloride generation seemed like an attractive method for polymerization, but it was eliminated due to the competing chlorination of the OH group by thionyl chloride ${ }^{211}$.

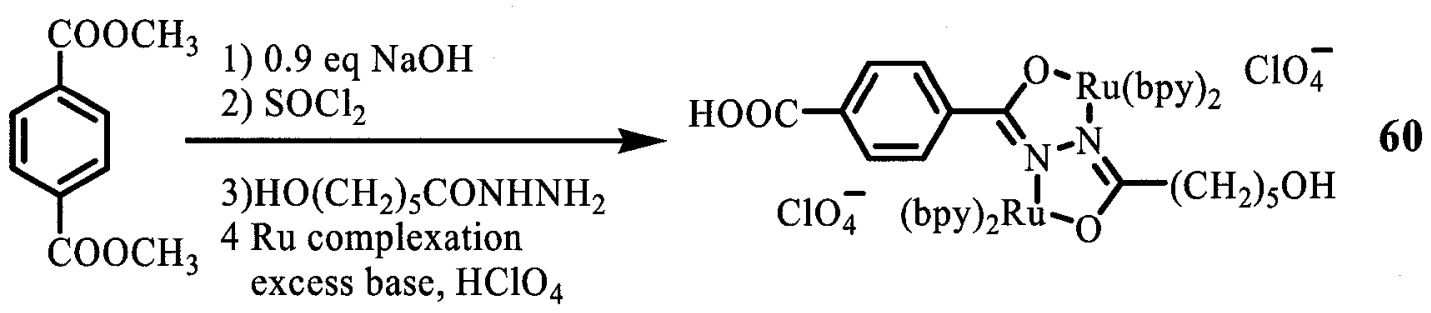

Figure 4.8 - Hydroxyacid complex synthesis

To polymerize $60,1,1^{\prime}$-carbonyldiimidazole (CDI) assisted esterification was considered. The CDI activates the carboxylic acid by the formation of an initial ester which is readily displaced by weaker nucleophilic species. Dicyclohexylcarbodiimide (DCC), and p-toluenesulfonic acid catalyzed esterification are other methods. Water was removed from the reaction medium via freshly activated molecular sieves or by a Dean- 
Stark trap. Even with all these refinements, high molecular weight was not achieved, regardless of the conditions utilized.

Recent dendrimer advances by Fréchet used the triazole moiety to prepare high generation dendrimers. The reaction is clean, requiring only an azide, a terminal acetylene and a copper(I) catalyst, generated from $\mathrm{CuSO}_{4}$ and sodium ascorbate (Figure 4.9). Utilizing propargyl amine, the diacetylene oxamide ligand 61 was prepared readily and $\alpha, \alpha^{\prime}$-p-xylene diazide was easily obtained from the dichloro precursor ${ }^{212}$. The polymerization was perfomed on the bare ligand to assess its potential. Some methanolinsoluble solid was obtained following workup and NMR did confirm the triazole moiety. NMR also showed that the reaction, as expected, is not regioregular as the acetylene can be turned $180^{\circ}$ and still react with the azide, although there is surely a degree of steric control.
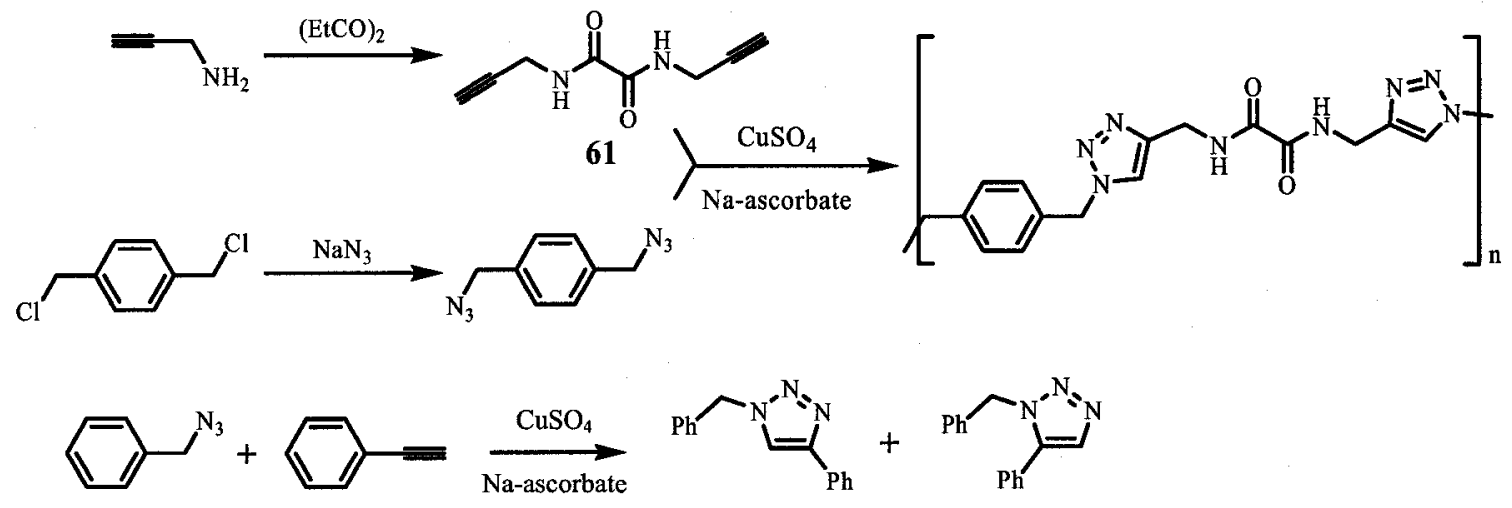

Figure 4.9 - Ligand 61 and triazole 'click' chemistry (showing possible isomers)

The complexation reaction on ligand $\mathbf{6 1}$ did not produce the expected dinuclear complex 62. ESI-MS did not show the expected peaks (Figure 4.10), which should have been at $1279\left(\mathrm{M}^{+}\right), 1134\left(\left[\mathrm{M}-\mathrm{PF}_{6}\right]^{+}\right)$and $495\left(\left[\mathrm{M}-2 \mathrm{PF}_{6}\right]^{+2}\right)$. Instead, a m/z peak at 1670 is observed, 391 amu higher than the expected molecular ion. After consulting the 
literature, it was found in a few papers that non-terminated acetylenes, deprotonated by base, can also complex to ruthenium ${ }^{213,214}$, which could be competing with the oxamide site, preventing the formation of the desired dinuclear complex. However, a molecular species corresponding to the 1670 peak could not be deduced. Peaks at 1836, 1693 and $774 \mathrm{~m} / \mathrm{z}$ would be observed if a third ruthenium atom complexed to the ligand, which is not the case. The situation where four ruthenium atoms are complexed, does not fit either.

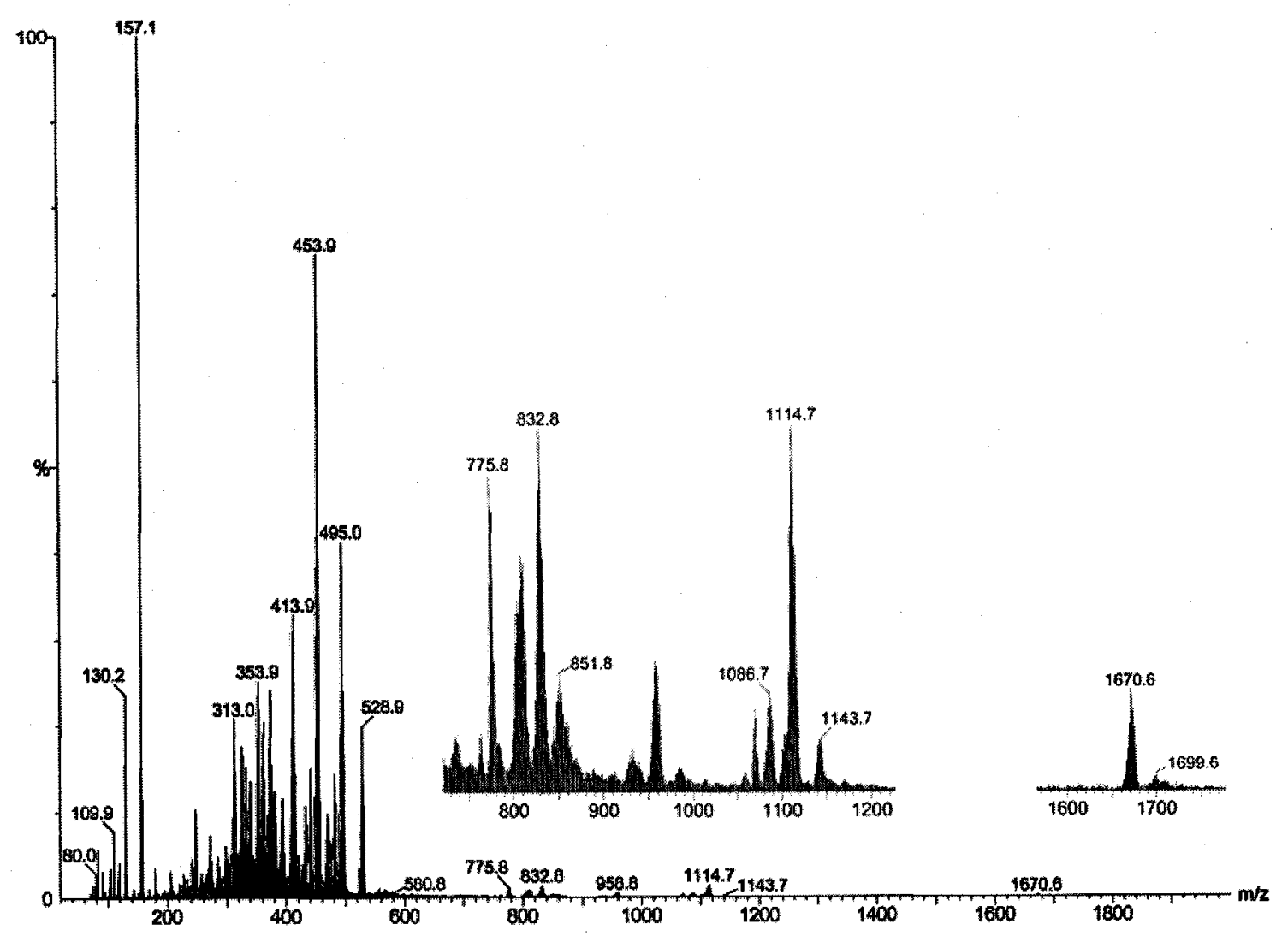

Figure 4.10 - ESI-MS of the attempted complexation of 61

A last effort to obtain a diacetylene ruthenium complex was made via an indirect route, by reacting an excess of propargyl chloroformate with 33. Surprizingly, ESI-MS did not confirm the diacetylene complex although a portion was converted to the monoacetylene. Longer reaction times, higher temperatures, larger excess of 
chloroformate, repurifying the complex or additional complex drying time failed to produce the desired diacetylene in high yield. The complexes are normally stable in basic conditions, but not necessarily so in acidic conditions. TEA was added to the reaction to neutralize the formed acid. Perhaps the acetylene is a stronger ligand, compared to the DCH moiety which resulted in a rearrangement of the DCH complex.

\subsection{3 - Hydrogels and sol-gels}

When considering options in designing a biosensor, aqueous chemistry is necessary in order to preserve the activity of the enzymatic system employed. Immobilizing both the ruthenium complex and an enzyme within a porous, polymeric network called for hydrogels or sol-gels.

Polyacrylamide hydrogels were first considered because of their easy preparation. This process requires water soluble ruthenium complexes which is unfortunately not the case with $\mathrm{PF}_{6}$ salts. Fortunately, the $\mathrm{PF}_{6}$ counterion can be exchanged to chlorine by addition of excess tetrabutylammonium chloride to an acetone solution of the complex. As the dichloro complex is insoluble in acetone, a simple workup ensues and the complex can be doped into the reaction medium uniformly. A solution of each reagent, acrylamide (AM), mehylene bisacrylamide (MBA), tetramethylene ethylene diamine (TMED) and water-soluble complex 35 was prepared. The radical initiator, ammonium persulfate (APS), was added last. Instead of obtaining a gel, the solution, originally purple, turned green. Furthermore, within an hour, the solution had become yellow. This was an interesting result and the discovery of an unexplored property of the biurea ruthenium complexes; they are strong radical quenchers, or antioxidants, owing to their low redox 
potentials. The initial addition of APS was sufficient to fully oxidize 35 to its $\mathrm{Ru}^{\mathrm{III}} / \mathrm{Ru}^{\mathrm{III}}$ state which was then reduced to the $\mathrm{Ru}^{\mathrm{II}} / \mathrm{Ru}^{\mathrm{III}}$ state. There may be some degree of cycling available as the mixed valence state could be re-oxidized again. Adding 1.2 equivalents of APS, based on the quantity of $\mathbf{3 5}$, yielded gels where the complex oxidized to its mixed valence state. Since the complex is water soluble and not covalently bound to the polymer network, some leaching occurred by diffusion through the pores of the gel. This should have been easily remediated by acrylating the hydroxyl groups of the complex but, as it was with the similar case of propargyl chloride, acryloyl chloride only decomposed the complex (deduced by the ESI-MS spectra of the recovered product) was obtained. The dinuclear ruthenium complexes are base stable but even with the addition of triethylamine (quantity based on molar equivalent of complex), the excess acid chloride employed could have reduced the $\mathrm{pH}$ to a level that caused degradation. Further discussion regarding the incorporation of the enzyme into the gel and biosensor scheme will be detailled in Chapter 5 .

Next, sol-gels containing 35 which were prepared using an oxdized complex were explored. Tetraethoxysilane was hydrolyzed to a gel using a common procedure ${ }^{215}$ by casting the fluid solution onto glass plates. Cetyltrimethylammonium bromide (CTAB) was added as a surfactant to minimize shrinkage and cracking of the gel. Two DCH-Ru complexe concentrations were prepared: $1.2 \mathrm{mg}$ (A series) and $2.4 \mathrm{mg}$ (B series) per 0.4 $\mathrm{mL}$ of sol solution. Unfortunately, the resulting gel films did crack and did not adhere strongly to the glass substrate. The films were prepared in triplicate and UV-Vis-NIR of these, were surprisingly reproducible, considering the randomness of the cracks observed (Figure 4.11). 
Chapter 4-Macromolecular materials of ruthenium complexes

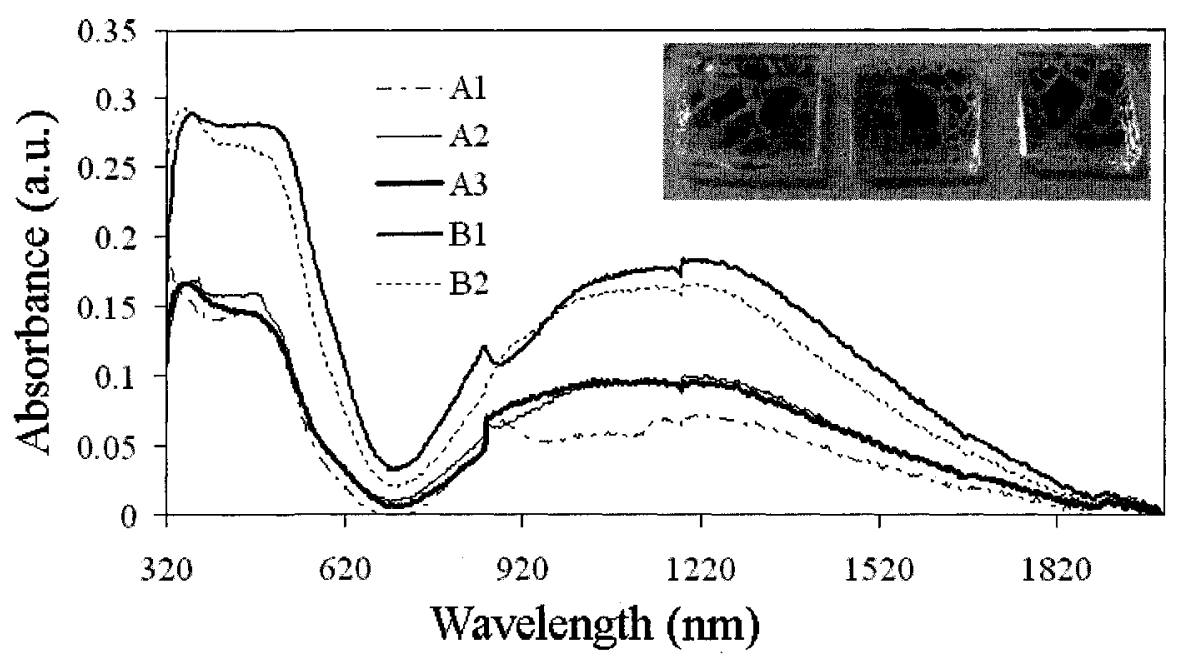

Figure 4.11 - Absorption spectra of solgel films containing 35 (inset: picture of ' $A$ ' films)

\subsection{4 - Hyperbranched polymers}

Following these obstacles, hyperbranched systems, which have been previously employed in our group ${ }^{73}$ were considered. Conditions, such as reagent concentration, reaction time, spin coating speed and curing temperature were optimized in order to obtain the thinnest film possible containing a maximum amount of ruthenium complex.

A triisocyanate, derived from trimethylolpropane and xylene diisocyanate was mixed with trimethylolpropane to produce urethane hyperbranched polymers. Initially, a monomer concentration of $50 \%$ by weight in $1: 1 \mathrm{MeCN}$ :THF was utilized, maintaining a $50 \%$ excess of isocyanato group over the hydroxyl group. Once mixed, the solutions gelled within a few minutes when at $50^{\circ} \mathrm{C}$. The gellation time increased to 10 minutes without heating, for a longer working window. Spin coating at $1000 \mathrm{rpm}$ for 30 seconds and curing at $150^{\circ} \mathrm{C}$ resulted in films on the order of $10-15$ microns in thickness. Increasing the spin speed gradually decreased the thickness to 4-6 microns, which was 


\section{Chapter 4-Macromolecular materials of ruthenium complexes}

higher still than the sub-micron goal that we had established. Diluting the monomers to 5 $\%$ by weight, increasing the spin coating speed to $3000 \mathrm{rpm}$ and curing at $150^{\circ} \mathrm{C}$ were required to obtain high-quality, transparent thin films on the order of $400 \mathrm{~nm}$ in thickness (Figure 4.12).
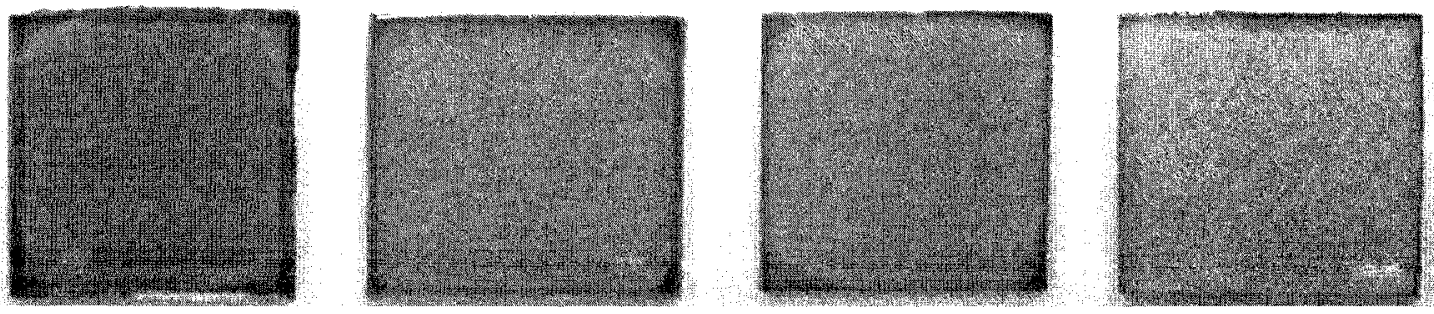

Figure 4.12 - Sample spin-coated crosslinked films containing 41

With the model system now optimized, the diol complex concentration was gradually increased, while decreasing the trimethylolpropane concentration by the same hydroxyl equivalent, to maintain the $50 \%$ excess isocyanato group. It was found that $48 \%$ by weight of complex was the highest concentration possible that produced clear films as phase separation occurred, during spin coating, at concentrations exceeding this value.

\section{3 - Conclusion}

A few synthetic pathways to dendrimers were considered and it was found that hydrazinolysis of ester groups, in the presence of already-formed DCH sites, is not selective to only ester groups. Hydrazine is such a strong nucleophile that it also hydrolyzes the existing DCH ligands, preventing the formation of higher generation dendrons. Suzuki coupling methodology applied to a G2 dendrimer scheme also failed due to the lack of coupling between a triboronic acid G1 DCH dendrimer core and a di- 
DCH bromo dendron. A potentially photocrosslinkable tetra-DCH G1 dendrimer was readily obtained; however, UV irradiation failed to produce crosslinking. This might be due to steric repulsions and the globular nature of the nearby complex sites, preventing two cinnamyl groups from interacting and photodimerizing. Redesigning this route with an extended chain separating the cinnamyl group from the complexation site might enable photocrosslinking. This is also dependant on the effect of UV absorbance of the bpy moieties, as they outnumber the cinnamyl groups 4 to 1 and can absorb the bulk of the UV radiation.

Many polymerization methods were considered to prepare macromolecular materials containing the dinuclear ruthenium complex moiety. As unfortunate as it is, most of them only produced low molecular weight materials, unsuitable for application purposes. High molecular weights play an important role for good film-forming properties and having reliable, stable physical and optical properties. The conducting element that ensures uniform conductivity across the film is normally an electrolyte, such as an ionic liquid, or a polyelectrolyte based on dissolved lithium perchlorate. The latter is able to dissolve low molecular weight ruthenium complex polymers, as they are essentially ionic compounds as well. Only hyperbranched polyurethanes produced adequate materials and a procedure to prepare high-quality thin films containing up to 48 $\%$ by weight of ruthenium complex was devised and optimized. Their optical and electrochemical properties will be discussed in chapter 5 . 


\section{Chapter 4-Macromolecular materials of ruthenium complexes}

\section{4 - Experimental}

Polymerization reactions were performed under inert atmosphere, usually argon, using in-house Shlenk lines, having screw caps on both ends, permitting the use of septa. A small side hole was blown on small test tubes with threaded top and a standard GC vial, its bottom cut out, was fused to the side opening, facilitating the use of needles to supply the inert gas. Acetonitrile was distilled over $\mathrm{CaH}_{2}$ and kept in a bottle which was placed in a dessicator. $\mathrm{N}, \mathrm{N}$-Dimethylformamide (DMF) was distilled over $\mathrm{CaH}_{2}$ and stored over $4 \AA$ molecular sieves. Reagents such as trimethylolpropane, carbamate with xylene diisocyanate (TMP-NCO), trimethylolpropane (TMP), and DCC were purchased from Aldrich and used as received. The complexes were prepared, isolated, purified and analyzed as described in Chapter 3. NMR characterization of the organic synthons was achieved as described in Chapter 2. Spin-coated films were prepared using a Chemat Technology Spin Coater, model KW-4B. UV irradiation was done using an EFOS N2001-A1 Novacure spot curing light source.

\section{Dendrimer related synthesis}

Dimethyl 5-[N'-(6-Hydroxy-hexanoyl)-hydrazinocarbonyl]isophthalate (50). Trimethyl 1,3,5-benzenetricarboxylate $(5.05 \mathrm{~g}, 20 \mathrm{mmol})$, dissolved in $200 \mathrm{~mL}$ of methanol was partially hydrolyzed by adding 0.9 equivalent of $\mathrm{NaOH}(18 \mathrm{~mL}, 1 \mathrm{M})$ and stirred overnight at room temperature. The solution was rotoevaporated to dryness. The resulting salt was dissolved in $50 \mathrm{~mL}$ of distilled water (DW) and the solution was acidified to $\mathrm{pH}$ $=3$ using concentrated $\mathrm{HCl}$. The white precipitate ws filtered, washed with $\mathrm{DW}$ and dried 
in a vacuum oven at $50^{\circ} \mathrm{C}$ overnight. This monoacid was converted to an acid chloride in refluxing thionyl chloride $(1 \mathrm{~g}$ of monoacid in $10 \mathrm{~mL} \mathrm{SOCl} 2)$ for 4 hours. The excess thionyl chloride was rotoevaporated and $0.924 \mathrm{~g}$ of the formyl chloride $(3.6 \mathrm{mmol})$ is dissolved in $25 \mathrm{~mL}$ of DCM and added dropwize to a solution of 6-hydroxyhexanoic hydrazide $^{134}(3.4 \mathrm{mmol})$ and TEA $(0.38 \mathrm{~g}, 3.8 \mathrm{mmol})$ in THF. After stirring for 3 hours, the TEA-HCl salt was filtered off and the filtrate was concentrated to dryness. The solid was triturated with DCM (50 is soluble in THF) to remove impurities and air dried. The overall yield of 50 (three steps) was 82\%. ${ }^{1} \mathrm{H}$ NMR (400 MHz, DMSO- $\left.d_{6}\right): 10.79$ (s, $1 \mathrm{H}$, H8); 10.00 (s, 1H, H9); 8.70 (d, 2H, H2, $\left.{ }^{4} \mathrm{~J}=1.5 \mathrm{~Hz}\right) ; 8.62\left(\mathrm{t}, 1 \mathrm{H}, \mathrm{H} 4,{ }^{4} \mathrm{~J}=1.5 \mathrm{~Hz}\right) ; 4.37$ (t, $\left.1 \mathrm{H}, \mathrm{OH},{ }^{3} \mathrm{~J}=5 \mathrm{~Hz}\right) ; 3.94(\mathrm{~s}, 6 \mathrm{H}, \mathrm{H} 6) ; 3.40\left(\mathrm{td}, 2 \mathrm{H}, \mathrm{H} 15,{ }^{3} \mathrm{~J}=5 \mathrm{~Hz}\right) ; 2.20\left(\mathrm{t}, 2 \mathrm{H}, \mathrm{H} 11,{ }^{3} \mathrm{~J}=\right.$ $5 \mathrm{~Hz}) ; 1.57\left(\mathrm{tt}, 2 \mathrm{H}, \mathrm{H} 14,{ }^{3} \mathrm{~J}=7 \mathrm{~Hz}\right) ; 1.44\left(\mathrm{tt}, 2 \mathrm{H}, \mathrm{H} 12,{ }^{3} \mathrm{~J}=7 \mathrm{~Hz},{ }^{3} \mathrm{~J}=6.5 \mathrm{~Hz}\right)$ and $1.34(\mathrm{tt}$, $\left.2 \mathrm{H}, \mathrm{H} 13,{ }^{3} \mathrm{~J}=7 \mathrm{~Hz},{ }^{3} \mathrm{~J}=6.5 \mathrm{~Hz}\right)$. MP: $182-184{ }^{\circ} \mathrm{C}$.

3,5-Bis(phenylhydrazido)bromobenzene (53). Isophthalic acid (12.17 g, $73 \mathrm{mmol}$ ), silver sulphate (13.32 g, $43 \mathrm{mmol})$ and bromine $(5 \mathrm{~mL}, 97 \mathrm{mmol})$ were stirred in concentrated sulfuric acid $(60 \mathrm{~mL})$ at $100{ }^{\circ} \mathrm{C}$ for 32 hours. The remaining bromine was distilled out and the mixture was poured in $500 \mathrm{~mL}$ of cold water (ice bath). The white solid and silver bromide were collected transferred into $700 \mathrm{~mL}$ of $\mathrm{DW}$ to which $\mathrm{NaHCO}_{3}$ was added until only lime green $\mathrm{AgBr}$ remains suspended. $\mathrm{AgBr}$ was filtered off and kept $\left(\mathrm{AgSO}_{4}\right.$ can be regenerated). The aqueous phase was concentrated to $250 \mathrm{~mL}$ and concentrated sulfuric acid was added until $\mathrm{pH}=3$ was reached. The white precipitate was filtered, rinced with cold DW and dried overnight under vacuum at $70^{\circ} \mathrm{C}(15.7 \mathrm{~g}$ obtained). 5bromoisophthaloyl dichloride was prepared by treatment with $\mathrm{SOCl}_{2}$ as previously 
described for 50, and was dissolved in $50 \mathrm{~mL}$ of THF. A solution of benzoic hydrazide (2.2 molar equivalents and TEA 2.2 molar equivalents) in $50 \mathrm{~mL}$ of THF was added dropwize to the acid chloride solution. The reaction was poured in water and $\mathbf{5 3}$ was filtered, washed with DW, cold acetone and air dried under vacuum. Overall yield (three steps) was 63\%. ${ }^{1} \mathrm{H}$ NMR (400 MHz, DMSO-d $d_{6}$ ): 10.83 (s, 1H, H6); 10.66 (s, 1H, H7); 8.49 (s, 1H, H4); $8.32\left(\mathrm{~d}, 2 \mathrm{H}, \mathrm{H} 2,{ }^{4} \mathrm{~J}=1.2 \mathrm{~Hz}\right) ; 7.94\left(\mathrm{~d}, 4 \mathrm{H}, \mathrm{H} 10,{ }^{3} \mathrm{~J}=7 \mathrm{~Hz}\right) ; 7.66(\mathrm{t}, 2 \mathrm{H}$, $\left.\mathrm{H} 12,{ }^{3} \mathrm{~J}=7 \mathrm{~Hz}\right)$ and $7.54\left(\mathrm{dd}, 4 \mathrm{H}, \mathrm{H} 11,{ }^{3} \mathrm{~J}=7 \mathrm{~Hz}\right)$. MP: $266-268^{\circ} \mathrm{C}$. EI-MS: $482\left(\mathrm{M}^{+}, 1.7\right.$ $\%) ; 446\left(\left[\mathrm{M}-2 \mathrm{H}_{2} \mathrm{O}\right]^{+}, 3.2\right) ; 406\left(\left[\mathrm{M}-\mathrm{C}_{6} \mathrm{H}_{5}\right]^{+}, 0.4\right) ; 327\left(\left[\mathrm{M}-\mathrm{C}_{6} \mathrm{H}_{5}-\mathrm{Br}\right]^{+}, 2.4\right) ; 256(2.5) ; 224$ (1.6); 192 (2.1); $160(5.0) ; 122(22) ; 105$ (100) and 77 (39).

Tri-boronic acid GI dendrimer core (56). Boronic acid $\mathbf{5 4}$ was prepared as described by $\mathrm{Chen}^{216} .54$ was refluxed in $\mathrm{SOCl}_{2}$ for 4 hours and $\mathbf{5 5}$ was isolated after rotoevaporating the excess thionyl chloride and used without further purification. $55(1.71 \mathrm{~g}, 9.3 \mathrm{mmol})$, diluted in $15 \mathrm{~mL}$ of THF, was added dropwize to a 1,2-dimethoxyethane (DME):DMF (60 mL 1:1) solution of trihydrazide $52(0.76 \mathrm{~g}, 3 \mathrm{mmol})$ and TEA $(0.94 \mathrm{~g}, 3 \mathrm{mmol})$ under inert atmosphere. The mixture was heated to maintain a gentle reflux for 16 hours. The cooled reaction mixture was poured in to $150 \mathrm{~mL}$ DW and the resulting pale yellow solid washed with DW and air dried under vacuum. $0.68 \mathrm{~g}$ was recovered. Yield: 32\%. ${ }^{1} \mathrm{H}$ NMR (400 MHz, DMSO- $d_{6}$ ): 10.95 (s, 3H, H4); 10.65 (s, 3H, H5); 8.72 (s, 3H, H4); $8.29(\mathrm{~s}, 6 \mathrm{H}, \mathrm{H} 11) ; 7.92\left(\mathrm{~d}, 6 \mathrm{H}, \mathrm{H} 8,{ }^{3} \mathrm{~J}=8 \mathrm{~Hz}\right)$ and $7.89\left(\mathrm{~d}, 6 \mathrm{H}, \mathrm{H} 9,{ }^{3} \mathrm{~J}=8 \mathrm{~Hz}\right)$.

Cinnamoyl-terminated Gl dendrimer (58). The starting tetrahydrazide was prepared according to a procedure published by Vercruyss $\mathrm{e}^{208}$. This hydrazide $(0.43 \mathrm{~g}, 1 \mathrm{mmol})$ 
and TEA (0.41 g, $4 \mathrm{mmol})$ were placed in a $50 \mathrm{~mL}$ RBF containing dry DMF (25 mL) under inert atmosphere. A solution of cinnamoyl chloride $(0.75 \mathrm{~g}, 4.5 \mathrm{mmol})$ in dry DMF $(5 \mathrm{~mL})$ was added dropwize to the flask at room temperature. Once the addition is complete, the mixture was heated to $80^{\circ} \mathrm{C}$ and stirred overnight. The mixture was rotoevaporated to half volume and, once cooled, was poured in $150 \mathrm{~mL}$ acetone. The resulting slurry was cooled to $-20^{\circ} \mathrm{C}$ for 1 hour before collecting the white solid, washing it with small portions of acetone. The solid was dried in a vacuum oven overnight at room temperature. $0.83 \mathrm{~g}$ of a white powdery 58 was obtained. Yield: $87 \%{ }^{1} \mathrm{H}$ NMR (300 MHz, DMSO- $\left.d_{6}\right): 10.37$ (s, 4H, H7); 10.26 (s, 4H, H6); 7.57 (s, 8H, H12); 7.54 (d, $4 \mathrm{H}, \mathrm{H} 10,{ }^{3} \mathrm{~J}=15 \mathrm{~Hz}$ ); 7.39 (s, 12H, H13 and H14); 6.74 (d, 4H, H9, ${ }^{3} \mathrm{~J}=15 \mathrm{~Hz}$ ); 3.30 (s, $8 \mathrm{H}, \mathrm{H} 4) ; 3.08$ (s, 4H, H2); 2.77 (s, 8H, H3) and 1.75 (s, 4H, H1). ${ }^{13} \mathrm{C}$ NMR (75 MHz, DMSO- $\left.d_{6}\right): 168.3$ (C5); 164.2 (C8); 140.7 (C10); 135.0 (C14); 130.3 (C11); 129.4 (C12); 128.2 (C13); $119.8(\mathrm{C} 9) ; 48.8(\mathrm{C} 4) ; 45.8(\mathrm{C} 3) ; 31.2(\mathrm{C} 2)$ and $8.9(\mathrm{C} 1)$.

Octanuclear ruthenium complex of $\mathbf{5 8}$ (59). The same procedure as described in Chapter 3 was used to prepare the complex. Yield: $72 \%$. ESI-MS: $1662\left(\left[\mathrm{M}-3 \mathrm{PF}_{6}\right]^{+3}, 0.7 \%\right)$; $1210\left(\left[\mathrm{M}-4 \mathrm{PF}_{6}\right]^{+4}, 4.4\right) ; 939\left(\left[\mathrm{M}-5 \mathrm{PF}_{6}\right]^{+5}, 43\right) ; 758\left(\left[\mathrm{M}-6 \mathrm{PF}_{6}\right]^{+6}, 100\right) ; 629\left(\left[\mathrm{M}-7 \mathrm{PF}_{6}\right]^{+7}\right.$, 16), $535\left(\left[\mathrm{M}-8 \mathrm{PF}_{6}+\mathrm{H}_{2} \mathrm{O}\right]^{+8}, 46\right)$ and $533\left(\left[\mathrm{M}-8 \mathrm{PF}_{6}\right]^{+8}, 6.6\right)$.

\section{Linear polymerization procedures}

Polyesters: Equimolar amounts of monomers (diol, diacid chloride and TEA) were charged in a small custom schlenk line and dissolved in $1 \mathrm{~mL}$ dry MeCN. Reactions were normally performed at either $5 \% \mathrm{~m} / \mathrm{v}$ (diol complex: $50 \mathrm{mg}, 0.04 \mathrm{mmol}$ ) or $10 \%$ (diol 
complex: $100 \mathrm{mg}, 0.08 \mathrm{mmol}$ ) and under inert atmosphere. Due to the small volume of solvent, the temperatures never exceeded $60^{\circ} \mathrm{C}$. The reactions were monitored by IR (ester $\mathrm{C}=\mathrm{O}$ band) periodically during $24-72$ hour periods. Viscosity was not measured since no appreciable increase was noted. Gel permeation chromatography (GPC) was not performed neither for fear to permanently contaminate the column based on the low-butpermanent adsorption of ruthenium complex on alumina.

In the case of $\mathrm{AB}$ monomers, the polymerization reaction was done using a coupling agent such as DCC or CDI. Essentially, 60 (100 mg, $0.08 \mathrm{mmol})$ was dissolved in $2 \mathrm{~mL}$ of 1:1 THF:MeCN with DCC or CDI $(0.21 \mathrm{mmol}) .4$-Dimethylaminopyridine (DMAP) was added as a catalyst $(5 \mathrm{mg})$. The mixture was stirred at room temperature overnight.

p-Toluenesulfonic acid catalyzed esterification of $\mathbf{6 0}(100 \mathrm{mg})$, in refluxing 2.5 $\mathrm{mL}$ of 1:1 toluene: dimethylacetamide (DMAc) showed some success.

\section{Synthesis of $\mathrm{AB}$ ruthenium complex monomer 60}

Dimethyl terephthalate was partially hydrolyzed to the monoacid using the saponification procedure described in preparing $\mathbf{5 0}$. The monoacid $(1 \mathrm{~g}, 5.6 \mathrm{mmol})$ was refluxed in 15 $\mathrm{mL}$ of $\mathrm{SOCl}_{2}$ and $20 \mathrm{~mL}$ of THF overnight. The excess solvent was rotoevaporated and the acide choride was dissolved in $10 \mathrm{~mL}$ of THF which was then added dropwize to a 20 $\mathrm{mL}$ solution of 6-hydroxyhexanoic hydrazide $(0.85 \mathrm{~g}, 5.8 \mathrm{mmol})$ and equimolar amount of TEA. The reaction was stirred at $50^{\circ} \mathrm{C}$ for 3 hours. The ligand was significantly water soluble. The reaction solvent was removed and the solid was washed with hot acetone. The filtrate was poured in ethyl ether and the resulting white precipitate was collected, 
washed with ethyl ether and air dried. $0.94 \mathrm{~g}$ of the hydroxyester ligand 60pre (see appendix 1 for structure) was obtained. Yield: $55 \%$. ${ }^{1} \mathrm{H}$ NMR (400 MHz, DMSO- $d_{6}$ ): 10.52 (s, 1H, H7); 9.94 (s, 1H, H8); 8.07 (dd, 2H, H3, $\left.{ }^{3} \mathrm{~J}=8 \mathrm{~Hz},{ }^{4} \mathrm{~J}=1.4 \mathrm{~Hz}\right) ; 8.01$ (dd, $\left.2 \mathrm{H}, \mathrm{H} 4,{ }^{3} \mathrm{~J}=8 \mathrm{~Hz},{ }^{4} \mathrm{~J}=1.4 \mathrm{~Hz}\right) ; 3.89(\mathrm{~s}, 3 \mathrm{H}, \mathrm{H} 15) ; 3.77(\mathrm{~s}, 1 \mathrm{H}, \mathrm{OH}) ; 3.41\left(\mathrm{t}, 2 \mathrm{H}, \mathrm{H} 14,{ }^{3} \mathrm{~J}=\right.$ $6 \mathrm{~Hz}) ; 2.20\left(\mathrm{t}, 2 \mathrm{H}, \mathrm{H} 10,{ }^{3} \mathrm{~J}=7 \mathrm{~Hz}\right) ; 1.57\left(\mathrm{tt}, 2 \mathrm{H}, \mathrm{H} 11,{ }^{3} \mathrm{~J}=7 \mathrm{~Hz}\right) ; 1.45\left(\mathrm{tt}, 2 \mathrm{H}, \mathrm{H} 13,{ }^{3} \mathrm{~J}=\right.$ $6 \mathrm{~Hz},{ }^{3} \mathrm{~J}=7 \mathrm{~Hz}$ ) and 1.35 (m, 2H, H12). ${ }^{13} \mathrm{C}$ NMR (100 MHz, DMSO- $\left.d_{6}\right): 171.5$ (C1); 165.6 (C6); 164.6 (C9); 136.6 (C2); 132.2 (C5); 129.2 (C3); 127.8 (C4); 160.5 (C14); 52.3 (C15); 33.3 (C10); 32.2 (C13); 25.1 (C11) and 24.9 (C10). EI-MS: $308\left(\mathrm{M}^{+}, 0.3 \%\right)$; $290\left(\left[\mathrm{M}-\mathrm{H}_{2} \mathrm{O}\right]^{+}, 1.3\right) ; 259$ (1.1); 230 (7.7); 194 (34); 181 (2.0); 163 (100); 149 (3.2); 135 (13); 115 (27); 97 (13) and 69 (31). MP: $149-150^{\circ} \mathrm{C}$.

The ligand was complexed in the usual manner, with the exception that excess base was utilized to ensure hydrolysis of the ester group and perchloric acid was used as the precipitating and neutralizing agent. Complex 60 was obtained, after purification on deactivated neutral alumina (adding $3 \%$ by weight of water, $\mathrm{MeCN}$ used for eluent), in $82 \%$ yield. ESI-MS: $1318\left(\mathrm{M}^{+},<0.1 \%\right) ; 1219\left(\left[\mathrm{M}-\mathrm{ClO}_{4}\right]^{+}, 2.2\right) ; 1119\left(\left[\mathrm{M}+\mathrm{H}-2 \mathrm{ClO}_{4}\right]^{+}\right.$, $0.7) ; 706\left(\left[\mathrm{M}-\mathrm{Ru}(\mathrm{bpy})_{2}-2 \mathrm{ClO}_{4}\right]^{+}, 1.2\right)$ and $560\left(\left[\mathrm{M}-2 \mathrm{ClO}_{4}\right]^{+2}, 100\right)$.

Polyurethanes: Same as described for the polyesters except that no base was added. Higher viscosity was obtained however, only a small fraction of the polymer would be soluble in $\mathrm{DMF}$ - any polymer soluble in $\mathrm{MeCN}$ was deemed as too low molecular weight to be considered for device applications. In addition, only film casting is possible when using DMF due to its low volatility, which produces thicker films, often of lesser quality than with spin coating. 
Polytriazoles: The diacetylene oxamide ligand 61 was prepared following a previously described method ${ }^{132}$. Equimolar parts of propargyl amine and diethyl oxalate were added to $20 \mathrm{~mL} \mathrm{THF} \mathrm{and} \mathrm{stirred} \mathrm{under} \mathrm{inert} \mathrm{atmosphere} \mathrm{for} \mathrm{two} \mathrm{hours} \mathrm{at} \mathrm{room} \mathrm{temperature.} 50$ $\mathrm{mL}$ ethyl ether was added to the mixture. The white solid was filtered and air dried. ${ }^{1} \mathrm{H}$ NMR (300 MHz, DMSO- $\left.d_{6}\right): 9.22\left(\mathrm{t}, 2 \mathrm{H}, \mathrm{H} 2,{ }^{3} \mathrm{~J}=6 \mathrm{~Hz}\right) ; 3.90\left(\mathrm{~d}, 4 \mathrm{H}, \mathrm{H} 3,{ }^{3} \mathrm{~J}=6 \mathrm{~Hz}\right)$ and 3.10 (s, 2H, H5). ${ }^{13} \mathrm{C}$ NMR (75 MHz, DMSO- $\left.d_{6}\right): 160.0$ (C1); 80.8 (C4); 73.4 (C5) and $28.8(\mathrm{C} 3)$.

Procedure for hydrogel formation

The procedure is based on J. Franklyn's ${ }^{217} \mathrm{PhD}$ thesis with the exception that a 1.2 molar excess of APS, based on the quantity of ruthenium complex, was required to obtain suitable gels.

Exchanging the counterion of ruthenium complexes from $\mathrm{PF}_{6}$ to $\mathrm{Cl}$ was relatively simple. Dissolving the $\mathrm{PF}_{6}$ complex in acetone and adding excess tetrabutyl ammonium chloride permitted the exchange. The dichloro ruthenium complex precipitated out of the acetone solution and simply filtering and washing it with acetone produced the complex in a water soluble form.

Procedure for sol-gel formation

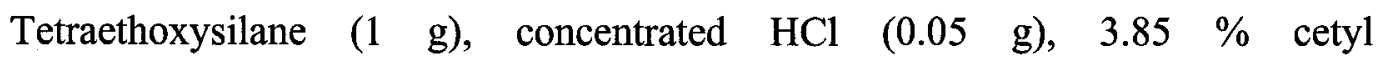
trimethylammonium bromide (CTAB) in ethanol 95\% (0.25 g), and $\mathrm{H}_{2} \mathrm{O}(0.04 \mathrm{~g})$ were mixed in a small Erlenmeyer and vortexed at low speed for one hour. This solution was used to cast blank sol-gels on glass slides (four drops of solution per $1 \times 1 \mathrm{~cm}$ slides). 
Water soluble ruthenium complex (chloride counter anion) in the mixed valence state was added at $1.2 \mathrm{mg}$ and $2.4 \mathrm{mg}$ per $0.4 \mathrm{~mL}$ of blank solution. Once the solution was deposited on the glass slides, they were placed in a refrigerator at $5^{\circ} \mathrm{C}$ until the solgel film formation was complete. The remaining, unused solution completely gelled up, with no cracks or defects, within a few days. Unfortunately, the cast films were always cracked and did not adhere strongly to the substrate.

\section{Preparation of the crosslinked films of ruthenium complex}

Indium-doped tin oxide (ITO) coated glass strips $(0.9 \times 4.0 \mathrm{~cm})$ were cut from 15 x $15 \mathrm{~cm}$ sheets using a diamond glass cutter and washed, with gloved hands, using $10 \%$ wt $\mathrm{K}_{3} \mathrm{PO}_{4}$ solution, rinsed with hot water followed by distilled water. The strips were 'towelled' off using Kimwipe $($ tissues and air dried. The procedure was repeated if smudges were still present. The clean strips were kept in a Petri dish.

Ruthenium complex 41 (7 mg), tetrabutylammonium hexafluorophosphate (TBAH, $2 \mathrm{mg}$ ), $0.018 \mathrm{~mL}$ of $5 \%$ wt TMP solution (250 mg in $4.75 \mathrm{~g}$ THF:MeCN 1:1) and $1 \mathrm{mg}$ of 1,2-diazabicyclo[2,2,2]octane (DABCO) were added to a $1.5 \mathrm{~mL}$ screw cap vial. Lastly, $0.125 \mathrm{~mL}$ of 5\% wt TMP-NCO solution (333 mg in $3.92 \mathrm{~g}$ THF:MeCN 1:1) was added to the vial and the mixture was vortexed at high speed for 10 seconds. The mixture was immediately spin coated into films (3000 rpm for 30 seconds) on the ITO strips. The solution was deposited on one side of the strip only, as to obtain a film that is about $2 \mathrm{~cm}$ in length. Duplicate films of each batch were prepared. Any solution that did spread over to the other half of the ITO strip was rubbed off with an acetone-soaked 


\section{Chapter 4-Macromolecular materials of ruthenium complexes}

cotton swab to ensure that this section of ITO was bare. The films were then cured on a digital hotplate at $150^{\circ} \mathrm{C}$ for two hours.

Using less of the ruthenium complex or higher organic monomer concentrations, no leaching occurred when washing the film with acetone, confirming that the crosslinking was complete; however, the best results were obtained with the above mentioned quantity of ruthenium, even though a small amount of surface complex did leach out when washed with acetone. In the case of biureas such as 39 , a significant portion of the ruthenium complex leached out of the cured film. Increasing the isocyanate concentration or curing time did not prevent leaching. 


\section{Chapter 5 - Device applications based on dinuclear ruthenium complexes}

\section{1 - Introduction}

In the scope of this project, biosensor and VOA applications were developed. Based on the action of the glucose oxidase (GOX) enzyme (Figure 5.1), the glucose biosensor scheme is able to evaluate the glucose content of various matrices. This wellknown scheme has been tested against many sensoring materials in optical ${ }^{218-232}$ and in amperometric configurations ${ }^{39}, 233-244$. This particular enzyme, along with many others (cholesterol oxidase $^{245}$, alcohol oxidase ${ }^{246}$, amine oxidase ${ }^{247}$ and cocaine oxidase ${ }^{248}$ ), produces hydrogen peroxide as a byproduct, at the expense of an equimolar amount of substrate, rendering the concentration correlation process simple. The active site of the enzyme contains a flavenoid core (FAD, Flavin-Adenine Dinucleotide) which is oxidized by molecular oxygen, generating the active form of the enzyme GOX and producing hydrogen peroxide. With molecular oxygen being plentiful, the oxidized form of the enzyme is dominant. When the substrate, glucose, reaches the FAD core, it is oxidized to gluconic acid while the enzyme is reduced to its non-active $\mathrm{GOX}-\mathrm{H}_{2}$ form.

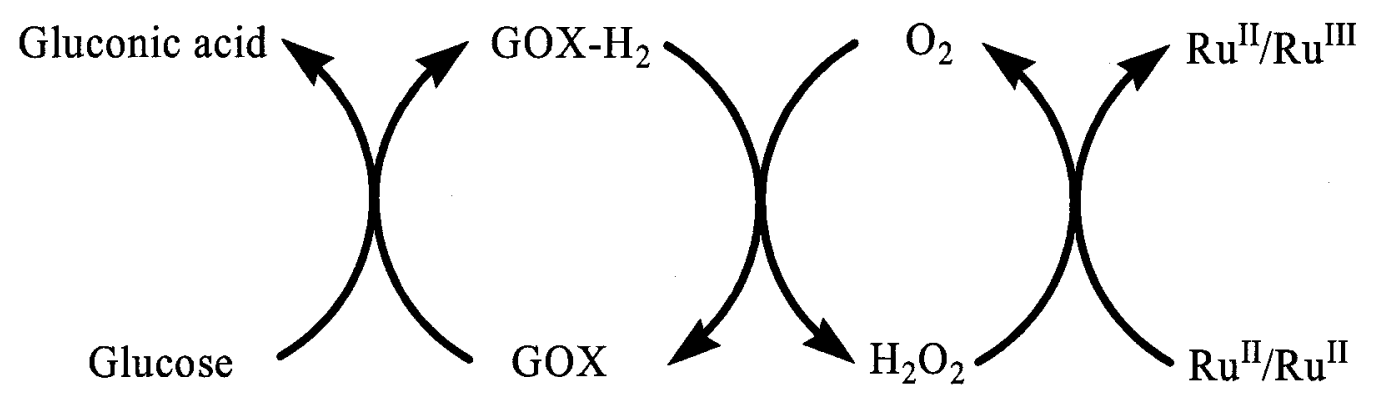

Figure 5.1 - Glucose oxidase sensoring scheme considered 


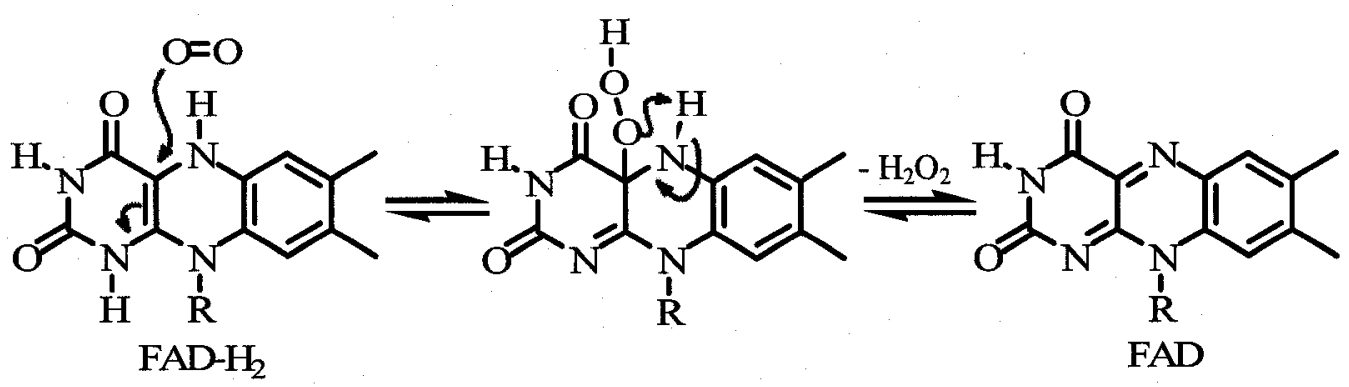

Figure 5.2-GOX active site mechanism

The chemical sensoring materials are normally redox active and it is the current change from their oxidation by $\mathrm{H}_{2} \mathrm{O}_{2}$ that is monitored through amperometric means, which is the working principle of current human blood sugar apparatus. This redox titration can also be used to determine the concentration of glucose in various matrices, as long as the conditions are sufficient to ensure proper enzyme activity. Since redox materials usually change color, the monitoring can also be achieved via optical means.

Variable optical attenuators (VOA) are devices that can affect the amount of light that reaches its intended target. Electrochromic VOAs vary their attenuation capability through an applied potential. The optical attenuation can be achieved by micromechanical means, where a slit or other moving parts physically block the incident beam ${ }^{249-251}$. Unfortunately, the moving parts tend to be bulky and make the devices noisy ${ }^{252}$. In comparison, a VOA device using an EC material to absorb the light does not require the use of any moving parts and can be operated or switched on and off by applying a low voltage. The dinuclear ruthenium complexes are suitable materials for NIR VOA applications with further potential in controlling and processing light signals in linear and nonlinear optics $^{70,}$ 253-256. McDonagh and coworkers have studied the NIR electrochromism of dinuclear molybdenum complexes in a 6-mm-thick liquid cell design 
for their VOA properties at $1300 \mathrm{~nm}$ and achieved high attenuation ${ }^{70}$. Optical attenuation can also be achieved by thermooptic-based planar lightwave circuits ${ }^{257-262}$, where an applied voltage generates heat that induces a drop in the refractive index of a fiber optic cable cladding, allowing light to 'escape' the fiber, weakening the signal strength and through the use of liquid crystals which also relies on refractive index manipulation via an applied voltage to the liquid crystal.

Two optical configurations can be considered. The first is a transmission-based design where the incident beam passes through a clear EC material film sandwiched between two ITO plates. The second is a refletion-based design where the indicent beam passes through the EC film and is reflected back through the same film, theoretically doubling the attenuation efficiency per thickness unit compared to transmissive configurations. A conducting element, such as a polymer electrolyte gel, completes the circuit in both cases.

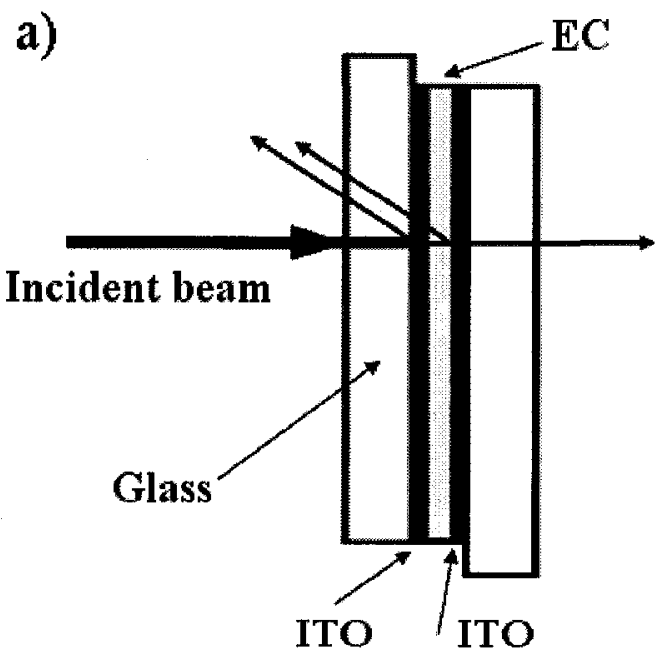

b)

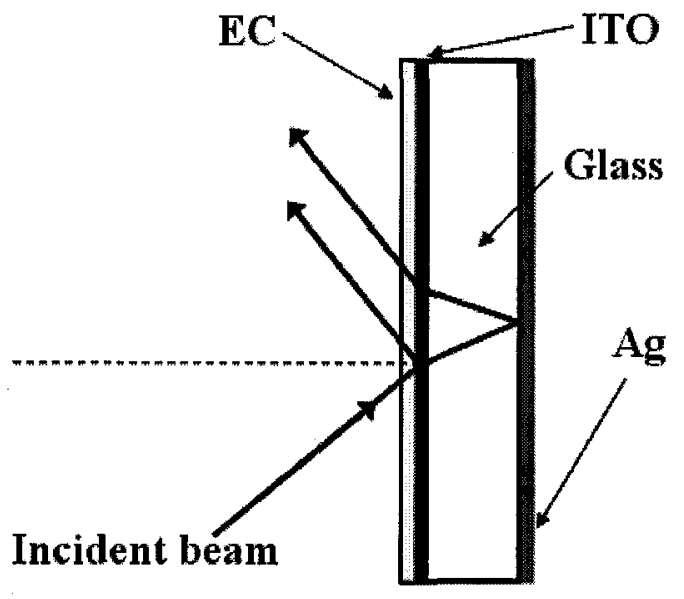

Figure $5.3-$ a) transmisive and b) reflective VOA constructs 
A reflective design may offer higher attenuation but requires more space to accommodate the incident and reflected beams particularly when compared to transmissive designs, which can be placed in line with the incident beam source.

While ITO is employed as a colorless electrode in visible applications, it starts reflecting NIR light from $1000 \mathrm{~nm}$ (Figure 5.4). Furthermore, tranmissive designed VOAs, will loose signal strength each time an ITO layer is encountered. This property can be harnessed when operating in a reflective mode. However, double reflection can occur since ITO will partially reflect the incident beam, potentially reducing the overall signal strength. These and other optical losses were not considered when evaluating the VOA properties of the films in this study.

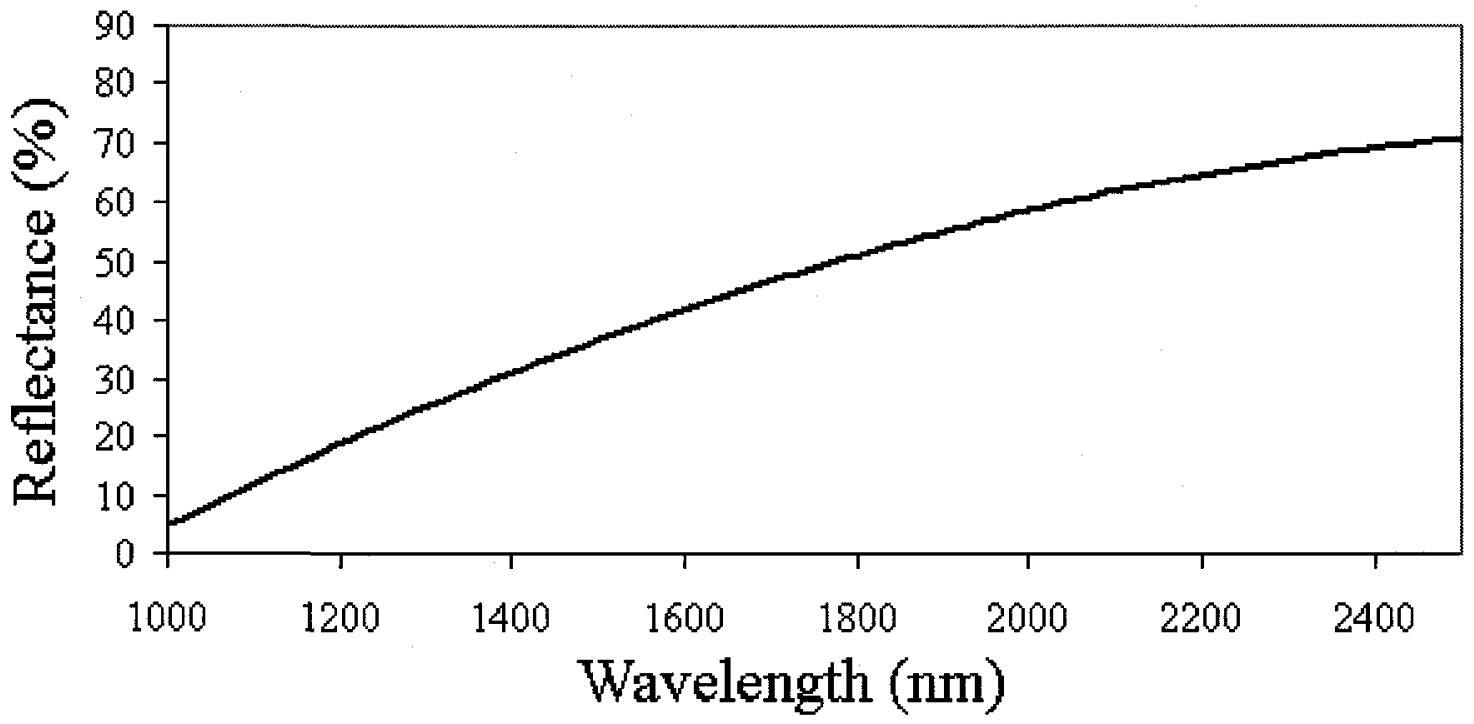

Figure 5.4 - ITO NIR reflectance (100 nm thick coating) 
5.2 - Results and discussion

\subsection{1 - Glucose biosensor}

The first sensoring tests were performed using hydrogen peroxide (concentration range reflecting the normal blood sugar levels) and complex 34, to evaluate the oxidation potential of the complex in $0.1 \mathrm{M}$ Tris (2-Amino-2-(hydroxymethyl)-1,3-propanediol) buffered at $\mathrm{pH}=7.4$ and containing $10 \% \mathrm{v} / \mathrm{v} \mathrm{MeCN}$. The solution absorbance was monitored at $1200 \mathrm{~nm}$ in real time for a period of 10 minutes at various peroxide concentrations. A good calibration curve was observed at different reaction times (Figure 5.5). Note that the trend line did not pass through the zero intercept. The solution, minus the hydrogen peroxide, was used as the baseline. As discussed in Chapter 3, the low redox potential biureas, such as $\mathbf{3 4}$, can be oxidized by oxygen. Therefore, any NIR absorbance observed at $0 \mathrm{mM}$ concentration is due to the complex oxidation by dissolved oxygen.

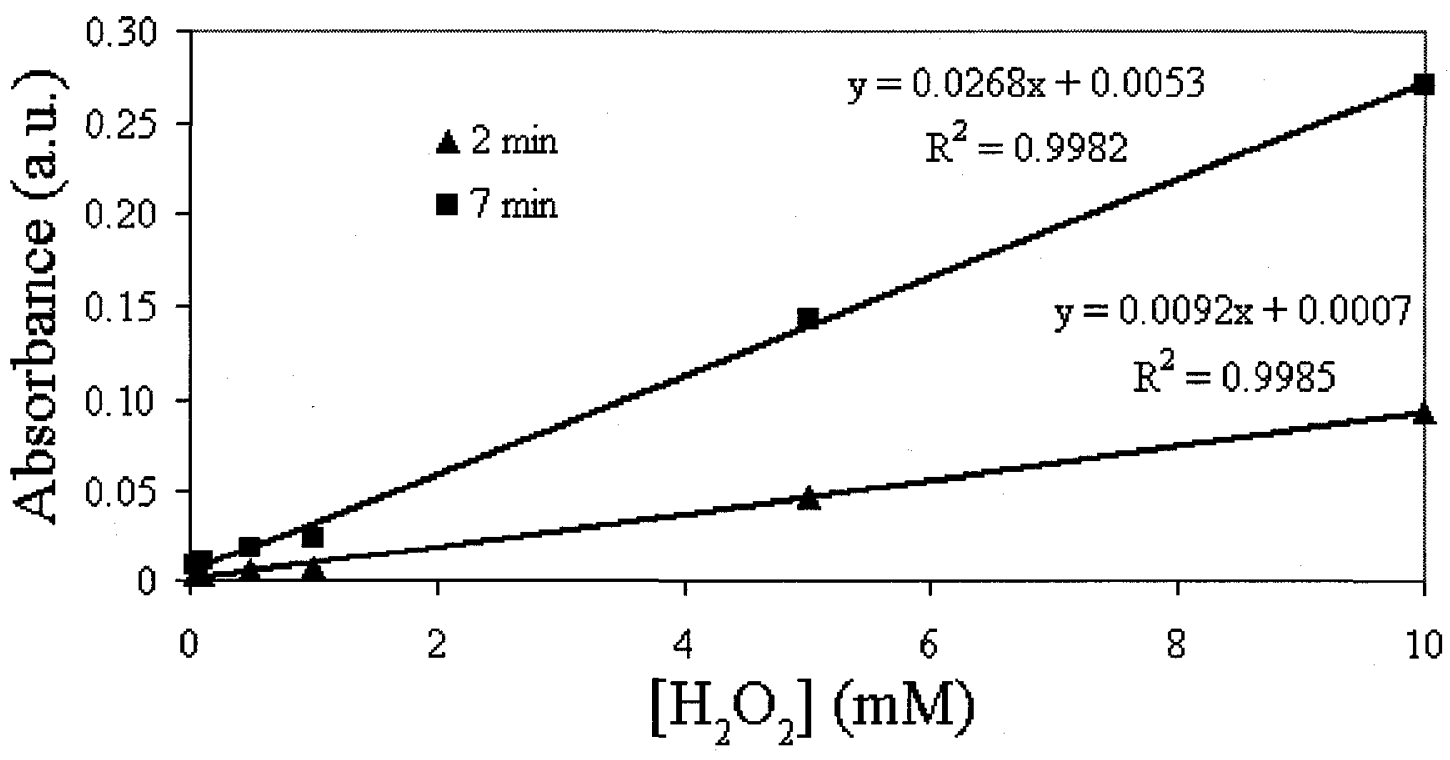

Figure 5.5 - Oxidation of 34 with hydrogen peroxide 


\section{Chapter 5-Device applications based on dinuclear ruthenium complexes}

With the NIR monitoring conditions set, the biosensoring scheme was evaluated by adding glucose and GOX into the equation. Solutions of glucose and GOX enzyme were prepared in the same solvent system and incubated at $37^{\circ} \mathrm{C}$ for 30 minutes to generate the hydrogen peroxide. An aliquot of a $10^{-4} \mathrm{M}$ solution of $\mathbf{3 4}$ was then added to the incubated solutions and the absorbance was monitored at $1200 \mathrm{~nm}$ in real time (Figure 5.6).

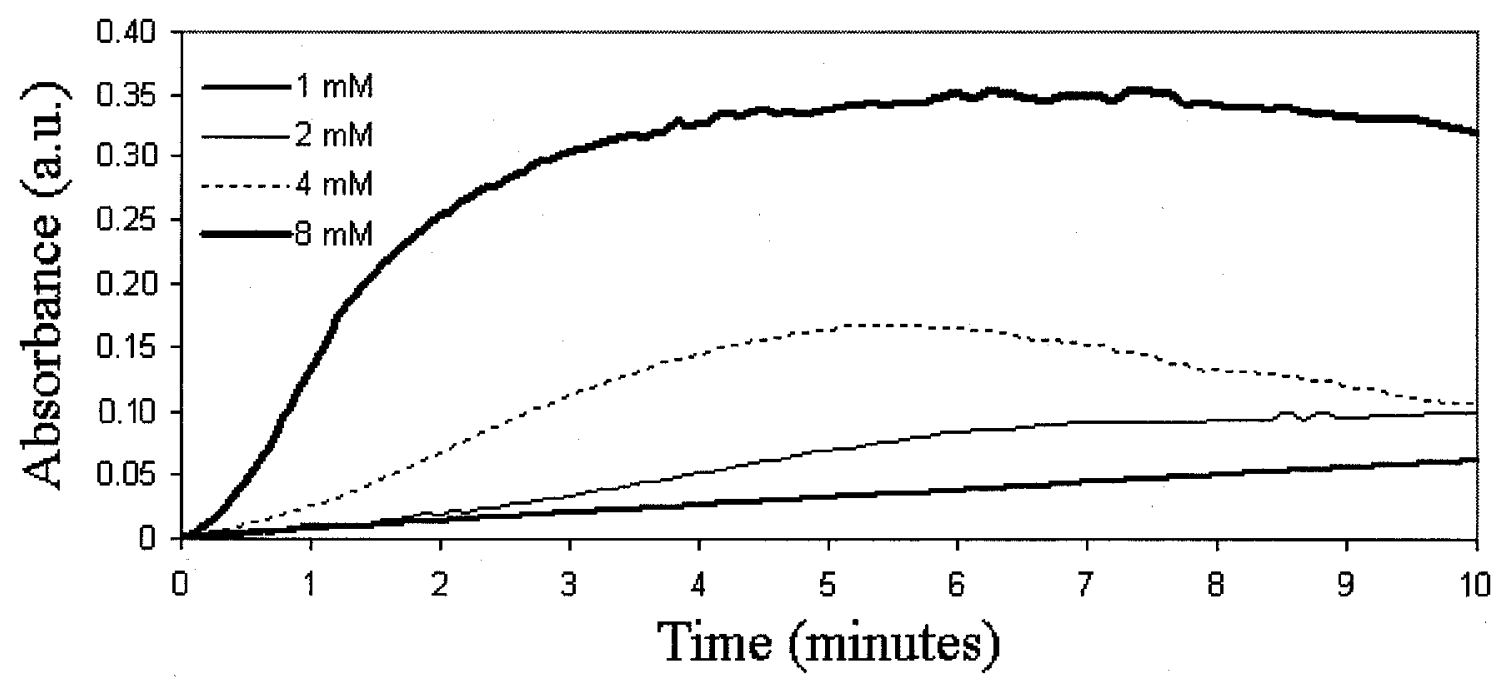

Figure 5.6- Enzymatic oxidation of $\mathbf{3 4}$ by GOX at various glucose concentrations

The resulting calibration curve, using a linear regression, was not as good as previously. However, using a second order polynomial regression, very good fits were obtained. One feature of Figure 5.6 is that the absorbance peaks and begins decreasing with time for the higher glucose concentrations. This is due to the excess of hydrogen peroxide being produced, compared to the amount of complex present, which oxidized the complex to the non NIR active $\mathrm{Ru}^{\text {III }} / \mathrm{Ru}^{\text {III }}$ state. 
It was also found that the current system had poor reproducibility from one preparation to another. This can be justified by the lack of sample mixing during the measurement. Even though the solutions were mixed a few seconds prior to absorbance monitoring, diffusion, which is totally random, governs the rate of oxidation as a molecule must first dock with the enzyme active site. The produced peroxide must then also diffuse towards a DCH-Ru complex to oxidize it. Using a small electrical motor, magnets were mounted on the rotor shaft using plexiglass disks. The motor was mounted under the cuvette holder and mixing of sample was enabled. Given the size of the cuvette, we were limited to micro stir bars. Also, the spinning speed was kept low enough to prevent air bubbles or a vortex to perturbe the optical path. Although the oxidation rate did increase with stirring, it was not sufficient to obtain reproducible results. Incubating the solutions at $37{ }^{\circ} \mathrm{C}$ for a period of time prior to measuring the final absorbance did speed up the oxidation process, but did not significantly improve the reproducibility.

Expecting to obtain better results in a solid state configuration, hydrogels containing the enzyme and DCH-Ru complex were prepared as described in Chapter 4. Even if the initiator used in acrylamide crosslinking reaction oxidized the complex to its NIR active redox state, it could be electrochemically reduced to the ground state. With diffusion being the limiting factor to our sensor sensitivity, preparation of a hydrogel, within a plastic $1 \times 1 \mathrm{~cm}$ cuvette was attempted and modified to obtain a crude flowcell. It was found that the porosity of the gel was not sufficient to enable a reasonable amount of glucose solution to be filtered through. Increasing the pressure only compressed the gel against the opposite opening of the cell. 
Sol-gels, which are known to be porous, could have been tested as a solid sensor matrix if a solution to the cracking and low adhesion to glass substrates would have been established. Crosslinked polyurethane thin films of 41, prepared as described in Chapter 4, were submerged in dilute acidified hydrogen peroxide. Although the films switched rapidly to the mixed-valence state by electrochemical means, the hydrophobicity of the film hindered the migration of the peroxide into the film. Only when using $30 \%$ hydrogen peroxide was the desired oxidative effect achieved. Given that the time scale and harsh conditions required to effectively oxidize the complex to its NIR active state were more demanding than current commercialized glucose sensors, it became apparent that a glucose optical biosensor using dinuclear ruthenium complexes would not create interest for commercialization.

\subsection{2 - Reflective NIR variable optical attenuator}

Transmissive VOAs, thin films and solution configurations, have been employed by previous members of our group ${ }^{263,264}$. Designing a reflective film and evaluating its attenuation properties would shed some light on the optical losses stemming from the dual layers of ITO. The crosslinked complex films, prepared as described in Chapter 4, retained their electrochemical properties relative to the complex monomer itself (Figure 5.7). 
Chapter 5-Device applications based on dinuclear ruthenium complexes

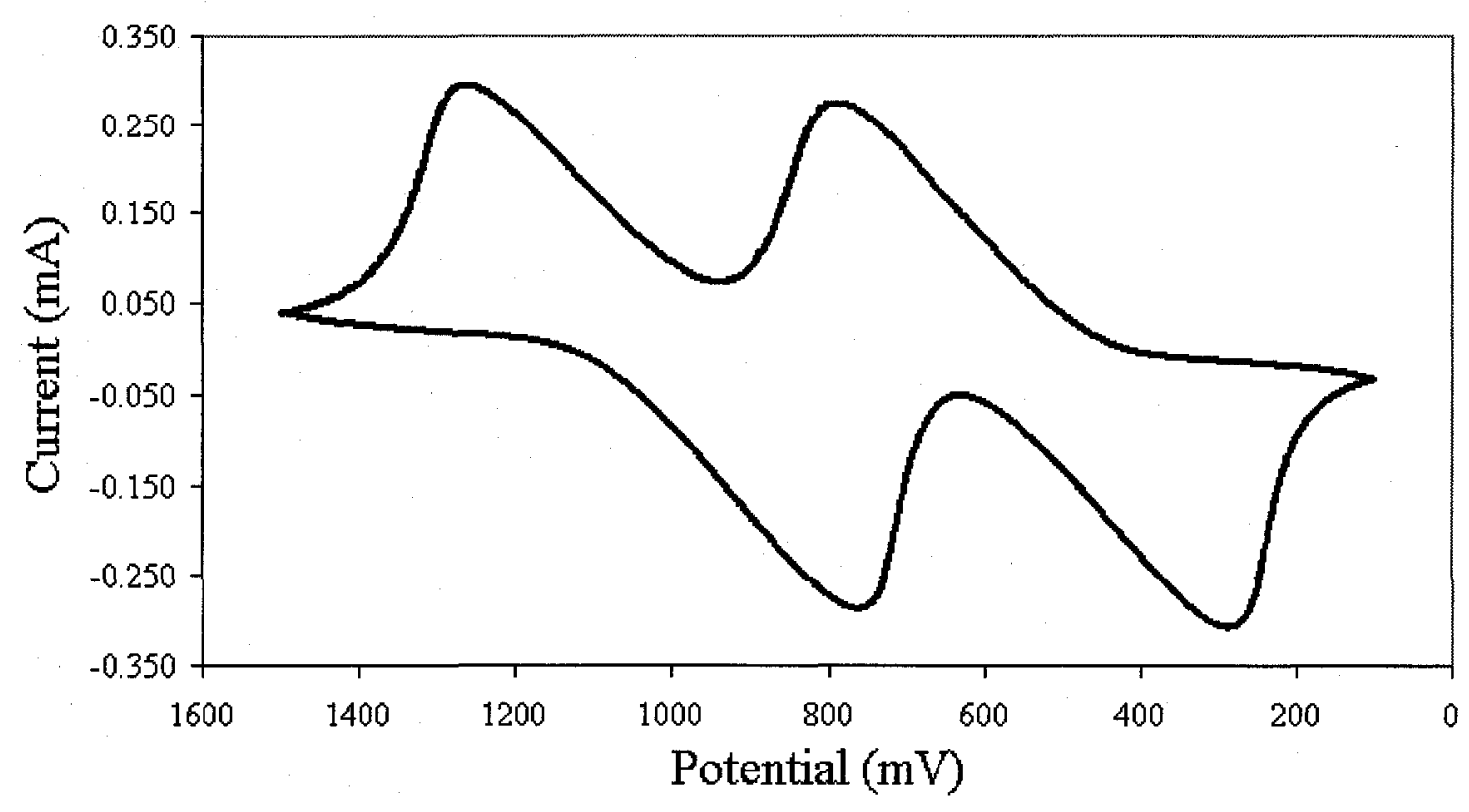

Figure 5.7-CV of crosslinked polyurethane film of $\mathbf{4 1}$

As expected, the redox couples ( $\mathrm{E}_{\mathrm{PA}}$ and $\mathrm{E}_{\mathrm{PC}}$ ) of the crosslinked complex film show a larger separation than of those of the monomer due to slow counter ion diffusion through the polymer network. This effect is expected to lessen with each cycle as the counter ion, once within the polymer network, will tend to remain within this network and will be 'available' for the next cycle. Swelling with the electrolyte solution (e.g., acetonitrile) may also be playing a role in diffusion, since a fresh film is dry and has a slower diffusion rate than the wet film. A 65 -fold increase in peak current generated from the films was also noted which can easily be explained from the much larger working electrode surface area available $\left(1.5 \mathrm{~cm}^{2}\right)$ compared to a 1.5 -mm-diameter platinum disk electrode used for $\mathrm{CV}$ measurements.

Chronoamperometry of the films was monitored at the $1550 \mathrm{~nm}$ wavelength by cycling the potential from $-0.5 \mathrm{~V}$ to $0.8 \mathrm{~V}$. Silvered films based on 41 showed about $80 \%$ optical contrast (recorded in a static mode), which is defined as the difference in 
transmission between the two redox states considered at a particular wavelength. The absorbance of the ground state was set as the baseline $(100 \%$ transmission, without consideration of any optical loss due to absorption and/or scattering). Since the intensity of the reflected light depends on the angle of incident light, the signal strength was probed within a range of incident angles from $30^{\circ}$ to $70^{\circ}$. The highest signal strength was attained with an incident angle of $56^{\circ}$. Thus, the reflectance was measured at this incident angle. Prolonged switching between the two states showed that the polymeric films posessed good cycling stability. In fact, the attenuation improved slightly with time, due to swelling of the film from being submerged in an electrolytic solution as well as the migration of the counter anion factor.

The attenuation of an EC material can be evaluated using the following equation:

$$
\text { Attenuation }=10 \log \left(\frac{T_{b}}{T_{c}}\right)
$$

where $T_{b}$ is the transmission of the bleached state $\left(\mathrm{Ru}^{\mathrm{II}} / \mathrm{Ru} \mathrm{u}^{\mathrm{II}}\right.$ state, approximately $\left.100 \%\right)$ and $T_{c}$ is the transmission of the colored state. For example, an $80 \%$ optical contrast would translate into an attenuation of $7 \mathrm{~dB}$. The attenuation is dependent on film thickness and taking the $400 \mathrm{~nm}$ thickness into consideration, the intrinsic attanuation is $17.5 \mathrm{~dB} / \mu \mathrm{m}$. When the film is rapidly switched between redox states, the attenuation range obtained is dynamic and normally lower since the oxidation is incomplete due to the time limitations. Using a 5 second stepping time, a dynamic range attenuation of 14.5 $\mathrm{dB} / \mu \mathrm{m}$ was achieved (Figure 5.8), $15 \%$ lower than in the static mode, meaning that $85 \%$ 
Chapter 5-Device applications based on dinuclear ruthenium complexes

of the EC is oxidized in 5 seconds. As expected, similar films that were not silvered only displayed an attenuation of $1.6 \mathrm{~dB}$, due to partial NIR reflection from the ITO WE.

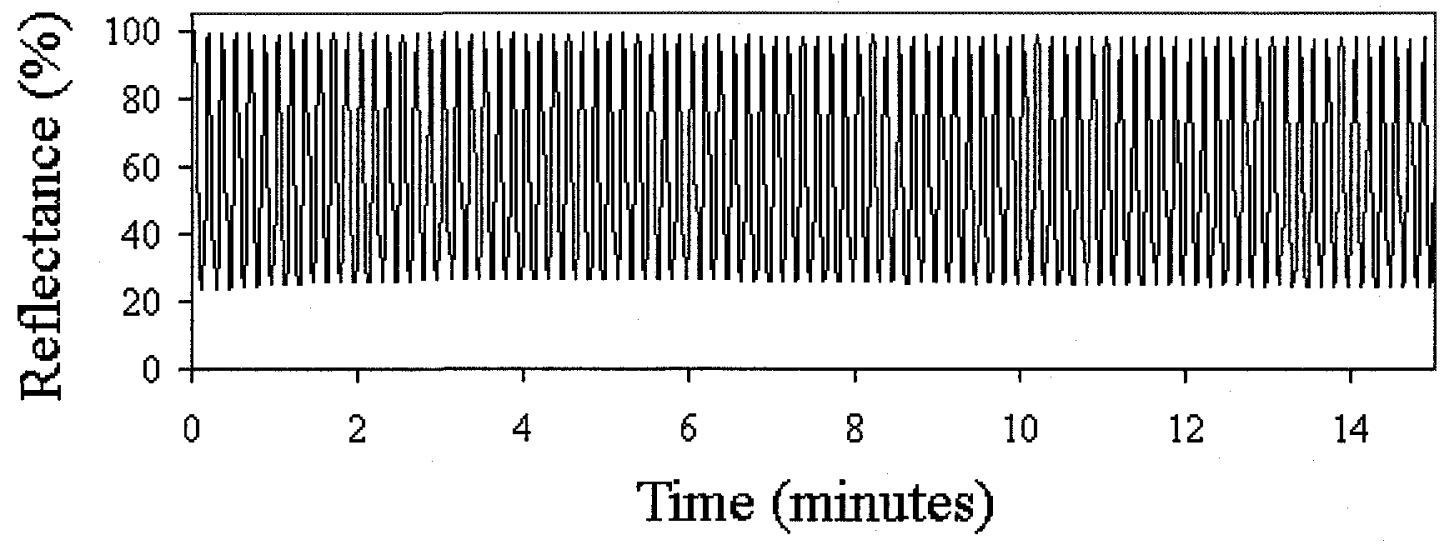

Figure 5.8 - Chronoamperometry of a crosslinked polyurethane film of 41 using a 5 second stepping time

In comparison with the transmissive device, the similar ruthenium complex gave attenuation values of $0.05 \mathrm{~dB} / \mu \mathrm{m}$ in a $100-\mu \mathrm{m}$ (path length) solution-based device assembly ${ }^{264}$ and $4.9-5.4 \mathrm{~dB} / \mu \mathrm{m}$ in a film-based device ${ }^{134}$. Also, optical attenuation of the dinuclear molybdenum complex, when thickness is taken into consideration, becomes $0.01 \mathrm{~dB} / \mu \mathrm{m}^{70}$. While some variation can be accounted by the differences in molar extinction coefficients of the complexes used, it is clear that the device configuration also plays a role in performance. When the stepping time was reduced to 2.5 seconds, a drop in dynamic attenuation range of $10.9 \mathrm{~dB} / \mu \mathrm{m}$ was observed (Figure 5.9). 
Chapter 5 - Device applications based on dinuclear ruthenium complexes

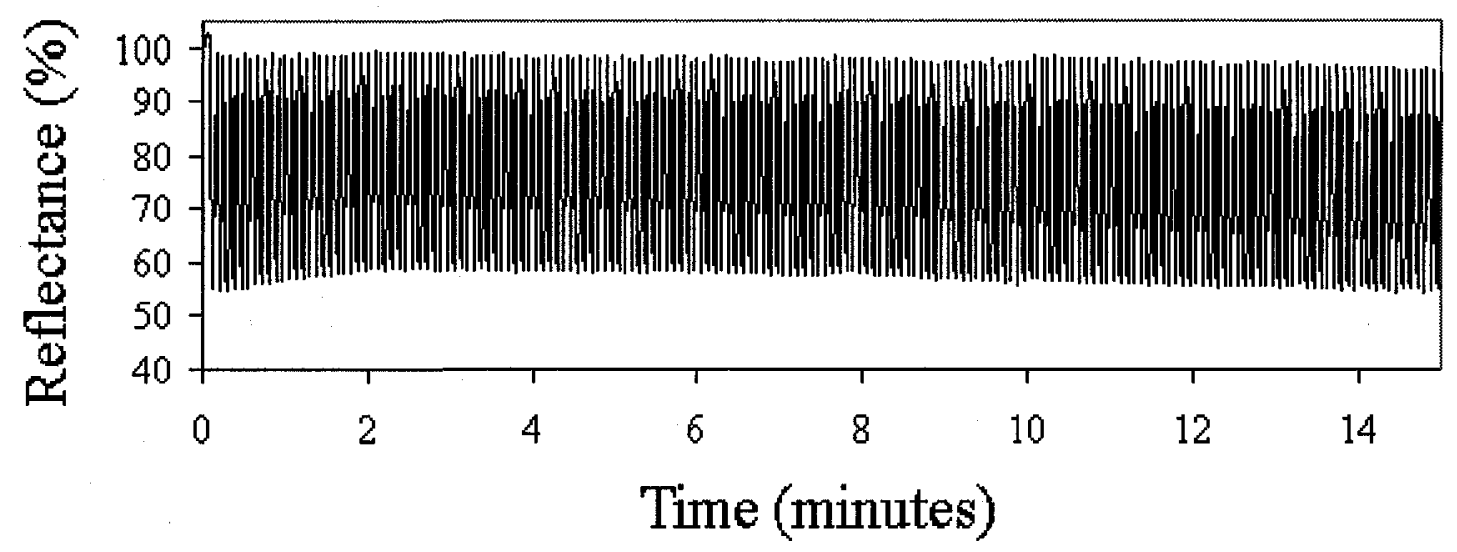

Figure 5.9 - Chronoamperometry of a crosslinked polyurethane film of 41 using a 2.5 second stepping time

A common practice is to use higher potentials in order to reduce the response time ${ }^{265}$, but biurea-based dinuclear ruthenium complexes can be further oxidized to the $\mathrm{Ru}^{\mathrm{III}} / \mathrm{Ru}{ }^{\mathrm{III}}$ specie which, in this case, forms at potentials above $850 \mathrm{mV}$ (based on Figure 5.7) and does not express NIR activity. Since the redox process must pass through the mixed-valence state, it is probable that faster stepping time and higher potentials could generate the NIR active state exclusively. Improving the conductivity within the film should yield faster switching times.

The wavelength of $1550 \mathrm{~nm}$ is a major telecommunication band. Using the biurea complex 39, similar crosslinked films were prepared on silvered ITO. Strangely, a significant portion of the EC material leached from the film when being washed with $\mathrm{MeCN}$, indicating an incomplete curing. Increasing the temperature resulted in the initially brown-purple films to turn green which were no longer electrochromic. Having lost so much EC component, it was no surprise that the intrinsic dynamic attenuation of the resulting films, using a 5 second stepping time, was only 5.1 (Figure 5.10) and 3.9 
$\mathrm{dB} / \mu \mathrm{m}$ (Figure 5.11) at the 1310 and $980 \mathrm{~nm}$ bands respectively. In the case of the 980 $\mathrm{nm}$ band, the MLCT of the $\mathrm{Ru}^{\mathrm{III}} / \mathrm{Ru}^{\mathrm{III}}$ was utilized and the redox cycling was done between $-0.5 \mathrm{~V}$ to $0.9 \mathrm{~V}$.

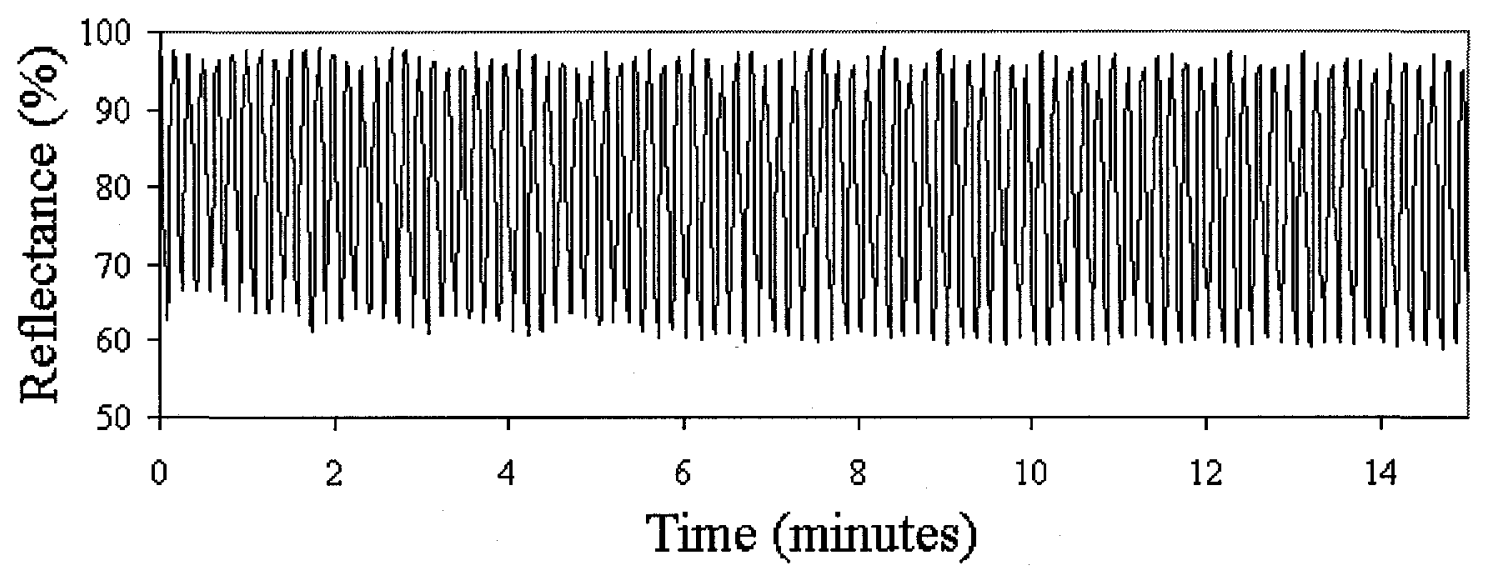

Figure 5.10 - Chronoamperometry at $1310 \mathrm{~nm}$ of a crosslinked polyurethane film of $\mathbf{3 9}$ using a 5 second stepping time

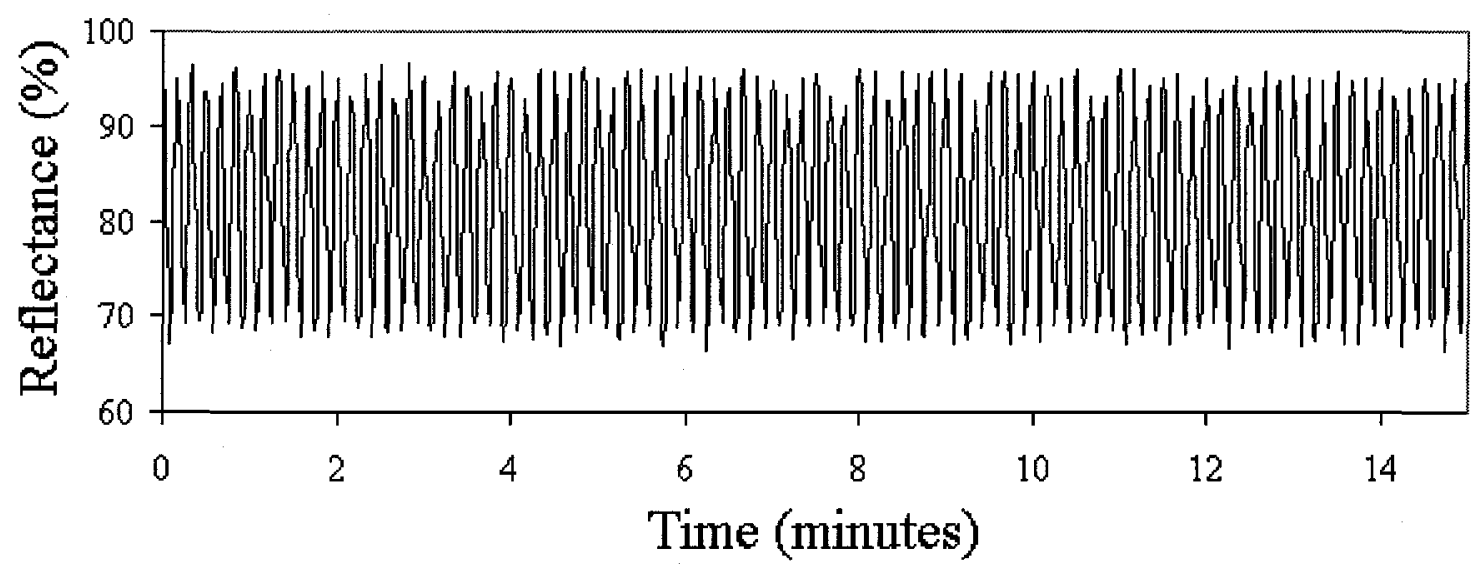

Figure 5.11 - Chronoamperometry at $980 \mathrm{~nm}$ of a crosslinked polyurethane film of $\mathbf{3 9}$ using a 5 second stepping time 


\section{$5.3-$ Conclusion}

The working concept of a glucose biosensor by monitoring the NIR absorbance at $1200 \mathrm{~nm}$ of a biurea DCH-Ru complex was demonstrated. The results point to a viable system; however the slow response time and reproducibility issues could not be overcome by increasing the temperature, the enzyme concentration, the incubation time or agitation.

Thin films of 41 prepared in Chapter 4 displayed a dynamic range of $14.7 \mathrm{~dB} / \mu \mathrm{m}$ at $1550 \mathrm{~nm}$ while similar films of 39 only offered a dynamic range of 5.1 and $3.9 \mathrm{~dB} / \mu \mathrm{m}$ at the 1310 and $980 \mathrm{~nm}$ telecomunication bands due to low EC content (incomplete crosslinking).

It was shown that a three-fold increase in optical attenuation was achieved for ruthenium complex polymer films when operating in a reflective mode and cycling from -0.5 to $0.8 \mathrm{~V}$ compared to a transmissive device based on similar EC materials. Faster response time could be expected if higher oxidation potentials were used, but only if the mixed-valence state $\left(\mathrm{Ru}^{\mathrm{II}} / \mathrm{Ru}^{\mathrm{III}}\right)$ can be generated selectively. It is expected that resolving the crosslinking issue with complex $\mathbf{3 9}$ will result in superior attenuation at both 1310 and $980 \mathrm{~nm}$ telecomunication wavelengths. Larger dynamic range in optical attenuation and faster switching can be expected for an electrochromic VOA with a well-designed reflective configuration. 


\section{4 - Experimental}

\section{Materials}

Tris base, $\beta$-D-glucose, glucose oxidase (type VII from Aspergillus niger, 192,000-217,000 units/g), silver nitrate and potassium sodium tartrate (Rochelle salt) were purchased from Aldrich and used as received. The enzyme was stored at $-20^{\circ} \mathrm{C}$. The two-part conductive silver epoxy paste was purchased from a local electronics shop.

\section{Sample preparations for glucose sensing}

Tris base buffer $\mathrm{pH} 7.4$ was prepared by dissolving 0.01 mole of base in $90 \mathrm{~mL}$ of $\mathrm{DW}$, adjusting the $\mathrm{pH}$ with concentrated $\mathrm{HCl}$, transferring the solution to a $100 \mathrm{~mL}$ volumetric flask and completing the volume with DW. The enzyme was dissolved in Tris buffer ( $5 \mathrm{mg} / \mathrm{mL}$ ) to create a stock solution containing $960-1085$ units $/ \mathrm{mL}$ of enzyme.

The stock solution of enzyme $(0.3 \mathrm{~mL}), \mathrm{MeCN}(0.1 \mathrm{~mL})$ and a known concentration of glucose were adjusted to $1 \mathrm{~mL}$ using Tris buffer and incubated at $37^{\circ} \mathrm{C}$ for 30 minutes and degassed with nitrogen gas for one minute. A ruthenium complex aliquot was added so that the concentration of the complex is $10^{-4} \mathrm{M}$. The solution was mixed a few seconds, transferred to a quartz cuvette, the absorbance zeroed at $1200 \mathrm{~nm}$ and monitored for 10 minutes. This was repeated for various glucose concentrations.

\section{Optical attenuation setup and measurement}

The electrochromic films were prepared as described in Chapter 4 and their thickness was measured wity a Tencor Instruments Alpha-step 200 profiler. The 
Chapter 5-Device applications based on dinuclear ruthenium complexes

electrochemical and spectroelectrochemical properties of the films were investigated using a Bioanalytical Systems ${ }^{\mathrm{TM}}$ BAS100 potentiostat coupled to a Perkin Elmer Lambda 900 spectrophotometer. Reflectance measurements were done using a Harrick Scientific $^{\mathrm{TM}}$ variable angle specular reflectance module and an in-house cuvette holder (see Appendix 6).

To measure the CV of the thin but long films, a specialized glass tube with inward blown spikes to hold the glass slide in place as well as two downward open spikes as ports for the other two electrodes (CE and RE). The working electrode lead was attached either by using an alligator clip directly to the ITO or by attaching a section of copper wire to the bare ITO using conductive silver epoxy paste, which was cured at $60^{\circ} \mathrm{C}$ for two hours and left to harden overnight at room temperature.

For silvering of the glass side of ITO glass strips, the Rochelle Salts process was used $^{266}$. The ITO layer was first masked using clear adhesive tape and then placed, taped side facing down, in a glass Petri dish. A mixture of equal parts of a silver nitrate/ammonium hydroxide aqueous solution and a silver nitrate/potassium sodium tartrate aqueous solution was poured over the exposed slides to completely cover them. The silver deposition proceeded at $38^{\circ} \mathrm{C}$. Once completed, the ITO strips were taken out and washed off using distilled water. The silvering process could be repeated to obtain a thicker layer of silver but it must be done while the silver layer is still damp. Since only the ITO surface was masked, silver was also deposited on the cross-section side of the ITO glass strips. It was necessary to remove this extra silver (using a rotary tool and polishing head) as it became apparent that an electrical contact with the ITO existed. 
Failure to break the contact while applying a positive potential resulted in oxidation of the silver, effectively destroying the mirror finish.

The optical contrast of the films (ITO and silvered ITO) was measured using a Harrick Scientific ${ }^{\mathrm{TM}}$ variable angle specular reflectance module and an hand built inhouse plexiglass cuvette holder (see appendix 6). The coated ITO strip $(8 \times 40 \mathrm{~mm})$ was submerged in a four-sided $1-\mathrm{cm}$ quartz cuvette containing $0.1 \mathrm{M} \mathrm{TBAH}$ in acetonitrile as supporting electrolyte solution. Silver and platinum wires were used as pseudo reference and counter electrodes, respectively. The $\mathrm{Ru}^{\mathrm{II}} / \mathrm{Ru}^{\mathrm{II}}$ state of the complex in the polymer film (electrochemically reduced at $-0.5 \mathrm{~V}$ ) was used as the background correction. Since the intensity of the reflected light depends on the angle of incident light, the signal strength was probed within a range of incident angles from $30^{\circ}$ to $70^{\circ}$. The highest signal strength was attained with an incident angle of $56^{\circ}$. Thus, the reflectance was measured at this incident angle, while the polymer film was electrochemically oxidized and reduced between the two oxidation states $\left(\mathrm{Ru}^{\mathrm{II}} / \mathrm{Ru}^{\mathrm{II}}\right.$ and $\mathrm{Ru} / \mathrm{Ru} \mathrm{III}^{\mathrm{III}}$ states). 


\section{Claim to original research}

NIR active dinuclear ruthenium complexes have been known for many years and some success has been demonstrated towards making film-forming macromolecules containing this moiety, by complexing ligand oligomers. In considering functional groups for use in polymerization, long chain aliphatic hydroxyl ligands were chosen to ensure that the hydroxyl group would not be hindered by the bulky $\mathrm{Ru}(\mathrm{bpy})_{2}$ groups. Various classes of polymerizations were explored, but only crosslinked polymers gave sasifactory films that could be used in devices.

The variable optical attenuator device application is the usual end point of optoelectronic research and such was the case in the scope of this project. The common transmissive configuration was replaced with a reflective one and a three fold increase in intrinsic attenuation was achieved compared to similar transmissive devices. These results were published in the Journal of Solid State Electrochemistry ${ }^{267}$.

The preparation of low redox potential complexes resulted in readily oxidizable materials which are adequate in optical biosensoring schemes. The working concept of a glucose biosensor, based on the enzyme glucose oxidase, was demonstrated. Even though the response time was somewhat slow, this scheme could be adapted to other substrates, based on other peroxide-forming oxidases. These results were published in Organic Letters $^{268}$. 
The IVTC transition observed in DCH-Ru complexes should theoretically be present in other dinuclear metal complexes based on the DCH bridging ligand, more so if the metal considered has two redox states that are linked through a one-electron redox process. Dinuclear complexes of platinum were successfully prepared and their phosphorescent properties studied. However, variations of the bridging ligand had little effect on the emission wavelength, but modifying the peripheral ligand had a significant impact on the emission color. Unfortunately, the second goal to achieve NIR emission was not reached, although deep red emission was observed from one complex. With many peripheral ligands accessible via simple synthetic routes, the potential of breaching the NIR emission barrier, at $700 \mathrm{~nm}$, is tangible. 


\section{References}

1. Platt, J. R., Journal of Chemical Physics 1961, 34, 862-3.

2. Monk, P. M. S.; Mortimer, R. J.; Rosseinsky, D. R., Electrochromism: Fundamentals and Applications. VCH, Weinheim, 1995, p 217.

3. Monk, P. M. S.; Mortimer, R. J.; Rosseinsky, D. R., Electrochromism and Electrochromic Devices. Cambridge University Press, New York, 2007, p 483.

4. Izutsu, K., Electrochemistry in Nonaqueous Solutions. Wiley-VCH, Weinheim, 2002, p 330.

5. Gritzner, G.; Kuta, J., Pure and Applied Chemistry 1984, 56, 461-466.

6. Connelly, N. G.; Geiger, W. E., Chemical Reviews 1996, 96, 877-910.

7. Dautremont-Smith, W. C., Displays 1982, 3, 3-22.

8. Dautremont-Smith, W. C., Displays 1982, 3, 67-80.

9. Baucke, F. G. K.; Bange, K.; Gambke, T., Displays 1988, 9, 179-87.

10. Kang, K. S.; Shay, J. L., Journal of the Electrochemical Society 1983, 130, 766-9.

11. Hiruta, Y.; Kitao, M.; Yamada, S., Japanese Journal of Applied Physics, Part 1 1984, 23, 1624-7.

12. Talledo, A.; Andersson, A. M.; Granqvist, C. G., Journal of Applied Physics 1991, 69, 3261-5.

13. Fu, Z.; Kong, J.; Qin, Q.; Tian, Z., Science in China, Series B 1999, 42, 493-500.

14. Lee, G. R.; Crayston, J. A., Journal of Materials Chemistry 1991, 1, 381-6.

15. Polo da Fonseca, C. N.; De Paoli, M. A.; Gorenstein, A., Advanced Materials 1991, 3, 553-5.

16. Isidorsson, J.; Granqvist, C. G., Solar Energy Materials and Solar Cells 1996, 44, 375-381.

17. Richardson, T. J.; Slack, J. L.; Rubin, M. D., Electrochimica Acta 2001, 46, 22812284.

18. Ozer, N.; Tepehan, F., Solar Energy Materials and Solar Cells 1999, 56, 141-152.

19. Pifer, J. H.; Sichel, E. K., Journal of Electronic Materials 1979, 9, 129-40.

20. Owen, J. F.; Teegarden, K. J.; Shanks, H. R., Physical Review B: Condensed Matter and Materials Physics 1978, 18, 3827-37.

21. Deneuville, A.; Gerard, P., Journal of Electronic Materials 1978, 7, 559-88.

22. Taylor, D. J.; Cronin, J. P.; Allard, L. F. J.; Birnie III, D. P., Chemistry of Materials 1996, 8, 1396-1401.

23. Deepa, M.; Srivastava, A. K.; Singh, S.; Agnihotry, S. A., Journal of Materials Research 2004, 19, 2576-2585.

24. Bange, K.; Gambke, T., Advanced Materials (Weinheim, Germany) 1990, 2, 10-16.

25. Goettsche, J.; Hinsch, A.; Wittwer, V., Solar Energy Materials and Solar Cells 1993, 31, 415-28.

26. Ohtani, B.; Masuoka, M.; Atsumi, T.; Nishimoto, S.; Kagiya, T., Chemistry Express 1988, 3, 319-22.

27. Ozkan, E.; Lee, S.-H.; Liu, P.; Tracy, C. E.; Tepehan, F. Z.; Pitts, J. R.; Deb, S. K., Solid State Ionics 2002, 149, 139-146.

28. Neff, V. D., Journal of the Electrochemical Society 1978, 125, 886-7.

29. Yano, Y.; Kinugasa, N.; Yoshida, H.; Fujino, K.; Kawahara, H., Proceedings Electrochemical Society 1990, 90-2, 125-36. 
30. Ellis, D.; Eckhoff, M.; Neff, V. D., Journal of Physical Chemistry 1981, 85, 122531.

31. Ho, K.-C., Proceedings - Electrochemical Society 1994, 94-2, 170-84.

32. Gomathi, H.; Rao, G. P., Journal of Applied Electrochemistry 1990, 20, 454-6.

33. Kellawi, H.; Rosseinsky, D. R., Journal of Electroanalytical Chemistry and Interfacial Electrochemistry 1982, 131, 373-6.

34. Miller, L. L.; Duan, R. G.; Hong, Y.; Tabakovic, I., Chemistry of Materials 1995, 7, 1552-7.

35. Almlof, J. E.; Feyereisen, M. W.; Jozefiak, T. H.; Miller, L. L., Journal of the American Chemical Society 1990, 112, 1206-1214.

36. Hu, Y.-z.; Chiang, L.-j. J., Journal of Photochemistry and Photobiology, A: Chemistry 1996, 94, 37-41.

37. Qiao, W.; Zheng, J.; Wang, Y.; Zheng, Y.; Song, N.; Wan, X.; Wang, Z. Y., Organic Letters 2008, 10, 641-644.

38. Moskalev, P. N.; Kirin, I. S., Optika i Spektroskopiya 1970, 29, 414-15.

39. Zhang, J.; Lu, F.; Huang, H.; Wang, J.; Yu, H. a.; Jiang, J.; Yan, D.; Wang, Z., Synthetic Metals 2005, 148, 123-126.

40. Kim, Y. H.; Jeong, D. H.; Kim, D.; Jeoung, S. C.; Cho, H. S.; Kim, S. K.; Aratani, N.; Osuka, A., Journal of the American Chemical Society 2001, 123, 76-86.

41. Miyahara, T.; Nakatsuji, H.; Hasegawa, J.; Osuka, A.; Aratani, N.; Tsuda, A., Journal of Chemical Physics 2002, 117, 11196-11207.

42. Tsuda, A.; Furuta, H.; Osuka, A., Journal of the American Chemical Society 2001, 123, 10304-21.

43. Tsuda, A.; Osuka, A., Science 2001, 293, 79-82.

44. Cho, H. S.; Jeong, D. H.; Cho, S.; Kim, D.; Matsuzaki, Y.; Tanaka, K.; Tsuda, A.; Osuka, A., Journal of the American Chemical Society 2002, 124, 14642-14654.

45. Ou, Z.; E, W.; Shao, J.; Burn, P. L.; Sheehan, C. S.; Walton, R.; Kadish, K. M.; Crossley, M. J., Journal of Porphyrins and Phthalocyanines 2005, 9, 142-151.

46. Kobayashi, N.; Numao, M.; Kondo, R.; Nakajima, S.; Osa, T., Inorganic Chemistry 1991, 30, 2241-4.

47. Paolesse, R.; Jaquinod, L.; Della Sala, F.; Nurco, D. J.; Prodi, L.; Montalti, M.; Di Natale, C.; D'Amico, A.; Di Carlo, A.; Lugli, P.; Smith, K. M., Journal of the American Chemical Society 2000, 122, 11295-11302.

48. Silverstein, R. M.; Webster, F. X.; Kiemle, D. J., Spectrometric Identification of Organic Compounds. John Wiley \& Sons, Hoboken, 2005, p 512.

49. Chiang, C. K.; Druy, M. A.; Gau, S. C.; Heeger, A. J.; Louis, E. J.; MacDiarmid, A. G.; Park, Y. W.; Shirakawa, H., Journal of the American Chemical Society 1978, 100, 1013-1015.

50. Elsenbaumer, R. L.; Jen, K. Y.; Oboodi, R., Synthetic Metals 1986, 15, 169-74.

51. Mastragostino, M., Applications of Electroactive Polymers. Chapman and Hall, London, 1993, p 354.

52. Cotton, F. A.; Wilkinson, G., Advanced Inorganic Chemistry: A Comprehensive Text. John Wiley \& Sons, New York, 1980, p 1396.

53. Laporte, O.; Meggers, W. F., Journal of the Optical Society of America 1925, 11, 459-64. 
54. McCleverty, J. A., Metal 1,2-dithiolene and related complexes in Progress in Inorganic Chemistry. John Wiley \& Sons, New York, 1968, Vol. 10, p 49-221.

55. Schrauzer, G. N.; Mayweg, V. P., Journal of the American Chemical Society 1965, 87, 3585-92.

56. Baker-Hawkes, M. J.; Billig, E.; Gray, H. B., Journal of the American Chemical Society 1966, 88, 4870-5.

57. Williams, R.; Billig, E.; Waters, J. H.; Gray, H. B., Journal of the American Chemical Society 1966, 88, 43-50.

58. Shupack, S. I.; Billig, E.; Clark, R. J. H.; Williams, R.; Gray, H. B., Journal of the American Chemical Society 1964, 86, 4594-602.

59. Creutz, C.; Taube, H., Journal of the American Chemical Society 1973, 95, 108694.

60. Laye, R. H.; Couchman, S. M.; Ward, M. D., Inorganic chemistry 2001, 40, 408992.

61. Kasack, V.; Kaim, W.; Binder, H.; Jordanov, J.; Roth, E., Inorganic Chemistry 1995, 34, 1924-33.

62. Rocha, R. C.; Toma, H. E., Canadian Journal of Chemistry 2001, 79, 145-156.

63. Mosher, P. J.; Yap, G. P.; Crutchley, R. J., Inorganic chemistry 2001, 40, 1189-95.

64. Rastegar, M. F.; Todd, E. K.; Tang, H.; Wang, Z. Y., Organic Letters 2004, 6, 4519-4522.

65. Haga, M.; Dodsworth, E. S.; Lever, A. B. P., Inorganic Chemistry 1986, 25, 44753.

66. Lee, S.-M.; Marcaccio, M.; McCleverty, J. A.; Ward, M. D., Chemistry of Materials 1998, 10, 3272-3274.

67. Harden, N. C.; Humphrey, E. R.; Jeffery, J. C.; Lee, S.-M.; Marcaccio, M.; McCleverty, J. A.; Rees, L. H.; Ward, M. D., Journal of the Chemical Society, Dalton Transactions 1999, 2417-2426.

68. Bayly, S. R.; Humphrey, E. R.; de Chair, H.; Paredes, C. G.; Bell, Z. R.; Jeffery, J. C.; McCleverty, J. A.; Ward, M. D.; Totti, F.; Gatteschi, D.; Courric, S.; Steele, B. R.; Screttas, C. G., Journal of the Chemical Society, Dalton Transactions 2001, 1401-1414.

69. McDonagh, A. M.; Ward, M. D.; McCleverty, J. A., New Journal of Chemistry 2001, 25, 1236-1243.

70. McDonagh, A. M.; Bayly, S. R.; Riley, D. J.; Ward, M. D.; McCleverty, J. A.; Cowin, M. A.; Morgan, C. N.; Varrazza, R.; Penty, R. V.; White, I. H., Chemistry of Materials 2000, 12, 2523-2524.

71. Kowallick, R.; Jones, A. N.; Reeves, Z. R.; Jeffery, J. C.; McCleverty, J. A.; Ward, M. D., New Journal of Chemistry 1999, 23, 915-921.

72. Barthram, A. M.; Cleary, R. L.; Kowallick, R.; Ward, M. D., Chemical Communications 1998, 2695-2696.

73. Qi, Y.; Desjardins, P.; Wang, Z. Y., Journal of Optics A: Pure and Applied Optics 2002, 4, S273-S277.

74. Azens, A.; Granqvist, C. G., Journal of Solid State Electrochemistry 2003, 7, 64-68.

75. Lampert, C. M., Solar Energy Materials and Solar Cells 1998, 52, 207-221.

76. Rosseinsky, D. R.; Mortimer, R. J., Advanced Materials 2001, 13, 783-793. 
77. Inaba, H.; Iwaku, M.; Nakase, K.; Yasukawa, H.; Seo, I.; Oyama, N., Electrochimica Acta 1995, 40, 227-32.

78. Leventis, N.; Chen, M.; Liapis, A. I.; Johnson, J. W.; Jain, A., Journal of the Electrochemical Society 1998, 145, L55-L58.

79. Yasuda, A.; Seto, J., Journal of Electroanalytical Chemistry and Interfacial Electrochemistry 1988, 247, 193-202.

80. Panero, S.; Scrosati, B.; Baret, M.; Cecchini, B.; Masetti, E., Solar Energy Materials and Solar Cells 1995, 39, 239-46.

81. Passerini, S.; Scrosati, B.; Hermann, V.; Holmblad, C.; Bartlett, T., Journal of the Electrochemical Society 1994, 141, 1025-8.

82. Jelle, B. P.; Hagen, G.; Sunde, S.; Oedegaard, R., Synthetic Metals 1993, 54, 31520.

83. Takeyasu, T.; Takase, S.; Shimizu, Y., Chemical Sensors 2006, 22, 97-99.

84. Apetrei, C.; Casilli, S.; De Luca, M.; Valli, L.; Jiang, J.; Rodriguez-Mendez, M. L.; De Saja, J. A., Colloids and Surfaces, A: Physicochemical and Engineering Aspects 2006, 284+285, 574-582.

85. Walczak, R. M.; Reynolds, J. R., Advanced Materials 2006, 18, 1121-1131.

86. de Saja, J. A.; Rodriguez-Mendez, M. L., Advances in Colloid and Interface Science 2005, 116, 1-11.

87. Demiryont, H., Proceedings of SPIE-The International Society for Optical Engineering 1991, 1536, 2-28.

88. Buyan, M.; Brühwiler, P. A.; Azens, A.; Gustavsson, G.; Karmhag, R.; Granqvist, C. G., International Journal of Industrial Ergonomics 2006, 36, 11-16.

89. Heckner, K.-H.; Kraft, A., Solid State Ionics 2002, 152-153, 899-905.

90. Sapers, S. P.; Cumbo, M. J.; Sargent, R. B.; Raksha, V. P.; Wang, L. S.; Lahaderne, R. B.; Hichwa, B. P., Annual Technical Conference Proceedings - Society of Vacuum Coaters 1996, 39th, 248-255.

91. Nazeeruddin, M. K.; Grätzel, M., Conversion and storage of solar energy using dye-sensitized nanocrystalline $\mathrm{TiO}_{2}$ cells. In Comprehensive Coordination Chemistry II: From Biology to Nanotechnology. Elsevier, Oxford, 2003, Vol. 9, p 719-758.

92. Dai, J.; Jiang, X.; Wang, H.; Yan, D., Applied Physics Letters 2007, 91, 253503/1$253503 / 3$.

93. DeBreuil, R.; Nord, S. P.; Cavinato, A. G.; Mayes, D. M.; Lin, M.; Rasco, B. A., Abstracts of Papers, 223rd ACS National Meeting, Orlando, FL, United States, April 7-11, 2002 2002, CHED-264.

94. Bonnett, R., Metal complexes for photodynamic therapy. In Comprehensive Coordination Chemistry II: From Biology to Nanotechnology. Elsevier, Oxford, 2003, Vol. 9, p 945-1003.

95. Barone Paul, W.; Baik, S.; Heller Daniel, A.; Strano Michael, S., Nature materials 2005, 4, 86-92.

96. Costello, K. A. GaAs photocathode wavelength extension for back-thinned silicon CMOS OR CCD image array sensors. 2004-7640492005161703, 20040123., 2005.

97. Siddiqi, M. A.; Kilduff, G. M.; Gearhart, J. D., J Microsc FIELD Full Journal Title:Journal of microscopy 2003, 212, 132-43.

98. Norton, P., Opto-Electronics Review 2006, 14, 1-10. 
99. Chandrasekhar, P.; Zay, B. J.; Ross, D.; McQueeney, T.; Birur, G. C.; Swanson, T.; Kauder, L.; Douglas, D., Far-IR-through-Cisible Electrochromics Based on Conducting Polymers for Spacecraft Thermal Control and Military Uses. In Chromogenic Phenomena in Polymers: Tunable Optical Properties. Oxford University Press, Washington DC, 2005, p 434 pp.

100. Ward, M. D., Journal of Solid State Electrochemistry 2005, 9, 778-787.

101. Wang, Z. Y.; Zhang, J.; Wu, X.; Birau, M.; Yu, G.; Yu, H.; Qi, Y.; Desjardins, P.; Meng, X.; Gao, J. P.; Todd, E.; Song, N.; Bai, Y.; Beaudin, A. M. R.; LeClair, G., Pure and Applied Chemistry 2004, 76, 1435-1443.

102. Card, R. J.; Neckers, D. C., Journal of the American Chemical Society 1977, 99, 7733-4.

103. Muehlebach, A.; Bernhard, P.; Buehler, N.; Karlen, T.; Ludi, A., Journal of Molecular Catalysis 1994, 90, 143-56.

104. Cheng, K. W.; Mak, C. S. C.; Chan, W. K.; Ng, A. M. C.; Djurisic, A. B., Journal of Polymer Science, Part A: Polymer Chemistry 2008, 46, 1305-1317.

105. Desjardins, P. Synthesis and characterization of novel organometallic and organic electrochromic materials. PhD Dissertation, Carleton University, Ottawa, 2001.

106. Xun, S.; LeClair, G.; Zhang, J.; Chen, X.; Gao, J. P.; Wang, Z. Y., Organic Letters 2006, 8, 1697-1700.

107. Wu, D.-Y.; Herbst, R. M., Journal of Organic Chemistry 1952, 17, 1216-27.

108. Lee, K.; Kim, H.-J.; Cho, J. C.; Kim, J., Macromolecules 2007, 40, 6457-6463.

109. Yeh, K.-M.; Chen, Y., Journal of Polymer Science, Part A: Polymer Chemistry 2007, 45, 2259-2272.

110. Li, X.-C.; Spencer, G. C. W.; Holmes, A. B.; Moratti, S. C.; Cacialli, F.; Friend, R. H., Synthetic Metals 1996, 76, 153-6.

111. Ye, X.-Y.; Robl, J. A.; Hanson, R. L.; Guo, Z.; Patel, R. N. Cyclic compounds as 11-b-hydroxysteroid dehydrogenase type 1 inhibitors and their preparation, pharmaceutical compositions and use in the treatment of diseases. 2007-US76593 2008024892, 20070823., 2008.

112. Planken, S. P.; Sutton, S. C.; Chen, R. Preparation of pyrazole derivatives as cytochrome P450 inhibitors. 2007-IB18782008004096, 20070625., 2008.

113. Myers, M. C.; Shah, P. P.; Diamond, S. L.; Huryn, D. M.; Smith, A. B., Bioorganic \& Medicinal Chemistry Letters 2008, 18, 210-214.

114. Boschelli, D. H.; Connor, D. T.; Bornemeier, D. A.; Dyer, R. D.; Kennedy, J. A.; Kuipers, P. J.; Okonkwo, G. C.; Schrier, D. J.; Wright, C. D., Journal of Medicinal Chemistry 1993, 36, 1802-10.

115. Khau, V. V.; Martinelli, M. J., Tetrahedron Letters 1996, 37, 4323-4326.

116. Kraebel, C. M.; Davis, S. M., Journal of Chemical and Engineering Data 1969, 14, 133-5.

117. Lisitsyn, V. N.; Bolkvadze, L. I., Khimiya i Tekhnologiya Krasheniya, Sinteza Krasitelei i Polimernykh Materialov 1981, 36-41.

118. Kulkarni, P. P.; Kadam, A. J.; Desai, U. V.; Mane, R. B.; Wadgaonkar, P. P., Journal of Chemical Research, Synopses 2000, 184-185.

119. Marcotullio, M. C.; Epifano, F.; Curini, M., Trends in Organic Chemistry 2003, 10, 21-34. 
120. Tamhankar, B. V.; Desai, U. V.; Mane, R. B.; Kulkarni, P. P.; Wadgaonkar, P. P., Synthetic Communications 2002, 32, 3643-3646.

121. Jadhav, V. K.; Wadagaonkar, P. P.; Salunkhe, M. M., Journal of the Chinese Chemical Society 1998, 45, 831-833.

122. Hoffman, R. V.; Kumar, A., Journal of Organic Chemistry 1984, 49, 4014-17.

123. Hacking, M. A. P. J.; van Rantwijk, F.; Sheldon, R. A., Journal of Molecular Catalysis B: Enzymatic 2000, 9, 183-191.

124. Liu, Y.; Bei, M.; Zhou, Z.; Takaki, K.; Fujiwara, Y., Chemistry Letters 1992, $1143-$ 4.

125. Neveux, M.; Bruneau, C.; Lecolier, S.; Dixneuf, P. H., Tetrahedron 1993, 49, 2629 40.

126. Alstrum-Acevedo, J. H.; Brennaman, M. K.; Meyer, T. J., Inorganic Chemistry 2005, 44, 6802-6827.

127. Eskelinen, E.; Luukkanen, S.; Haukka, M.; Ahlgren, M.; Pakkanen, T. A., Dalton 2000, 2745-2752.

128. Belser, P.; Von Zelewsky, A. Synthese, spektroskopische Eigenschaften und elektrochemisches Verhalten von Ruthenium(II)-Komplexen mit zweizähnigen Stickstoffliganden. 1980.

129. Thimmaiah, M.; Fang, S., Tetrahedron 2007, 63, 6879-6886.

130. More, S. V.; Sastry, M. N. V.; Wang, C.-C.; Yao, C.-F., Tetrahedron Letters 2005, 46, 6345-6348.

131. Koenig, E.; Thoma, W.; Pedain, J.; Koenig, K. Thermosetting reactive polyurethane coating composition poor in solvent and its use in a direct or conversion coating process. 82-10403465688, 19820510., 1982.

132. Wolfs, I.; Desseyn, H. O.; Perlepes, S. P., Spectrochimica Acta, Part A: Molecular and Biomolecular Spectroscopy 1994, 50A, 1141-52.

133. Gojon-Zorrilla, G. A preparation of amides via amidation of esters. 2004-858057 2005027120, 20040602., 2005.

134. Qi, Y.; Wang, Z. Y., Macromolecules 2003, 36, 3146-3151.

135. Broussard, F.; Neri, C.; Somenzi, F. Process for the manufacture of symmetrical diacylhydrazines. WO 2000034227, 1999/12/03., 2000.

136. Broussard, F.; Neri, C.; Somenzi, F. Process for the preparation of symmetrical diacylhydrazines. US 6,444,848 B1, 1999/12/03, 2002.

137. Wu, D.-Y.; Herbst, R. M., Journal of Organic Chemistry 1952, 17, 1216-27.

138. Cariati, F.; Caruso, U.; Centore, R.; De Maria, A.; Fusco, M.; Panunzi, B.; Roviello, A.; Tuzi, A., Optical Materials (Amsterdam, Netherlands) 2004, 27, 91-97.

139. Hou, J.-L.; Shao, X.-B.; Chen, G.-J.; Zhou, Y.-X.; Jiang, X.-K.; Li, Z.-T., Journal of the American Chemical Society 2004, 126, 12386-12394.

140. Furdik, M.; Mikulasek, S.; Livar, M.; Priehradny, S., Chemicke Zvesti 1967, 21, 427-42.

141. Hammami, A.; Cavalie-Kosheiry, H.; Armand, M., Bulletin of the Chemical Society of Japan 2004, 77, 165-167.

142. Shah, M. H.; Mhasalkar, M. Y.; Patki, V. M.; Deliwala, C. V.; Sheth, U. K., Journal of Pharmaceutical Sciences 1969, 58, 1398-401.

143. Rice, L. M.; Grogan, C. H.; Reid, E. E., Journal of the American Chemical Society 1953, 75, 242-3. 
144. Trout, G. E.; Levy, P. R., Recueil des Travaux Chimiques des Pays-Bas 1966, 85, 765-73.

145. Wen, Y. H.; Shen, X.; Bi, S.; Zhang, S. S., Acta Crystallographica, Section E: Structure Reports Online 2006, E62, o3780-o3781.

146. Stylianides, N.; Danopoulos, A. A.; Pugh, D.; Hancock, F.; Zanotti-Gerosa, A., Organometallics 2007, 26, 5627-5635.

147. Brooks, J.; Babayan, Y.; Lamansky, S.; Djurovich, P. I.; Tsyba, I.; Bau, R.; Thompson, M. E., Inorganic Chemistry 2002, 41, 3055-3066.

148. Keus, D.; Kaminski, M.; Warkentin, J., Journal of Organic Chemistry 1984, 49, 343-7.

149. Xun, S.; LeClair, G.; Zhang, J.; Xin, C.; Gao, J. P.; Wang Zhi, Y., Organic Letters 2006, 8, 1697-1700.

150. Borek, C.; Hanson, K.; Djurovich, P. I.; Thompson, M. E.; Aznavour, K.; Bau, R.; Sun, Y.; Forrest, S. R.; Brooks, J.; Michalski, L.; Brown, J., Angewandte Chemie, International Edition 2007, 46, 1109-1112.

151. Brinas, R. P.; Troxler, T.; Hochstrasser, R. M.; Vinogradov, S. A., Journal of the American Chemical Society 2005, 127, 11851-11862.

152. Cocchi, M.; Virgili, D.; Fattori, V.; Williams, J. A. G.; Kalinowski, J., Applied Physics Letters 2007, 90, 023506/1-023506/3.

153. Dienel, T.; Proehl, H.; Fritz, T.; Leo, K., Journal of Luminescence 2004, 110, 253 257.

154. O'Riordan, T. C.; Fitzgerald, K.; Ponomarev, G. V.; Mackrill, J.; Hynes, J.; Taylor, C.; Papkovsky, D. B., American Journal of Physiology 2007, 292, R1613-R1620.

155. Kim, D. U.; Paik, S.-H.; Kim, S.-H.; Tak, Y.-H.; Kim, S.-D.; Han, Y.-S.; Kim, T.J.; Ko, T.-H.; Yoon, U.-C.; Mariano, P. S., Colloids and Surfaces, A: Physicochemical and Engineering Aspects 2008, 313+314, 444-447.

156. Cardolaccia, T.; Li, Y.; Schanze, K. S., Journal of the American Chemical Society 2008, 130, 2535-2545.

157. Zhou, G.-J.; Wang, X.-Z.; Wong, W.-Y.; Yu, X.-M.; Kwok, H.-S.; Lin, Z., Journal of Organometallic Chemistry 2007, 692, 3461-3473.

158. Yan, B.-P.; Cheung, C. C. C.; Kui, S. C. F.; Xiang, H.-F.; Roy, V. A. L.; Xu, S.-J.; Che, C.-M., Advanced Materials 2007, 19, 3599-3603.

159. Saito, T.; Asakura, N.; Kamachi, T.; Okura, I., Journal of Porphyrins and Phthalocyanines 2007, 11, 160-164.

160. Niedermair, F.; Waich, K.; Kappaun, S.; Mayr, T.; Trimmel, G.; Mereiter, K.; Slugovc, C., Inorganica Chimica Acta 2007, 360, 2767-2777.

161. Wong, W.-Y.; Poon, S.-Y.; Shi, J.-X.; Cheah, K.-W., Journal of Polymer Science, Part A: Polymer Chemistry 2006, 44, 4804-4824.

162. Scriban, C.; Wicht, D. K.; Glueck, D. S.; Zakharov, L. N.; Golen, J. A.; Rheingold, A. L., Organometallics 2006, 25, 3370-3378.

163. Jain, V. K.; Jain, L., Coordination Chemistry Reviews 2005, 249, 3075-3197.

164. Klein, A., Reviews in Inorganic Chemistry 2000, 20, 283-303.

165. Anderson, G. K.; Nair, P.; Rath, N. P., Book of Abstracts, 219th ACS National Meeting, San Francisco, CA, March 26-30, 2000 2000, INOR-151.

166. Steenwinkel, P.; Kooijman, H.; Smeets, W. J. J.; Spek, A. L.; Grove, D. M.; Van Koten, G., Organometallics 1998, 17, 5411-5426. 
167. Jain, N.; Mittal, R.; Srivastava, T. S.; Satyamoorthy, K.; Chitnis, M. P., Journal of Inorganic Biochemistry 1994, 53, 79-94.

168. Mansuri-Torshizi, H.; Srivastava, T. S.; Parekh, H. K.; Chitnis, M. P., Journal of Inorganic Biochemistry 1992, 45, 135-48.

169. Gokagac, G.; Isci, H.; Mason, W. R., Inorganic Chemistry 1992, 31, 2184-91.

170. Gruff, E. S.; Orgel, L. E., Nucleic Acids Research 1991, 19, 6849-54.

171. Harvey, P. D.; Gray, H. B., Polyhedron 1990, 9, 1949-53.

172. Pelova, R.; Wolowiec, S.; Spasovska, N.; Ivin, A., Nauchni Trudove - Plovdivski Universitet Paisii Khilendarski 1987, 25, 11-20.

173. Whangbo, M. H.; Canadell, E., Inorganic Chemistry 1986, 25, 1726-8.

174. Vlasov, V. V.; Kazakov, S. A., Bioorganicheskaya Khimiya 1983, 9, 530-8.

175. Muraveiskaya, G. S.; Orlova, V. S.; Golovaneva, I. F.; Shchelokov, R. N., Zhurnal Neorganicheskoi Khimii 1981, 26, 3300-7.

176. Bancroft, G. M.; Chan, T.; Puddenphatt, R. J.; Brown, M. P., Inorganica Chimica Acta 1981, 53, L119-L120.

177. Abel, E. W.; Khan, A. R.; Kite, K.; Orrell, K. G.; Sik, V., Journal of the Chemical Society, Dalton Transactions 1980, 2208-19.

178. Kuehn, A.; Werner, H., Journal of Organometallic Chemistry 1979, 179, 421-38.

179. Balch, A. L.; Benner, L. S.; Olmstead, M. M., Inorganic Chemistry 1979, 18, 29963003.

180. Takeda, A.; Igarashi, T. Organic electroluminescent device and complex compound. 2006-5183552007059552, 20060911., 2007.

181. Ma, B.; Djurovich, P. I.; Garon, S.; Alleyne, B.; Thompson, M. E., Advanced Functional Materials 2006, 16, 2438-2446.

182. Ma, B.; Li, J.; Djurovich Peter, I.; Yousufuddin, M.; Bau, R.; Thompson Mark, E., Journal of the American Chemical Society 2005, 127, 28-9.

183. Crutchley, R. J., Electrochemistry: mixed valence systems. In Comprehensive Coordination Chemistry II: From Biology to Nanotechnology. Elsevier, Oxford, 2003, Vol. 2, p 235-244.

184. Ren, X.; Huo, S. Light-emitting devices containing cyclometallated phosphorescent platinum or iridium complexes. 2007-US154402008010915, 20070705., 2008.

185. Yasukawa, N.; Oshiyama, T.; Kato, E. Organic electroluminescent devices having regulated emission wavelength, their materials, displays, and illumination apparatuses therewith. 2005-1896572007009009, $20050629 ., 2007$.

186. Yang, C.-H. Organic light-emitting materials based on transition metal complexes having five-five-membered rings in ligand and organic light-emitting devices employing the materials. 2006-4099342007054150, 20060424., 2007.

187. Ren, X. Blue-emitting organic electroluminescent devices based on a phosphorescent transition metal complex. 2005-216948

2007048546, 20050831., 2007.188. Cocchi, M.; Virgili, D.; Fattori, V.; Rochester, D. L.; Williams, J. A. G., Advanced Functional Materials 2007, 17, 285-289.

189. Chou, P.-T.; Chi, Y., Chemistry--A European Journal 2007, 13, 380-395.

190. Cho, J.-Y.; Domercq, B.; Barlow, S.; Suponitsky, K. Y.; Li, J.; Timofeeva, T. V.; Jones, S. C.; Hayden, L. E.; Kimyonok, A.; South, C. R.; Weck, M.; Kippelen, B.; Marder, S. R., Organometallics 2007, 26, 4816-4829. 
191. Camerel, F.; Ziessel, R.; Donnio, B.; Bourgogne, C.; Guillon, D.; Schmutz, M.; Iacovita, C.; Bucher, J.-P., Angewandte Chemie, International Edition 2007, 46, 2659-2662.

192. He, Z.; Wong, W.-Y.; Yu, X.; Kwok, H.-S.; Lin, Z., Inorganic Chemistry 2006, 45, 10922-10937.

193. Liu, Q.-D.; Wang, R.; Wang, S., Dalton Transactions 2004, 2073-2079.

194. Thompson, M. E.; Lamansky, S.; Djurovich, P.; Murphy, D.; Abdel-Razzaq, F.; Forrest, S. R.; Baldo, M.; Burrows, P. E., Polymeric Materials Science and Engineering 2000, 83, 202-203.

195. Ma, B.; Djurovich, P. I.; Thompson, M. E., Coordination Chemistry Reviews 2005, 249, 1501-1510.

196. Che, C. M.; Wan, K. T.; He, L. Y.; Poon, C. K.; Yam, V. W. W., Journal of the Chemical Society, Chemical Communications 1989, 943-4.

197. Bancroft, D. P. The synthesis and characterization of binuclear complexes of platinum(III). 1986.

198. Lamansky, S.; Kwong, R. C.; Nugent, M.; Djurovich, P. I.; Thompson, M. E., Organic Electronics 2001, 2, 53-62.

199. Hollis, L. S.; Lippard, S. J., Journal of the American Chemical Society 1981, 103, 6761-3.

200. Bryan, S. A. Thermal, photochemical and electrochemical reactions of dinuclear platinum(III) complexes. 1985.

201. Kvam, P.-I.; Puzyk, M. V.; Balashev, K. P.; Songstad, J., Acta Chemica Scandinavica 1995, 49, 335-43.

202. Williams, A. T. R.; Sinfield, S. A.; Miller, J. N., Analyst 1983, 108, 1067-1071.

203. Kaim, W.; Kasack, V., Inorganic Chemistry 1990, 29, 4696-9.

204. Sullivan, B. P.; Salmon, D. J.; Meyer, T. J., Inorganic Chemistry 1978, 17, 333441.

205. Cowie, J. M. G., Polymers: chemistry and physics of modern materials. Chapman \& Hall, Cheltenham, 2001, p 436.

206. Newkome, G. R.; Moorefield, C. N.; Vogtle, F., Dendrimers and Dendrons: Concepts, Syntheses, Applications. John Wiley \& Sons, Weinheim, 2001, p 635.

207. Rau, H.; Waldner, I., Physical Chemistry Chemical Physics 2002, 4, 1776-1780.

208. Vercruysse, K. P.; Marecak, D. M.; Marecek, J. F.; Prestwich, G. D., Bioconjugate Chemistry 1997, 8, 686-694.

209. Ito, Y.; Matsuura, T., Journal of Photochemistry and Photobiology, A: Chemistry 1989, 50, 141-6.

210. Ito, Y.; Kajita, T.; Kunimoto, K.; Matsuura, T., Journal of Organic Chemistry 1989, 54, 587-91.

211. Szilagyi, L.; Kasa, I.; Bitter, I., Periodica Polytechnica, Chemical Engineering 1973, 17, 125-33.

212. Zhang, G.; Fang, L.; Zhu, L.; Sun, D.; Wang, P. G., Bioorganic \& Medicinal Chemistry 2006, 14, 426-434.

213. Adams, C. J.; Bowen, L. E.; Humphrey, M. G.; Morrall, J. P. L.; Samoc, M.; Yellowlees, L. J., Dalton Transactions 2004, 4130-4138.

214. Wong, C.-Y.; Chan, M. C. W.; Zhu, N.; Che, C.-M., Organometallics 2004, 23, 2263-2272. 
215. Brinker, C. J.; Scherer, G. W., Sol-gel science : the physics and chemistry of sol-gel processing. Academic Press, Inc., Boston, 1990, p 908.

216. Chen, S.-1.; Xu, C.-g.; Zhao, K.-q.; Hu, P., Sichuan Shifan Daxue Xuebao, Ziran Kexueban 2000, 23, 511-512.

217. Franklin, J. D. Development and optimisation of polymeric matrices for use in biomolecular devices. Dissertation, Carleton University, Ottawa, 2003.

218. Azarnia, R.; Fuentes, S.; Russel, T. Apparatus for measuring analytes in a fluid sample. 96-US41139630751, 19960326., 1996.

219. Barie, N. Development of a universal process for biofunctionalization of surfaces to be used in sensor technology by surface acoustic wave (SAW) devices; Inst. Instrumentelle Analytik,Germany.: 2000; pp i-xvi, 1-171, A1-A34.

220. Bharathi, S.; Lev, O., Applied Biochemistry and Biotechnology 2000, 89, 209-216.

221. de Marcos, S.; Galindo, J.; Sierra, J. F.; Galban, J.; Castillo, J. R., Sensors and Actuators, B: Chemical 1999, B57, 227-232.

222. Desprez, V.; Oranth, N.; Spinke, J.; Tusa, J. K. Nanoparticles for optical sensors. 2004-161511496126, 20040708., 2005.

223. Endo, H. Biosensor oxygen-sensitive optical fiber and oxidase, and its production method. 2006-JP3023532006090596, 20060210., 2006.

224. Jiang, D.; Liu, E.; Chen, X.; Huang, J., Chinese Optics Letters 2003, 1, 108-110.

225. Kuenzelmann, U.; Boettcher, H., Sensors and Actuators, B: Chemical 1997, B39, 222-228.

226. McCurley, M. F.; Seitz, W. R., ACS Symposium Series 1992, 487, 301-9.

227. Osada, T. Optical enzyme biosensor. 92-20304006027023, 19920707., 1994.

228. Saito, A.; Shionoya, K. Microscopic system for evaluating defect of biosensor membrane. 91-35078305196578, 19911212., 1993.

229. Schueler, R.; Wittkampf, M.; Chemnitius, G. C.; Sperveslage, G.; Grobe, J. Biosensor consisting of a membrane-coated transducer and an immobilized biological component. 97-1971187919711879, 19970321., 1998.

230. Shah, R.; Margerum, S. C.; Gold, M., Proceedings of SPIE-The International Society for Optical Engineering 1988, 906, 65-73.

231. Trettnak, W.; Wolfbeis, O. S., Analytica Chimica Acta 1989, 221, 195-203.

232. Turner, R. F. B.; Kilburn, D. G.; Phelps, M. R. Biosensor and interface membrane. 94-3093385624537, 19940920., 1997.

233. Olea, D.; Viratelle, O.; Faure, C., Biosensors \& Bioelectronics 2008, 23, 788-794.

234. Xu, L.; Zhu, Y.; Tang, L.; Yang, X.; Li, C., Electroanalysis 2007, 19, 717-722.

235. Reyes-De-Corcuera, J. I.; Cavalieri, R. P.; Powers, J. R.; Tang, J.; Kang, D. H., Journal of Agricultural and Food Chemistry 2005, 53, 8866-8873.

236. Alonso Lomillo, M. A.; Ruiz, J. G.; Pascual, F. J. M., Analytica Chimica Acta 2005, 547, 209-214.

237. Mailley, P.; Cummings, E. A.; Mailley, S.; Cosnier, S.; Eggins, B. R.; McAdams, E., Bioelectrochemistry 2004, 63, 291-296.

238. Guemas, Y.; Boujtita, M.; El Murr, N., Applied Biochemistry and Biotechnology 2000, 89, 171-181.

239. Guiomar, A. J.; Evans, S. D.; Guthrie, J. T., Supramolecular Science 1997, 4, 279291.

240. Varadi, M.; Adanyi, N.; Szabo, E. E., Acta Alimentaria 1995, 24, 365-377. 
241. Bilitewski, U.; Chemnitius, G. C.; Rueger, P.; Schmid, R. D., Sensors and Actuators, B: Chemical 1992, B7, 351-5.

242. Fortier, G.; Brassard, E.; Belanger, D., Biosensors \& Bioelectronics 1990, 5, 473 90.

243. Lomen, C. E.; De Alwis, U.; Wilson, G. S., Journal of the Chemical Society, Faraday Transactions 1 1986, 82, 1265-70.

244. Reyes-De-Corcuera Jose, I.; Cavalieri Ralph, P.; Powers Joseph, R.; Tang, J.; Kang Dong, H., Journal of agricultural and food chemistry 2005, 53, 8866-73.

245. Deacon, A. C.; Dawson, P. J., Clinical chemistry 1979, 25, 976-84.

246. Ozimek, P.; Veenhuis, M.; van der Klei, I. J., FEMS Yeast Research 2005, 5, $975-$ 983.

247. Ralph, E. C.; Hirschi, J. S.; Anderson, M. A.; Cleland, W. W.; Singleton, D. A.; Fitzpatrick, P. F., Biochemistry 2007, 46, 7655-7664.

248. Rahman, M. A.; Kwon, N.-H.; Won, M.-S.; Choe, E. S.; Shim, Y.-B., Analytical Chemistry 2005, 77, 4854-4860.

249. Cai, H.; Zhang, X. M.; Lu, C.; Liu, A. Q., IIEEE Sensors 2005, 4th IEEE Conference on Sensors, Irvine, CA, United States, Oct. 30-Nov. 3, 2005 2005, 1, 508-511.

250. Lee, C., Sensors and Actuators, A: Physical 2005, A123-A124, 596-601.

251. Wu, Y.-H.; Lin, Y.-H.; Lu, Y.-Q.; Ren, H.; Fan, Y.-H.; Wu, J. R.; Wu, S.-T., Proceedings of SPIE-The International Society for Optical Engineering 2005, 5936, $59360 \mathrm{~J} / 1-59360 \mathrm{~J} / 8$.

252. O'Brien, N. A.; Mathew, J. G. H.; Hichwa, B. P., OFC Proceedings, Optical Fiber Communication Conference 1999, Supplement, PD26/21-PD26/23.

253. Cifuentes, M. P.; Powell, C. E.; Morrall, J. P.; McDonagh, A. M.; Lucas, N. T.; Humphrey, M. G.; Samoc, M.; Houbrechts, S.; Asselberghs, I.; Clays, K.; Persoons, A.; Isoshima, T., Journal of the American Chemical Society 2006, 128, 1081910832.

254. McDonagh, A. M.; Humphrey, M. G.; Samoc, M.; Luther-Davies, B.; Houbrechts, S.; Wada, T.; Sasabe, H.; Persoons, A., Journal of the American Chemical Society 1999, 121, 1405-1406.

255. Powell, C. E.; Cifuentes, M. P.; Morrall, J. P.; Stranger, R.; Humphrey, M. G.; Samoc, M.; Luther-Davies, B.; Heath, G. A., Journal of the American Chemical Society 2003, 125, 602-610.

256. Powell, C. E.; Morrall, J. P.; Ward, S. A.; Cifuentes, M. P.; Notaras, E. G. A.; Samoc, M.; Humphrey, M. G., Journal of the American Chemical Society 2004, $126,12234-12235$.

257. Jin, Y.-S.; Lee, S.-S.; Son, Y.-S., Electronics Letters 1999, 35, 916-917.

258. Kawai, T.; Koga, M.; Okuno, M.; Kitoh, T., Electronics Letters 1998, 34, 264-265.

259. Kim, S.; Hung, Y.-C.; Geary, K.; Yuan, W.; Fetterman, H. R.; Jin, D.; Dinu, R.; Steier, W. H., IEEE Photonics Technology Letters 2006, 18, 1055-1057.

260. Ma, H.; Jen, A. K. Y.; Dalton, L. R., Advanced Materials 2002, 14, 1339-1365.

261. Uetsuka, H., IEEE Journal of Selected Topics in Quantum Electronics 2004, 10, 393-402.

262. Wolfs, I.; Desseyn, H. O.; Perlepes, S. P., Spectrochimica Acta, Part A: Molecular and Biomolecular Spectroscopy 1994, 50A, 1141-52. 
263. Qi, Y. H.; Desjardins, P.; Meng, X. S.; Wang, Z. Y., Optical Materials 2003, 21, 255-263.

264. Zhang, J.; Wu, X.; Yu, H.; Yan, D.; Wang, Z., Chinese Science Bulletin 2005, 50, 2688-2690.

265. Deng, X.; Zheng, X.; Cao, Z.; Shen, Q.; Li, H., Applied Physics Letters 2007, 90, $151124 / 1-151124 / 3$.

266. Curtis, H. D., Publications of the Astronomical Society of the Pacific 1911, 23, 1332.

267. LeClair, G; Wang, Z.Y., Journal of Solid State Electrochemistry published online May $6^{\text {th }} 2008$ (DOI: $10.1007 / \mathrm{s} 10008-008-0562-y$ )

268. Xun, S.; LeClair, G.; Zhang, J.; Chen, X.; Gao, J. P.; Wang, Z. Y., Organic Letters 2006, 8, 1697-1700. 


\section{Appendices}

Appendix $1-{ }^{1} \mathrm{H}$ and ${ }^{13} \mathrm{C}$ NMR spectra of ligands 
4-hydroxy-N'-propionylbutanehydrazide (1)
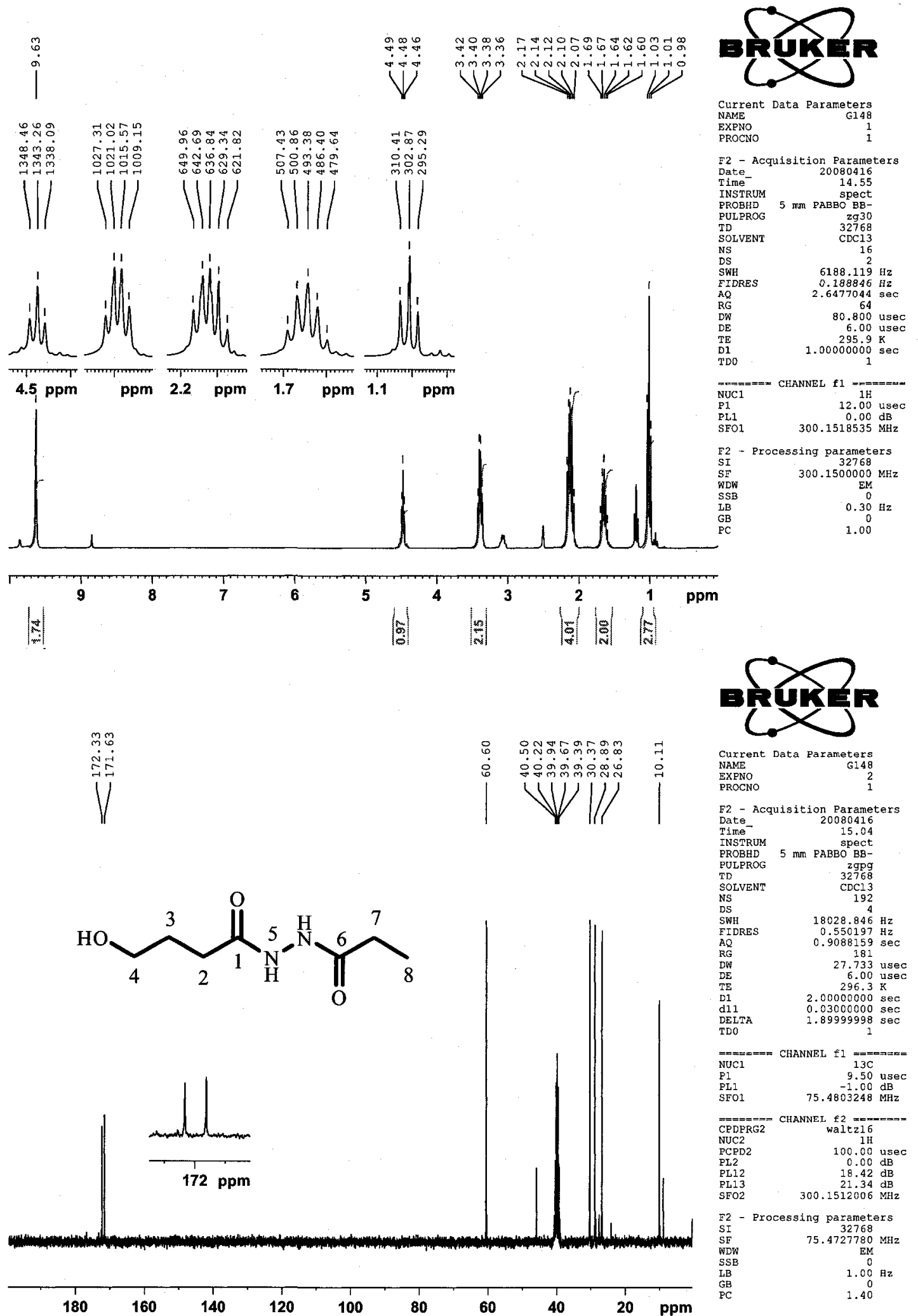
6-hydroxy-N'-propionyhexanehydrazide (2)

$\stackrel{0}{0}$

|
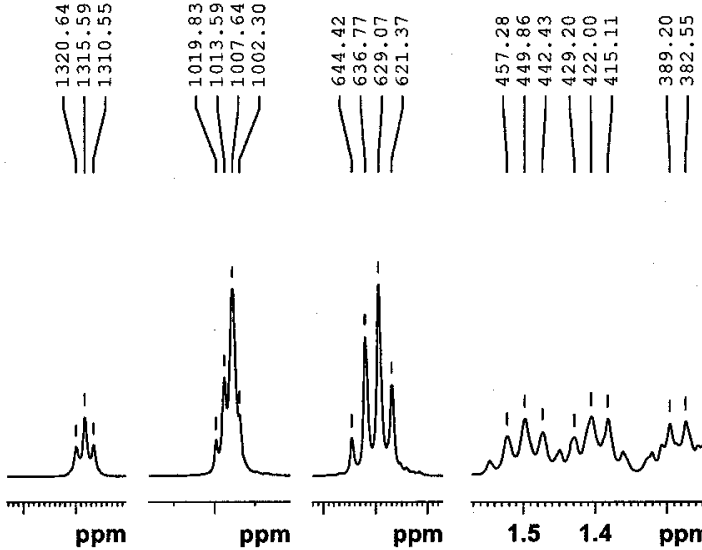

NMón
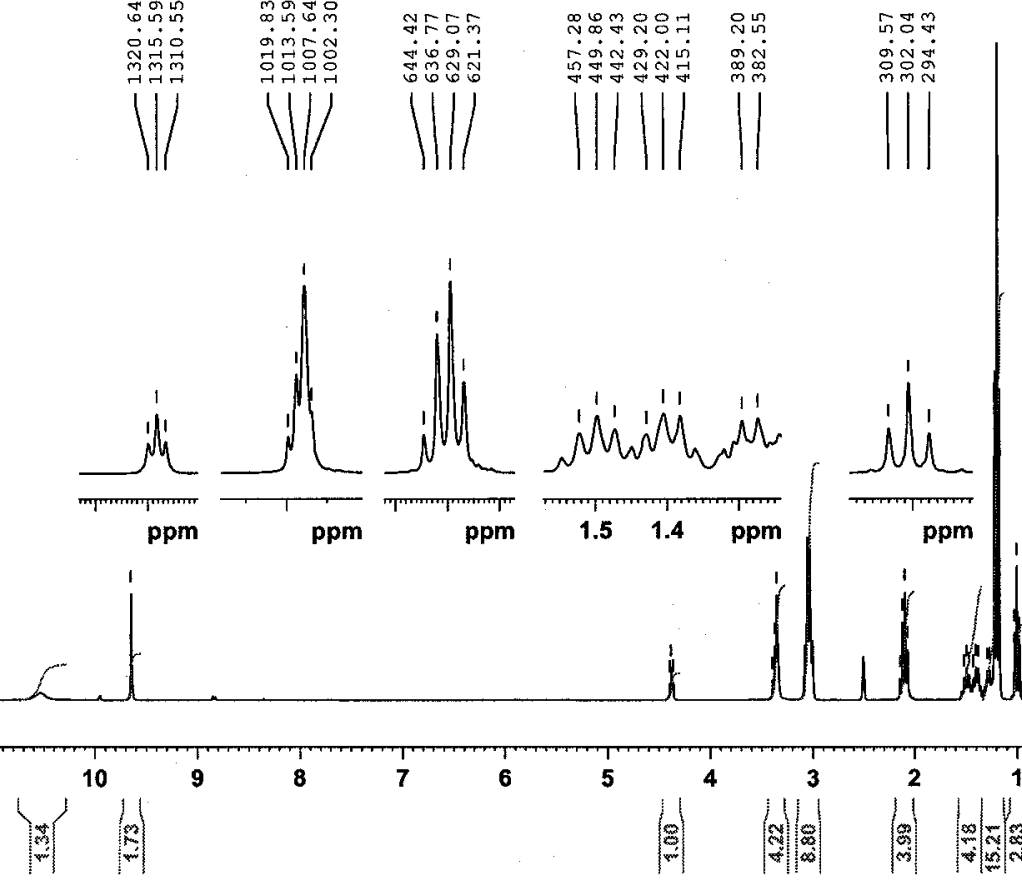

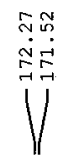
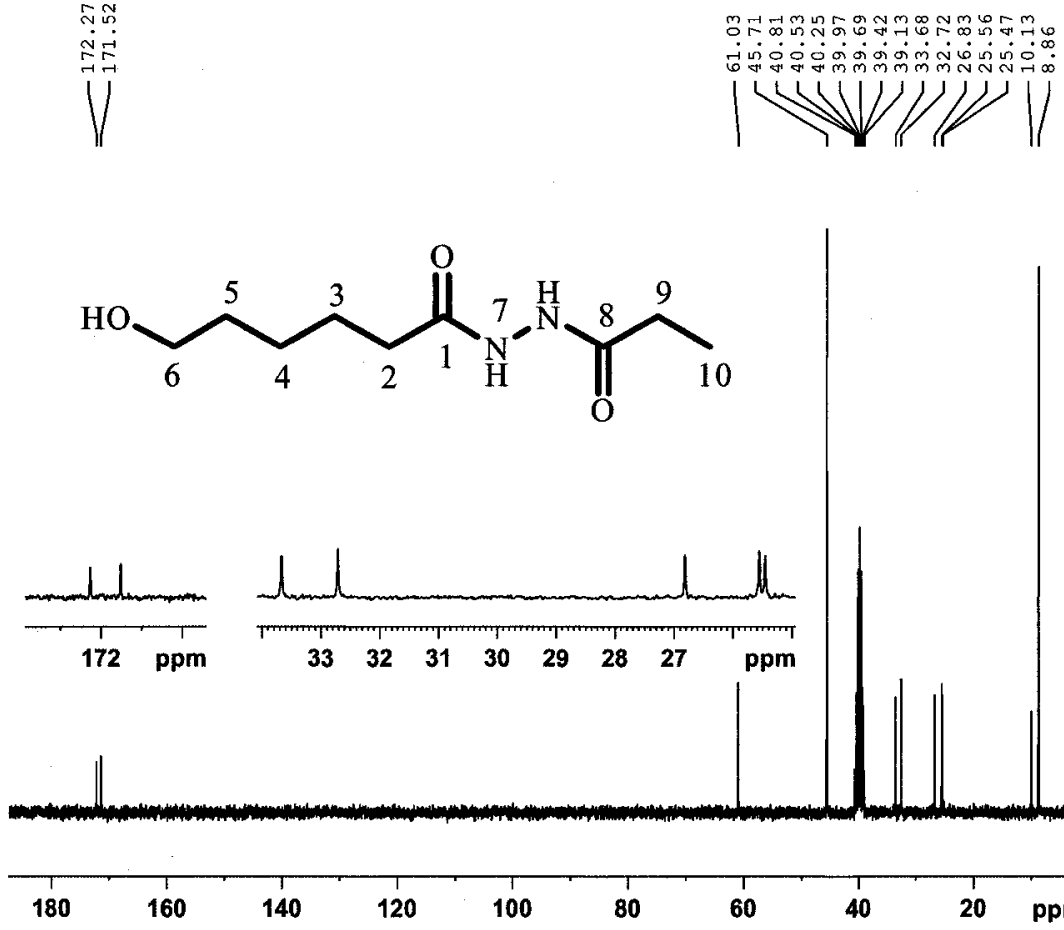

80

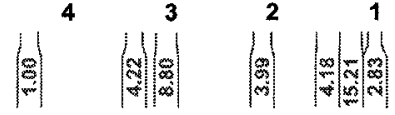

ppm

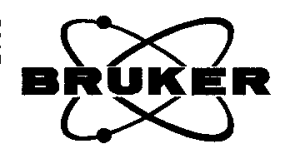

Current Data Parameters NAME

ROCNO

F2 - Acquisition Parameters
Date 20080412

Time ${ }^{-}$

PROBHD $5 \mathrm{~mm}$ PABBO BB-

PULPROG

OLVEN

$\begin{array}{lc}\text { DS } & 2 \\ \text { SWH } & 6188.119 \mathrm{~Hz} \\ \text { FIDRES } & 0.188846 \mathrm{~Hz}\end{array}$

$\begin{array}{ll}\text { AQ } & 0.188846 \mathrm{~Hz} \\ \text { RG } & 2.6477044 \mathrm{se}\end{array}$

TE

$\begin{array}{ll}295.5 \mathrm{~K} \\ \mathrm{D} 1 & 1.00000000 \mathrm{sec}\end{array}$

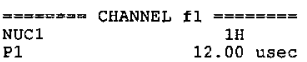

$\begin{array}{lr}\text { P1 } & 12.00 \text { use } \\ \text { PL1 } & 0.00 \mathrm{~dB} \\ \text { SFO1 } & 300.1518535 \mathrm{MHE}\end{array}$

F2 - Processing parameters

$\begin{array}{lc} & \\ \text { S1 } & \text { Processing parameters } \\ \text { SE } & 32768 \\ \text { WD } & 300.1500000 \mathrm{MHz}\end{array}$

SE

SB

$\mathrm{PC}$

$0.30 \mathrm{~Hz}$ 

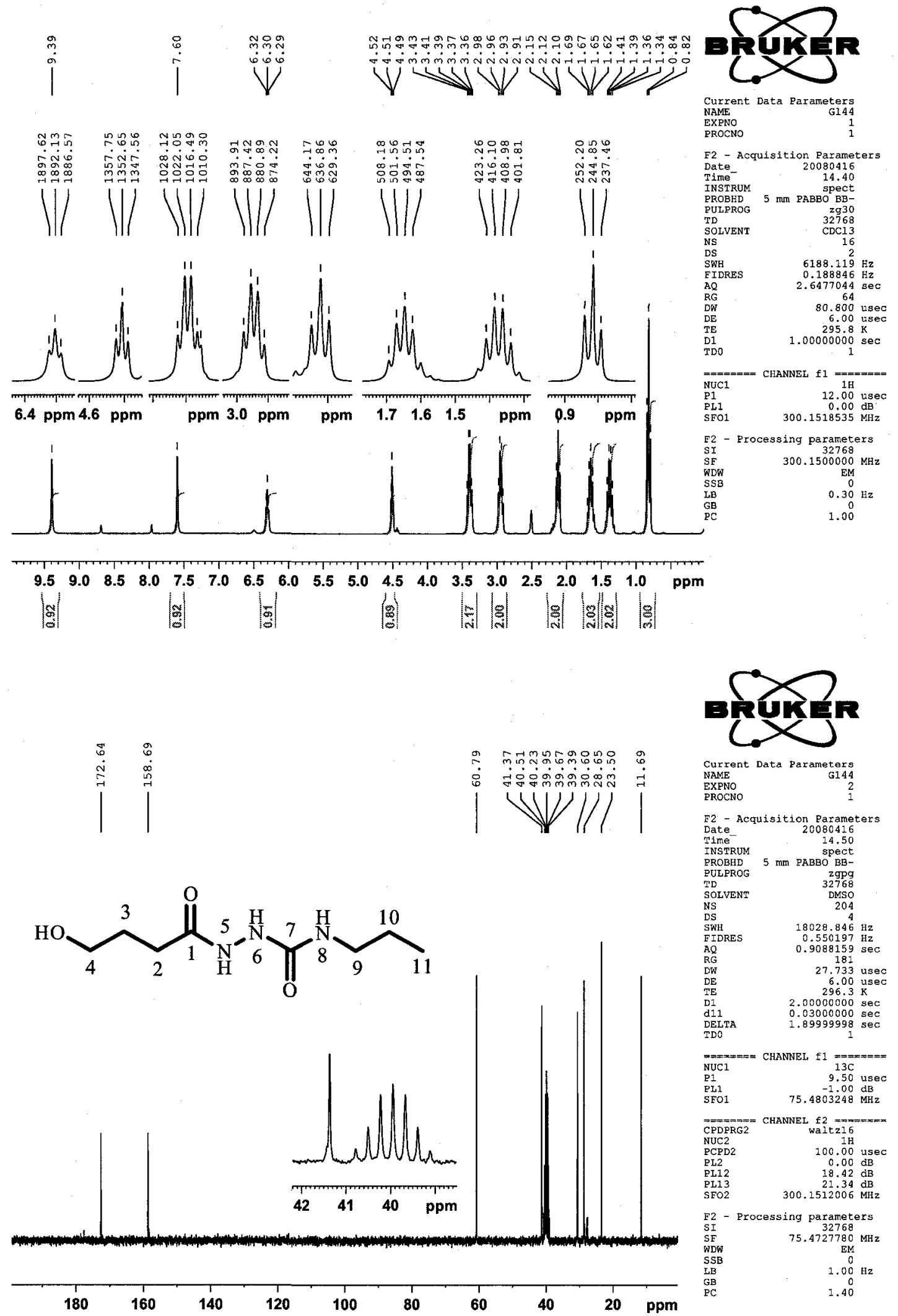


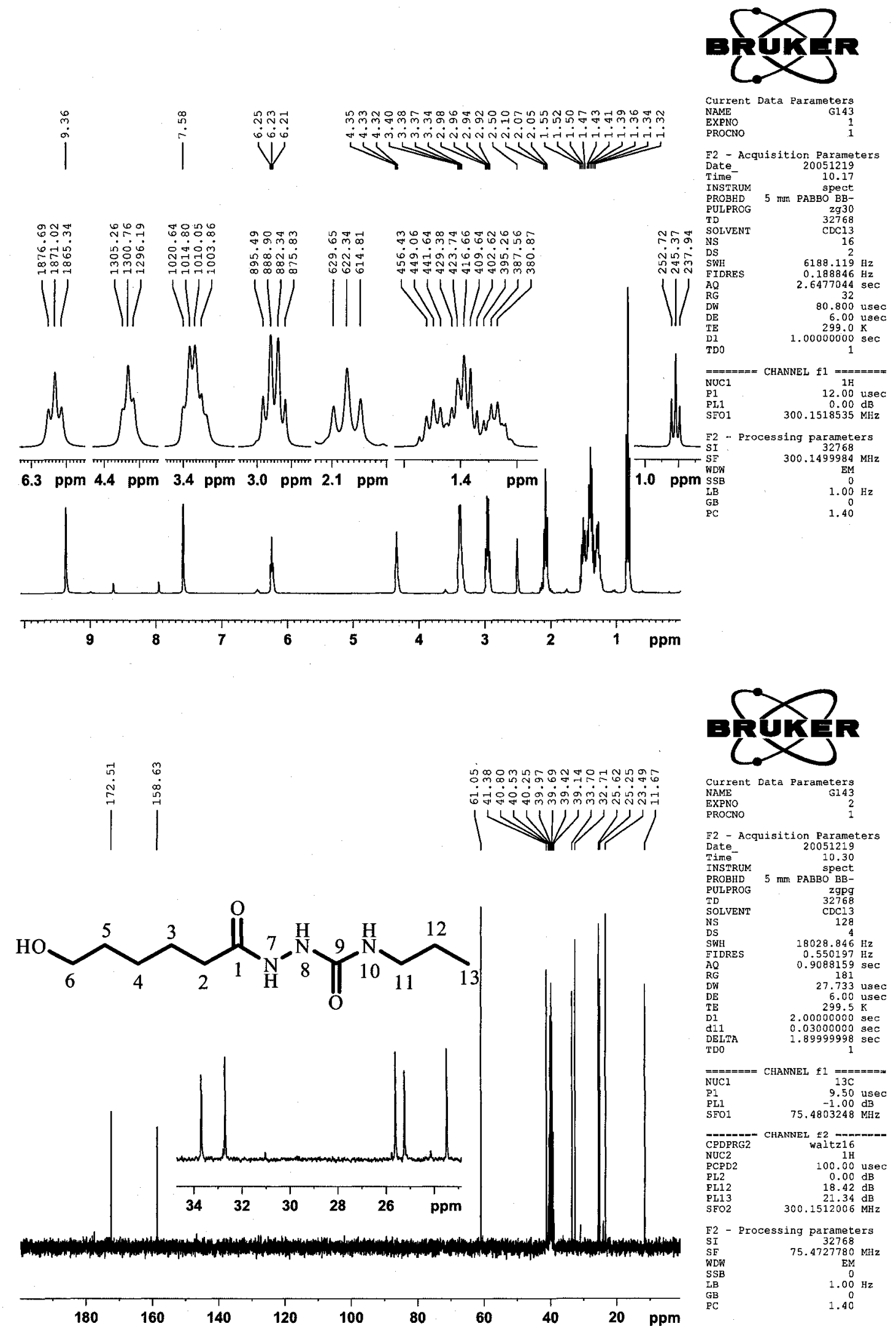


6-hydroxy-N'-(6-hydroxyhexanoyl)hexanehydrazide (5)
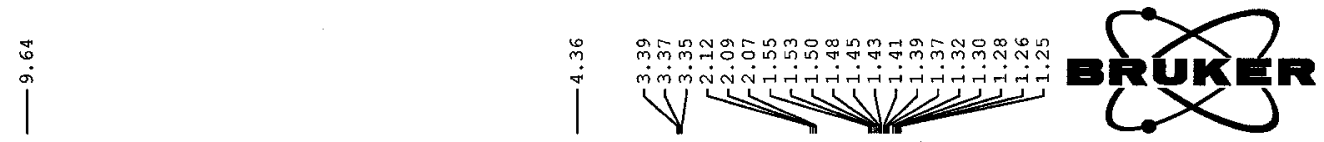

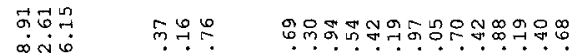

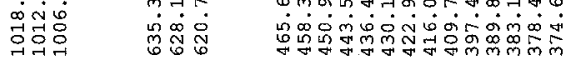

||| ||| ||||||||||||||
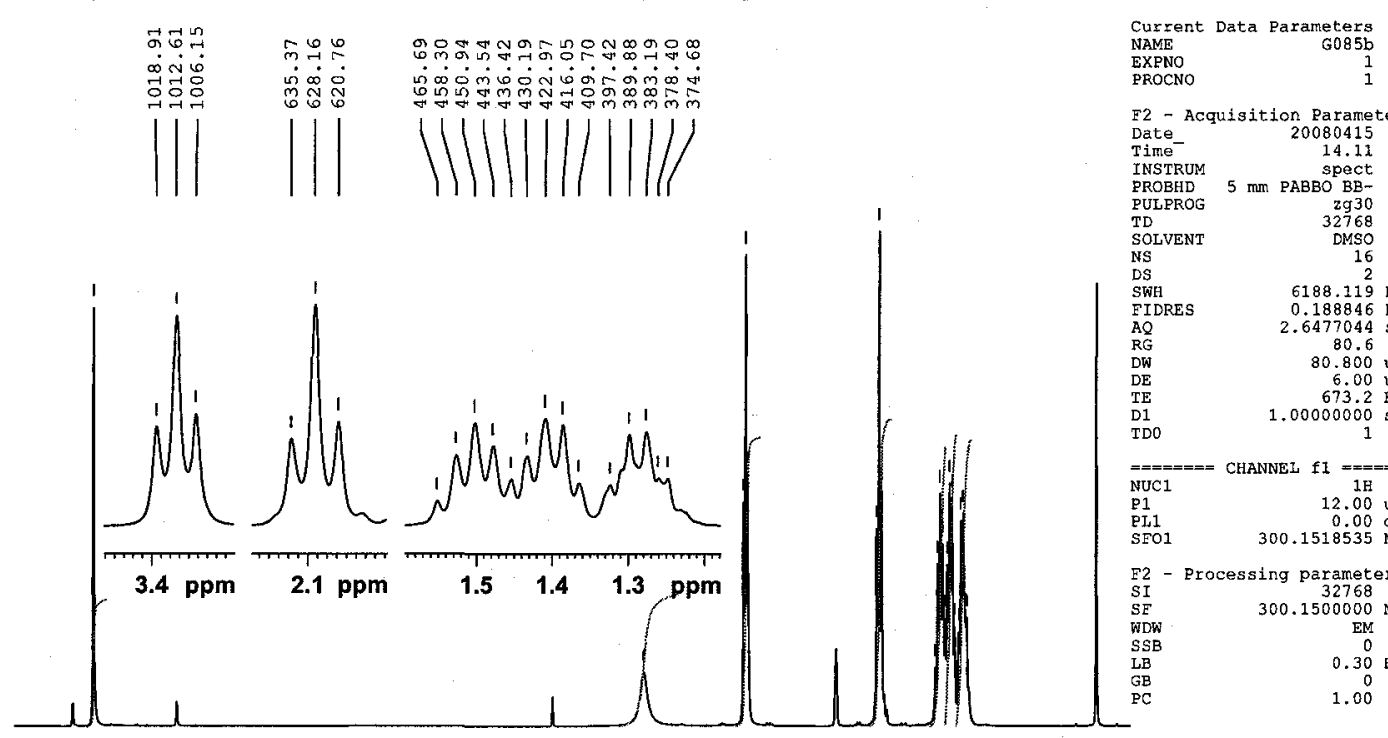

ExRTO

F2 - Acquisition Parameters
Date_ 20080415

Time ${ }^{-}$

INSTRUM spect

PUEPRO

TD

SOLVE
NS
DS
SWH

IDR

RQ

RG

TE

$1.00000000 \mathrm{Kec}$

$======$ CHANNEI $\mathrm{fl}=x======$
wUC1 $1 \mathrm{H}$
12.00 usec SE01 $\quad 300.1518535 \mathrm{~dB}$

F2 - Processing parameters

$\begin{array}{lr}\text { FI } & \text { Processing parameters } \\ S T & 32768 \\ S P & 300.1500000\end{array}$ $\begin{array}{lr}S E & 300.1500000 \\ W D W & \mathrm{EM}\end{array}$
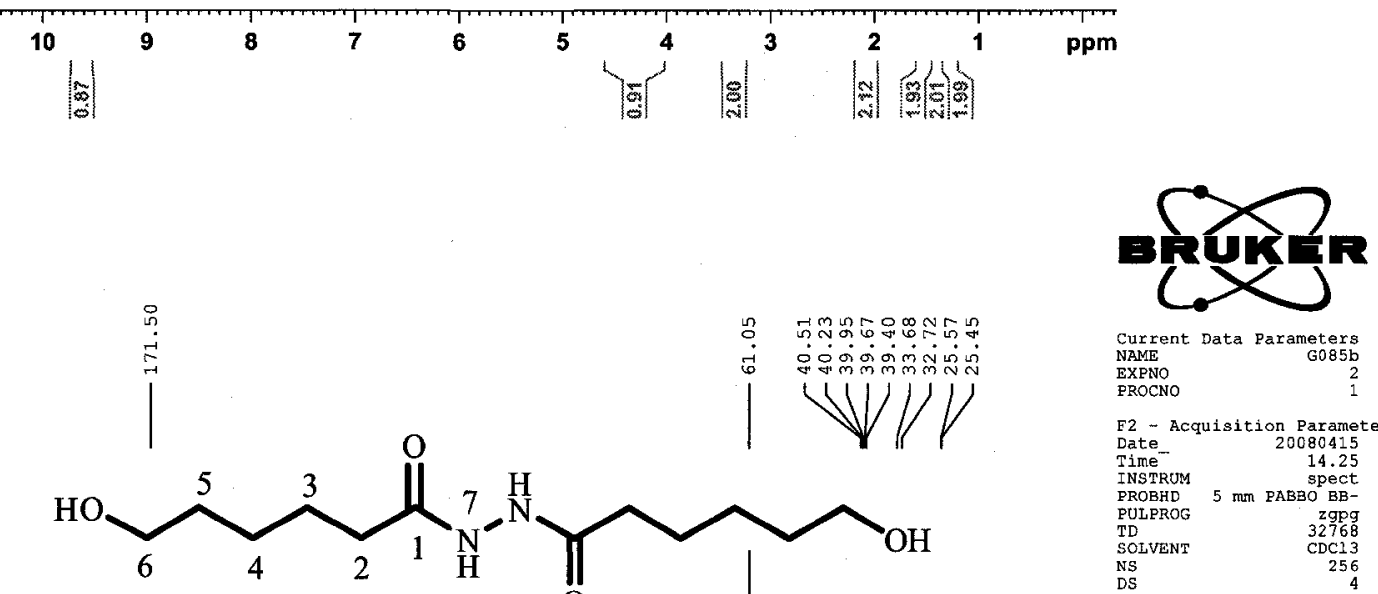

${ }^{\mathrm{N}}$
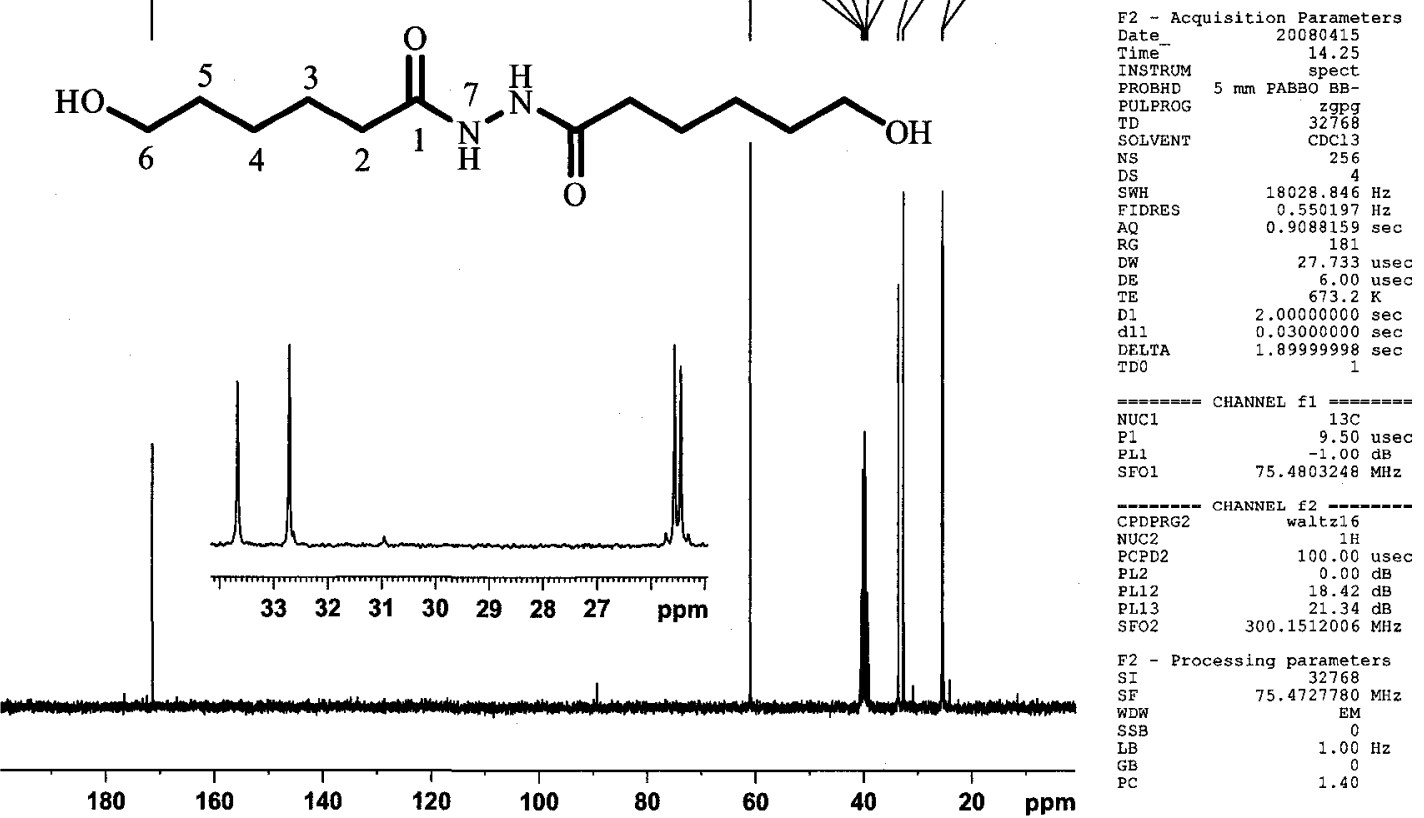
$N^{1}, N^{2}$-bis(3-hydroxypropyl)hydrazine-1,2-dicarboxamide (6)
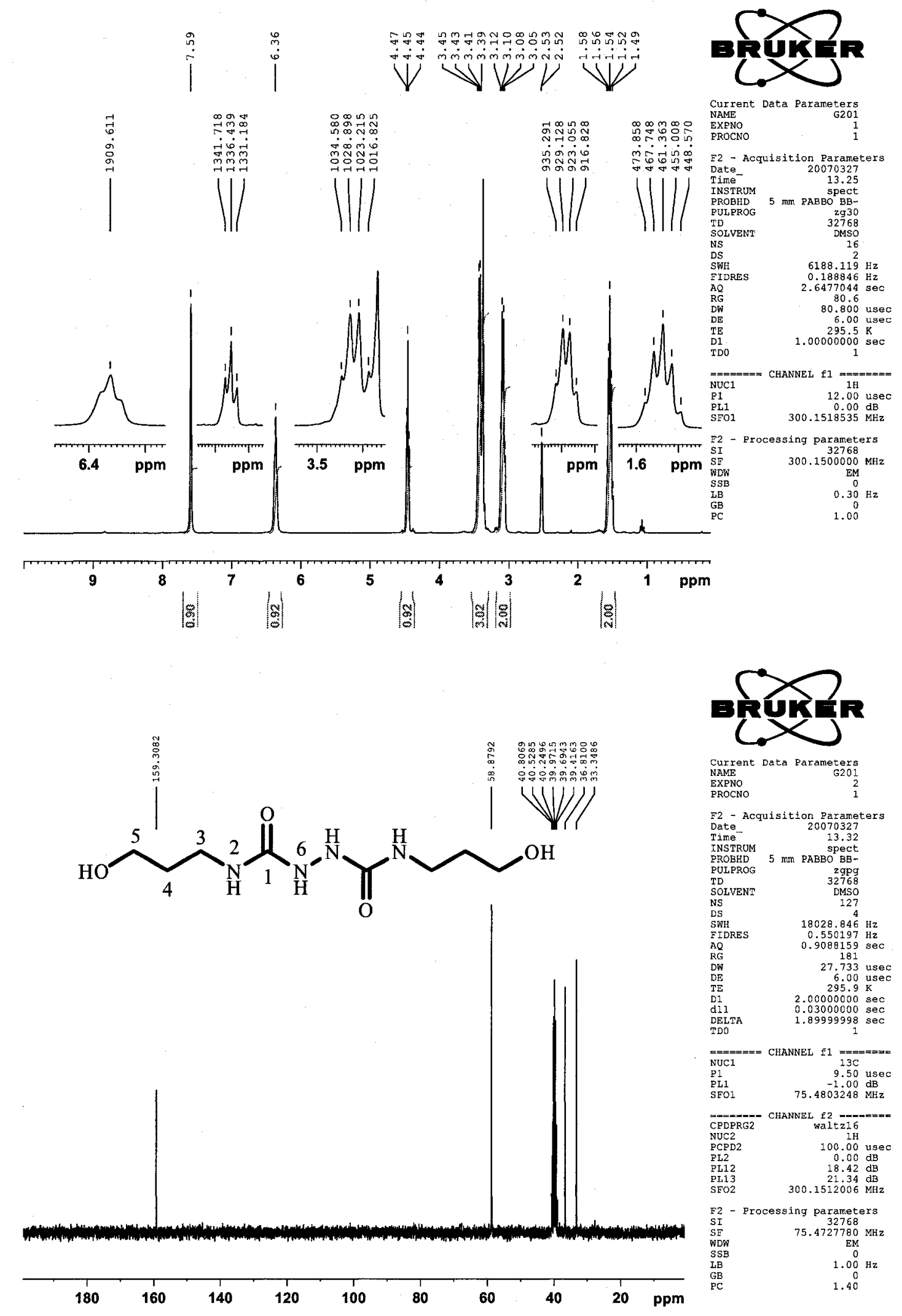
$N^{l}, N^{2}$-bis(5-hydroxypentyl)hydrazine-1,2-dicarboxamide (7)

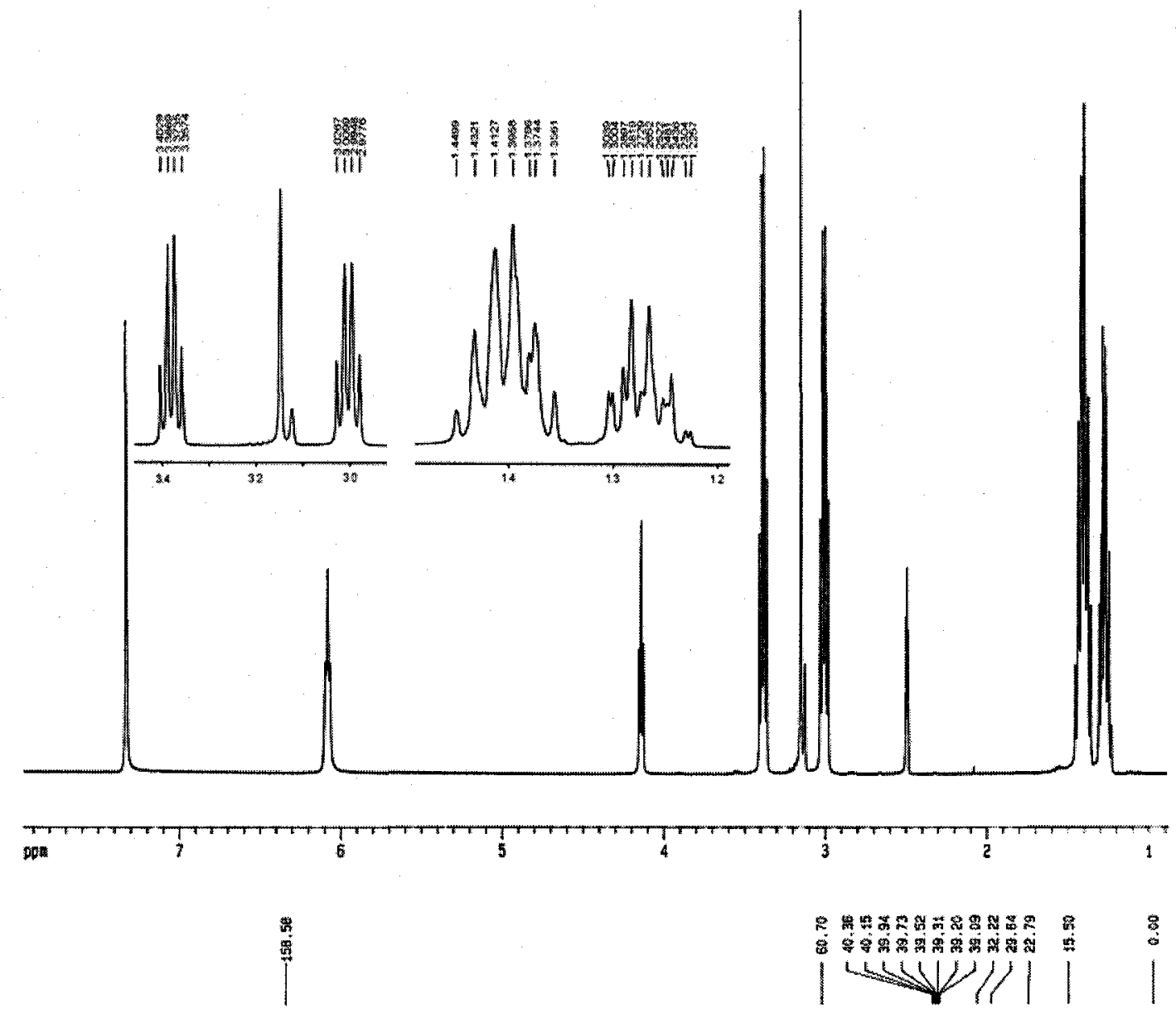

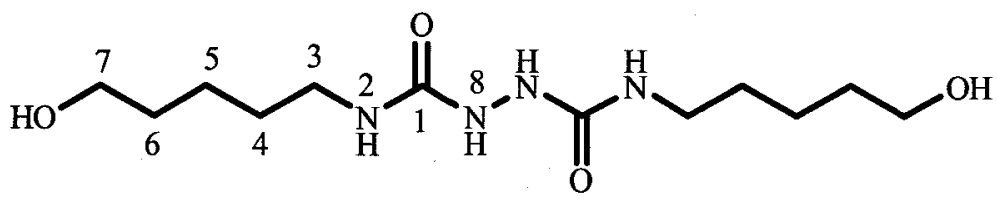
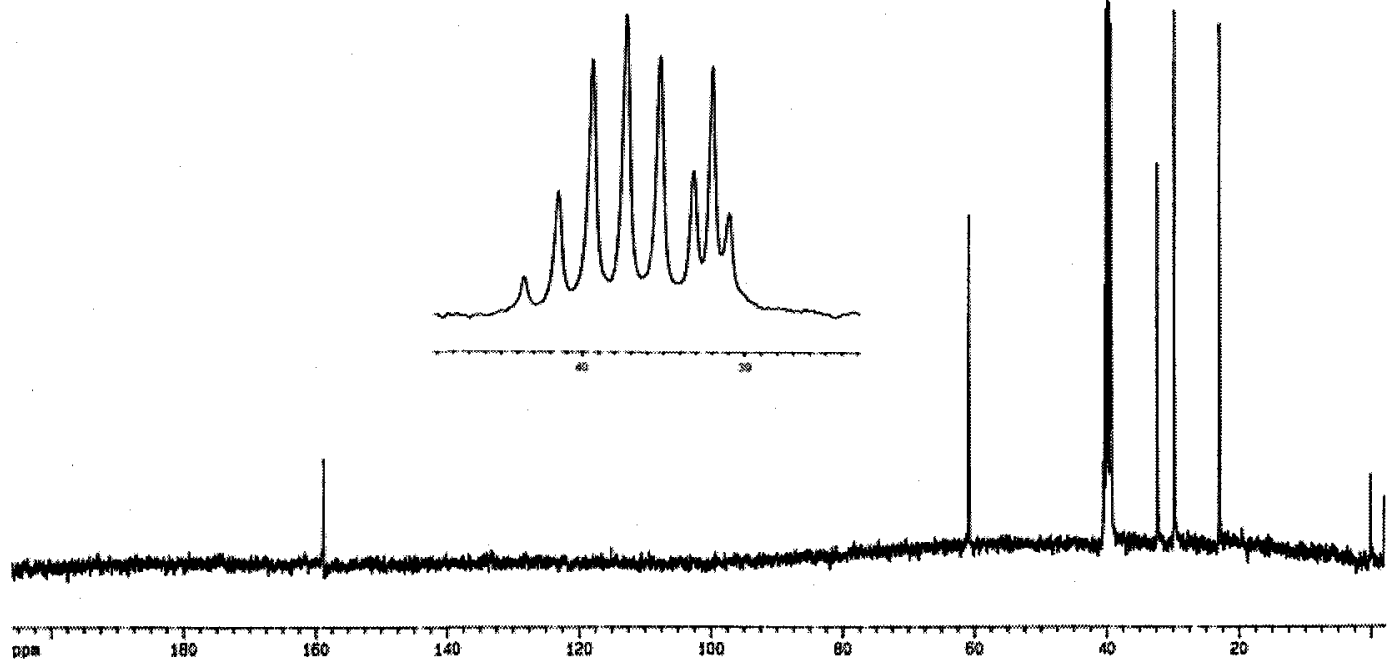
$N^{1}, N^{2}$-bis(1,3-dihydroxy-2-methylpropan-2-yl)hydrazine-1,2-dicarboxamide (8)

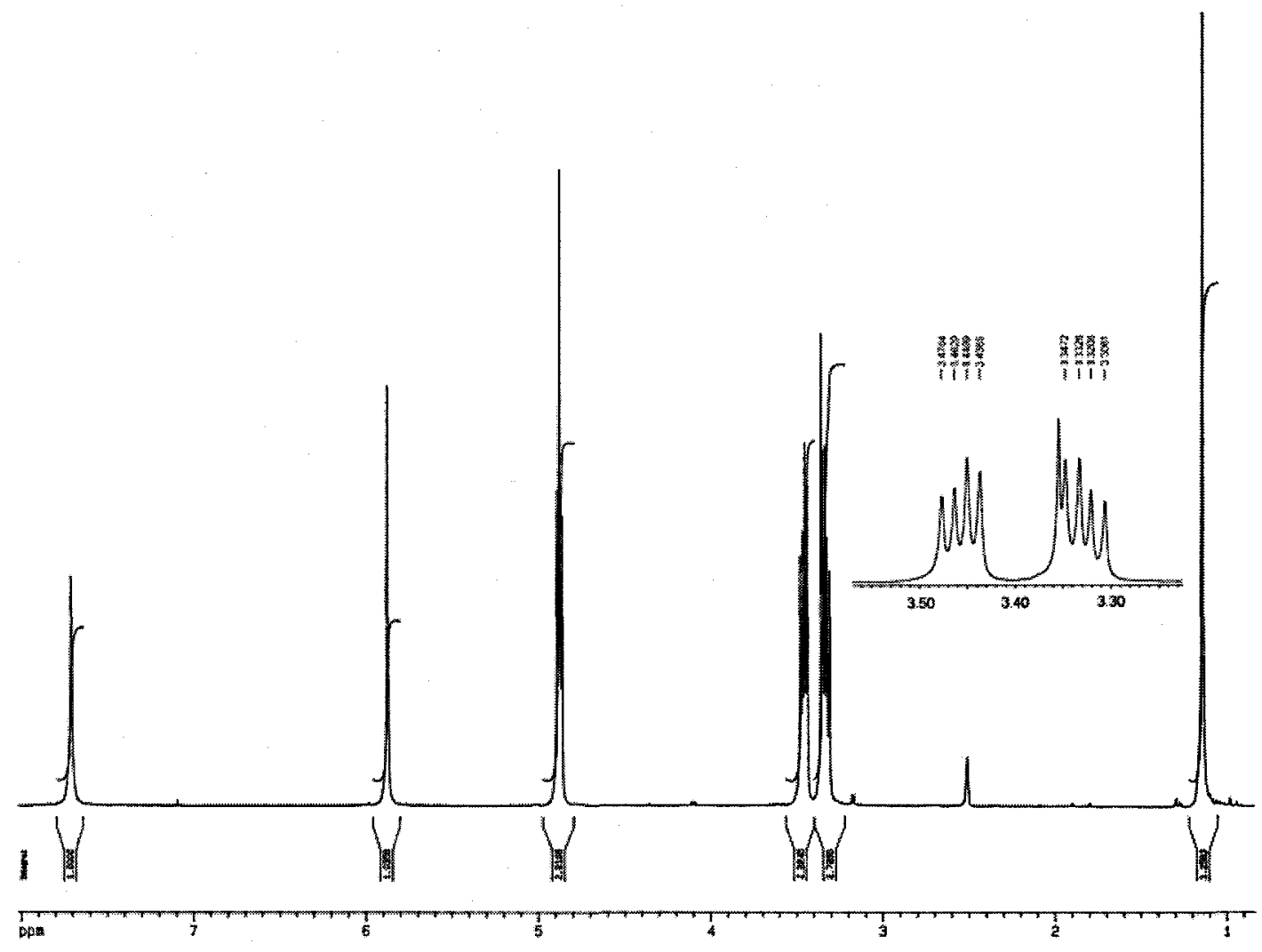<smiles>CC(CO)(CO)NC(=O)NNC(=O)NC(C)(CO)CO</smiles>

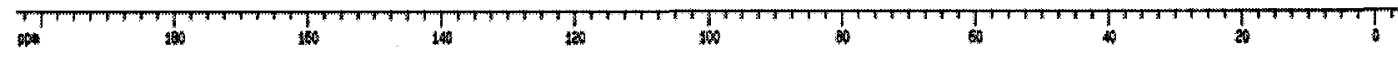




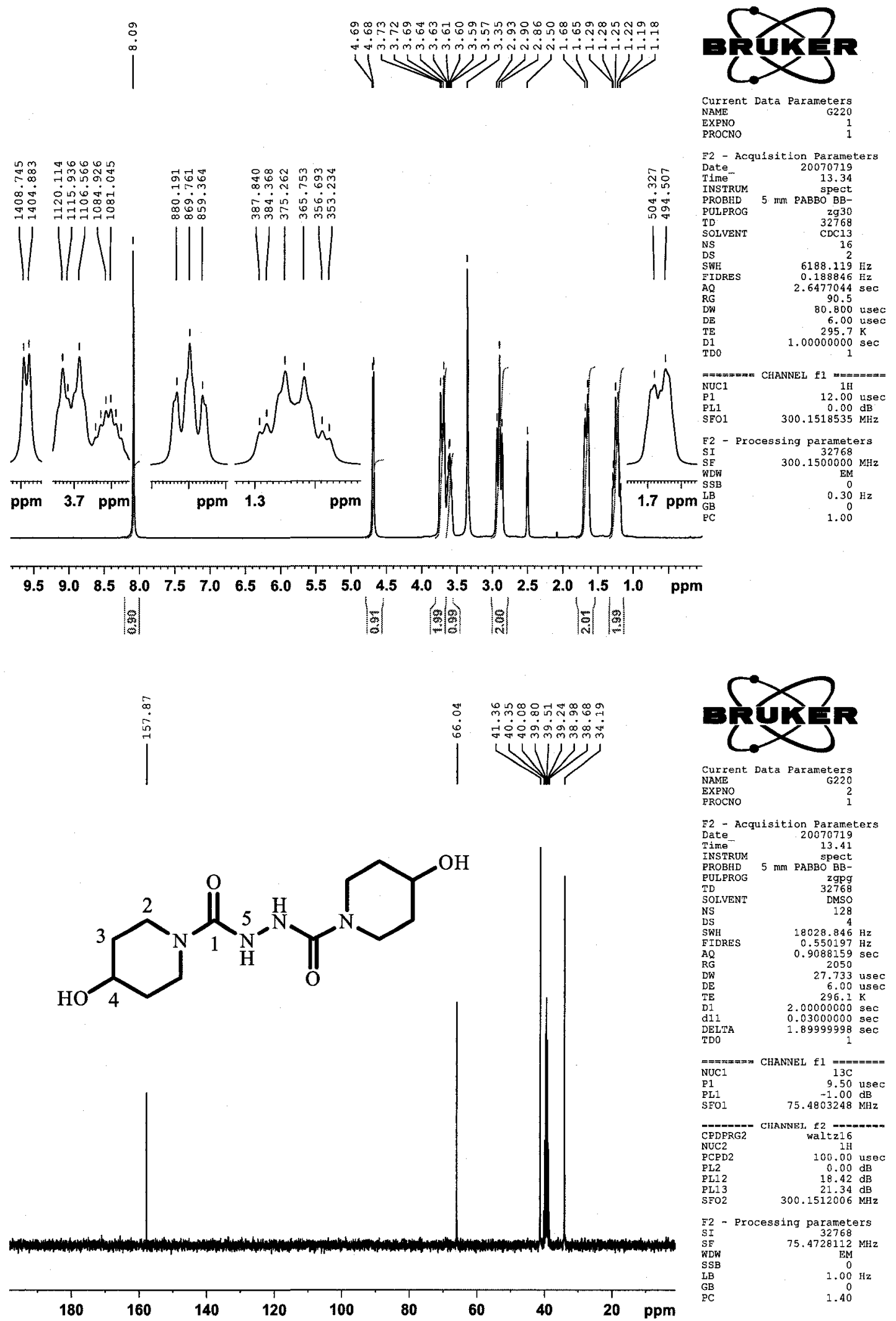


4-(hydroxymethyl)-N'-(4-(hydroxymethyl)piperidine-1-carbonyl)piperidine-1carbohydrazide (11)

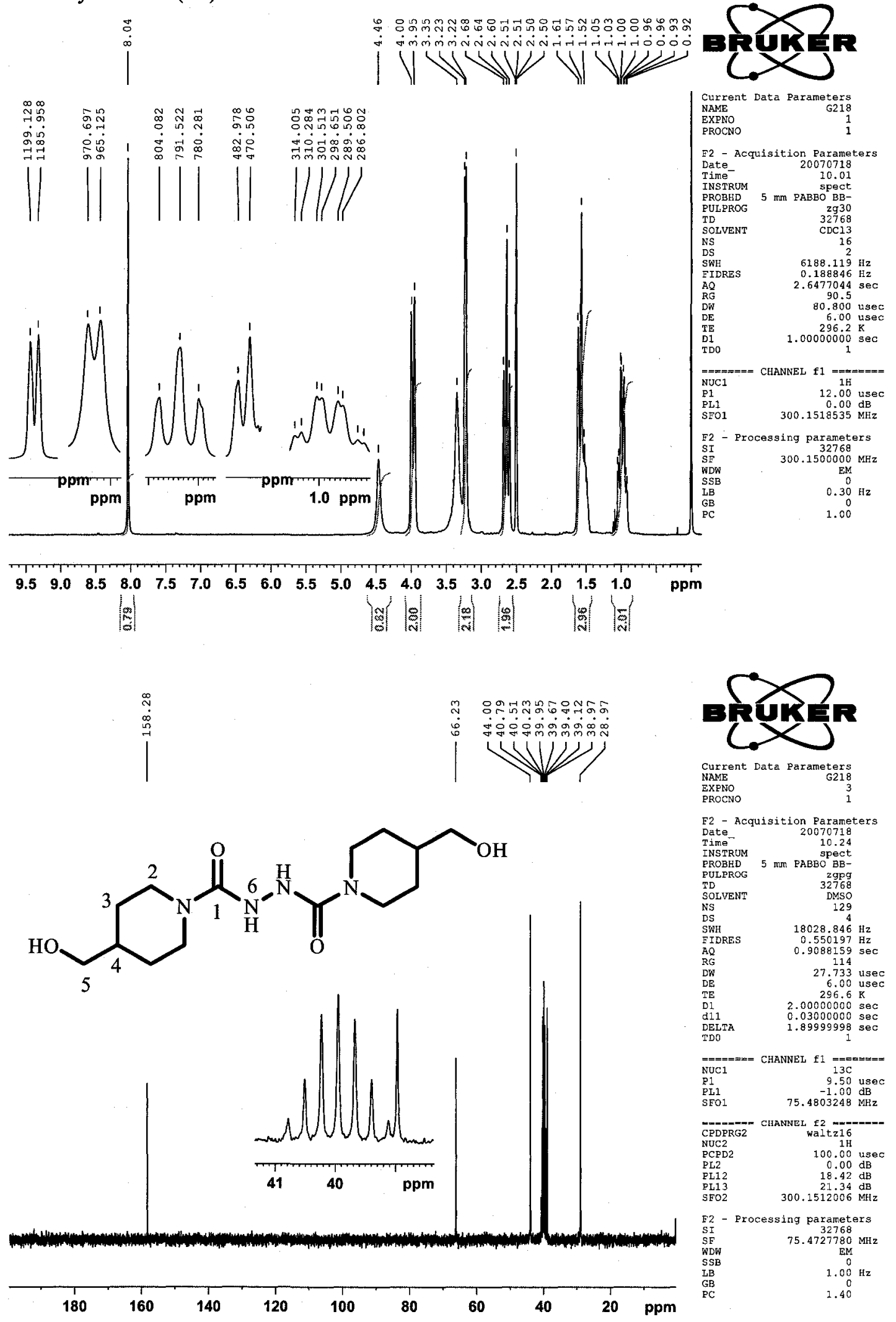



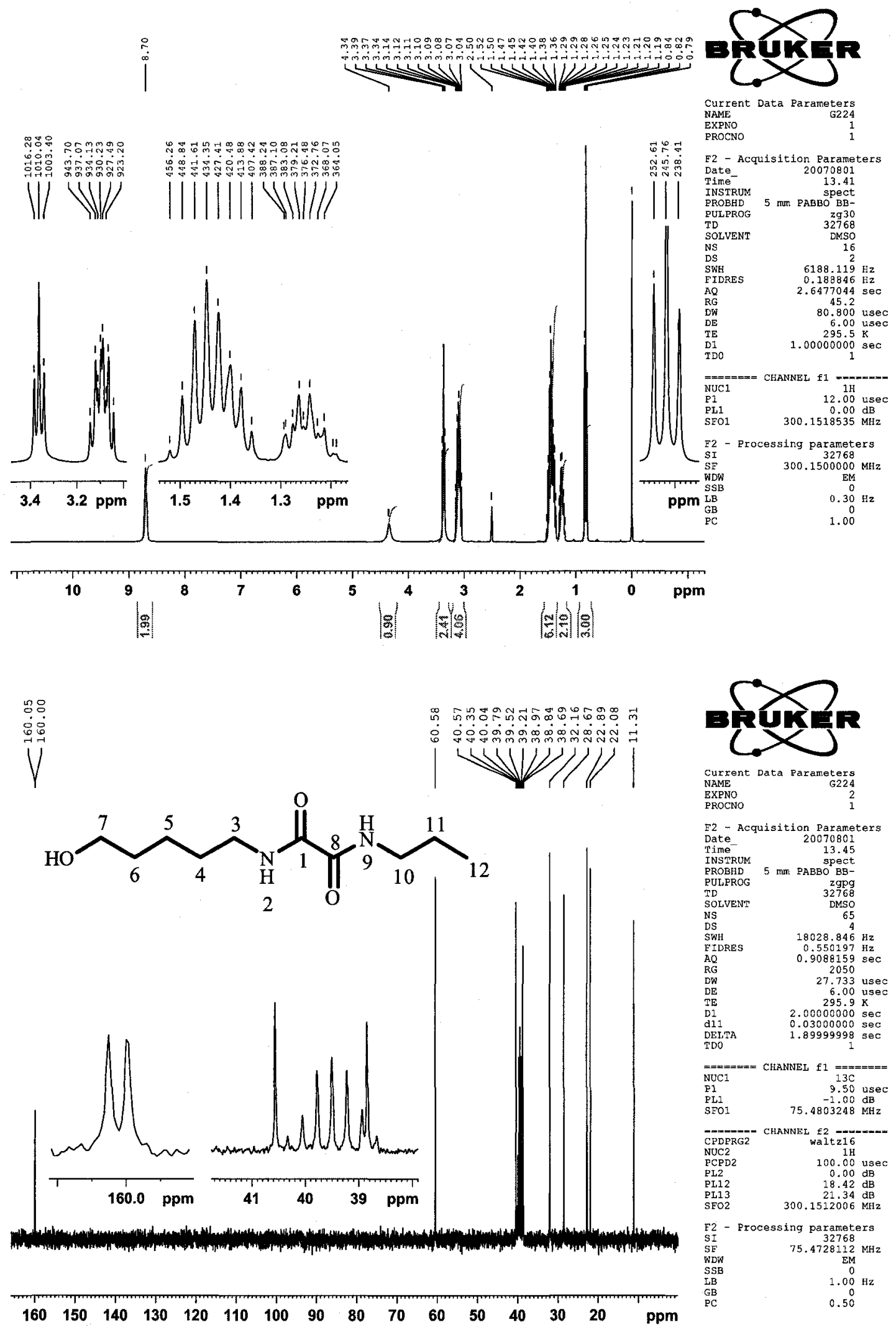
$N^{l}, N^{2}$-bis(4-aminobenzyl)hydrazine-1,2-dicarboxamide (21)
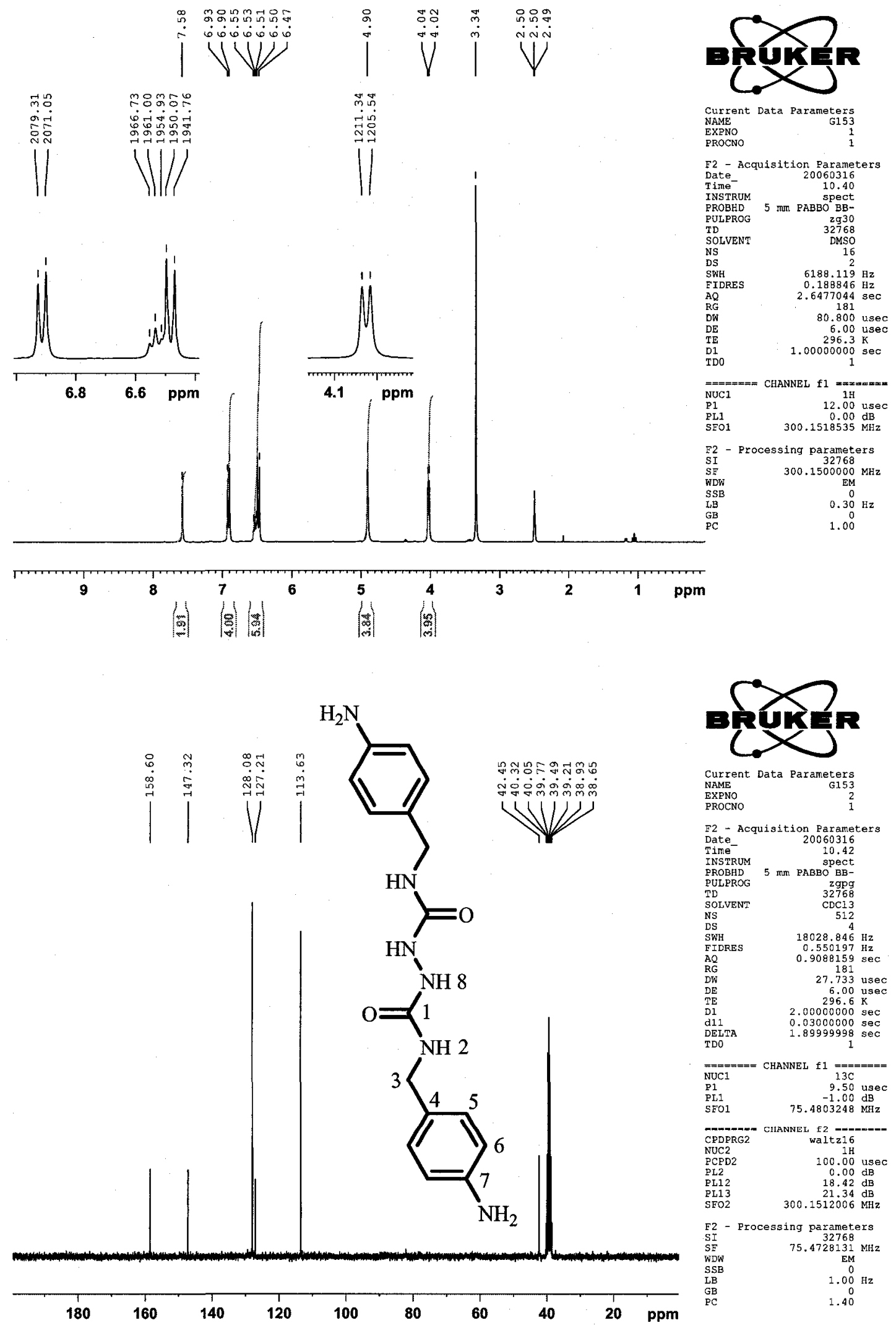

F2 - Acquisition Parameter
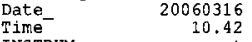

spect
INSTRUM 5 min PABBO BB-

zgpg

TD

NS
DS
SWH

4
$18028.846 \mathrm{~Hz}$

$\begin{array}{ll}\text { AODES } & 0.550197 \mathrm{~Hz} \\ \mathrm{CH} & 0.9088159 \mathrm{seC}\end{array}$

$\begin{array}{rr}\text { RG } & 181 \\ \text { DW } & 27.733 \text { usec } \\ \text { DE } & 6.00 \text { usec }\end{array}$

$\begin{array}{lr}\text { TE } & 6.00 \mathrm{us} \\ \mathrm{DI} & 296.6 \mathrm{~K} \\ \mathrm{Cl} & 2.00000000 \mathrm{sec}\end{array}$

$\begin{array}{ll}\text { d11 } & 0.03000000 \mathrm{sec} \\ \text { DELTA } & 1.89999998 \mathrm{sec}\end{array}$

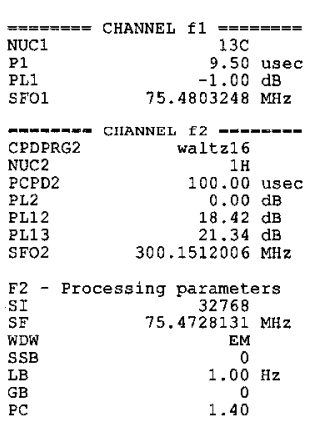



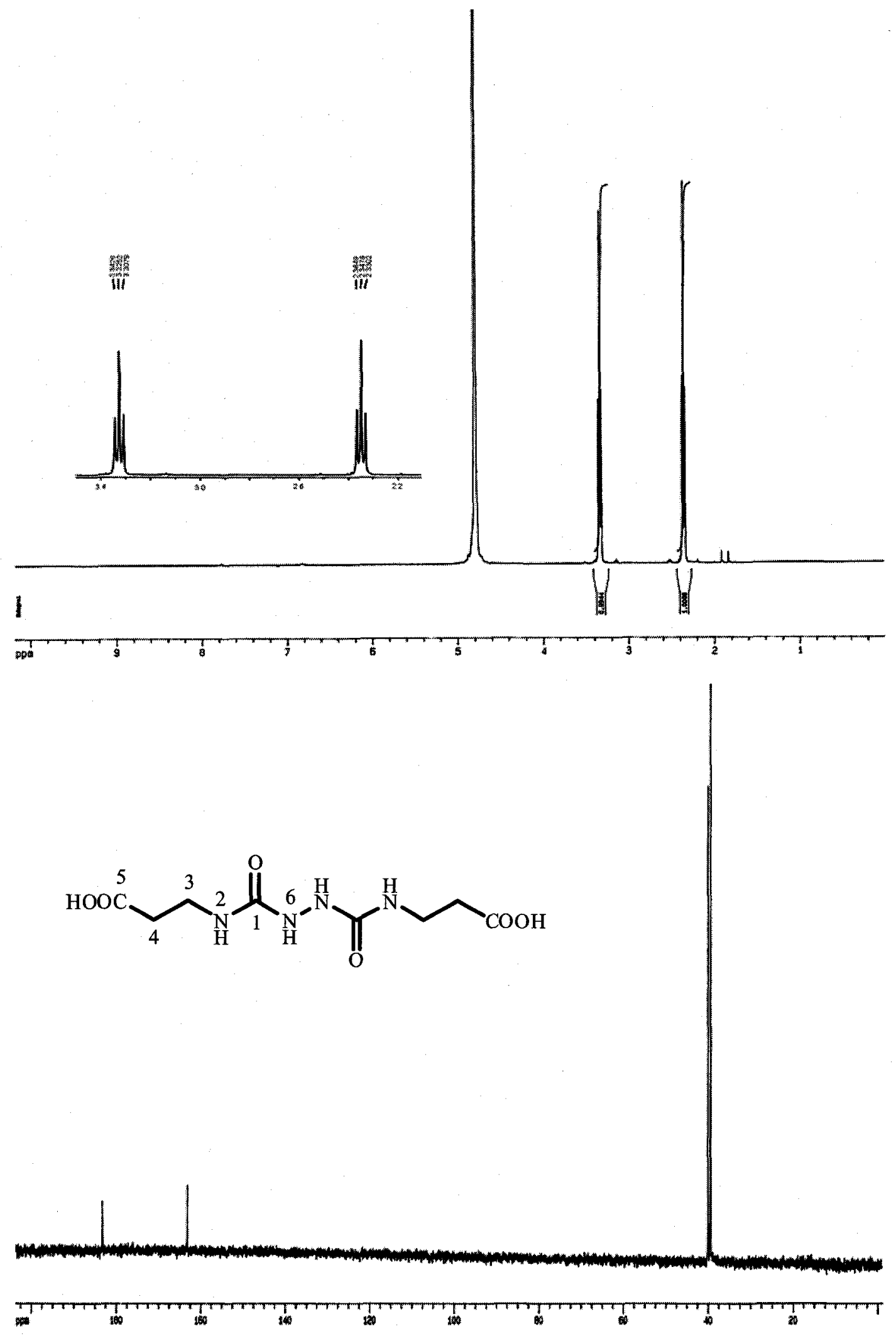

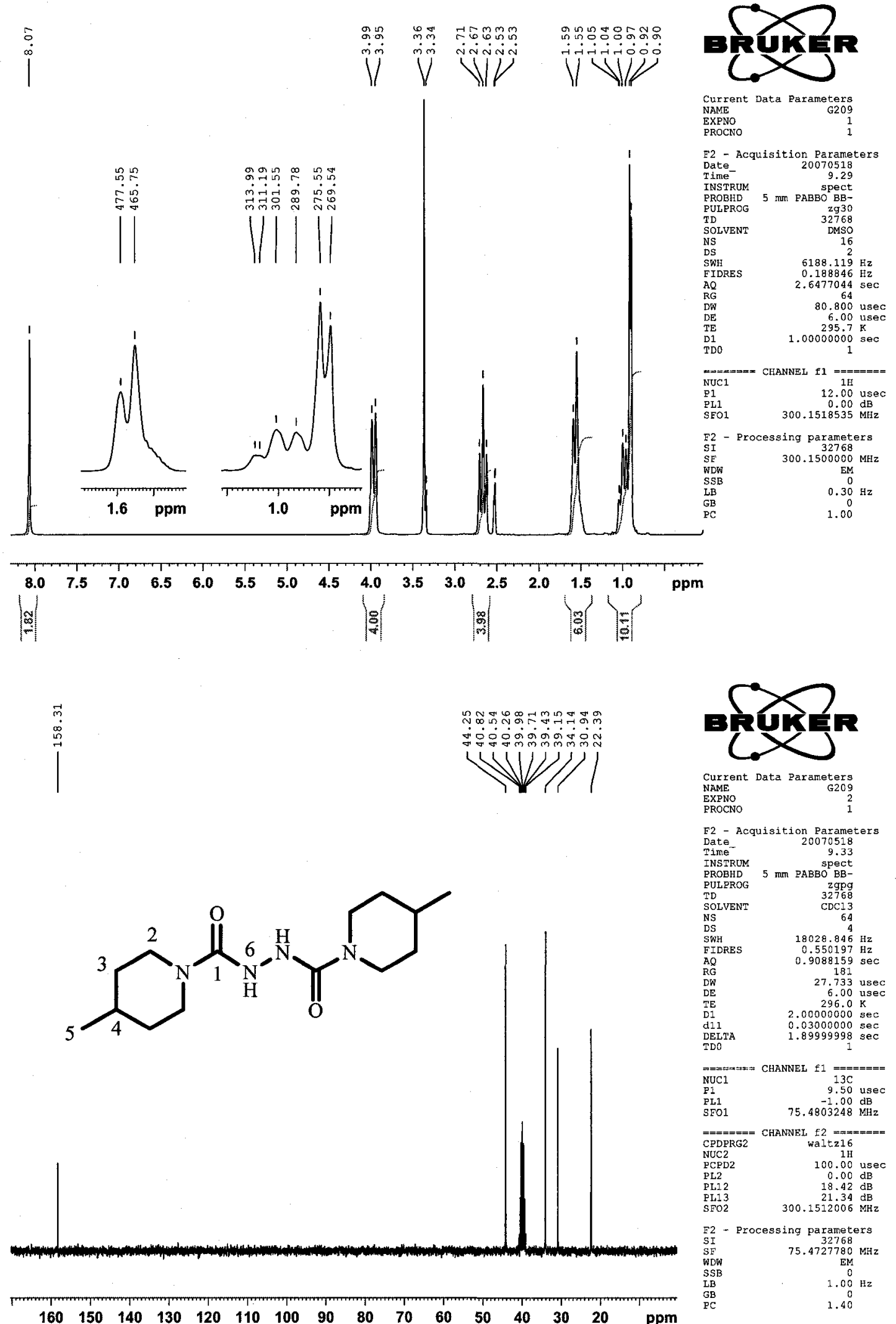


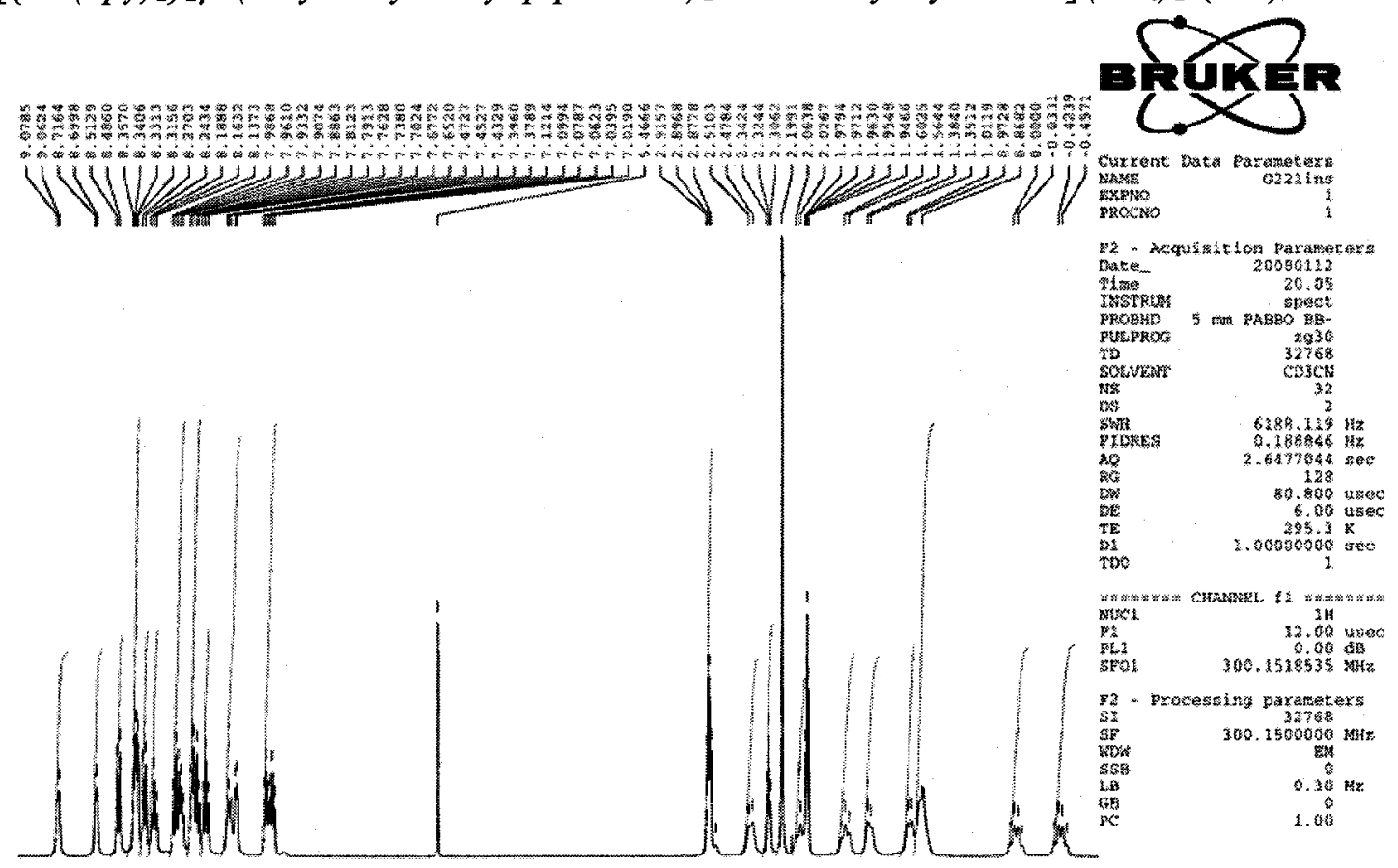

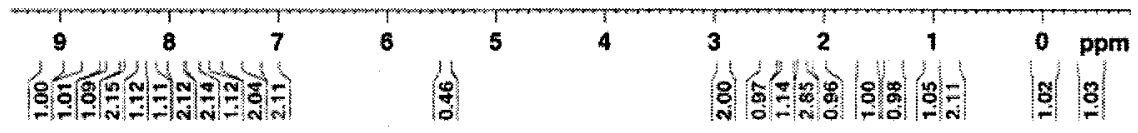

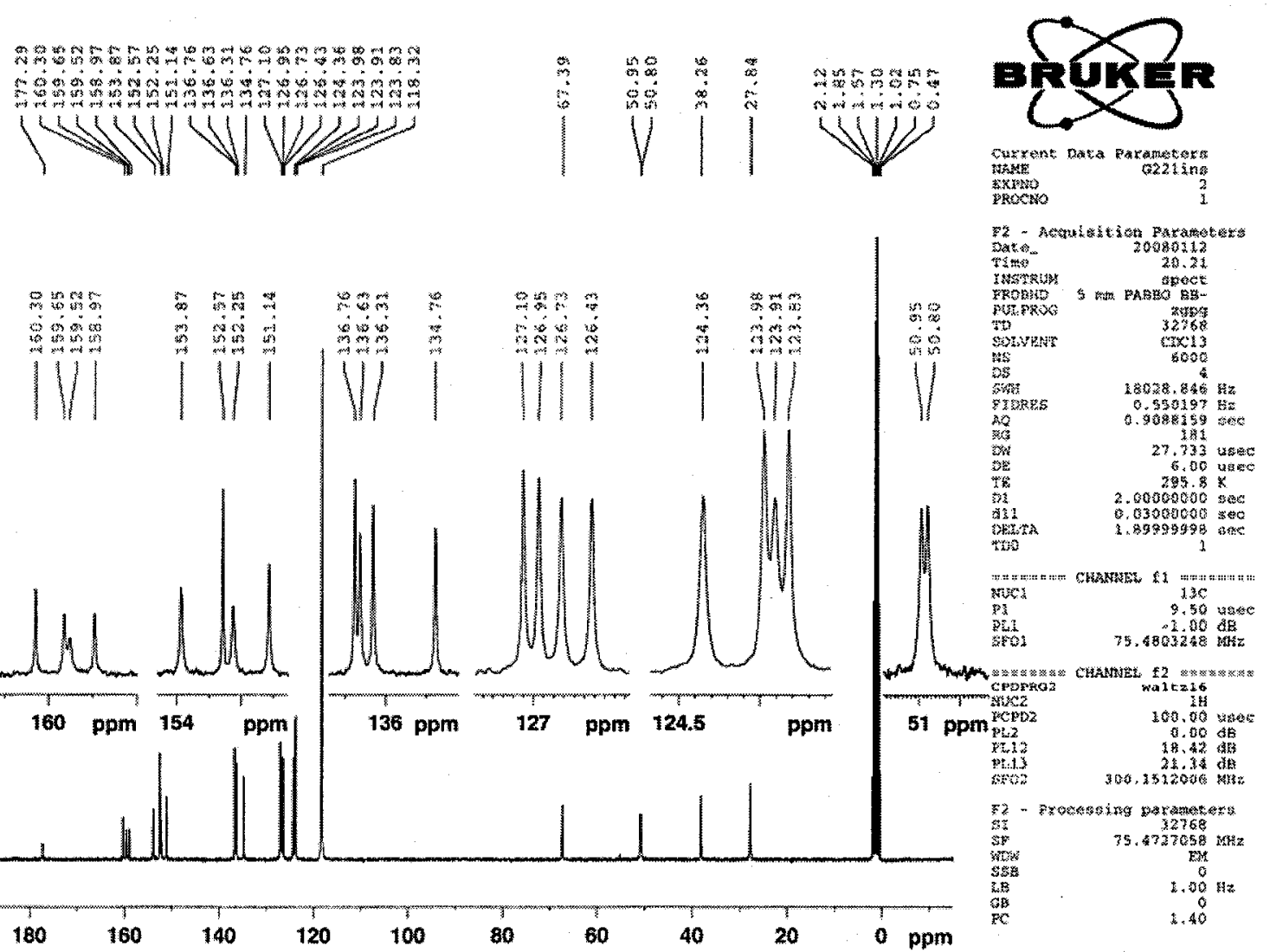


Structure model with atom numbering for resonance assignments (half the molecule is masked for clarity)

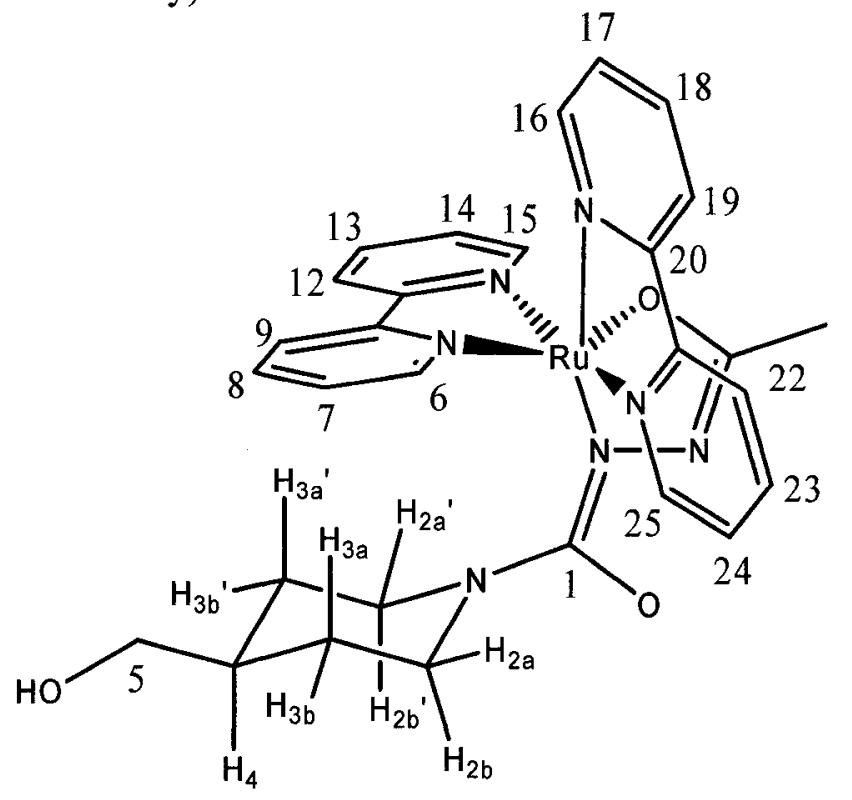

3-D model of 39 showing spacial interactions as seen from NOESY

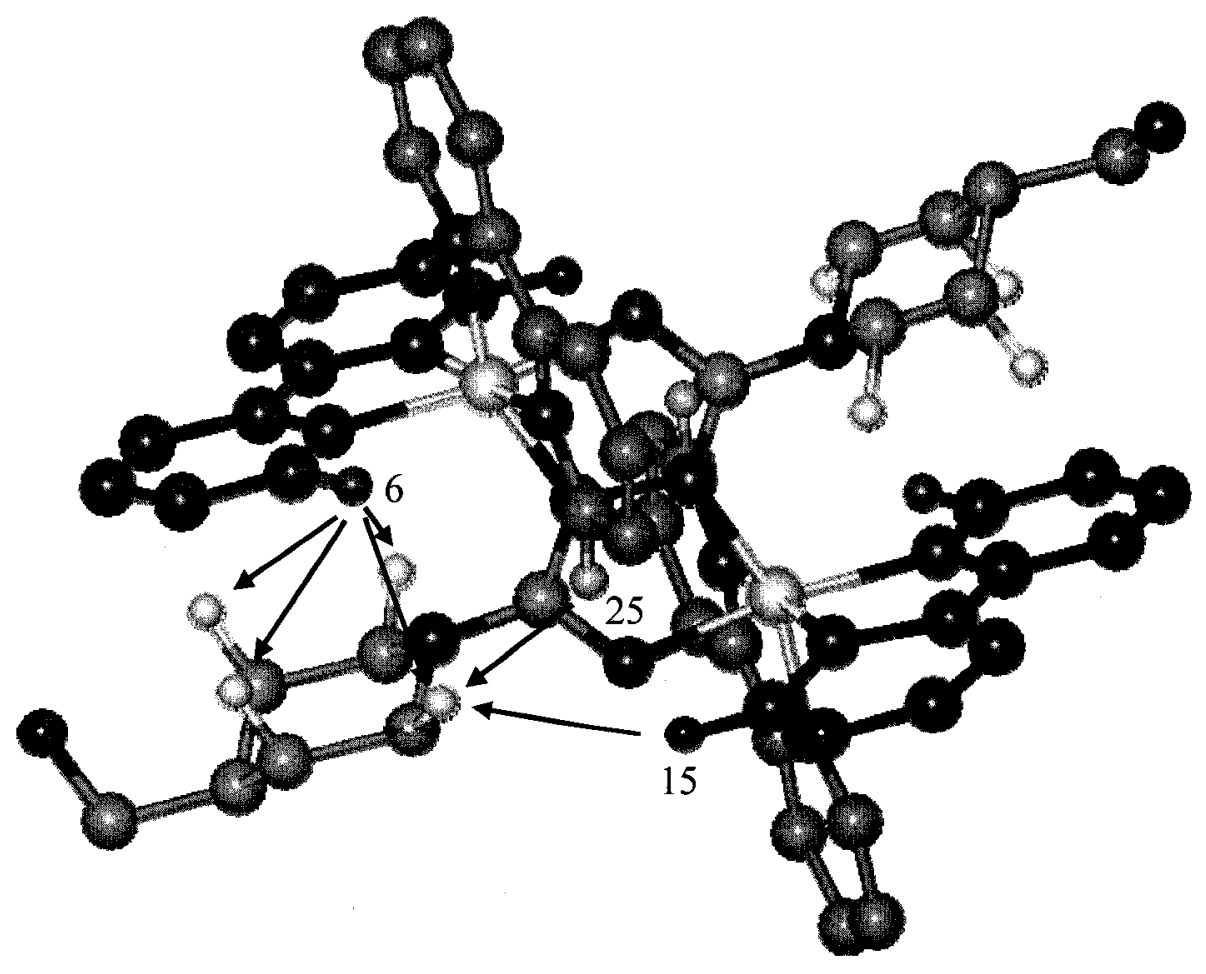



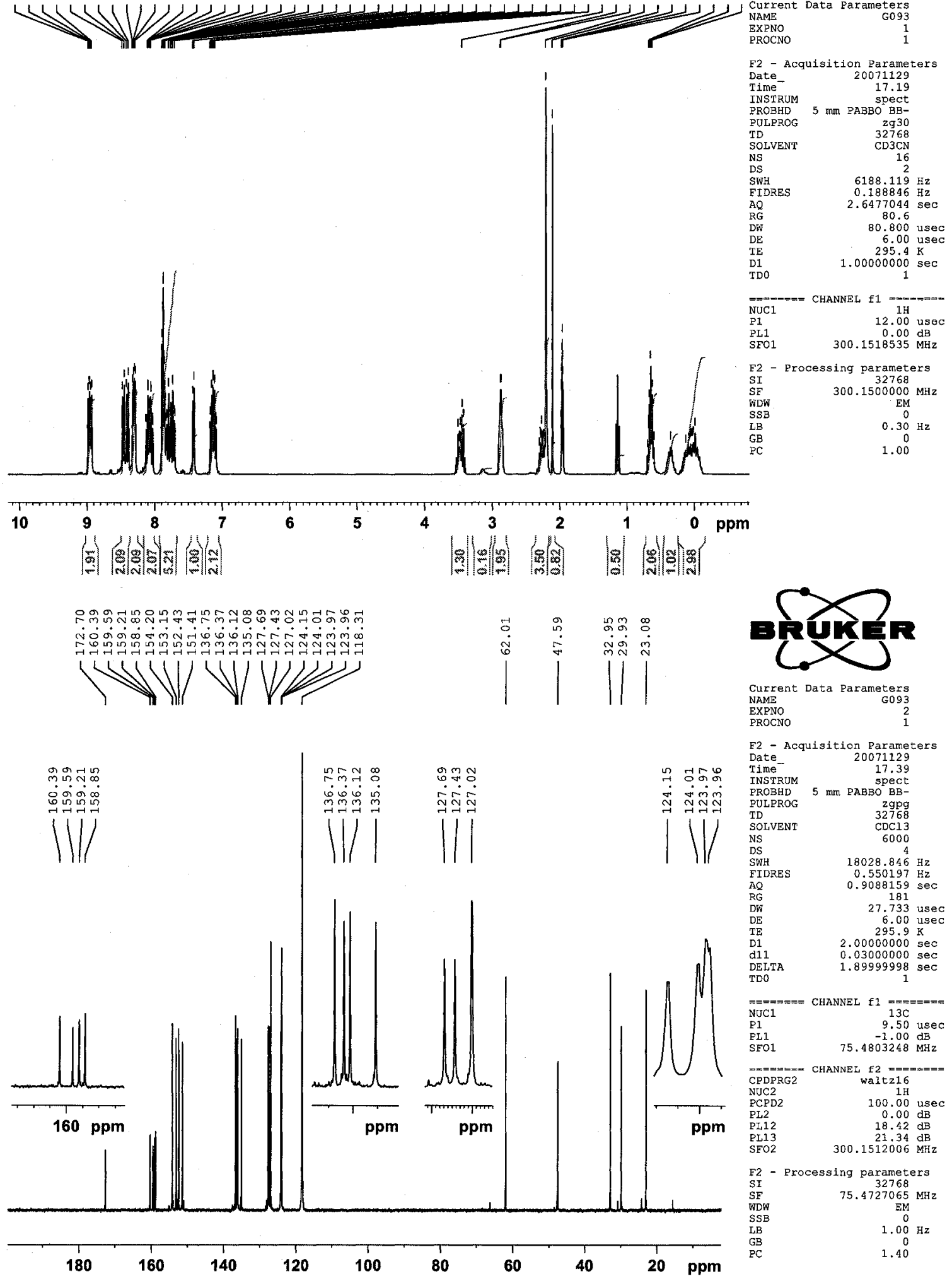
Structure model with atom numbering for resonance assignments (half the molecule is masked for clarity)

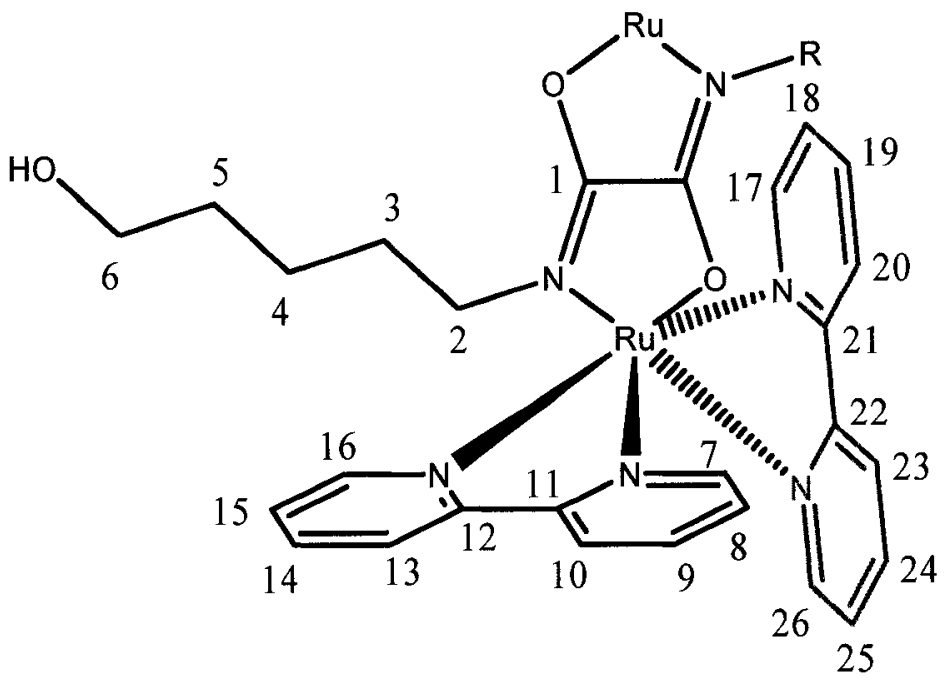

3-D model of 41 showing spacial interactions as seen from NOESY

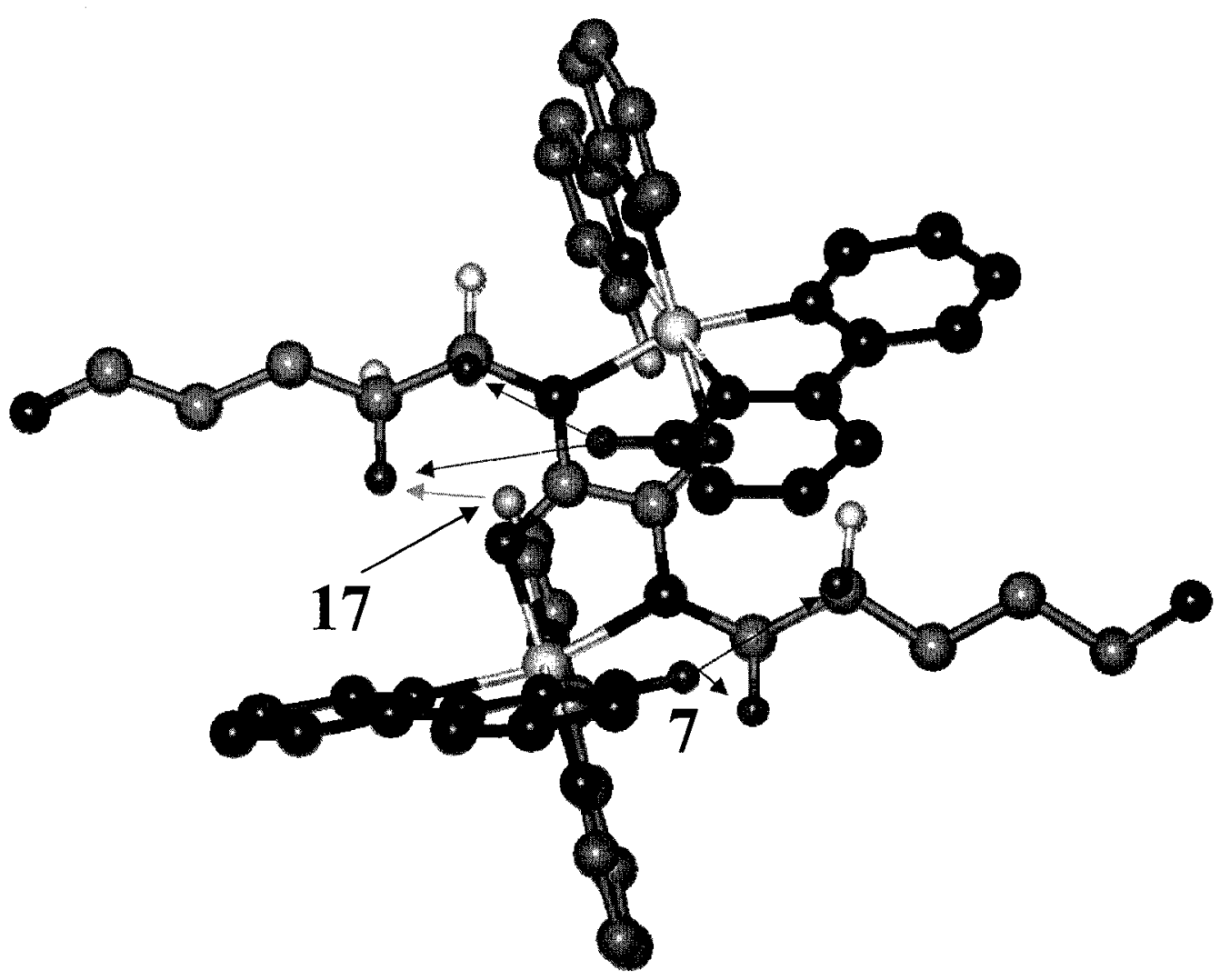


$\left[\{\text { Pt(ppy })_{2}\right\}_{2} \mu-(\text { heptyl })_{2}$-dicarbonyl hydrazine $]$ (44)
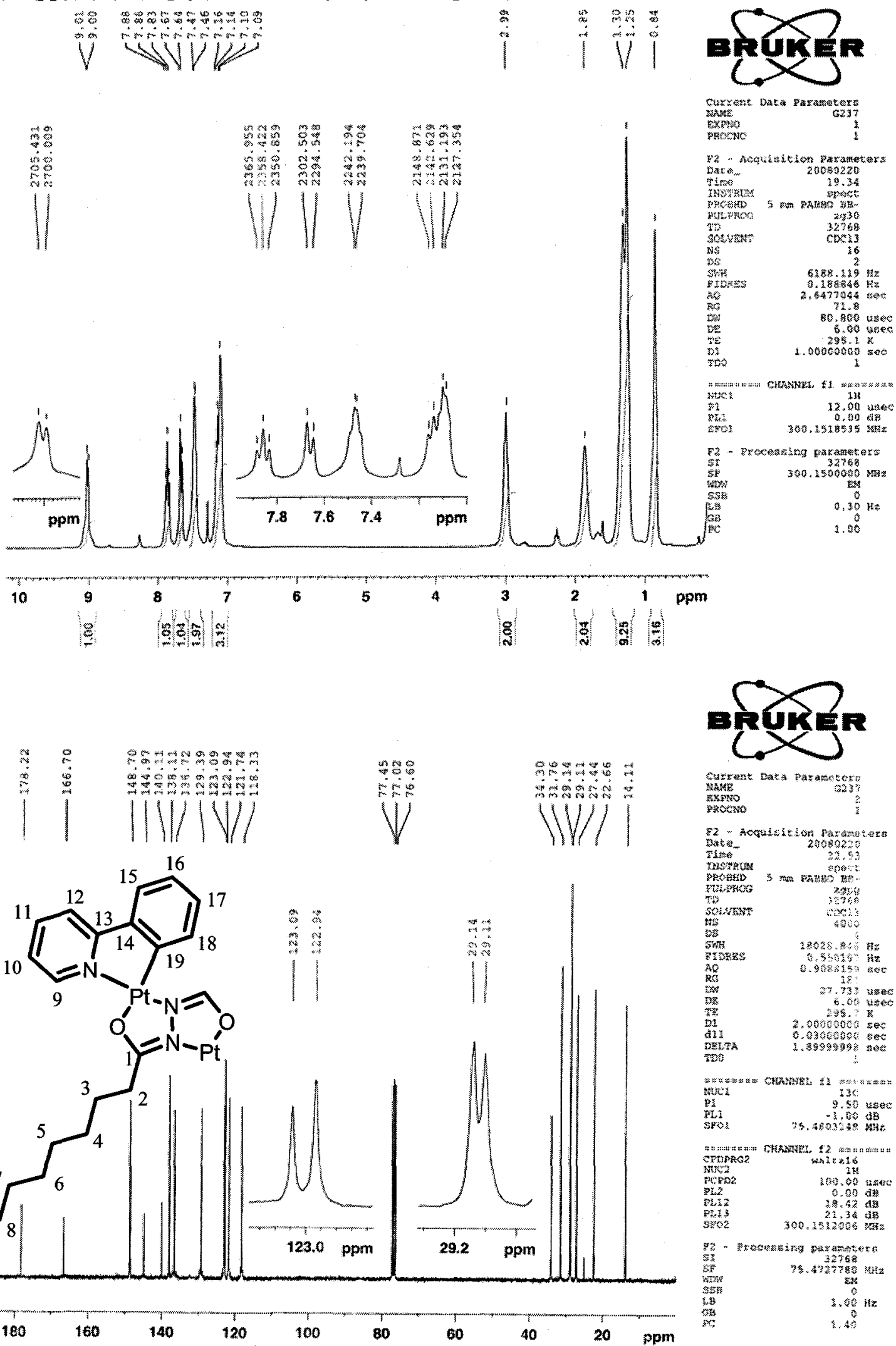


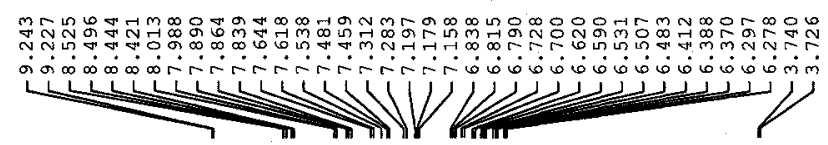<smiles></smiles>

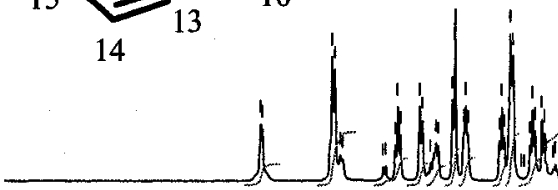

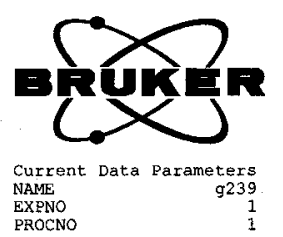

on Parameters

Time-

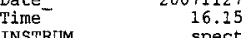

PROBHD $5 \mathrm{~mm}$ PABBO BB-

PULPROG

SOLVENT

NS
DS
SWH

FIDRES $\quad 6188.119 \mathrm{~Hz}$

AQ $\quad 2.6477044 \mathrm{sec}$

DW 80,800 usec

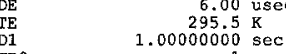

Do

\begin{tabular}{ll}
\hline$===m a \pi=$ CHANNEL & f1 $m====m=$ \\
NUC1 & $1 \mathrm{H}$ \\
P1 & 12.00 usec
\end{tabular}

$\begin{array}{lr}\text { PL1 } & 0.00 \mathrm{~dB} \\ \text { SFO1 } & 300.1518535 \mathrm{MHz}\end{array}$

F2 - processing parameters

$\begin{array}{lr}\text { E2 - Processing parameters } \\ \text { SI } & 32768 \\ \text { SF } & 300.1500000 \mathrm{MHz}\end{array}$

$\begin{array}{lc}\text { WDW } & \text { EM } \\ \text { SSB } & 0 \\ \text { LB } & 0.30 \mathrm{~Hz} \\ \text { GB } & 0\end{array}$

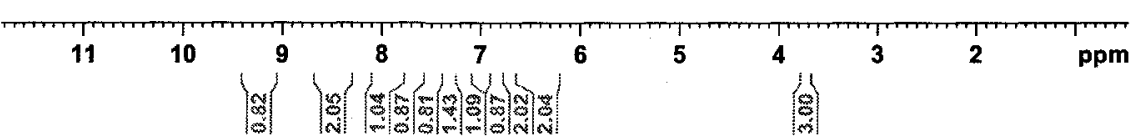

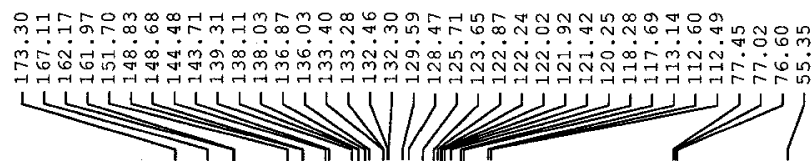
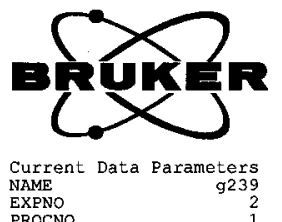

PROCNO

F2 - Acquisition Parameters

Date_r 20071127

Time-

INSTRUM

TDLPROG

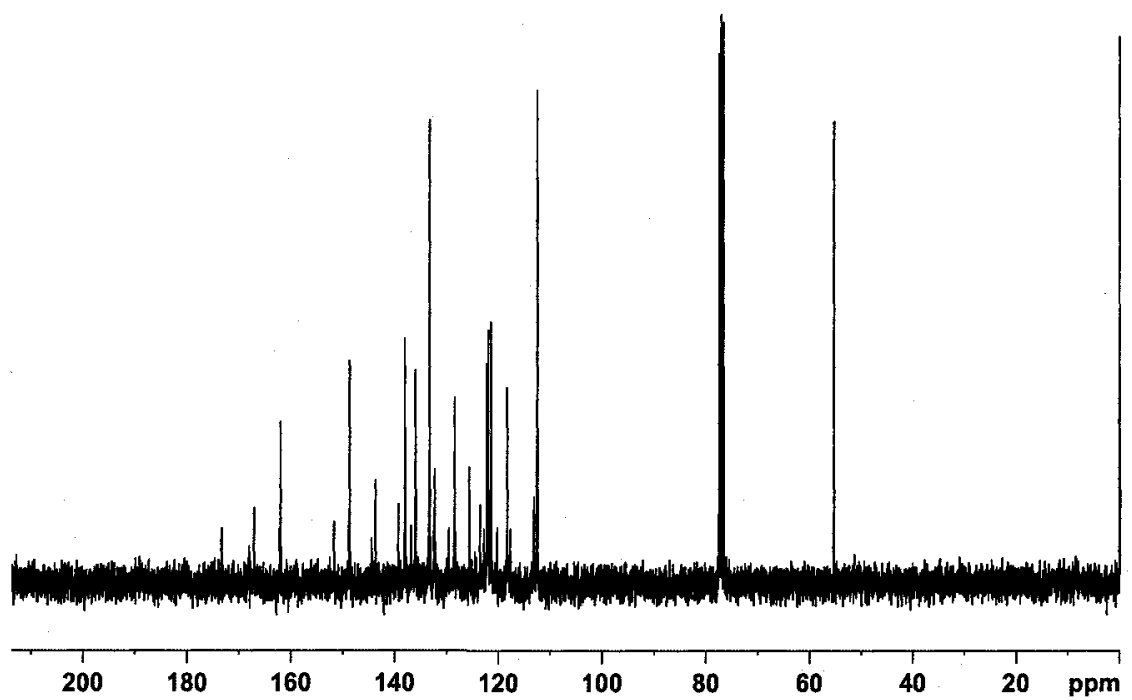

SS

$\begin{array}{lr}\text { NS } & 512 \\ \text { DS } & 4 \\ \text { SWH } & 18028.846 \mathrm{~Hz}\end{array}$

$\begin{array}{ll}\text { FIDRES } & 18028.846 \mathrm{~Hz} \\ 0.550197 \mathrm{~Hz} & 0.9088159 \mathrm{sec}\end{array}$

AQ $\quad 0.9088159 \mathrm{sec}$

RW $\quad 27.731$ usec

$\begin{array}{lr}\mathrm{DE} & 6.00 \mathrm{use} \\ \mathrm{TE} & 296.0 \mathrm{~K}\end{array}$

D1 $\quad \begin{array}{ll}2.00000000 \mathrm{sec} \\ \text { d11 }\end{array}$

DELTA $\quad 1.89999998 \mathrm{sec}$

$=======$ CHANNEL $\mathrm{fl} \underset{13 \mathrm{C}}{======}$

$\begin{array}{lr}\text { NUC1 } & 13 \mathrm{C} \\ \mathrm{P1} & 9.50 \text { usec }\end{array}$

PL1 $\quad 75.4803248 \mathrm{dBz}$

$== \pm==m==$ CHANNEL $f 2=== \pm==$
walt $z 16$

TUC2 waltz16

PCPD2 100.00 usec

PL2

$18.42 \mathrm{~dB}$

F2 - Processing parameters

SI $\quad 75.4727780 \mathrm{MH}$

WDW

$\begin{array}{ll}\mathrm{LB} & 0 \\ \mathrm{~GB} & 1.00 \mathrm{~Hz} \\ \mathrm{PC} & 1.40\end{array}$ 

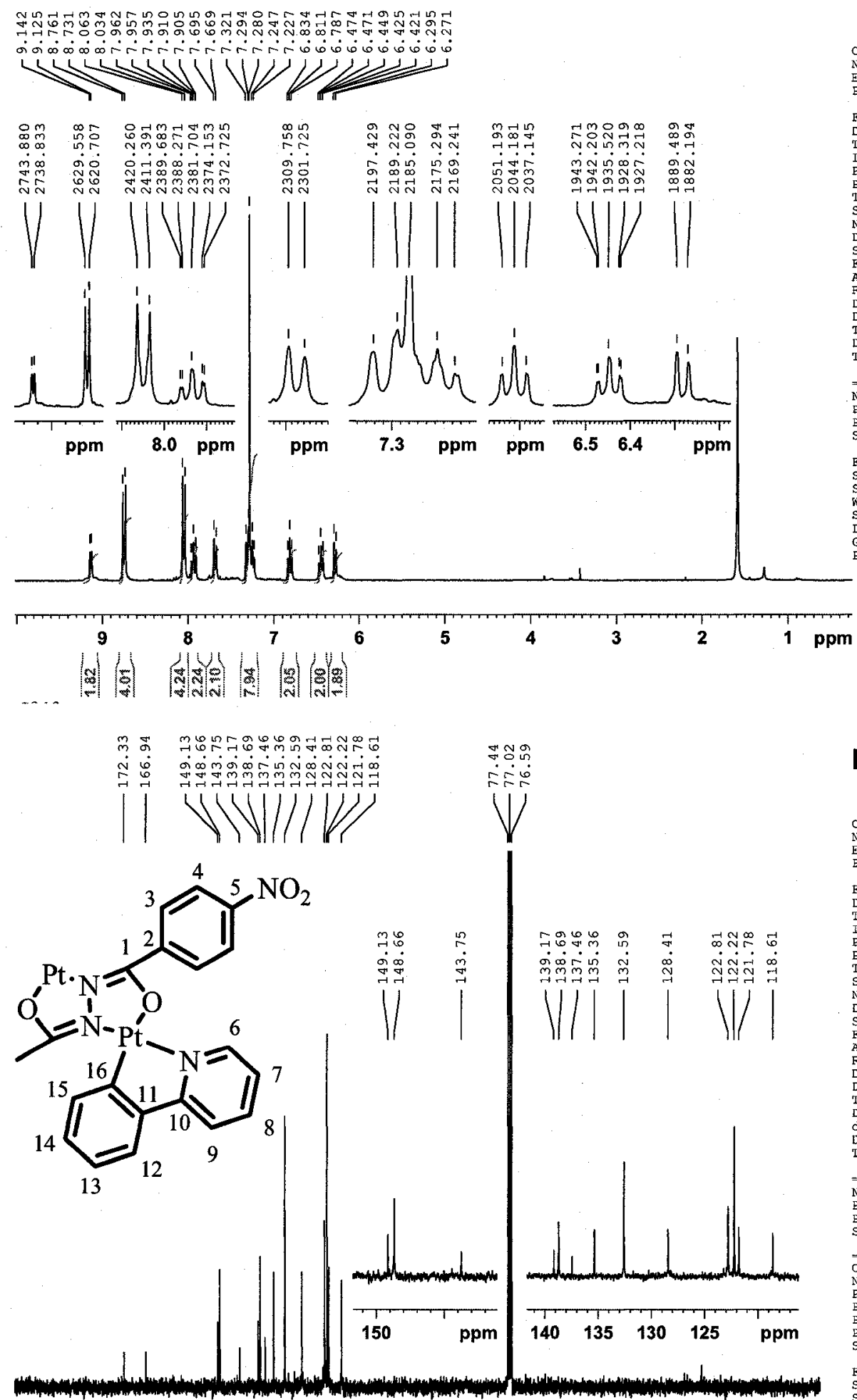

180
160

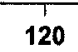

100

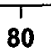

80
60
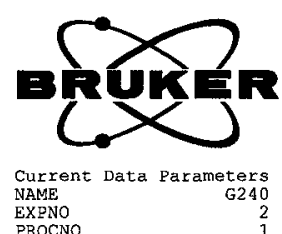

EXPNO

F2 - Acquisition Parameters

F2 - Acquisition Parameter
Date_r
Time

INSTRUM spect

PROBHD $5 \mathrm{~mm}$ PABBO BB-$$
\text { TD }
$$

TD

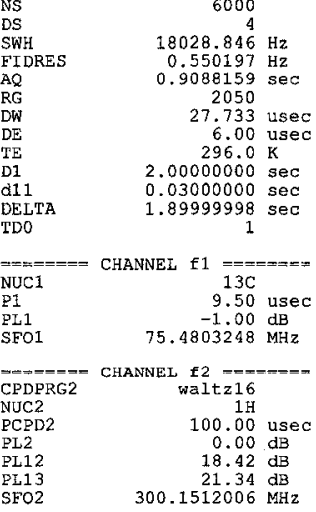

SFO2 $300.1512006 \mathrm{MH}$

$\begin{array}{lc}\text { F2 - Processing parameters } \\ \text { SI } & 32768 \\ \text { SF } & 75.4727780 \mathrm{MHz} \\ \text { WDW } & \text { EM } \\ \text { SSB } & 0 \\ \text { LB } & 0 \\ \text { GB } & 1.00 \mathrm{~Hz} \\ \text { PC } & 0 \\ & 1.40\end{array}$ 


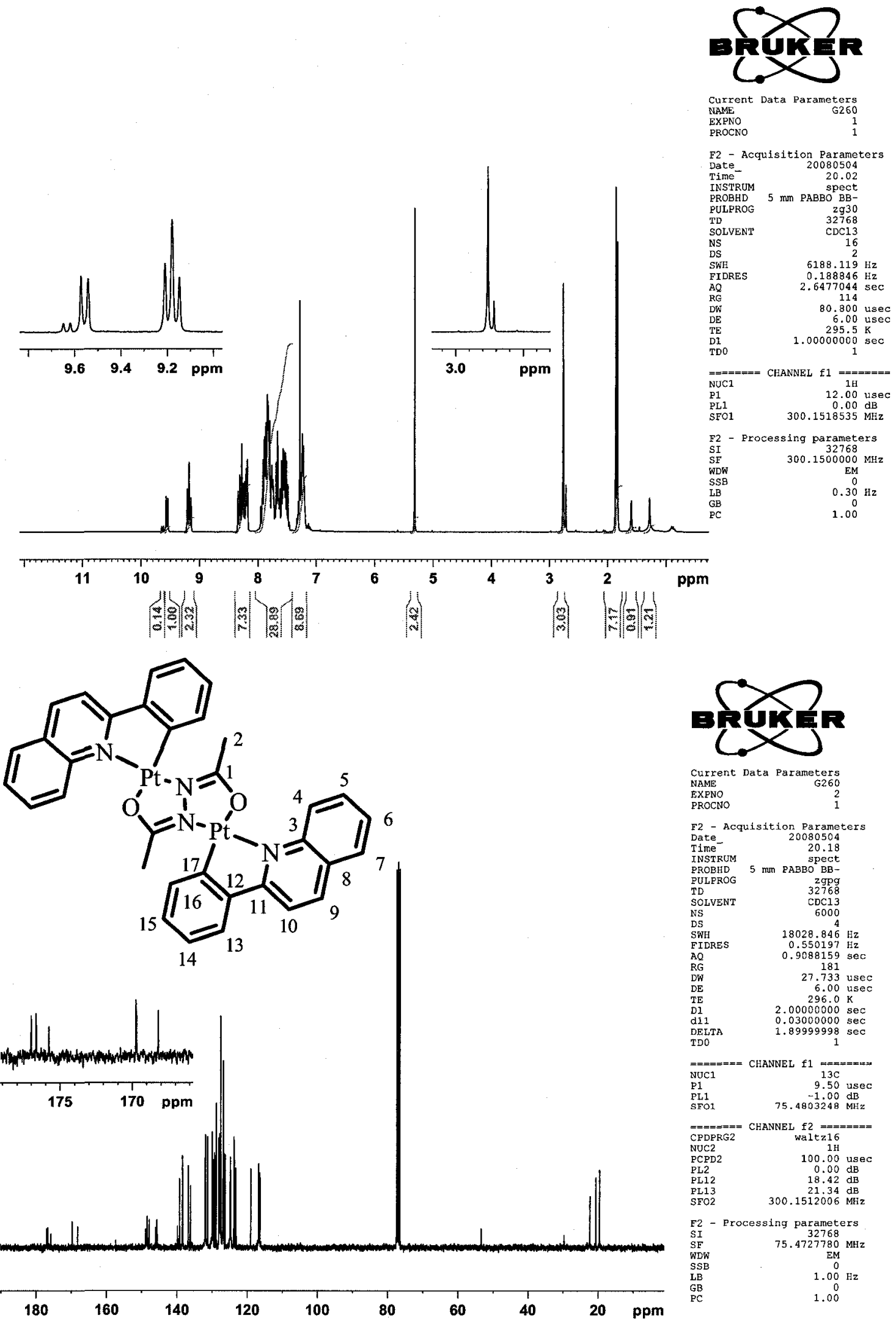




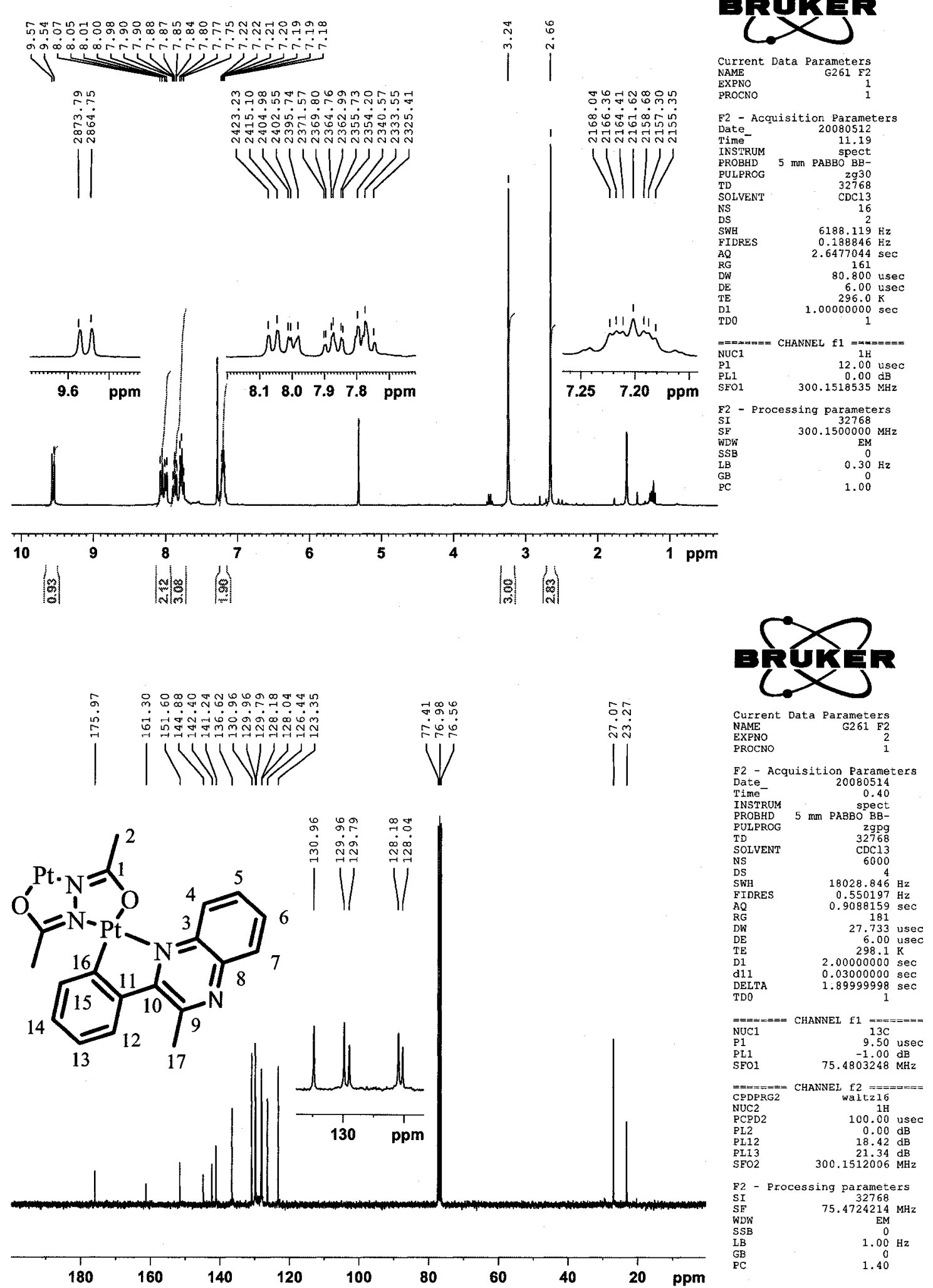




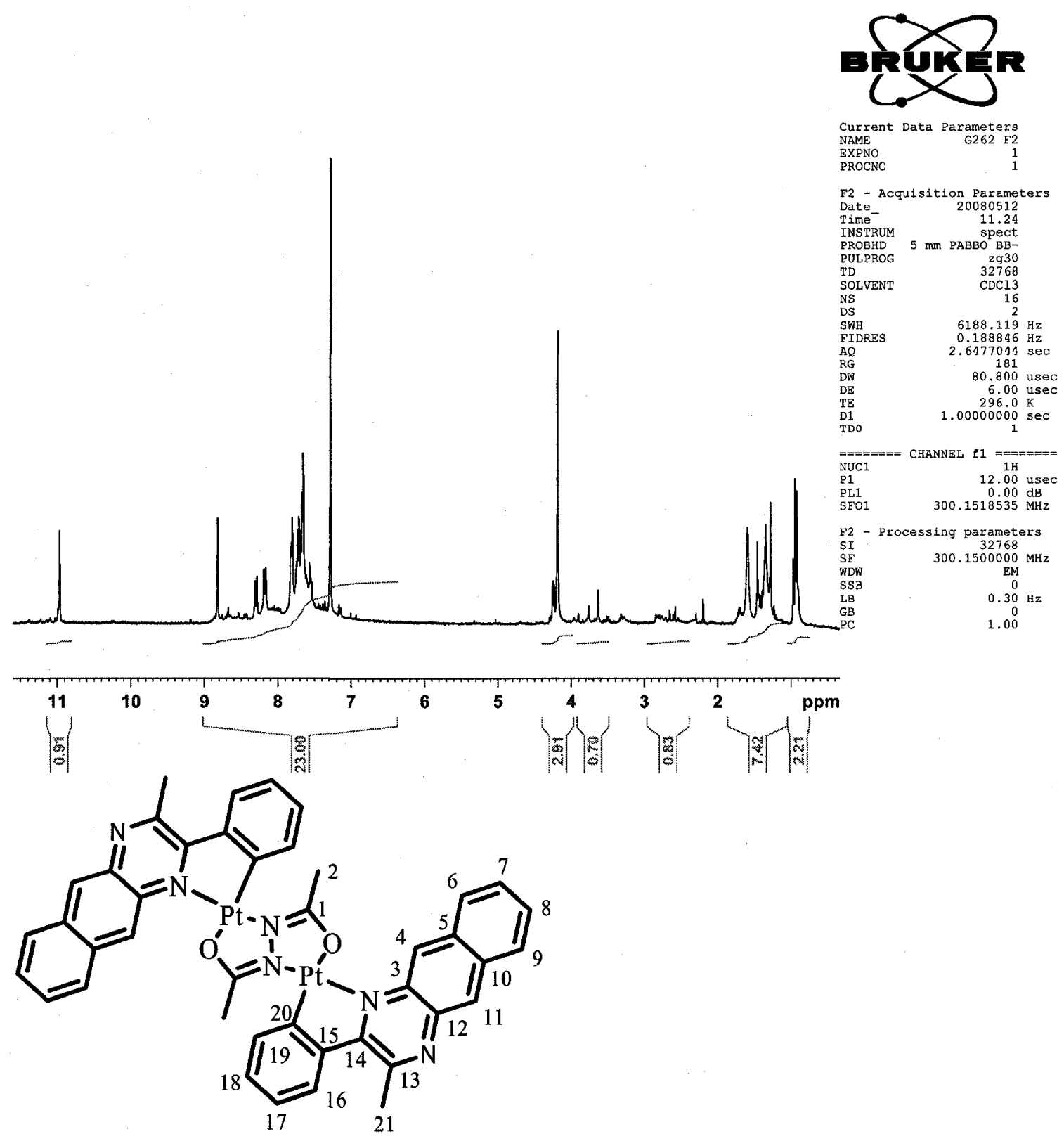




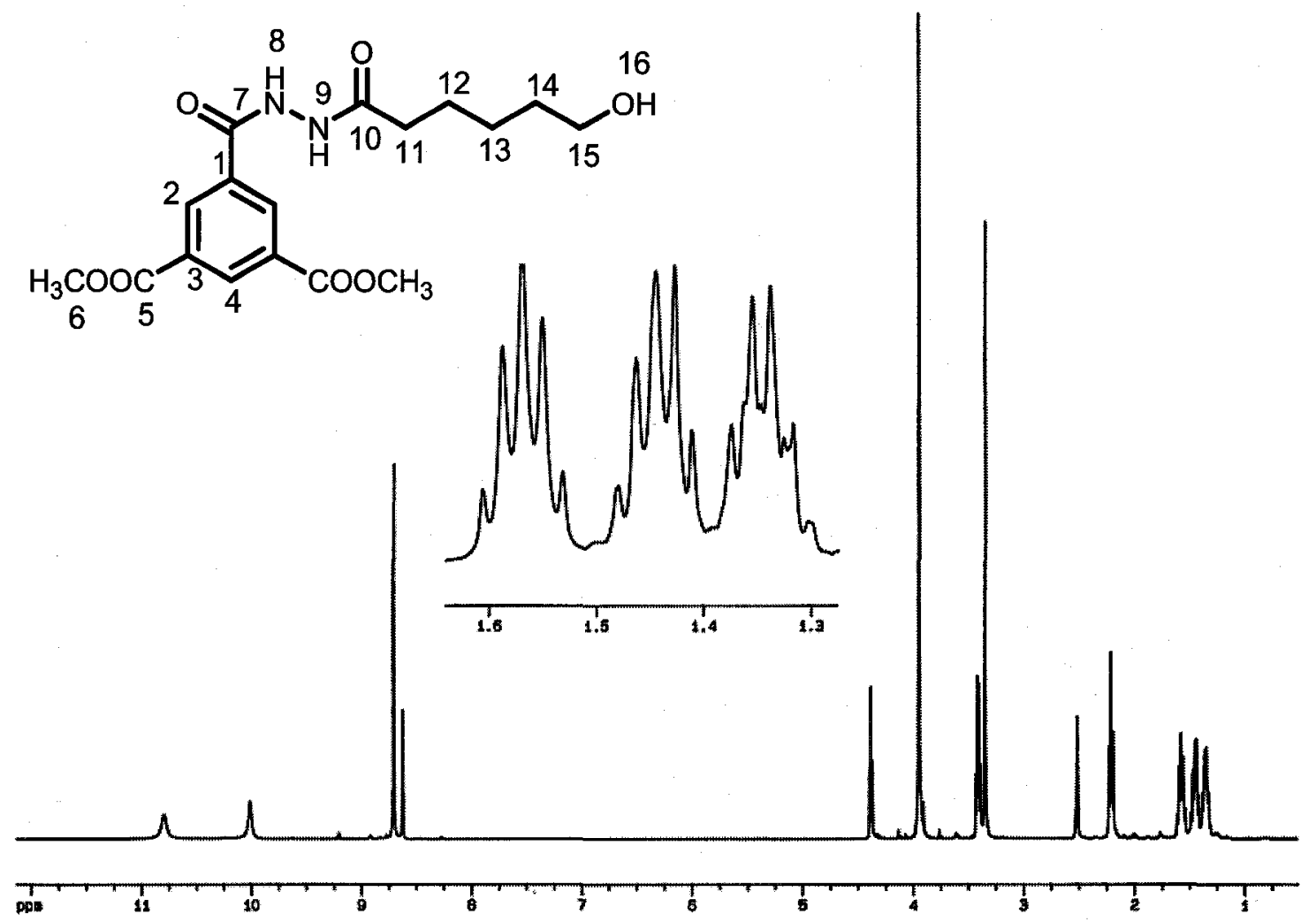




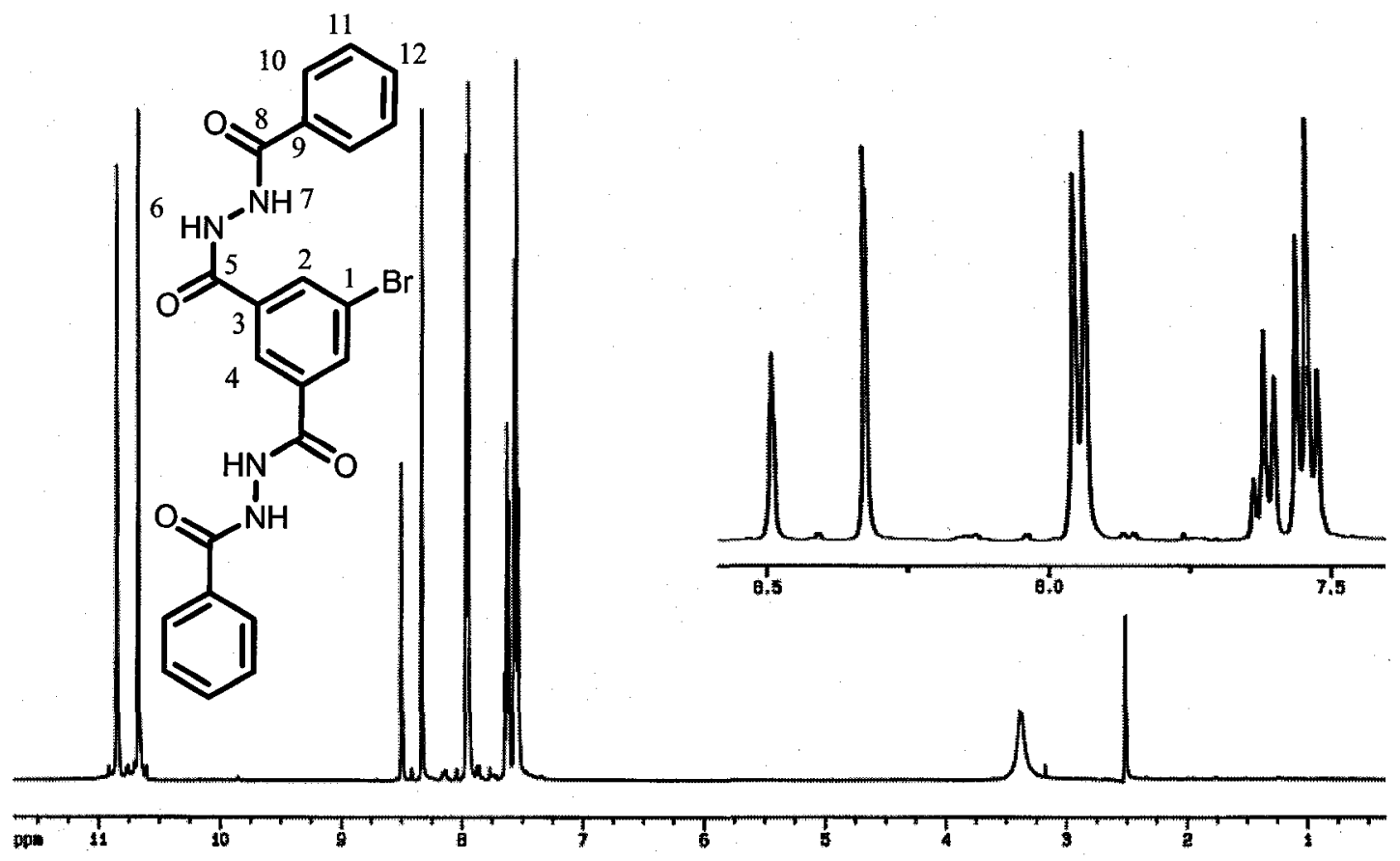


Tri-boronic acid G1 dendrimer core (56)

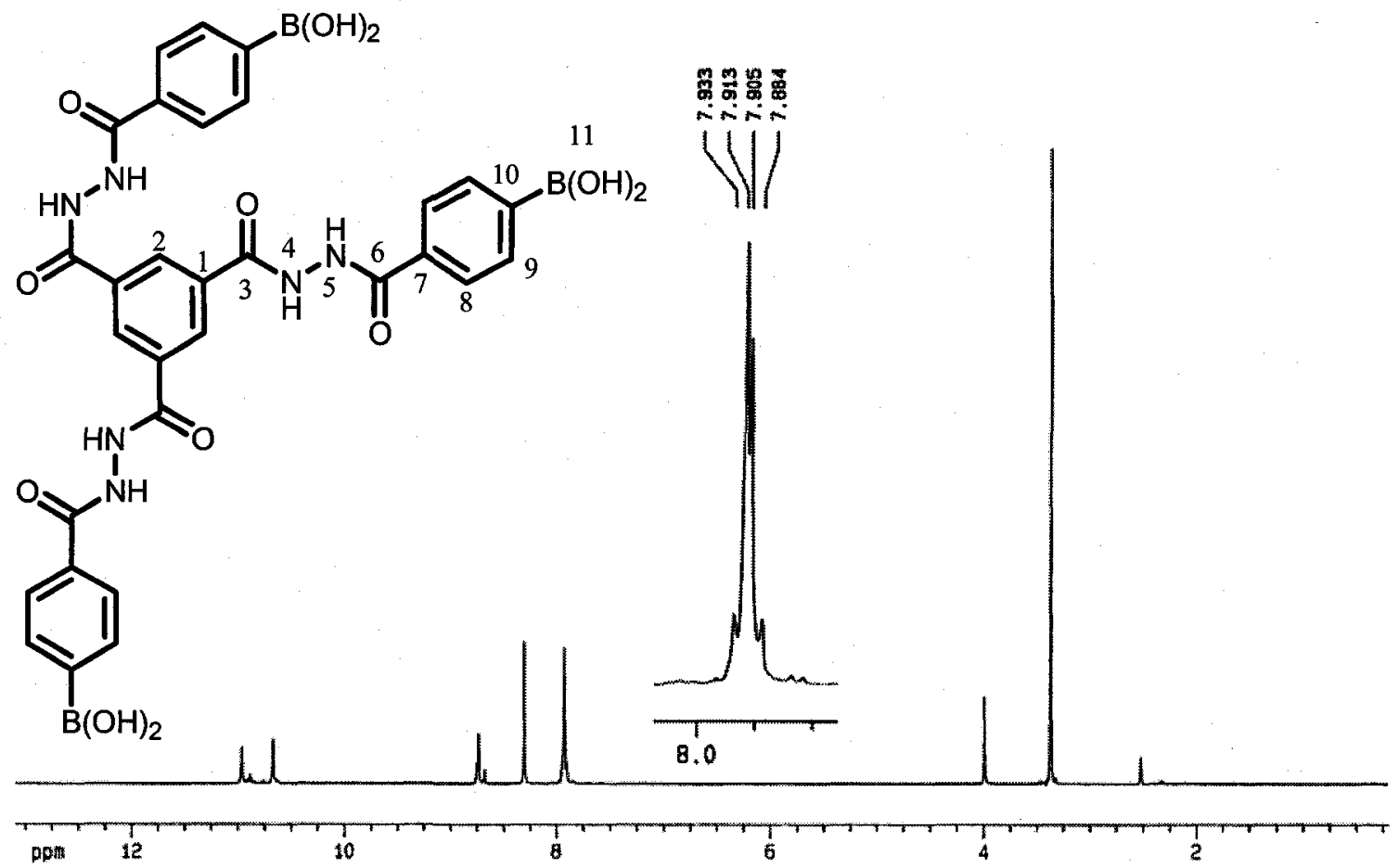


Cinnamoyl-terminated tetraDCH GI dendrimer (58)
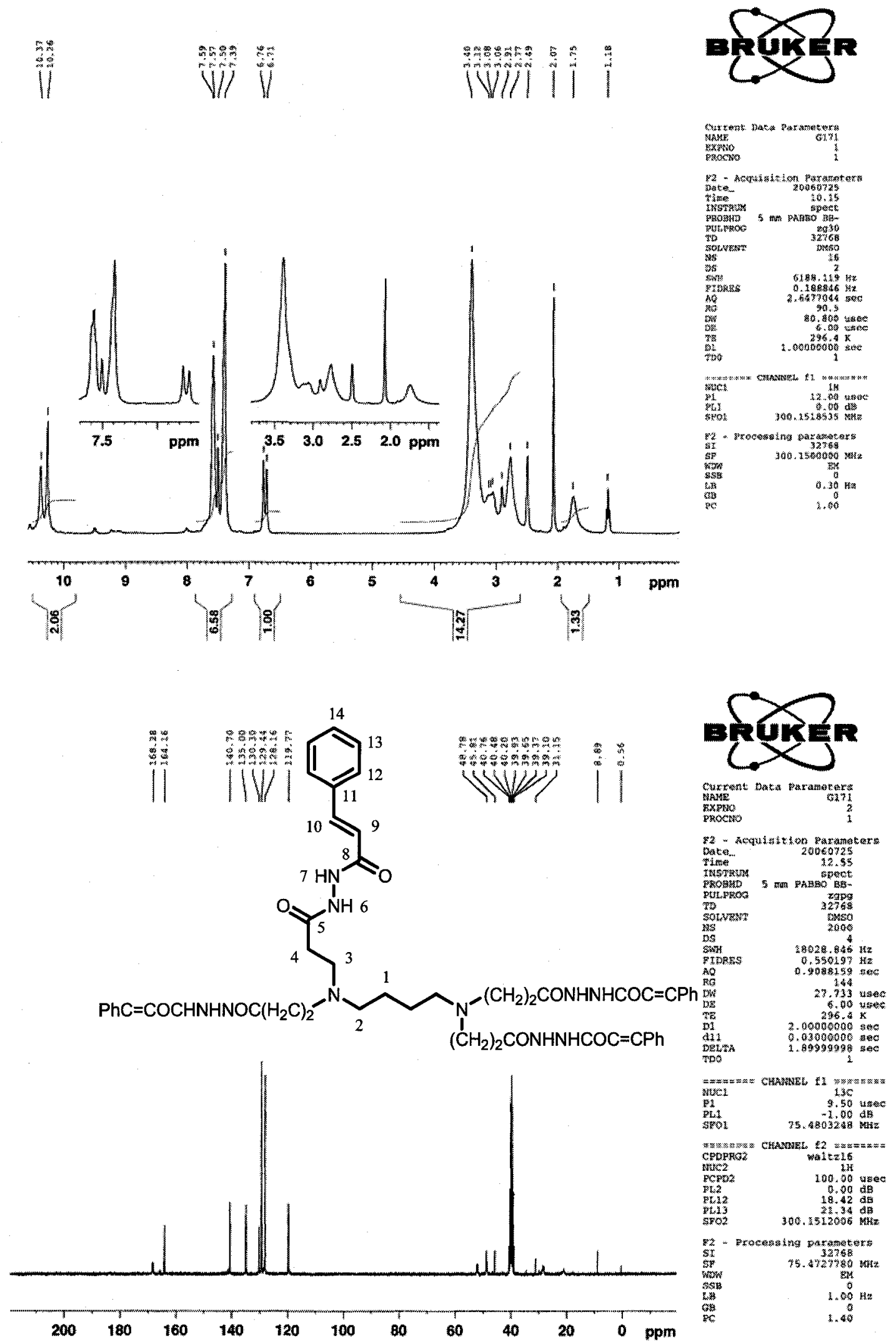


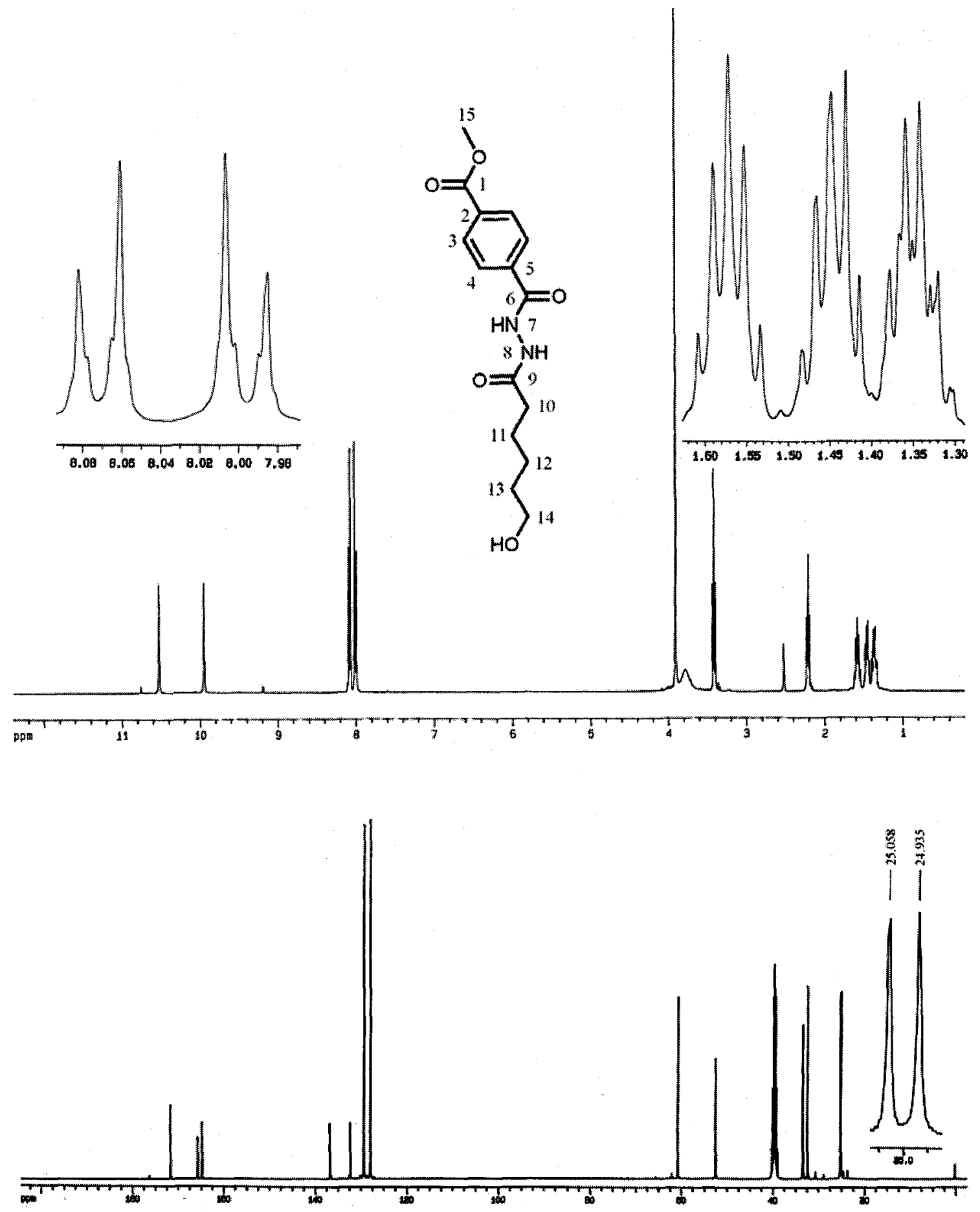


Propargyl oxamide (61)

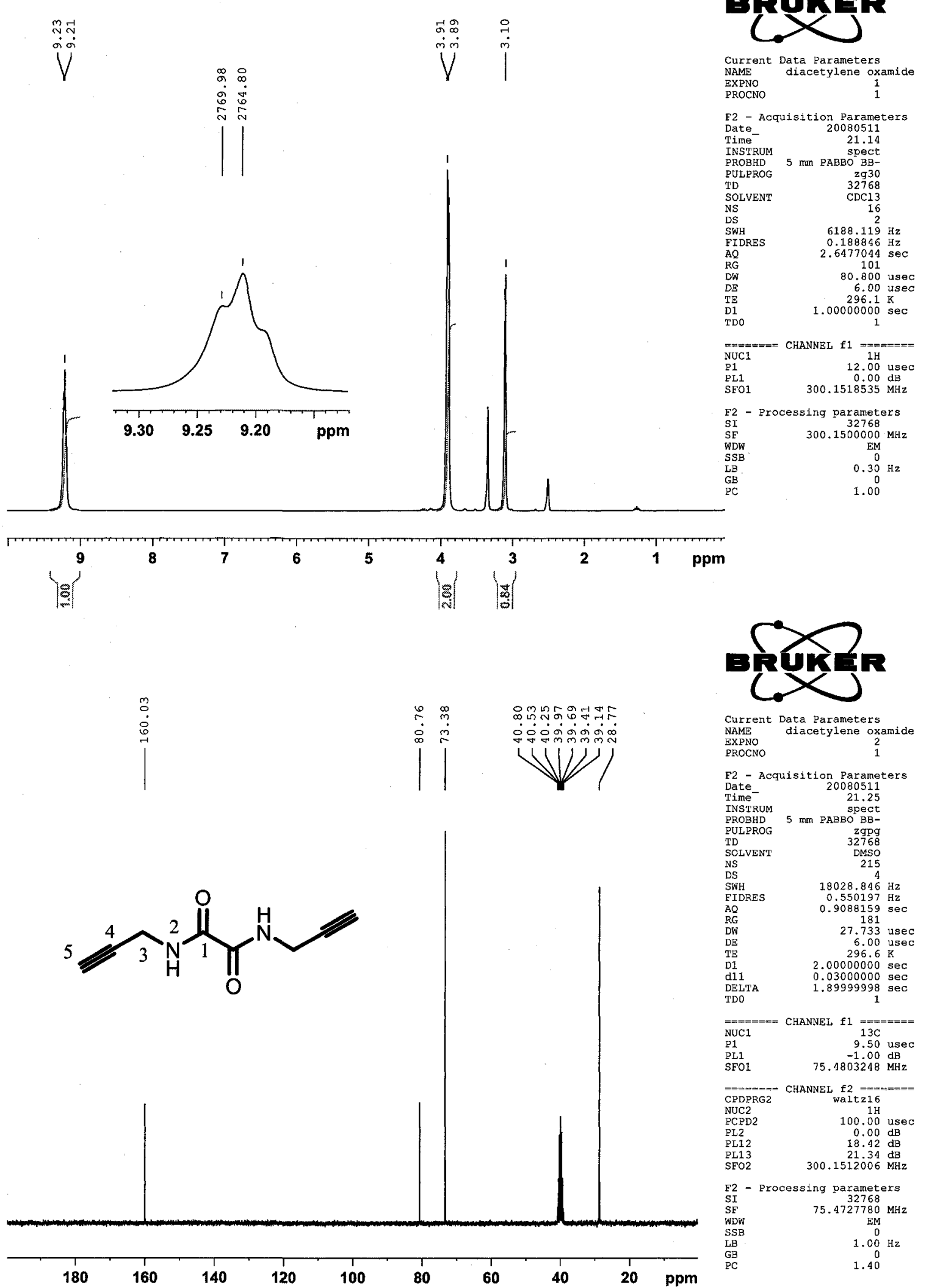


Appendix 2 - NMR of green impurity from biurea complex 


\section{NMR of 36G}
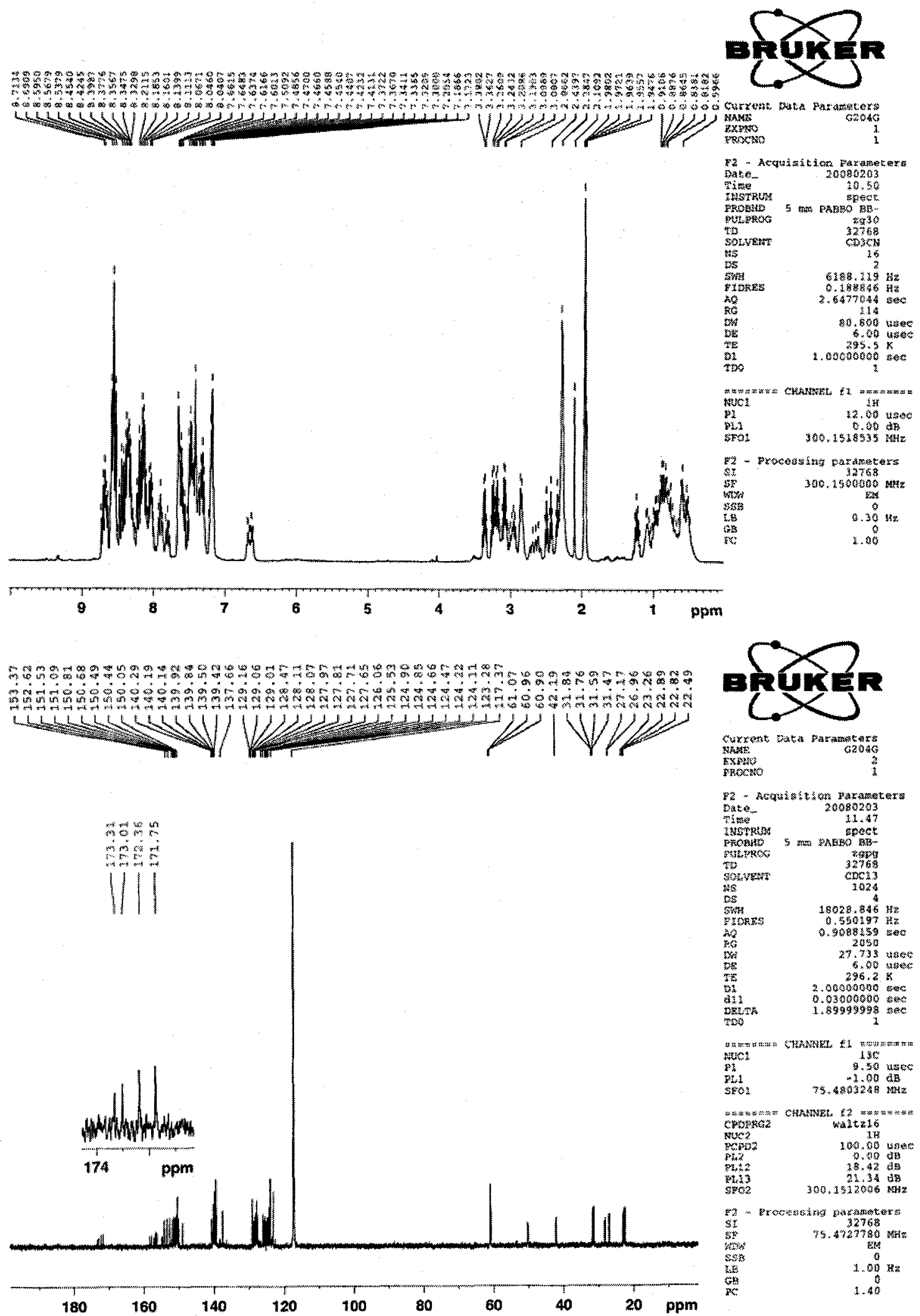
Appendix 3 - NMR of piperidine biurea complex soluble in DCM 

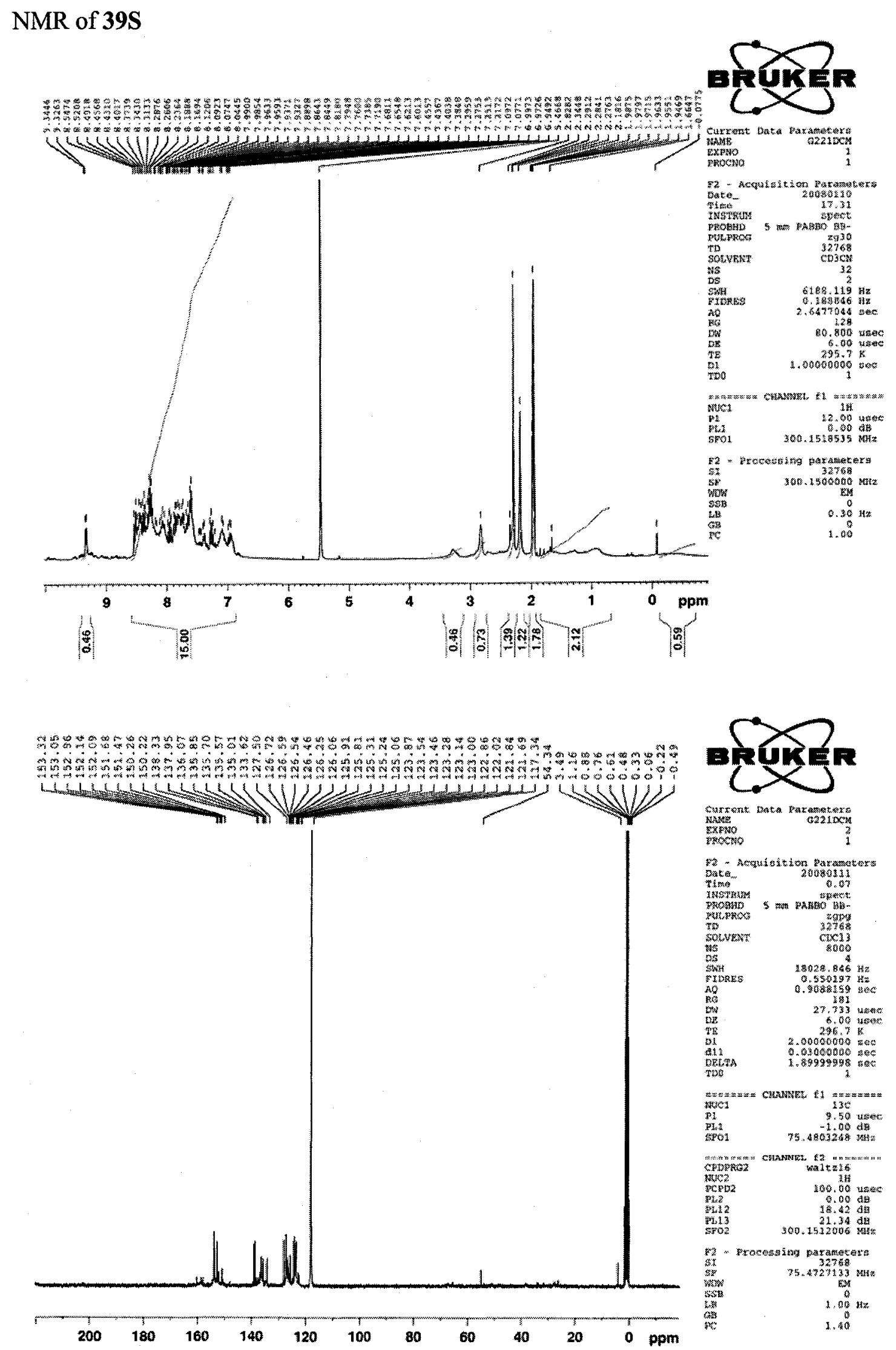
Appendix 4-Quantum yield determination of 44 


\begin{tabular}{ccc|ccc}
\hline \multicolumn{3}{c|}{$\mathrm{Alq}_{3}$} & \multicolumn{3}{c}{$\mathbf{4 4}$} \\
\hline Concentration $(\mu \mathrm{M})$ & Absorbance & PL $(494 \mathrm{~nm})$ & Concentration $(\mu \mathrm{M})$ & Absorbance & PL $(494 \mathrm{~nm})$ \\
\hline 0.4 & 0.02358 & 18.417 & 0.4 & 0.05425006 & 1.674 \\
0.6 & 0.02997 & 25.436 & 0.6 & 0.07502662 & 2.024 \\
0.8 & 0.04419 & 35.264 & 0.8 & 0.10391437 & 2.435 \\
1 & 0.05442 & 42.344 & 1 & 0.12449421 & 2.855 \\
1.5 & 0.08317 & 61.229 & 1.5 & 0.18461071 & 3.788 \\
\hline
\end{tabular}

refractive index of DCM $=1.4241$

refractive index of THF $=1.4072$
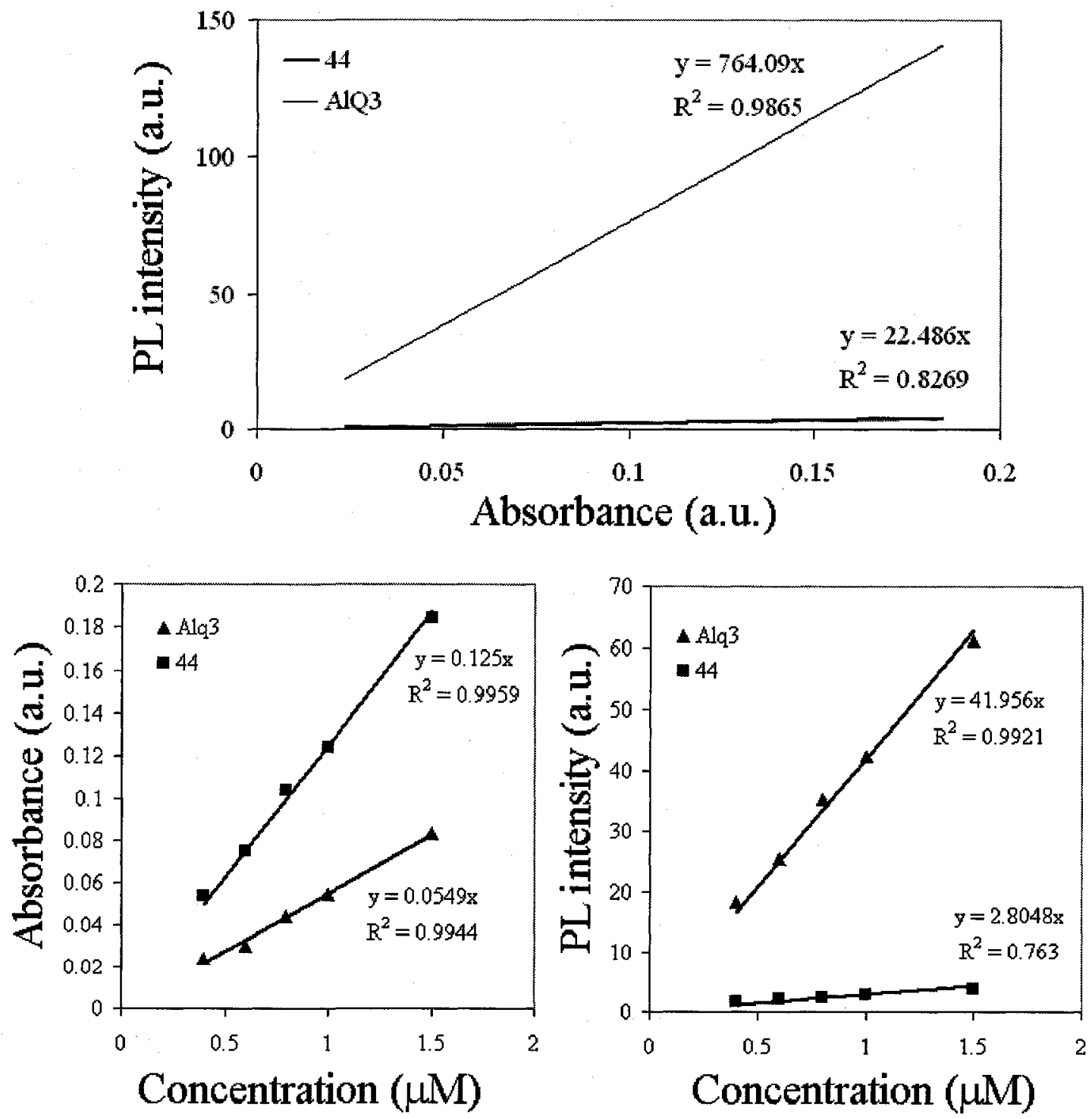
Appendix 5 - Crystallography data of 46 
Table 1. Crystal data and structure refinement for $\mathbf{4 6 .}$

Identification code

Empirical formula

Formula weight

Temperature

Wavelength

Crystal system

Space group

Unit cell dimensions

Volume

Z

Density (calculated)

Absorption coefficient

$\mathrm{F}(000)$

Crystal size

Theta range for data collection

Index ranges

Reflections collected

Independent reflections

Completeness to theta $=26.07^{\circ}$

Absorption correction

Max. and min. transmission

Refinement method

Data / restraints / parameters

Goodness-of-fit on $\mathrm{F}^{2}$

Final $\mathrm{R}$ indices [ $\mathrm{I}>2 \operatorname{sigma}(\mathrm{I})]$

$\mathrm{R}$ indices (all data)

Largest diff. peak and hole
46

C74 H52 Cl4 N12 O12 Pt4

2223.44

293(2) K

$0.71073 \AA$

Triclinic

P-1

$\mathrm{a}=7.5869(7) \AA$ $\alpha=112.5950(10)^{\circ}$.

$\mathrm{b}=14.8974(14) \AA$ $\beta=91.5210(10)^{\circ}$.

$c=17.0460(16) \AA$ $\gamma=90.1320(10)^{\circ}$.
$1778.0(3) \AA^{3}$

1

$2.077 \mathrm{Mg} / \mathrm{m}^{3}$

$8.067 \mathrm{~mm}^{-1}$

1056

$0.21 \times 0.08 \times 0.08 \mathrm{~mm}^{3}$

1.48 to $26.07^{\circ}$.

$-9<=\mathrm{h}<=8,-15<=\mathrm{k}<=18,-21<=1<=19$

9936

$6846[\mathrm{R}(\mathrm{int})=0.0221]$

$97.1 \%$

Semi-empirical from equivalents

0.5829 and 0.2860

Full-matrix least-squares on $\mathrm{F}^{2}$

$6846 / 0 / 475$

1.005

$\mathrm{R} 1=0.0339, \mathrm{wR} 2=0.0924$

$\mathrm{R} 1=0.0388, \mathrm{wR} 2=0.0968$

1.645 and -2.190 e. $\AA^{-3}$ 
Table 2. Atomic coordinates $\left(\times 10^{4}\right)$ and equivalent isotropic displacement parameters $\left(\AA^{2} \times 10^{3}\right)$ for 46. $U(e q)$ is defined as one third of the trace of the orthogonalized $U^{i j}$ tensor.

\begin{tabular}{|c|c|c|c|c|}
\hline & $\mathrm{x}$ & $\mathrm{y}$ & $\mathrm{z}$ & $\mathrm{U}(\mathrm{eq})$ \\
\hline $\operatorname{Pt}(1)$ & $2597(1)$ & $-5175(1)$ & $3977(1)$ & $35(1)$ \\
\hline $\operatorname{Pt}(2)$ & $3457(1)$ & $-8185(1)$ & $1782(1)$ & $34(1)$ \\
\hline $\mathrm{N}(1)$ & $7336(8)$ & $-9833(4)$ & $4795(4)$ & $65(2)$ \\
\hline $\mathrm{N}(2)$ & $3699(6)$ & $-7124(3)$ & $2960(3)$ & $36(1)$ \\
\hline $\mathrm{N}(3)$ & $3501(6)$ & $-6189(3)$ & $2898(3)$ & $35(1)$ \\
\hline $\mathrm{N}(4)$ & $5360(11)$ & $-2705(5)$ & $1627(5)$ & $85(2)$ \\
\hline$N(5)$ & $1857(6)$ & $-4240(3)$ & $5114(3)$ & $39(1)$ \\
\hline$N(6)$ & $3180(6)$ & $-9075(3)$ & $556(3)$ & $38(1)$ \\
\hline $\mathrm{O}(1)$ & $7186(9)$ & $-9741(4)$ & $5535(4)$ & $92(2)$ \\
\hline $\mathrm{O}(2)$ & $8141(11)$ & $-10486(5)$ & $4280(4)$ & $111(2)$ \\
\hline$O(3)$ & $3776(5)$ & $-6206(2)$ & $4384(2)$ & $40(1)$ \\
\hline $\mathrm{O}(4)$ & $4480(5)$ & $-6991(3)$ & $1555(2)$ & $43(1)$ \\
\hline $\mathrm{O}(5)$ & $5871(12)$ & $-1982(4)$ & $2222(5)$ & $124(3)$ \\
\hline $\mathrm{O}(6)$ & $5044(14)$ & $-2746(5)$ & $901(5)$ & $138(3)$ \\
\hline$C(1)$ & $6448(8)$ & $-9122(4)$ & $4518(4)$ & $48(1)$ \\
\hline$C(2)$ & $5590(10)$ & $-8373(5)$ & $5098(4)$ & $60(2)$ \\
\hline$C(3)$ & $4739(8)$ & $-7695(4)$ & $4840(3)$ & $46(1)$ \\
\hline$C(4)$ & $4777(7)$ & $-7806(4)$ & $3989(3)$ & $37(1)$ \\
\hline $\mathrm{C}(5)$ & $5663(7)$ & $-8581(4)$ & $3416(3)$ & $42(1)$ \\
\hline$C(6)$ & $6497(8)$ & $-9238(4)$ & $3669(4)$ & $49(1)$ \\
\hline$C(7)$ & $3994(7)$ & $-7013(4)$ & $3763(3)$ & $36(1)$ \\
\hline $\mathrm{C}(8)$ & $4121(7)$ & $-6200(4)$ & 2181(3) & $37(1)$ \\
\hline$C(9)$ & $4423(7)$ & $-5280(4)$ & $2057(3)$ & $41(1)$ \\
\hline$C(10)$ & $5120(8)$ & $-4452(4)$ & $2716(4)$ & $45(1)$ \\
\hline$C(11)$ & $5418(8)$ & $-3605(4)$ & 2571(4) & $52(2)$ \\
\hline $\mathrm{C}(12)$ & $5020(10)$ & $-3615(5)$ & $1773(4)$ & $60(2)$ \\
\hline$C(13)$ & $4391(10)$ & $-4425(5)$ & $1123(4)$ & $62(2)$ \\
\hline$C(14)$ & $4127(9)$ & $-5264(4)$ & $1253(4)$ & $53(2)$ \\
\hline$C(15)$ & $1289(7)$ & $-4226(4)$ & $3622(3)$ & $41(1)$ \\
\hline$C(16)$ & $861(8)$ & $-4283(4)$ & $2808(4)$ & $50(1)$ \\
\hline$C(17)$ & $51(9)$ & $-3520(5)$ & $2658(5)$ & $63(2)$ \\
\hline
\end{tabular}




\begin{tabular}{|c|c|c|c|c|}
\hline$C(18)$ & $-392(10)$ & $-2681(5)$ & $3337(5)$ & $70(2)$ \\
\hline$C(19)$ & $-98(9)$ & $-2626(4)$ & $4163(4)$ & $57(2)$ \\
\hline$C(20)$ & $727(7)$ & $-3412(4)$ & $4300(4)$ & $47(1)$ \\
\hline$C(21)$ & $1007(7)$ & $-3425(4)$ & $5131(4)$ & $44(1)$ \\
\hline$C(22)$ & $486(8)$ & $-2743(5)$ & $5910(4)$ & $58(2)$ \\
\hline$C(23)$ & $833(9)$ & $-2890(5)$ & $6652(4)$ & $62(2)$ \\
\hline$C(24)$ & $1689(8)$ & $-3720(5)$ & $6611(4)$ & $57(2)$ \\
\hline$C(25)$ & $2188(8)$ & $-4385(5)$ & 5832(4) & $50(1)$ \\
\hline$C(26)$ & $2319(7)$ & $-9317(4)$ & $1926(3)$ & $37(1)$ \\
\hline$C(27)$ & $1827(7)$ & $-9435(4)$ & $2663(3)$ & $45(1)$ \\
\hline$C(28)$ & $1067(8)$ & $-10283(5)$ & $2641(4)$ & $56(2)$ \\
\hline$C(29)$ & $794(10)$ & $-11082(5)$ & $1879(4)$ & $64(2)$ \\
\hline$C(30)$ & $1241(10)$ & $-10974(5)$ & $1144(4)$ & $60(2)$ \\
\hline$C(31)$ & $1975(8)$ & $-10117(4)$ & $1145(3)$ & $43(1)$ \\
\hline$C(32)$ & $2420(7)$ & $-9957(4)$ & $378(3)$ & $41(1)$ \\
\hline$C(33)$ & $2099(8)$ & $-10584(4)$ & $-458(4)$ & $52(2)$ \\
\hline$C(34)$ & $2540(8)$ & $-10303(5)$ & $-1099(4)$ & $54(2)$ \\
\hline$C(35)$ & $3351(8)$ & $-9414(5)$ & $-916(4)$ & $52(2)$ \\
\hline$C(36)$ & $3631(8)$ & $-8811(4)$ & $-81(3)$ & $45(1)$ \\
\hline$C(37)$ & $1605(15)$ & $-3627(7)$ & $-880(6)$ & $104(3)$ \\
\hline $\mathrm{Cl}(1)$ & $17(4)$ & $-3033(2)$ & $-1244(2)$ & $67(1)$ \\
\hline $\mathrm{Cl}(2)$ & $-282(11)$ & $-3068(6)$ & $-1035(5)$ & $72(2)$ \\
\hline $\mathrm{Cl}(3)$ & $1001(12)$ & $-4492(7)$ & $-529(6)$ & $95(2)$ \\
\hline $\mathrm{Cl}(4)$ & 141(19) & $-3619(10)$ & $268(9)$ & $144(4)$ \\
\hline $\mathrm{Cl}(5)$ & $877(12)$ & $-4000(7)$ & $-142(6)$ & $118(2)$ \\
\hline
\end{tabular}


Table 3. Bond lengths $[\AA]$ and angles $\left[{ }^{\circ}\right]$ for 46 .

\begin{tabular}{|c|c|c|c|c|c|}
\hline $\operatorname{Pt}(1)-C(15)$ & $1.995(6)$ & $\mathrm{C}(11)-\mathrm{C}(12)$ & $1.380(9)$ & $\mathrm{N}(5)-\mathrm{Pt}(1)-\mathrm{N}(3)$ & $173.81(17)$ \\
\hline $\mathrm{Pt}(1)-\mathrm{N}(5)$ & $2.000(4)$ & $C(12)-C(13)$ & $1.361(10)$ & $\mathrm{C}(15)-\mathrm{Pt}(1)-\mathrm{O}(3)$ & $175.24(18)$ \\
\hline $\operatorname{Pt}(1)-\mathrm{N}(3)$ & $2.018(4)$ & $C(13)-C(14)$ & $1.367(9)$ & $\mathrm{N}(5)-\mathrm{Pt}(1)-\mathrm{O}(3)$ & $97.70(16)$ \\
\hline $\mathrm{Pt}(1)-\mathrm{O}(3)$ & $2.106(4)$ & $C(15)-C(16)$ & $1.386(8)$ & $\mathrm{N}(3)-\mathrm{Pt}(1)-\mathrm{O}(3)$ & $76.25(15)$ \\
\hline $\operatorname{Pt}(2)-C(26)$ & $1.993(5)$ & $C(15)-C(20)$ & $1.393(8)$ & $\mathrm{C}(26)-\mathrm{Pt}(2)-\mathrm{N}(6)$ & $80.99(19)$ \\
\hline $\operatorname{Pt}(2)-N(6)$ & $2.003(4)$ & $C(16)-C(17)$ & $1.397(9)$ & $\mathrm{C}(26)-\mathrm{Pt}(2)-\mathrm{N}(2)$ & $106.25(19)$ \\
\hline $\mathrm{Pt}(2)-\mathrm{N}(2)$ & $2.027(4)$ & $C(17)-C(18)$ & $1.387(9)$ & $\mathrm{N}(6)-\mathrm{Pt}(2)-\mathrm{N}(2)$ & $171.57(17)$ \\
\hline $\mathrm{Pt}(2)-\mathrm{O}(4)$ & $2.111(4)$ & $C(18)-C(19)$ & $1.391(10)$ & $\mathrm{C}(26)-\mathrm{Pt}(2)-\mathrm{O}(4)$ & $175.03(18)$ \\
\hline $\mathrm{N}(1)-\mathrm{O}(2)$ & $1.210(8)$ & $C(19)-C(20)$ & $1.422(8)$ & $\mathrm{N}(6)-\mathrm{Pt}(2)-\mathrm{O}(4)$ & $95.96(15)$ \\
\hline $\mathrm{N}(1)-\mathrm{O}(1)$ & $1.224(7)$ & $C(20)-C(21)$ & $1.434(8)$ & $\mathrm{N}(2)-\mathrm{Pt}(2)-\mathrm{O}(4)$ & $76.50(15)$ \\
\hline $\mathrm{N}(1)-\mathrm{C}(1)$ & $1.473(8)$ & $C(21)-C(22)$ & $1.395(8)$ & $\mathrm{O}(2)-\mathrm{N}(1)-\mathrm{O}(1)$ & $123.4(6)$ \\
\hline $\mathrm{N}(2)-\mathrm{C}(7)$ & $1.326(6)$ & $C(22)-C(23)$ & $1.381(10)$ & $\mathrm{O}(2)-\mathrm{N}(1)-\mathrm{C}(1)$ & $118.8(6)$ \\
\hline $\mathrm{N}(2)-\mathrm{N}(3)$ & $1.445(6)$ & $C(23)-C(24)$ & $1.377(10)$ & $\mathrm{O}(1)-\mathrm{N}(1)-\mathrm{C}(1)$ & $117.8(6)$ \\
\hline$N(3)-C(8)$ & $1.314(7)$ & $C(24)-C(25)$ & $1.381(8)$ & $\mathrm{C}(7)-\mathrm{N}(2)-\mathrm{N}(3)$ & $110.4(4)$ \\
\hline $\mathrm{N}(4)-\mathrm{O}(5)$ & $1.216(8)$ & $C(26)-C(27)$ & $1.394(7)$ & $\mathrm{C}(7)-\mathrm{N}(2)-\mathrm{Pt}(2)$ & $140.4(4)$ \\
\hline $\mathrm{N}(4)-\mathrm{O}(6)$ & $1.233(9)$ & $C(26)-C(31)$ & $1.422(7)$ & $N(3)-N(2)-P t(2)$ & $109.1(3)$ \\
\hline $\mathrm{N}(4)-\mathrm{C}(12)$ & $1.492(8)$ & $\mathrm{C}(27)-\mathrm{C}(28)$ & $1.374(8)$ & $\mathrm{C}(8)-\mathrm{N}(3)-\mathrm{N}(2)$ & $111.1(4)$ \\
\hline$N(5)-C(25)$ & $1.339(7)$ & $\mathrm{C}(28)-\mathrm{C}(29)$ & $1.394(9)$ & $\mathrm{C}(8)-\mathrm{N}(3)-\mathrm{Pt}(1)$ & $136.4(4)$ \\
\hline $\mathrm{N}(5)-\mathrm{C}(21)$ & $1.368(7)$ & $C(29)-C(30)$ & $1.373(9)$ & $\mathrm{N}(2)-\mathrm{N}(3)-\mathrm{Pt}(1)$ & $112.1(3)$ \\
\hline$N(6)-C(36)$ & $1.341(7)$ & $C(30)-C(31)$ & $1.391(8)$ & $\mathrm{O}(5)-\mathrm{N}(4)-\mathrm{O}(6)$ & $124.9(7)$ \\
\hline$N(6)-C(32)$ & $1.354(7)$ & $C(31)-C(32)$ & $1.463(7)$ & $\mathrm{O}(5)-\mathrm{N}(4)-\mathrm{C}(12)$ & $118.9(7)$ \\
\hline $\mathrm{O}(3)-\mathrm{C}(7)$ & $1.275(6)$ & $C(32)-C(33)$ & $1.386(7)$ & $\mathrm{O}(6)-\mathrm{N}(4)-\mathrm{C}(12)$ & $116.2(7)$ \\
\hline $\mathrm{O}(4)-\mathrm{C}(8)$ & $1.285(6)$ & $C(33)-C(34)$ & $1.360(9)$ & $C(25)-N(5)-C(21)$ & $120.8(5)$ \\
\hline$C(1)-C(2)$ & $1.354(9)$ & $C(34)-C(35)$ & $1.377(8)$ & $\mathrm{C}(25)-\mathrm{N}(5)-\mathrm{Pt}(1)$ & $122.5(4)$ \\
\hline$C(1)-C(6)$ & $1.391(8)$ & $C(35)-C(36)$ & $1.371(8)$ & $\mathrm{C}(21)-\mathrm{N}(5)-\mathrm{Pt}(1)$ & $116.6(4)$ \\
\hline$C(2)-C(3)$ & $1.400(8)$ & $\mathrm{C}(37)-\mathrm{Cl}(5)$ & $1.666(13)$ & $\mathrm{C}(36)-\mathrm{N}(6)-\mathrm{C}(32)$ & $119.7(5)$ \\
\hline$C(3)-C(4)$ & $1.396(7)$ & $\mathrm{C}(37)-\mathrm{Cl}(3)$ & $1.685(13)$ & $\mathrm{C}(36)-\mathrm{N}(6)-\mathrm{Pt}(2)$ & $122.7(4)$ \\
\hline$C(4)-C(5)$ & $1.382(7)$ & $\mathrm{C}(37)-\mathrm{Cl}(2)$ & $1.722(14)$ & $\mathrm{C}(32)-\mathrm{N}(6)-\mathrm{Pt}(2)$ & $117.5(3)$ \\
\hline$C(4)-C(7)$ & $1.496(7)$ & $\mathrm{C}(37)-\mathrm{Cl}(1)$ & $1.733(11)$ & $\mathrm{C}(7)-\mathrm{O}(3)-\mathrm{Pt}(1)$ & $111.4(3)$ \\
\hline$C(5)-C(6)$ & $1.362(8)$ & $\mathrm{Cl}(3)-\mathrm{Cl}(5)$ & $0.783(10)$ & $\mathrm{C}(8)-\mathrm{O}(4)-\mathrm{Pt}(2)$ & $109.2(3)$ \\
\hline $\mathrm{C}(8)-\mathrm{C}(9)$ & $1.483(7)$ & $\mathrm{Cl}(3)-\mathrm{Cl}(4)$ & $1.630(16)$ & $C(2)-C(1)-C(6)$ & $121.6(6)$ \\
\hline$C(9)-C(14)$ & $1.393(8)$ & $\mathrm{Cl}(4)-\mathrm{Cl}(5)$ & $0.916(13)$ & $C(2)-C(1)-N(1)$ & $119.0(6)$ \\
\hline$C(9)-C(10)$ & $1.401(7)$ & $\mathrm{C}(15)-\mathrm{Pt}(1)-\mathrm{N}(5)$ & $80.3(2)$ & $C(6)-C(1)-N(1)$ & $119.4(5)$ \\
\hline $\mathrm{C}(10)-\mathrm{C}(11)$ & $1.395(8)$ & $\mathrm{C}(15)-\mathrm{Pt}(1)-\mathrm{N}(3)$ & $105.8(2)$ & $C(1)-C(2)-C(3)$ & $119.4(6)$ \\
\hline
\end{tabular}




\begin{tabular}{|c|c|c|c|c|c|}
\hline$C(4)-C(3)-C(2)$ & $119.5(5)$ & $\mathrm{C}(16)-\mathrm{C}(15)-\mathrm{Pt}(1)$ & $128.8(4)$ & $C(30)-C(31)-C(26)$ & $120.1(5)$ \\
\hline$C(5)-C(4)-C(3)$ & $119.4(5)$ & $C(20)-C(15)-\operatorname{Pt}(1)$ & $113.8(4)$ & $\mathrm{C}(30)-\mathrm{C}(31)-\mathrm{C}(32)$ & $124.4(5)$ \\
\hline$C(5)-C(4)-C(7)$ & $123.0(5)$ & $\mathrm{C}(15)-\mathrm{C}(16)-\mathrm{C}(17)$ & $122.2(6)$ & $\mathrm{C}(26)-\mathrm{C}(31)-\mathrm{C}(32)$ & $115.5(5)$ \\
\hline$C(3)-C(4)-C(7)$ & $117.3(5)$ & $C(18)-C(17)-C(16)$ & $120.0(7)$ & $\mathrm{N}(6)-\mathrm{C}(32)-\mathrm{C}(33)$ & $120.2(5)$ \\
\hline$C(6)-C(5)-C(4)$ & $121.0(5)$ & $C(17)-C(18)-C(19)$ & $119.5(6)$ & $\mathrm{N}(6)-\mathrm{C}(32)-\mathrm{C}(31)$ & $112.5(4)$ \\
\hline$C(5)-C(6)-C(1)$ & $119.1(5)$ & $C(18)-C(19)-C(20)$ & $119.5(6)$ & $C(33)-C(32)-C(31)$ & $127.2(5)$ \\
\hline $\mathrm{O}(3)-\mathrm{C}(7)-\mathrm{N}(2)$ & $122.6(5)$ & $C(15)-C(20)-C(19)$ & $121.2(6)$ & $\mathrm{C}(34)-\mathrm{C}(33)-\mathrm{C}(32)$ & $119.6(6)$ \\
\hline $\mathrm{O}(3)-\mathrm{C}(7)-\mathrm{C}(4)$ & $115.6(4)$ & $\mathrm{C}(15)-\mathrm{C}(20)-\mathrm{C}(21)$ & $116.1(5)$ & $\mathrm{C}(33)-\mathrm{C}(34)-\mathrm{C}(35)$ & $120.0(5)$ \\
\hline$N(2)-C(7)-C(4)$ & $121.5(4)$ & $C(19)-C(20)-C(21)$ & $122.6(5)$ & $\mathrm{C}(36)-\mathrm{C}(35)-\mathrm{C}(34)$ & $118.7(6)$ \\
\hline $\mathrm{O}(4)-\mathrm{C}(8)-\mathrm{N}(3)$ & $122.9(5)$ & $\mathrm{N}(5)-\mathrm{C}(21)-\mathrm{C}(22)$ & $118.8(6)$ & $N(6)-C(36)-C(35)$ & $121.8(6)$ \\
\hline $\mathrm{O}(4)-\mathrm{C}(8)-\mathrm{C}(9)$ & $116.5(5)$ & $\mathrm{N}(5)-\mathrm{C}(21)-\mathrm{C}(20)$ & $112.7(5)$ & $\mathrm{Cl}(5)-\mathrm{C}(37)-\mathrm{Cl}(3)$ & $27.0(4)$ \\
\hline $\mathrm{N}(3)-\mathrm{C}(8)-\mathrm{C}(9)$ & $120.6(5)$ & $C(22)-C(21)-C(20)$ & $128.4(6)$ & $\mathrm{Cl}(5)-\mathrm{C}(37)-\mathrm{Cl}(2)$ & $98.4(7)$ \\
\hline$C(14)-C(9)-C(10)$ & $119.6(5)$ & $C(23)-C(22)-C(21)$ & $120.4(6)$ & $\mathrm{Cl}(3)-\mathrm{C}(37)-\mathrm{Cl}(2)$ & $107.7(7)$ \\
\hline$C(14)-C(9)-C(8)$ & $119.0(5)$ & $C(24)-C(23)-C(22)$ & $119.2(6)$ & $\mathrm{Cl}(5)-\mathrm{C}(37)-\mathrm{Cl}(1)$ & $113.2(7)$ \\
\hline $\mathrm{C}(10)-\mathrm{C}(9)-\mathrm{C}(8)$ & $121.2(5)$ & $\mathrm{C}(23)-\mathrm{C}(24)-\mathrm{C}(25)$ & $119.4(6)$ & $\mathrm{Cl}(3)-\mathrm{C}(37)-\mathrm{Cl}(1)$ & $120.0(7)$ \\
\hline$C(11)-C(10)-C(9)$ & $119.6(5)$ & $\mathrm{N}(5)-\mathrm{C}(25)-\mathrm{C}(24)$ & $121.4(6)$ & $\mathrm{Cl}(2)-\mathrm{C}(37)-\mathrm{Cl}(1)$ & $14.8(3)$ \\
\hline $\mathrm{C}(12)-\mathrm{C}(11)-\mathrm{C}(10)$ & $118.3(6)$ & $\mathrm{C}(27)-\mathrm{C}(26)-\mathrm{C}(31)$ & $116.5(5)$ & $\mathrm{Cl}(5)-\mathrm{Cl}(3)-\mathrm{Cl}(4)$ & $17.8(10)$ \\
\hline$C(13)-C(12)-C(11)$ & $122.4(6)$ & $\mathrm{C}(27)-\mathrm{C}(26)-\mathrm{Pt}(2)$ & $130.1(4)$ & $\mathrm{Cl}(5)-\mathrm{Cl}(3)-\mathrm{C}(37)$ & $75.1(11)$ \\
\hline $\mathrm{C}(13)-\mathrm{C}(12)-\mathrm{N}(4)$ & $119.9(6)$ & $C(31)-C(26)-P t(2)$ & $113.4(4)$ & $\mathrm{Cl}(4)-\mathrm{Cl}(3)-\mathrm{C}(37)$ & $86.5(7)$ \\
\hline $\mathrm{C}(11)-\mathrm{C}(12)-\mathrm{N}(4)$ & $117.7(6)$ & $C(28)-C(27)-C(26)$ & $122.0(5)$ & $\mathrm{Cl}(5)-\mathrm{Cl}(4)-\mathrm{Cl}(3)$ & $15.2(8)$ \\
\hline$C(12)-C(13)-C(14)$ & $119.8(6)$ & $\mathrm{C}(27)-\mathrm{C}(28)-\mathrm{C}(29)$ & $121.6(6)$ & $\mathrm{Cl}(3)-\mathrm{Cl}(5)-\mathrm{Cl}(4)$ & $147.0(18)$ \\
\hline$C(13)-C(14)-C(9)$ & $120.1(6)$ & $\mathrm{C}(30)-\mathrm{C}(29)-\mathrm{C}(28)$ & $117.3(6)$ & $\mathrm{Cl}(3)-\mathrm{Cl}(5)-\mathrm{C}(37)$ & $77.8(11)$ \\
\hline$C(16)-C(15)-C(20)$ & $117.3(5)$ & $\mathrm{C}(29)-\mathrm{C}(30)-\mathrm{C}(31)$ & $122.4(6)$ & $\mathrm{Cl}(4)-\mathrm{Cl}(5)-\mathrm{C}(37)$ & $120.5(13)$ \\
\hline
\end{tabular}

Symmetry transformations used to generate equivalent atoms: 
Table 4. Anisotropic displacement parameters $\left(\AA^{2} \times 10^{3}\right)$ for 46 . The anisotropic displacement factor exponent takes the form: $-2 \pi^{2}\left[h^{2} a^{* 2} U^{11}+\ldots+2 h k a^{*} b^{*} U^{12}\right]$

\begin{tabular}{|c|c|c|c|c|c|c|}
\hline & $\mathrm{U}^{11}$ & $\mathrm{U}^{22}$ & $\mathrm{U}^{33}$ & $U^{23}$ & $\mathrm{U}^{13}$ & $\mathrm{U}^{12}$ \\
\hline $\operatorname{Pt}(1)$ & $34(1)$ & $30(1)$ & $39(1)$ & $11(1)$ & $-1(1)$ & $3(1)$ \\
\hline $\operatorname{Pt}(2)$ & $38(1)$ & $30(1)$ & $33(1)$ & $12(1)$ & $-1(1)$ & $3(1)$ \\
\hline$N(1)$ & $81(4)$ & $61(4)$ & $63(4)$ & $37(3)$ & $-3(3)$ & $12(3)$ \\
\hline $\mathrm{N}(2)$ & $44(3)$ & $26(2)$ & $38(2)$ & $13(2)$ & $0(2)$ & $4(2)$ \\
\hline $\mathrm{N}(3)$ & $43(2)$ & $30(2)$ & $34(2)$ & $14(2)$ & $-4(2)$ & $4(2)$ \\
\hline $\mathrm{N}(4)$ & $117(6)$ & $65(4)$ & $92(5)$ & $50(4)$ & $10(4)$ & $-3(4)$ \\
\hline $\mathrm{N}(5)$ & $39(2)$ & $32(2)$ & $41(2)$ & $8(2)$ & $-2(2)$ & $0(2)$ \\
\hline $\mathrm{N}(6)$ & $42(3)$ & $34(2)$ & $37(2)$ & $14(2)$ & $-3(2)$ & $3(2)$ \\
\hline$O(1)$ & $132(5)$ & $89(4)$ & $71(4)$ & $48(3)$ & $-7(3)$ & $32(4)$ \\
\hline $\mathrm{O}(2)$ & $165(7)$ & $92(4)$ & $94(4)$ & $53(4)$ & $27(4)$ & $77(5)$ \\
\hline$O(3)$ & $47(2)$ & $38(2)$ & $35(2)$ & $12(2)$ & $-3(2)$ & $4(2)$ \\
\hline $\mathrm{O}(4)$ & $54(2)$ & $37(2)$ & $37(2)$ & $14(2)$ & $3(2)$ & $0(2)$ \\
\hline$O(5)$ & $208(8)$ & $56(4)$ & $120(5)$ & $49(4)$ & $-26(5)$ & $-37(4)$ \\
\hline $\mathrm{O}(6)$ & $248(10)$ & $93(5)$ & $108(5)$ & $79(4)$ & $3(6)$ & $-26(5)$ \\
\hline$C(1)$ & $53(3)$ & $42(3)$ & $56(3)$ & $26(3)$ & $-4(3)$ & $8(3)$ \\
\hline $\mathrm{C}(2)$ & $89(5)$ & $52(4)$ & $43(3)$ & $24(3)$ & $1(3)$ & $8(3)$ \\
\hline$C(3)$ & $59(4)$ & $40(3)$ & $37(3)$ & $12(2)$ & $5(2)$ & $14(3)$ \\
\hline$C(4)$ & $37(3)$ & $39(3)$ & $39(3)$ & $19(2)$ & $1(2)$ & $3(2)$ \\
\hline$C(5)$ & $39(3)$ & $48(3)$ & $40(3)$ & $16(2)$ & $1(2)$ & $11(2)$ \\
\hline$C(6)$ & $49(3)$ & $49(3)$ & $52(3)$ & $22(3)$ & $5(3)$ & $13(3)$ \\
\hline$C(7)$ & $35(3)$ & $35(3)$ & $36(3)$ & $10(2)$ & $1(2)$ & $3(2)$ \\
\hline $\mathrm{C}(8)$ & $33(3)$ & $37(3)$ & $41(3)$ & $16(2)$ & $-8(2)$ & $0(2)$ \\
\hline$C(9)$ & $53(3)$ & $32(3)$ & $42(3)$ & $18(2)$ & $1(2)$ & $3(2)$ \\
\hline$C(10)$ & $47(3)$ & $43(3)$ & $45(3)$ & $17(3)$ & $-4(2)$ & $-6(3)$ \\
\hline$C(11)$ & $52(4)$ & $41(3)$ & $65(4)$ & $23(3)$ & $-2(3)$ & $-5(3)$ \\
\hline$C(12)$ & $71(4)$ & $50(4)$ & $70(4)$ & $34(3)$ & $4(3)$ & $-1(3)$ \\
\hline$C(13)$ & $85(5)$ & $63(4)$ & $47(3)$ & $30(3)$ & $0(3)$ & $3(4)$ \\
\hline$C(14)$ & $72(4)$ & $41(3)$ & $47(3)$ & $17(3)$ & $-4(3)$ & $0(3)$ \\
\hline$C(15)$ & $36(3)$ & $34(3)$ & $50(3)$ & $13(2)$ & $-3(2)$ & $0(2)$ \\
\hline$C(16)$ & $44(3)$ & $46(3)$ & $61(4)$ & $24(3)$ & $-6(3)$ & $8(3)$ \\
\hline$C(17)$ & $54(4)$ & $63(4)$ & $70(4)$ & $25(3)$ & $-12(3)$ & $16(3)$ \\
\hline
\end{tabular}




\begin{tabular}{lllllll}
$\mathrm{C}(18)$ & $64(4)$ & $55(4)$ & $98(6)$ & $37(4)$ & $-11(4)$ & $17(3)$ \\
$\mathrm{C}(19)$ & $56(4)$ & $36(3)$ & $75(4)$ & $17(3)$ & $6(3)$ & $9(3)$ \\
$\mathrm{C}(20)$ & $34(3)$ & $40(3)$ & $66(4)$ & $21(3)$ & $2(2)$ & $2(2)$ \\
$\mathrm{C}(21)$ & $29(3)$ & $38(3)$ & $57(3)$ & $8(3)$ & $2(2)$ & $0(2)$ \\
$\mathrm{C}(22)$ & $43(3)$ & $45(4)$ & $66(4)$ & $-1(3)$ & $7(3)$ & $5(3)$ \\
$\mathrm{C}(23)$ & $52(4)$ & $57(4)$ & $56(4)$ & $-1(3)$ & $8(3)$ & $-6(3)$ \\
$\mathrm{C}(24)$ & $50(4)$ & $65(4)$ & $49(3)$ & $15(3)$ & $3(3)$ & $-6(3)$ \\
$\mathrm{C}(25)$ & $44(3)$ & $54(4)$ & $49(3)$ & $16(3)$ & $3(3)$ & $2(3)$ \\
$\mathrm{C}(26)$ & $33(3)$ & $36(3)$ & $43(3)$ & $14(2)$ & $2(2)$ & $8(2)$ \\
$\mathrm{C}(27)$ & $45(3)$ & $47(3)$ & $41(3)$ & $15(2)$ & $4(2)$ & $4(3)$ \\
$\mathrm{C}(28)$ & $59(4)$ & $59(4)$ & $61(4)$ & $33(3)$ & $5(3)$ & $-2(3)$ \\
$\mathrm{C}(29)$ & $86(5)$ & $48(4)$ & $63(4)$ & $26(3)$ & $-3(4)$ & $-13(4)$ \\
$\mathrm{C}(30)$ & $79(5)$ & $39(3)$ & $58(4)$ & $17(3)$ & $-5(3)$ & $-11(3)$ \\
$\mathrm{C}(31)$ & $49(3)$ & $35(3)$ & $46(3)$ & $18(2)$ & $0(2)$ & $1(2)$ \\
$\mathrm{C}(32)$ & $43(3)$ & $38(3)$ & $40(3)$ & $14(2)$ & $0(2)$ & $5(2)$ \\
$\mathrm{C}(33)$ & $56(4)$ & $43(3)$ & $44(3)$ & $4(3)$ & $-2(3)$ & $-5(3)$ \\
$\mathrm{C}(34)$ & $58(4)$ & $56(4)$ & $39(3)$ & $7(3)$ & $-6(3)$ & $-4(3)$ \\
$\mathrm{C}(35)$ & $62(4)$ & $58(4)$ & $39(3)$ & $22(3)$ & $3(3)$ & $8(3)$ \\
$\mathrm{C}(36)$ & $49(3)$ & $45(3)$ & $44(3)$ & $20(3)$ & $-2(2)$ & $2(3)$ \\
& & & & & & \\
\hline & & & & & &
\end{tabular}


Table 5. Hydrogen coordinates ( $\left.\times 10^{4}\right)$ and isotropic displacement parameters $\left(\AA^{2} \times 10^{3}\right)$ for 46 .

\begin{tabular}{|c|c|c|c|c|}
\hline & $\mathrm{x}$ & $\mathrm{y}$ & $\mathrm{z}$ & $U(e q)$ \\
\hline $\mathrm{H}(2 \mathrm{~A})$ & 5567 & -8310 & 5662 & 72 \\
\hline $\mathrm{H}(3 \mathrm{~A})$ & 4152 & -7175 & 5232 & 55 \\
\hline $\mathrm{H}(5 \mathrm{~A})$ & 5691 & -8655 & 2849 & 51 \\
\hline $\mathrm{H}(6 \mathrm{~A})$ & 7092 & -9756 & 3280 & 59 \\
\hline $\mathrm{H}(10 \mathrm{~A})$ & 5381 & -4467 & 3247 & 54 \\
\hline $\mathrm{H}(11 \mathrm{~A})$ & 5874 & -3048 & 3001 & 62 \\
\hline $\mathrm{H}(13 \mathrm{~A})$ & 4143 & -4407 & 592 & 75 \\
\hline$H(14 A)$ & 3748 & -5826 & 803 & 64 \\
\hline $\mathrm{H}(16 \mathrm{~A})$ & 1122 & -4847 & 2347 & 59 \\
\hline $\mathrm{H}(17 \mathrm{~A})$ & -191 & -3574 & 2104 & 75 \\
\hline $\mathrm{H}(18 \mathrm{~A})$ & -881 & -2159 & 3240 & 84 \\
\hline $\mathrm{H}(19 \mathrm{~A})$ & -439 & -2079 & 4623 & 68 \\
\hline $\mathrm{H}(22 \mathrm{~A})$ & -100 & -2187 & 5931 & 69 \\
\hline $\mathrm{H}(23 \mathrm{~A})$ & 494 & -2433 & 7172 & 74 \\
\hline $\mathrm{H}(24 \mathrm{~A})$ & 1928 & -3832 & 7103 & 68 \\
\hline $\mathrm{H}(25 \mathrm{~A})$ & 2766 & -4946 & 5805 & 60 \\
\hline $\mathrm{H}(27 \mathrm{~A})$ & 2018 & -8924 & 3185 & 54 \\
\hline $\mathrm{H}(28 \mathrm{~A})$ & 728 & -10325 & 3146 & 67 \\
\hline $\mathrm{H}(29 \mathrm{~A})$ & 328 & -11664 & 1868 & 77 \\
\hline $\mathrm{H}(30 \mathrm{~A})$ & 1046 & -11493 & 627 & 71 \\
\hline $\mathrm{H}(33 \mathrm{~A})$ & 1586 & -11192 & -581 & 62 \\
\hline $\mathrm{H}(34 \mathrm{~A})$ & 2294 & -10711 & -1661 & 65 \\
\hline $\mathrm{H}(35 \mathrm{~A})$ & 3701 & -9227 & -1350 & 62 \\
\hline $\mathrm{H}(36 \mathrm{~A})$ & 4147 & -8203 & 47 & 54 \\
\hline
\end{tabular}


Appendix 6 - Reflective VOA attenuation measurement apparatus 


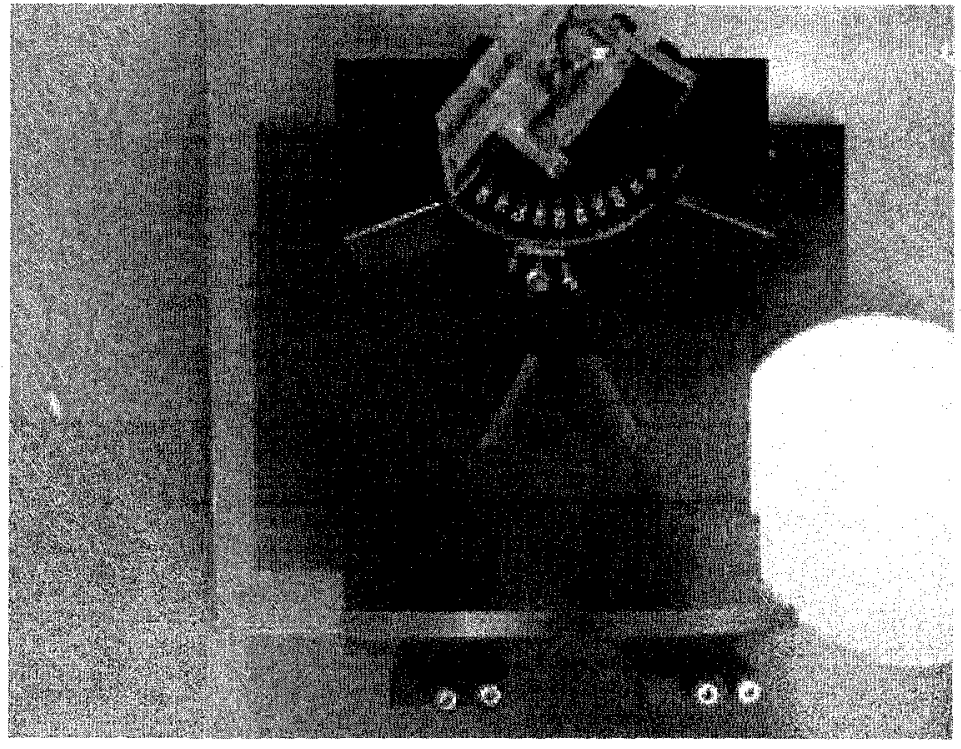

Harrick Scientific ${ }^{\mathrm{TM}}$ Variable angle specular reflectance module (Cuvette holder in place)

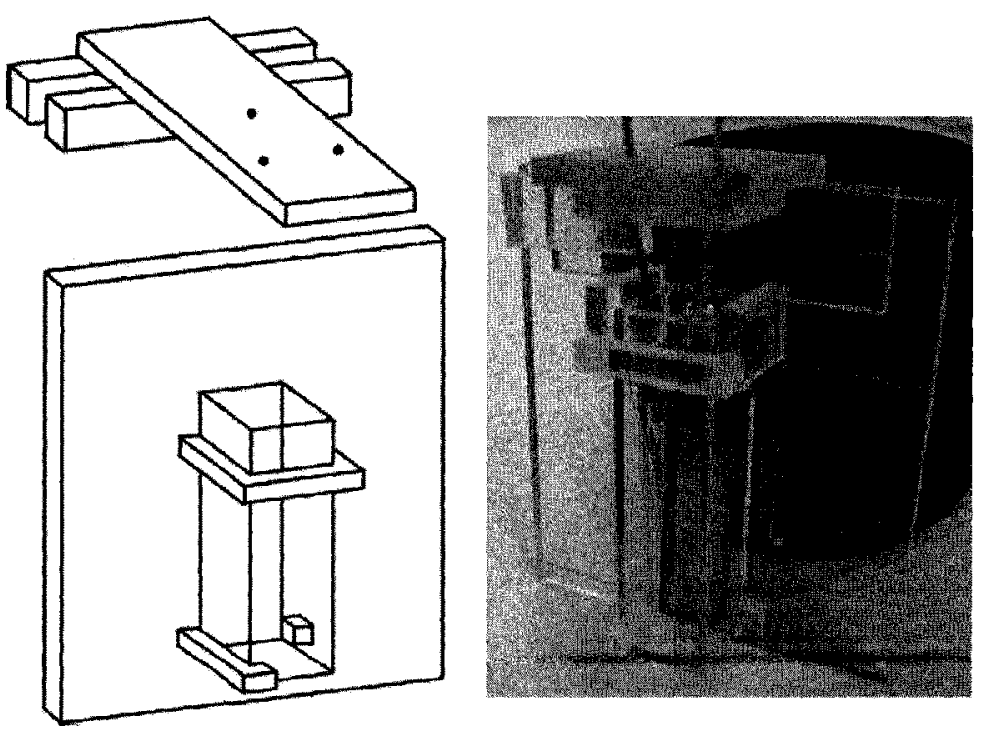

Plexiglass cuvette holder construct with film and electrodes in place 